\title{
VÍNCULOS EXISTENTES ENTRE LA FORMACIÓN DOCENTE POSGRADUAL Y EL OFICIO DE SER MAESTRXS DE PRIMARIA Y BACHILLERATO EN DOS CIUDADES DE COLOMBIA: PASTO Y VALLEDUPAR
}

Autora: Mg. ALEJANDRA DALILA RICO MOLANO

Tesis para optar por el grado de Doctora en Ciencias de la Educación

Directora: Dra. Sofia Picco

DOCTORADO EN CIENCIAS DE LA EDUCACIÓN

LA PLATA, ARGENTINA,

Octubre, 2020 


\section{Resumen}

Esta tesis doctoral tiene como propósito comprender la formación docente -en adelante $\mathrm{fd}$ - posgradual desde el uso de la narrativa, teniendo en cuenta los aprendizajes obtenidos en el periodo de formación posgradual: la configuración de nuevas trayectorias formativas y de la labor dxl maestrx; la incursión de la investigación como ejercicio para analizar y reflexionar las propias prácticas; y los sentidos que $x l x$ maestrx logra en la fd posgradual vinculados a las prácticas y a su labor en escenarios escolares. Para el desarrollo de esta tesis se tuvo como enfoque y método la investigación narrativa a partir de los postulados teóricos de Bolívar, Porta, Suárez, Rivas, Brunner, Larrosa, entre otrxs investigadorxs que han abordado la narrativa en la educación y, puntualmente, han estudiado la formación del profesorado. Este análisis narrativo permitió concluir que la fd posgradual tiene relación directa con las transformaciones y modos de pensar el oficio dxl maestrx; lxs maestrxs narrantes se ubican en perspectivas nuevas para generar prácticas situadas y coherentes en los contextos en donde laboran. Estas trasformaciones son fruto de la investigación realizada en la etapa de la fd posgradual, no son aisladas de la cotidianidad dxlx maestrx, sino que su estudio es la razón principal para re-trazar su oficio.

Por otro lado, esta investigación se realiza contando con maestrxs de diferentes instituciones educativas rurales y se plantean cuestiones como: ¿qué buscan aquellxs maestrxs que toman la decisión de hacer una maestría luego de un largo período sin asistir a la universidad?, ¿cuáles son las intenciones?, ¿qué quieren conocer o formarse con ello? Son tres cuestionamientos que he tenido a lo largo de mi trayectoria como docente formadorx de formadorxs y son el motor de esta pesquisa.

Esta pesquisa se desarrolla en el contexto de la Maestría en Educación de la Universidad Santo Tomás en Colombia, la cual hace presencia en diferentes departamentos del país y brinda programas de pregrado y posgrado presencial y a distancia. En este caso, la Maestría es a distancia con modalidad de 
investigación y profundización, situación que permite tomar como participantes, maestrxs de dos ciudades: Pasto y Valledupar, en donde se desarrolla esta investigación.

Son seis maestrxs lxs seleccionadxs para esta investigación. Estas voces son escogidas por lo que han cultivado, por el poder del relato que está a la espera de ser develado, de ser escuchado. Solo basta el encuentro personal, la pregunta inicial y xlx maestrx hace de su voz el principal atractivo para la investigadora, para quien la voz del que relata, del que teje palabras, debe ser fantástica. El que está escuchando no cumple un papel insensible, a medida que escucha necesariamente siente las palabras, se adentra en ellas, siente la emoción del que narra, de los trazos, se vale de su imaginación para ir entrelazando hechos.

\section{Palabras clave}

Formación docente - Investigación - Narrativas - Oficio dxl maestrx - Trazos formativos. 


\section{Abstract}

The purpose of this doctoral thesis is to understand post-graduate teacher training - henceforth fd - from the use of narrative, taking into account the learning obtained in the post-graduate training period: the configuration of new training paths and the work of the teacher; the incursion of research as an exercise to analyze and reflect on its own practices; and the meanings that the teacher achieves in post-graduate fd linked to their practices and their work in school environments. For the development of this thesis, the focus and method used was narrative research based on the theoretical postulates of Bolivar, Porta, Suárez, Rivas, Brunner, and Larrosa, among other researchers who have addressed narrative in education and, specifically, have studied teacher training. This narrative analysis allowed to conclude that postgraduate education has a direct relationship with the transformations and ways of thinking about the teacher's profession; teacher-narrators are placed in new perspectives in order to generate practices that are situated and coherent in the contexts where they work. These transformations are the result of research carried out in the postgraduate phase. They are not isolated from the day-to-day life of the teacher, but rather their study is the main reason for re-thinking their craft.

On the other hand, this research is carried out with teachers from different rural educational institutions and questions such as: what are those teachers who make the decision to do a master's degree after a long period without attending university looking for?, what are their intentions?, what do they want to know or be trained by? These are three questions that I have had throughout my career as a teacher-trainer and are the driving force behind this research.

This research is being developed in the context of the master's degree in Education at the Universidad Santo Tomás in Colombia, which is present in different departments of the country and offers professional and post-graduate programs, both in person and through distance learning. In this case, the master's degree is a distance learning program with a research and in-depth 
modality, which allows teachers from two cities to participate: Pasto and Valledupar, where this research is carried out.

There are six teachers selected for this research. These voices are chosen for what they have cultivated, for the power of the story that is waiting to be unveiled, to be heard. Only the personal encounter is enough, the initial question and the teacher makes his voice the main attraction for the researcher, for whom the voice of the one who tells, of the one who weaves words, must be fantastic. The one who is listening does not play an insensitive role; as the researcher listens, necessarily feels the words, goes into them, feels the emotion of the one who is telling, of the lines, uses his imagination to interweave facts.

\section{Keywords}

Teacher education - Research - Narratives - Teacher's trade - Formative Strokes. 


\section{Tabla de contenido}

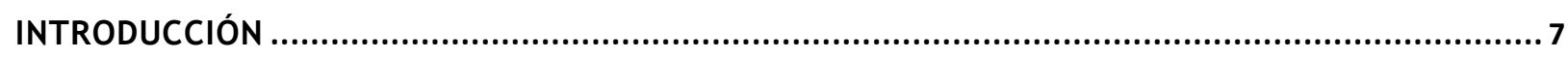

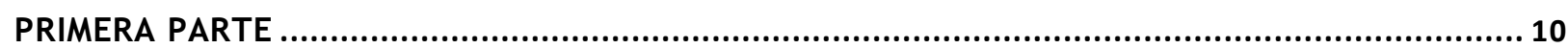

LO QUE SE QUIERE “PESQUISAR”: ¿SOBRE QUÉ NARRAR? ................................................... 10

CAPÍTULO I. INDAGAR, PLANTEAR Y TRAZAR LA CUESTIÓN: PRIMERAS NARRACIONES .............................. 13

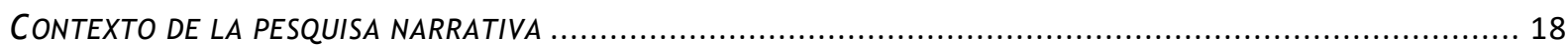

CAPÍTULO II. EL SENTIDO DE LAS POLÍTICAS PÚBLICAS EN EDUCACIÓN: LOS RETOS PARA LA FD EN COLOMBIA 24

CAPÍtULO III. ENTRE LAS INVESTIGACIONES SOBRE FD. ABORDAJES Y ANÁLISIS DE ANTECEDENTES ............... 34

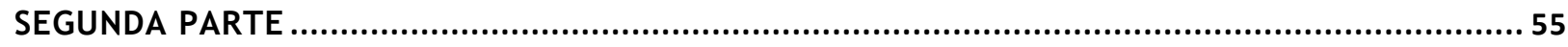

ANÁLISIS HERMENÉUTICO DESDE LA DIVERSIDAD TEÓRICA SOBRE LA FD .............................. 55

CAPÍtUlo IV. Fd: TRAMAS DISCURSIVAS, TRAMAS TEÓRICAS VINCULANTES ......................................... 57

CAPÍtULO V. MAESTRXS EMANCIPADXS: LA FD DESDE UNA PERSPECTIVA REFLEXIVA Y PARTICIPATIVA ........... 78

TERCERA PARTE

EL USO DE LA NARRATIVA PARA PESQUISAR: EL DESPERTAR DE LAS VOCES NARRANTES SOBRE

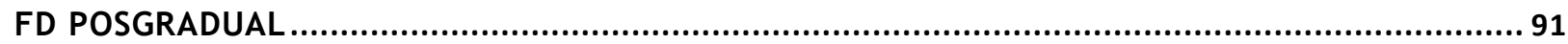

CAPÍtUlo VI. ACERCAMIENTOS NARRATIVOS: DisERTACIONES TEÓRICAS NARRADAS ............................... 93

CAPítulo VII. El Relato dXLX MAESTRX De ESCUELA RURAL: NARRACIONES PERIFÉRICAS (DEL PUEBLO)....105

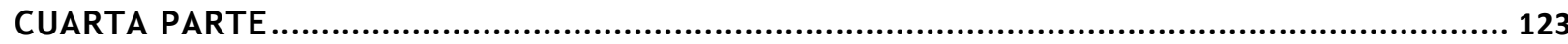

PALABRAS DE MAESTRXS SOBRE LAS TRAYECTORIAS DE FD POSGRADUAL EN COLOMBIA:

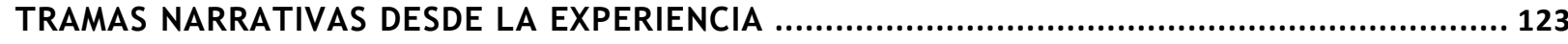

CAPÍtUlo VIII. ReCONSTRUYENDO NARRATIVAS PASAdAS SOBRE LA FD PARA DEVELAR LOS ACONTECIMIENTOS

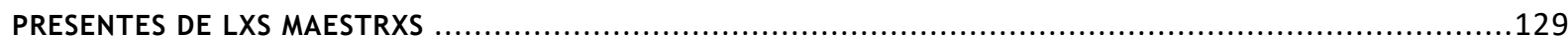

CAPÍTULO IX. TRAYECTORIAS Y SENTIDOS DXLX MAESTRX EN EJERCICIO SOBRE LA FD ...........................154

CAPÍtUlO X. MANIFESTACIONES EMERGENTES DE LA FD POSGRAdUAL VINCULADAS AL OFICIO DXLX MAESTRX

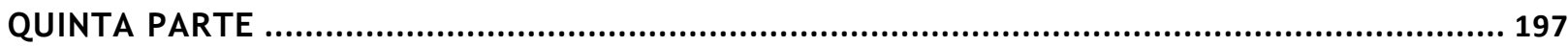

CONCLUSIONES: LAS APERTURAS DE LO QUE SE NARRÓ .................................................... 197

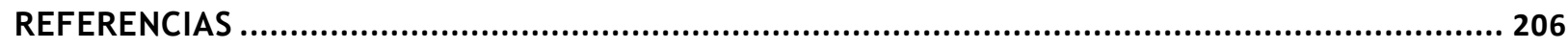

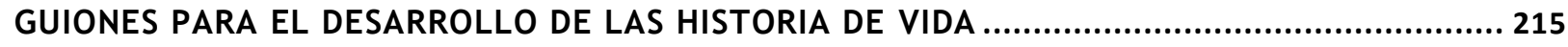

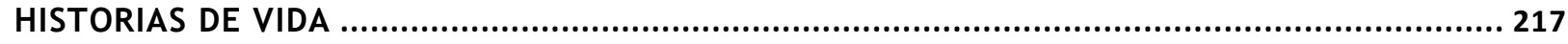

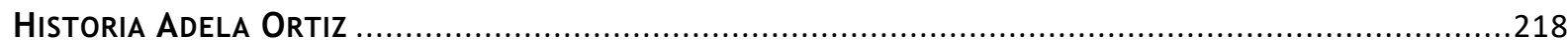

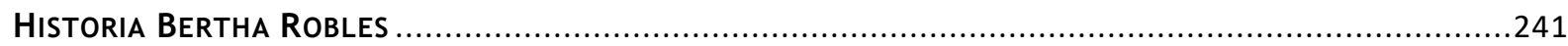

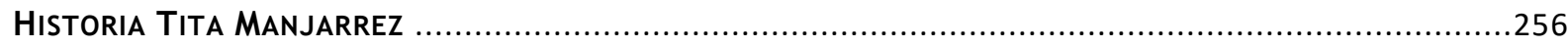

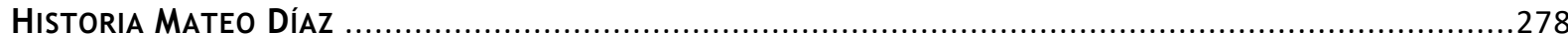

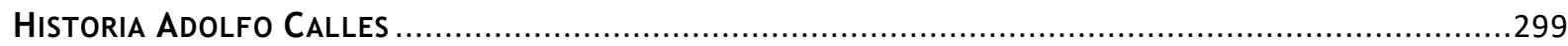

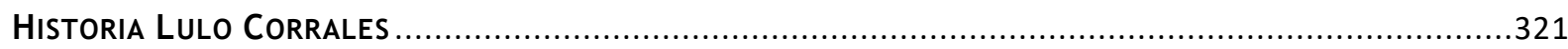




\section{Lista de tablas}

Tabla 1

\section{Lista de ilustraciones}

Ilustración 1. Tramas discursivas/vinculantes sobre la fd. Fuente. Suceso producido por

la investigadora.

Ilustración 2. Características dxlx maestrx emancipado a partir de los procesos de fd posgradual. Fuente. Suceso producido por la investigadora.

Ilustración 3. Las intersecciones narrativas. Fuente. Suceso producido por la investigadora.

Ilustración 4. Proceso metodológico de la narrativa: maestrxs narrantes. Fuente. Suceso producido por la investigadora.

Ilustración 5. Criterios para el perfil de lxs maestrxs narrantes. Fuente. Suceso producido por la investigadora.

Ilustración 6. Características de la investigación narrativa. Suceso producido por la investigadora. 


\section{Introducción}

La fd posgradual ha sido un tema que ha generado diversas discusiones en el ámbito educativo desde los interrogantes: ¿qué fd posgradual reciben lxs maestrxs de las escuelas públicas de Colombia?, ¿cómo las universidades conciben la formación de maestrxs?, ¿cuáles son las estrategias de formación posgradual más apropiadas? Cuestionamientos que han generado debates desde diferentes sectores, como el universitario, el Estado, el Ministerio de Educación, los gremios de maestrxs de la educación pública y otros sectores de académicos e investigadorxs que durante años han reflexionado y participado en la creación de políticas públicas en educación para la fd inicial y posgradual.

Este escenario y la diversidad que presenta en tanto discusiones y debates se trate, conduce al estudio más detallado de la fd posgradual de lxs maestrxs de escuelas públicas de Colombia. Sin embargo, en esta investigación se considera necesario que la fd sea analizada desde las voces de maestrxs formadxs como magíster en educación, que laboran en regiones rurales del país. Desde luego, vinculando teorías e investigaciones sobre el tema que son re-analizadas para darle paso a otras posturas y definiciones de la fd posgradual.

De este modo, esta tesis se desglosa en diez capítulos, distribuidos en cinco partes. La primera: Lo que se quiere "pesquisar”: ¿Sobre qué narrar? Esta parte aborda tres capítulos: I. Indagar, plantear y trazar la cuestión: primeras narraciones, contexto de la pesquisa narrativa; II. El sentido de las políticas 
públicas en educación: Los retos para la fd en Colombia; y, III. Entre las investigaciones sobre fd. Abordajes y análisis de antecedentes. Es decir, esta parte, da cuenta de las razones y las finalidades que hay para realizar esta investigación.

La segunda parte: Análisis hermenéutico desde la diversidad teórica sobre la fd es el abordaje teórico sobre ella y el diálogo compartido con algunas narrativas de lxs maestrxs participantes. Para ello, se desglosa en dos capítulos: IV. Formación docente: Tramas discursivas, tramas teóricas vinculantes ; y, V. Maestrxs emancipadxs: La fd desde una perspectiva reflexiva y participativa.

En la tercera parte, el lector se encuentra con el corazón de la investigación: El uso de la narrativa para pesquisar: El despertar de las voces narrantes sobre fd posgradual, que parte de hacer un análisis detallado de la investigación narrativa y su incursión en la educación, particularmente, en el estudio de la formación del profesorado, en este caso, de maestrxs de escuelas públicas. Para ello, se abordan dos grandes temas: el primero, los acercamientos narrativos: Disertaciones teóricas narradas; $y$, el relato $\mathrm{dxlx}$ maestrx de escuela rural: Narraciones periféricas (del pueblo).

En la cuarta parte el lector llegará al análisis hermenéutico de las narrativas: Palabras de maestrxs sobre las trayectorias de fd posgradual en Colombia. En este apartado se hace un amplio ejercicio interpretativo desde tres lugares: el primero, la reconstrucción de las narrativas pasadas sobre la fd para develar los acontecimientos presentes de lxs maestrxs; el segundo, se hace referencia a las 
trayectorias y sentidos $d x l x$ maestrx en ejercicio sobre la fd; $y$, finalmente, las manifestaciones emergentes de la fd posgradual vinculadas al oficio de maestrx.

Todo ello, es una apertura a la quinta parte, que trata de las conclusiones de esta pesquisa narrativa. Conclusiones que parten de definir la fd desde las narrativas y configurar los sentidos que estas tienen en dos lugares: la fd posgradual y el oficio $d x l x$ maestrx.

Este recorrido teórico - narrativo va a conducir al lector a reflexionar sobre la fd desde otro lugar, no partiendo de los pesimismos injustificados, donde todo se ha fatalizado y hemos sido testigos de la incredulidad descontrolada que se ha tomado como hogar a la humanidad. Es justamente eso lo que se intenta evitar aquí, continuar fortaleciendo el fatalismo y lo nocivo de las palabras que durante siglos han perpetuado todos los ámbitos posibles para investigar. Si pensamos por un momento, gran parte de lo que leemos -literatura, arte, política, economía, cultura, sexualidad, psicología, educación, pedagogía- está situado en el criterio de "lo que está mal”, lo que "está incompleto", "lo que es imperfecto" o lo que "no ha sido".

En resumen, no es posible continuar con una lectura desde la incomprensión y la dureza de las palabras, esta investigación es de corte romántico, la recuperación de las voces de lxs maestrxs permite que la fd sea vista desde el acontecer y la cotidianidad de ellxs. Esta tesis está escrita para comprender la fd desde la diversidad dxlx maestrx, así como sus experiencias de formación y las prácticas que realiza. 


\section{PRIMERA PARTE}

\section{Lo que se quiere "pesquisar": ¿Sobre qué narrar?}

Esta primera parte de la tesis tiene que ver con la propuesta de investigación, se presenta al detalle la conformación del problema, las partes que lo configuran y las cuestiones que permiten fundamentarlo y ahondar en lo que sería la fd posgradual, tema a ser investigado y lo que conlleva a la pesquisa narrativa. Hacer un recorrido inicial por el problema que centra este estudio conduce a recuperar y visualizar lo que realmente constituye la fd, no solo en el ámbito de educación posgradual sino en lo que la rodea.

Para ello, hay una exploración de algunos de los trayectos por los que ha pasado la fd en Colombia, empezando por los logros que en ciertas ocasiones realiza el Estado en el tema de fd, haciendo referencia de lo que es el programa de becas a lxs maestrxs del país en programas de maestrías, puntualmente, haciendo ver que este programa, llamado "Becas por la Excelencia docente" se extiende a todo el territorio nacional y no solo se queda en las principales ciudades del país.

Por otro lado, el vehículo de análisis de esta parte conduce a plantearse ¿qué buscan aquellxs maestrxs que toman la decisión de hacer una maestría luego de un largo periodo sin asistir a la universidad?, ¿cuáles son las intenciones?, ¿qué quieren conocer o formarse con ello? Son tres cuestionamientos que a lo largo de mi trayectoria como docente formadora de formadorxs he tenido y que son el motor de esta pesquisa. 
Así las cosas, se inicia con el primer capítulo, titulado "Indagar, plantear y trazar la cuestión: primeras narraciones"; tiene que ver con la presentación del tema a investigar, así como la necesidad de reflejar problemas para analizar desde el uso de la narrativa a la fd posgradual. El segundo capítulo, titulado "El sentido de las políticas públicas en educación: Los retos para la fd en Colombia" presenta un análisis de las principales políticas establecidas para la fd en Colombia. Aquí, se dan a conocer las vías que tiene el Estado para favorecer la fd, lo cual en ocasiones no presenta mayores avances, incluso en los últimos gobiernos el tema de la fd quedó olvidado y sin mayor elocuencia entre los congresistas.

Sin embargo, se rescata uno de los proyectos macro que tuvo el Estado en el 2014 que fue formar maestrxs en las diferentes regiones del país, claro que el enfoque de esta formación estaba centrado en el mejoramiento de las pruebas estandarizadas nacionales e internacionales. Asunto que en varios grupos de investigadorxs y académicxs se cuestionó ya que la fd posgradual debía conducir no solo a la obtención de resultados sino a la reflexión y análisis de las prácticas docentes. En resumen, a generar investigación desde la cotidianidad dxlx maestrx.

El capítulo tres, titulado “Entre las investigaciones sobre fd. Abordajes y análisis de antecedentes", es el análisis de diferentes investigaciones que han abordado el tema de la fd, no solo en el ámbito posgradual, sino desde otros sectores en donde hace presencia, como la gestión de la fd en la universidad, la fd inicial de maestrxs y otras categorías que emergen en este análisis de 
antecedentes, como la incursión de la investigación en la fd; las experiencias de reflexión que son reconsideradas por lxs maestrxs en formación; las prácticas que realiza xlx maestrxs en escenarios escolares y la necesidad de la actualización y continuación con la fd ya siendo maestrx en ejercicio laboral. 


\section{Capítulo I. Indagar, plantear y trazar la cuestión: primeras narraciones}

En Colombia la fd del sector público ha pasado por diferentes momentos de transición, está vinculada a las modificaciones de las políticas públicas educativas, que "rotan" según el gobierno de "turno", por decir, en los años ochenta, la fd de maestrxs a nivel de posgrado era escasa, la preocupación estaba centrada en la contratación de normalistas y licenciadxs, que de por sí en esa época, era también escasa.

La fd de maestrxs inició con fuerza desde la década de los noventa, con la creación de nuevas licenciaturas, no solo en la universidad pública sino en la universidad privada y con la apertura de una oferta de programas de posgrado, como especializaciones y maestrías relacionados con el campo de la educación.

La Universidad Pedagógica Nacional, la Universidad de Antioquia, la Universidad del Valle y otras son las pioneras en la creación de una gran oferta de licenciaturas y con ellas las especializaciones en informática educativa, pedagogía, lúdica, docencia, administración educativa, psicología educativa, entre otras; y las maestrías en educación, que la mayoría de universidades públicas y privadas la nombran así, aunque surgen otras en docencia, pedagogía, didáctica y las mismas en educación con diferentes líneas de profundización.

Sin embargo, con esta oferta de formación posgradual aún era reducido el porcentaje de maestrxs que iniciaban sus estudios en este nivel, una de las razones era que no contaban con los recursos económicos para realizar este tipo de estudio, los bajos salarios de lxs maestrxs, los pocos beneficios que ofrecía el 
gobierno y el decreto para el ascenso de escalafón, el cual no exigía formación, aunque, xlx maestrx que tomaba la decisión de continuar su formación posgradual, contaba con un valor agregado para ascender más rápido en el escalafón docente estatal.

Lo que sucedió entre 1990 y 2000 en el país frente a la formación de maestrxs es lo que empieza a generar cuestionamientos frente a las políticas en educación, desde diversas aristas, la primera, es que se pensaba la formación de maestrxs estrictamente en las grandes urbes (Bogotá, como el epicentro de la generación de políticas, grandes universidades y mejores beneficios, le sigue Medellín, Cali y Barranquilla, ciudades pequeñas en donde se localizan universidades públicas que ofertan programas en el campo educativo).

La segunda, como consecuencia de la primera, es que las ciudades y municipios retirados de las grandes urbes quedaban rezagados y lxs maestrxs no contaban con los recursos y la cercanía para realizar estudios de posgrado; la tercera, y no menor, es la desigualdad de oportunidades que tienen Ixs maestrxs frente a otras profesiones, en términos de condiciones salariales, lo cual representa que muchos de ellxs (incluso los que se localizan en grandes urbes) no lograban realizar estudios de posgrados, en otros casos, un porcentaje muy reducido lograba estudiar por medio de préstamos de entidades bancarias o del Instituto Colombiano de Crédito Educativo y Estudios Técnicos en el Exterior (ICETEX). 
En esta misma época, a finales de los 90 hasta que se expidió el decreto 1278 en el 2002, el gobierno implementó un programa de formación docente, ofertando en las Instituciones Educativas -en adelante IE- cursos de actualización y diplomados sobre lúdica, pedagogía, informática, tecnologías aplicadas a la educación, sistemas de evaluación, entre otros, estos cursos eran llevados a las $\mathrm{IE}$, aunque se seguía con el mismo inconveniente que solo aplicaban para las grandes ciudades y los municipios cercanos, viéndose afectados los más retirados, localizados en la montaña o implicados en el conflicto armado.

Este programa de apoyo para la fd abrió la puerta para que el gobierno iniciara con la reformulación de las políticas educativas, otorgando más valor a la formación docente como un criterio de mejoramiento en las prácticas escolares, pedagógicas y áulicas, y en las formas de aprendizaje dentro de la escuela, especialmente, el aprendizaje de las disciplinas.

Se hace mención al decreto 1278 del 2002, que tiene un énfasis en la formación posgradual de maestrxs de aula en el sector público, donde la formación como magíster en educación les puede otorgar unos puntos para el ascenso del escalafón, aunque no se trata solo de ganar ese ascenso que representa un alza en el salario, sino de comprender la necesidad de continuar con la fd estando en ejercicio, esto favorece las prácticas, la vinculación con la investigación educativa, nuevos escenarios para generar discusiones frente a las experiencias en el quehacer, hacer y ser como maestrxs. 
Esta política tomó fuerza aproximadamente 10 años atrás, en Bogotá, específicamente, en el gobierno del alcalde Antanas Mockus (2001 - 2003) quien impulsó esta iniciativa, y luego, Luis Eduardo Garzón (2004 - 2008) implementó un programa de auxilios educativos para lxs maestrxs del distrito (Bogotá) interesados en realizar estudios de maestría y doctorado, el programa otorgaba un crédito condonable ${ }^{1}$ a lxs maestrxs de $50 \%, 70 \%, 80 \%$ o $100 \%$ del valor de la matrícula por los dos años que dura una maestría en Colombia, desde luego, este auxilio estaba condicionado por unas cláusulas de cumplimiento.

Desde ese entonces, se mantiene esta política del sector público y ha sido promotora de la política nacional en educación frente a la $\mathrm{fd}$, asunto que se reflejó en 2014 cuando se propone el programa Becas por la Excelencia, el cual se aplicó a todos los departamentos, sus municipios y corregimientos ${ }^{2}$, es decir, tiene cobertura nacional. Se trata de otorgarle a lxs maestrxs de prescolar, primaria y bachillerato ${ }^{3}$ de las escuelas públicas, una beca que le permite hacer una maestría en el campo de la educación, esta beca es asignada a lxs maestrxs que cumplan con ciertos requisitos para acceder al beneficio.

Todas las universidades públicas y privadas que cuenten con acreditación de alta calidad ${ }^{4}$ pueden participar con sus programas de maestría y tener un número

\footnotetext{
${ }^{1}$ Crédito que otorga el Estado a lxs maestrxs seleccionados por convocatoria para realizar estudios de posgrado en universidades acreditadas colombianas. Se obsequia una parte del valor de la matricula a lxs maestrxs o la totalidad del valor de la matrícula en los dos años de estudio del posgrado.

${ }^{2}$ El corregimiento es una población muy pequeña que se encuentra en zonas del país aisladas y rurales. Dependen del municipio más cercano y en los últimos años son las zonas más afectadas por el conflicto armado, razón principal para que no vivan muchas personas allí.

${ }^{3}$ La educación colombiana cuenta con tres etapas, la primera es la educación inicial, que va de los 2 a los 6 años. La segunda etapa, es la educación primaria, que va del grado primero al quinto, lxs estudiantxs están entre los 7 y 12 años. Y, la tercera etapa, es la educación secundaria o lo que se conoce como el bachillerato, que va de los grados sexto al undécimo, lxs estudiantxs están entre los 12 y 18 años.

${ }^{4}$ Para la educación superior en Colombia la "acreditación de alta calidad" es entendida desde los lineamientos del Consejo Nacional de Acreditación -CNA-, quien reglamenta y regula todos los procesos de acreditación de los programas de pregrado y posgrado tanto de las universidades públicas y privada. Alta calidad tiene que ver con "la
} 
significativo de maestrxs como estudiantes de sus programas, desde luego, esto les genera beneficios y grandes oportunidades para hacer visible su apuesta curricular y formativa a nivel nacional.

A raíz de la incursión de estas políticas de fd, es que surge la inquietud por conocer y comprender los vínculos instaurados entre las experiencias formativas en la maestría y las construcciones de trayectorias como maestrxs en ejercicio, permitiendo la integración de saberes, sentidos, re-significados que llevan a lxs maestrxs a realizar una maestría en educación, ya que varios de ellxs, aparte de los cursos cortos $\mathrm{y} / \mathrm{o}$ actualización que recibieron, que se convierten en capacitaciones específicas, no han realizado un estudio formal, es decir, asistir a clases regulares, cumplir con trabajos, investigar, leer, trabajar en equipo, hacer un proyecto, entre otros asuntos inmersos en un posgrado.

Esta pesquisa se desarrolla teniendo en cuenta la Maestría en Educación de la Universidad Santo Tomás en Colombia, la cual hace presencia en diferentes departamentos del país y brinda programas de pregrado y posgrado presencial y a distancia. En este caso, la Maestría es bajo la metodología a distancia con modalidad de investigación y profundización, situación que permite tomar como participantes, maestrxs de dos ciudades: Pasto y Valledupar, en donde se desarrolla esta investigación de la que se desprende la pregunta:

evaluación de la calidad correspondiente a la acreditación institucional se centra en el cumplimiento de los objetivos de la educación superior que incluyen naturalmente, como elementos universales, la formación integral, la creación, el desarrollo y la transmisión del conocimiento y la contribución a la formación de profesionales y consolidación de las comunidades académicas. Se centra, además, en el logro de los postulados de las misiones y proyectos institucionales y en la pertinencia social, cultural y pedagógica de esas misiones y proyectos; además, atiende a la manera como la institución afronta el cumplimiento de sus funciones básicas en los distintos campos de acción de la educación superior, al clima institucional, a los recursos con que cuenta y a su desempeño global. Cuando se habla de instituciones resulta necesario enfatizar el vínculo entre pertinencia y calidad: a la exigencia académica sobre la calidad de los programas, que también resulta ser esencial cuando se juzga sobre la institución como un todo, se añade, en este caso, una exigencia particular relacionada con su papel social". (https://www.cna.gov.co/1741/article-190811.html). 
¿Qué vínculos se establecen entre la consolidación de experiencias formativas en la Maestría en Educación y las experiencias adquiridas en la trayectoria como maestrx en ejercicio en los niveles de primaria y bachillerato de las ciudades de Pasto y Valledupar? Se plantea como objetivo general comprender en las trayectorias formativas construidas por Ixs maestrxs en ejercicio los fundamentos que tienen para profundizar en su fd posibilitando cambios en sus prácticas docentes a través del periodo de formación en la Maestría en Educación.

De esta forma, como objetivos específicos se plantea, en primer lugar, recuperar los relatos sobre las experiencias de $\mathrm{fd}$ que han tenido seis maestrxs que ejercen en la primaria y el bachillerato. En segundo lugar, reconstruir a partir de las historias de vida las trayectorias y sentidos que circulan en la fd en ejercicio, teniendo en cuenta sus prácticas docentes y su experiencia formativa en la Maestría en Educación. Y, en tercer lugar, reconocer las transformaciones y manifestaciones emergentes de los procesos de fd desde los aprendizajes en investigación, los nuevos conocimientos situados en la práctica, en el acto pedagógico y social que se construye en el oficio dxlx maestrx.

Contexto de la pesquisa narrativa

Antes de continuar, es preciso describir el contexto donde se desarrolla la investigación, se trata de la Maestría en Educación de la Universidad Santo Tomás, el lugar físico del programa se ubica en la ciudad de Bogotá, sin 
embargo, el programa se oferta en los Centros de Atención Universitaria (CAU) localizados en diferentes ciudades del país, en estos centros se ofrecen los programas a distancia que tiene la universidad en dos facultades: Educación y Ciencia y tecnología. La Facultad de Educación cuenta con programas de licenciatura, especializaciones, maestrías y doctorado, cuya finalidad es formar personas con sentido humanista, encaminadas al progreso del país, con sentido de pertenencia y logrando el bien colectivo como profesionales de la educación, especialmente, desde su labor como maestrxs de las regiones en donde viven (Proyecto Educativo Institucional, 2004).

Igualmente, la Maestría en Educación se centra en la formación de maestrxs que laboran en la educación prescolar, primaria y el bachillerato, maestrxs universitarios, directivxs maestrxs, gestorxs educativxs e investigadorxs en el campo de la educación. De esta forma, su preocupación es consolidar la articulación entre los campos de formación que configuran el plan de estudios ${ }^{5}$, es para la Maestría en Educación la lógica que responde al propósito de generar reflexión y discusión sobre temas y problemas educativos que se integran desde la investigación en una dimensión conceptual y contextual. Con ello, se logra que Ixs maestrantes analicen las problemáticas del campo pedagógico y educativo, generando proyectos de investigación en un contexto específico que requiera del

\footnotetext{
${ }^{5}$ Los campos de formación que ha construido la Maestría en Educación son tres: el primero, humanista, que tiene que ver con los principios filosóficos de Santo Tomás de Aquino, lo cual es comprendido como principio de vida que orienta y actualiza su praxis pedagógica, sello identitario dxlx maestrx con compromiso ético, político e investigativo. El segundo, es el pedagógico, quiere encausar habilidades y competencias de Ixs estudiantes para reflexionar con criterio investigativo acciones, experiencias, enfatizando una postura crítica sobre los discursos establecidos en relación con el hecho educativo en lo pedagógico. Y, el tercer campo, investigativo, se trata de promover la capacidad creativa para plantear problemas, apoyar la construcción de la teoría educativa y pedagógica, es decir, orientar el diseño de proyectos de investigación pertinentes, con un impacto real. (Documento Maestro de la Maestría en Educación, 2015)
} 
aporte del investigadorx para obtener propuestas viables de sus propias cuestiones a partir de la construcción de conocimiento.

La formación de maestrxs en el programa se desarrolla por medio de diferentes recursos pedagógicos. El primero, es la implementación de la estrategia formativa para la construcción de un proceso investigativo alrededor de una situación de estudio. La Maestría a través de las diferentes reflexiones dadas en los comités del programa y el comité curricular propuso y estableció organizar equipos por binas de profesorxs investigadorxs, que trabajen colaborativamente los tres seminarios ${ }^{6}$, es decir, compartiendo espacios académicos, en los que la epistemología y la metodología están en diálogo.

Un segundo recurso tiene que ver con los llamados Coloquios de socialización de avances de los proyectos desarrollados por lxs estudiantxs, esta mediación permite que participen con un escrito tipo ponencia en la socialización de sus proyectos de investigación para que presenten los respectivos avances en diálogo con todos los grupos de la maestría, en donde se trabaja por ejes relacionados con los abordajes investigativos para la formación de maestrxs con que cuenta la maestría. Los coloquios son espacios de reflexiones en torno a las investigaciones de Ixs maestrantes, permiten que ellxs presenten y discutan sobre los temas abordados a lo largo de su formación como fruto del trabajo formativo e investigativo.

\footnotetext{
6 1) Seminario de epistemología de la investigación; 2) Seminario de metodología de la investigación; 3) Seminario de proyecto de trabajo de grado.
} 
Un último recurso pedagógico con que cuenta la Maestría es el equipo de maestrxs, quienes son especialistas en la formación de maestrxs en posgrado; son pedagogxs e investigadorxs en el campo de la educación en gran variedad de temas. Se concibe como un maestrx que enseña a investigar, que nutre con el conocimiento y que ayuda a potenciar en xlx estudiante sus capacidades cognitivas e investigativas desde el ejercicio problematizador del conocimiento. Es un orientadorx, facilitadorx y dinamizadorx que brinda apoyo y refuerza lo que va surgiendo como resultado de la ejecución de actividades de aprendizaje.

En resumen, la Maestría en sus 16 años de creación, ha generado profesionales de la educación, con formación como magíster con criterio pedagógico, humanista e investigativo (según los tres campos de formación), que se pueden desenvolver en diferentes escenarios como docente, gestorx, investigadorx, directivx y/o asesorx. La formación que recibe lo ubica como un ser íntegro, profesional con capacidades y habilidades para desarrollar proyectos encaminados hacia el beneficio de la educación del país, iniciando con pequeñas transformaciones en sus prácticas docentes, que le permiten la reflexión de su quehacer desde lo personal y colectivo.

De otro lado, es necesario explicar que el contexto en el que se sitúa esta pesquisa comprende dos antecedentes históricos que permiten ahondar un poco más en el tema de estudio, partiendo de que la formación de maestrxs en Colombia ha pasado por diferentes momentos y rupturas históricas, el primero de ello, es el surgimiento del Movimiento Pedagógico a inicios de 1980, este movimiento se generó con la participación de investigadorxs e intelectuales de la 
época de cuatro universidades colombianas, Universidad Nacional, Universidad de Antioquia, Universidad del Valle, Universidad Pedagógica Nacional.

Hay dos razones interesantes que dieron lugar a este Movimiento, la primera, la recuperación del sentido pedagógico dxlx maestrx colombianx; y la segunda, el empoderamiento de lxs maestrxs de este sentido, saber qué lo identifica y qué permite el reconocimiento cultural y social como generadorx de alternativas desde el pensamiento crítico para mejorar la calidad de vida de las sociedades.

Y es desde las nuevas discusiones del Movimiento Pedagógico que se dan visos para hablar de la formación de maestrxs y exigir al Estado mejores proyectos y recursos para garantizarla. Desde allí es que las políticas públicas en educación han fomentado la formación en posgrado de maestrxs de las principales ciudades del país, esta formación se centra en dos momentos, el primero, la formación de especialistas en distintas ramas de la educación (administración, recursos virtuales, lúdica, pedagogía, didáctica, otras), esto sucede desde la mitad de 1980 hasta el 2005 - 2007.

El segundo antecedente histórico, se ve marcado por el incremento en la oferta de programas de maestrías en educación en el país que sucede a mediados de la primera década del siglo XXI hasta nuestros días. La oferta de maestrías hizo que los gobiernos de las principales ciudades incluyeran en sus políticas sobre educación la formación de maestrxs. Asunto que se vio reflejado por auxilios y becas a lxs maestrxs de sector público de instituciones educativas de básica primaria y media. Política que aún continúa y que ha logrado convocar un 
gran número de maestrxs no solo de las grandes urbes sino de las regiones más apartadas de ellas. Análisis que se realiza en el siguiente capítulo. 
Capítulo II. El sentido de las políticas públicas en educación: Los retos para la fd en Colombia

La primera normativa sobre la formación docente está estipulada en la Ley 115 General de la Educación, expedida el 8 de febrero de 1994 en el gobierno del presidente Cesar Gaviria, la cual se formuló tres años después que se hizo la reforma constitucional en 1991, donde el proceso de descentralización de todos los sectores, incluida la Educación, partió del hecho que se promoviera una educación eficiente, eficaz y efectiva, fuese productiva y orientada al progreso de la nación.

La fd en Colombia, de acuerdo con las políticas establecidas por el Ministerio de Educación Nacional (en adelante: MEN) para la fd reza el artículo 112 de la Ley General de Educación, 1994. “Instituciones formadoras de educadores. Corresponde a las universidades y a las demás instituciones de educación superior que posean una facultad de educación u otra unidad académica dedicada a la educación, la formación profesional, la de posgrado y la actualización de los educadorxs" (p. 24).

A partir de dicha alteración es que surge esta Ley la cual formalizó muchos de los procesos internos del sector educativo, uno de ellos fue la fd, que estaba dirigida por las Escuelas Normales Superiores y la Universidad Pedagógica Nacional con algunas licenciaturas, en esta época aún no se hablaba con fuerza de una fd de posgrado, ser normalista o licenciadx ya facultaba a los profesorxs 
para enseñar en una institución educativa pública o privada de educación básica y media.

Más adelante, el 19 de junio de 2002, en el gobierno del presidente Andrés Pastrana, se expidió un nuevo decreto de escalafón docente, el 1278. Este tiene exigencias que difieren de la dinámica que se venía manejando con el decreto 2277 (expedido el 14 de septiembre de 1979). El nuevo decreto reglamentó que, para el ascenso de categoría, además de la experiencia, son exigencia los estudios profesionales y una prueba, aquí es donde inició la preocupación por la fd de posgrado, asunto que generó inconformismo en lxs maestrxs regidxs por el antiguo decreto (2277), esto hizo que varixs maestrxs iniciaran sus estudios profesionales, así como hizo que otros generaran resistencia a lo estimado por el decreto 1278.

Estos factores pueden explicar por qué la fd en Colombia ha pasado por una serie de alteraciones desde la década de los noventa, estos cambios se ven reflejados en algunos aspectos, con los que se hace necesario tener claridad; el primero de ellos, es la distinción entre la fd inicial y la fd de posgrado, se entiende fd inicial como la formación de grado, es una licenciatura en una institución de educación superior; hoy en día, por la alta demanda educativa que tiene Colombia, las universidades públicas y privadas han creado diversos programas de licenciatura presencial y a distancia, algunos de ellos son programas con acreditación de alta calidad, expedida por el Ministerio de Educación Nacional (MEN) y el Consejo Nacional de Acreditación (CNA), otros programas cuentan con registro calificado y están en proceso de acreditación. 
La fd inicial tiene una duración de 4 a 5 años, esto depende de los planes de estudio que ofrece cada universidad $y$ las intenciones formativas que promocionen, terminado este periodo se obtiene el título de licenciadx en cualquier área de educación. Sin embargo, con el decreto 1278 todos los profesionales de cualquier área pueden ser maestrxs, tienen la opción de realizar un curso de docencia de corta duración (especialización) en una universidad acreditada y tienen acceso al concurso docente nacional. Este asunto ha generado arduas discusiones en el gremio docente, ya que se considera que se está deslegitimando la profesión docente y lo que más se cuestiona es que la labor de un licenciadx sea reemplazada por otrx profesional no licenciadx, nombradxs por el Ministerio de Educación Nacional profesionales de la educación. ${ }^{7}$

Por otra parte, está la fd de posgrado, la cual el decreto 1278 válida para ascender de categoría ${ }^{8}$, esta formación la conforman maestrías y doctorados en educación, en este aspecto, el anterior decreto es preciso, al no aceptar títulos de maestrías o doctorados que no tengan relación directa con el campo educativo. En Colombia, una maestría se realiza en un periodo de 2 años y un doctorado entre 4 a 6 años. Es lo que se conoce como formación de posgrado a la cual acceden licenciadxs y profesionales no licenciadxs atendiendo al decreto 1278.

\footnotetext{
${ }^{7}$ Desde la expedición del decreto 1278 todo profesional puede acceder al concurso nacional docente por méritos, no es requisito que tenga un título de licenciadx en alguna disciplina de la educación. Se considera profesional lxs no licenciadxs, ejemplo: físicxs, matemáticxs, químicxs, abogadxs, administradorxs, ingenierxs, agrónomxs, filósofxs, otros. Ellxs pueden realizar una especialización en docencia para acreditar conocimientos en el campo de la educación y así poder ser maestrxs de la escuela básica y media del territorio colombiano por medio del concurso nacional docente por méritos.

8 En este enlace se especifica las categorías de los decretos 2277 y 1278. https://www.grupogeard.com/blog/colombia/concurso-maestrxs/313-estructura-actual-escalafon-docente-encolombia-y-salarios-actuales?fb_comment_id=1091823364219831_1092766794125488
} 
La fd de posgrado en Colombia es un requisito para ser docente en la educación superior, mientras que, en la educación básica y media, el requisito básico es ser licenciadx en alguna disciplina del campo de la educación o si se es profesional no licenciadx realizar un curso corto y/o especialización en pedagogía y/o docencia, avalado en una institución certificada por el MEN. Sin embargo, con el nuevo escalafón docente (1278), en el que la exigencia para ascenso es un título de maestría o doctorado, esta medida suscitó que en los últimos 10 años se promovieran nuevas políticas de fd.

Una de estas políticas es que las Secretarias de Educación de los diferentes departamentos ${ }^{9}$ implementaron un proyecto de auxilio educativo a maestrxs con contrato de planta $^{10}$ por las secretarias de educación de cada departamento, para realizar una maestría en educación en una universidad acreditada del país. En Bogotá, por ejemplo, están la Universidad de la Salle, Universidad Santo Tomás, Universidad Pedagógica Nacional, Universidad Externado, Universidad Distrital, entre otras; allí ingresan algunxs maestrxs seleccionadxs que pertenecen a la secretaría distrital para que inicien sus estudios de maestría. Este auxilio es del $80 \%$ del valor total del programa.

Por otra parte, desde 2014 el MEN avaló un proyecto, llamado "becas por la excelencia docente", se trata de otorgar becas que cubren el valor total de la matrícula a lxs maestrxs de diferentes regiones del país (en especial las más

\footnotetext{
${ }_{9}^{9}$ Colombia es un país divido territorialmente en 32 departamentos y un distrito capital.

${ }^{10}$ Maestrxs contratadxs por aprobar la prueba del concurso nacional docente por méritos. Contrato otorgado con todos los beneficios que reglamenta el Ministerio del trabajo, salario según categoría del escalafón docente a que pertenece (2277 o 1278) y contrato elaborado a término indefinido como trabajadorx del Estado colombiano.
} 
aisladas de las grandes urbes) para que realicen estudios de maestría en educación o en un área específica del campo (didáctica, pedagogía, evaluación, entre otras), llamado al que fueron convocadas únicamente las universidades acreditadas de alta calidad en el país, para ese entonces, once (11), entre ellas dos (2) públicas y nueve (9) privadas.

Por supuesto, para poder ser acreedor de una beca, debía pasar por un proceso de selección desde el MEN como en la universidad que le fuere asignada. Las becas adjudicadas tenían una intención primaria y era formar a lxs maestrxs para que lograran tener mejores resultados y conocimientos en dos lugares, el primero, en el proceso de enseñanza; y el segundo, en los resultados de aprendizaje obtenidos entre lxs estudiantes. Estas intenciones permitieron que maestrías de educación como la ofertada por la Universidad Santo Tomás se arriesgara a formar maestrxs en dos niveles, la investigación intervención en contextos escolares y la profundización en las disciplinas base (matemáticas, lenguaje, ciencias naturales y ciencias sociales) que era el interés directo del MEN. Todo ello, para crear una fortaleza de los procesos de enseñanza y aprendizaje en las instituciones educativas de las regiones más alejadas de las grandes urbes del país.

Con todo esto, en los últimos cinco años nuevamente la fd y por ende el trabajo docente son vistos con más fuerza desde la polarización del discurso político y económico del país, se forman como magíster en educación, pero su trabajo docente debe estar enmarcado en una lógica de rendimiento y cumplimiento de las dinámicas de medición del aprendizaje y de las lógicas de 
evaluación docente determinadas por estas nuevas políticas educativas. Frente a esta forma irrisoria de pensar las políticas en educación, Herrera e Infante (2004, p. 83) cuestionan enfáticamente cómo se ha caído en el instrumentalismo y unilateralidad de toma de decisiones, acotando "en detrimento de una noción que contemple la participación y fiscalización del conjunto social en el delineamiento de estas".

Incluso el trabajo que hace $x l x$ docente formadorx de magíster se ve limitado por estos discursos embotellados en paradójicos políticos y otros intereses que dejan de ser competencia de su labor y se dirigen a órdenes posiblemente internacionales, en la medida que debe responder a estándares de competencias y evaluación, para que lxs magísteres en educación fortalezcan su quehacer y las formas de enseñanza. En este orden de ideas, Martínez, et al. (2015) analizan los sentidos que puede tener la fd, por un lado, como formación propiamente dicha, en términos de articular teorías con las prácticas dxlx maestrx; y, por otro lado, la profesionalización dxlx docente, que recae en la necesidad de actuar y desempeñarse adecuadamente, con responsabilidad, en la cual se integre la formación, gestión y evaluación que fortalezca las habilidades, competencias y capacidad dxlx maestrx en sus prácticas laborales.

He dicho hasta aquí que la fd ha sido analizada desde dos frentes. El primer frente, por los investigadorxs educativxs y académicxs del gremio docente, que hacen un llamado a la reflexión sobre la labor docente y su papel dentro de la sociedad civil y la del conocimiento, por consiguiente, la fd en el nivel de 
posgrados permite tener nuevas percepciones sobre el quehacer docente y sus funciones escolares en distintos contextos regionales.

Esta primera alternativa desde donde es analizada la fd, también configura la generación de nuevo conocimiento frente al tema, no solamente desde la investigación docente en rigor, sino desde la investigación que se genera por parte de lxs estudiantes de maestrías y doctorados. El interés por aprender a investigar es lo que atrae al docente en ejercicio a continuar con su formación, considerando que le permite estar actualizado, tener más herramientas conceptuales, epistemológicas y metodológicas para el desarrollo de su labor. De por sí, Camargo (2007, p. 113) manifiesta que son las necesidades investigativas las que le permiten al docente documentar sus prácticas, conformar grupos de estudio y participar en redes académicas, "la investigación implica para ellxs otro estatus y reconocimiento. En este sentido, lxs maestrxs quieren aprender a investigar".

El segundo frente de análisis de la fd tiene que ver con las políticas públicas en educación de los últimos 10 años, en ellas se ven reflejados los criterios para la $\mathrm{fd}$, aunque no ha sido una constante ni un interés tener en cuenta en un porcentaje alto el tema de la formación, sí se ha procurado que desde el MEN se generen proyectos que permitan el acceso a programas de posgrado a maestrxs del régimen público.

Esto gracias a la generación de políticas instrumentalizadas y tecnificadas que se crean en cada gobierno de turno, sin embargo, la preocupación por una parte del sector educativo, en especial, lxs investigadorxs y académicxs por pensar la 
educación como un acto sociopolítico y colegiado, que está por encima del reduccionismo politizado y tecnócrata de los gobiernos y su perspectiva de educación, permite que se generen proyectos de formación continua de maestrxs de escuelas y colegios de orden público.

Este llamado por nuevas alternativas para la continuidad de formación de maestrxs a través de la generación de políticas educativas equitativas, consolidadas en un ejercicio colegiado y emergentes de sectores institucionalizados y no institucionalizados lo hacen Herrera e Infante (2004, p. 83) cuando consideran que es necesario "someter al análisis riguroso los resultados de implementación de las políticas neoconservadoras, como para construir y poner en marcha otras posibilidades pedagógicas y educativas".

Los recursos para la educación, las ciencias humanas y sociales se ven reducidos por el presupuesto asignado para los oficios técnicos y de ingenierías. A propósito, recientemente, en el primer semestre de 2018 las políticas para los auxilios becarios que se le otorgaban a lxs maestrxs del sector público se vieron notoriamente afectados, reduciendo de 70 cupos asignados para estudiar maestría en educación en la Universidad Santo Tomás a 10 cupos, razones de viabilidad financiera, procesos de escalafón docente, evaluación de procesos y otros factores que derivan en la reducción de este recurso, es lo que constantemente golpea la fd.

Los esfuerzos de las facultades de educación por las innovaciones introducidas en los programas de formación de nuevxs maestrxs, dirigidos a mejorar las competencias y habilidades indispensables que requiere $\mathrm{xlx}$ nuevx docente para asumir los retos que 
le plantean las nuevas formas de vida desde el despunte del nuevo milenio, con el papel protagónico de las nuevas tecnologías de la información y la comunicación, con el gran volumen de información y conocimiento, y por supuesto, para encarar con una actitud individual y grupal distinta los procesos de calidad en la educación básica y media del país (Univio y Osorio, 2015, p. 56).

Si bien las políticas públicas educativas con los años han sufrido transformaciones, hacen falta esfuerzos por fomentar y consolidar lineamientos sobre la fd, especialmente, la formación continua o posgradual. Desde las universidades, como focos formativos en los niveles de grado y posgrado, se generan lineamientos que permiten que esta formación ofrecida para las nuevas generaciones de maestrxs y los que están en ejercicio sean pertinentes y coherentes con las dinámicas vigentes de las sociedades, lo confirman los autorxs citados y Londoño (2010) desde una perspectiva que reconozca la generación de programas dinámicos y con espacios para la reflexión de la práctica docente, y en consecuencia, aprendizajes y enseñanzas en investigación que se consoliden en proyectos y propuestas para su quehacer.

También, los programas de maestría y doctorados se fortalezcan con currículos internacionales para la constitución de redes,

Encuentros, simposios, jornadas de estudio, grupos de reflexión o conferencias, coloquios, donde lxs maestrxs puedan tanto examinar el sentido de sus propias prácticas pedagógicas, como discutir diversos problemas de la docencia y la manera de vislumbrar alternativas de solución a los mismos (Londoño, 2010, p. 64).

En resumidas palabras, la conformación de políticas educativas acordes con los procesos sociales, escolares y formativos, es competencia de varios sectores, 
donde participen académicxs, investigadorxs, entes gubernamentales, estudiantes, para conformar procesos sólidos y viables de formación de maestrxs desde las universidades, las instituciones de educación pública y representantes del MEN, no es suficiente otorgar becas y auxilios, se hace necesario hacer seguimientos oportunos y colegiados de la formación que reciben lxs maestrxs, en este caso, en maestrías y doctorados, seguimiento no desde el reduccionismo evaluativo estadístico, sino desde la investigación, los espacios de diálogo y nuevas propuestas para garantizar no solo resultados óptimos de la práctica pedagógica sino resultados de aprendizaje y apropiación de conocimientos en lxs estudiantes. 
Capítulo III. Entre las investigaciones sobre fd. Abordajes y análisis de antecedentes

Este capítulo tiene la finalidad de presentar estudios sobre la $\mathrm{fd}$, que se abordan desde lo nacional e internacional, teniendo en cuenta la pertinencia con el tema de investigación. Desde luego, la categoría central es la fd, sin embargo, hay apertura a otras categorías que atraviesan esta investigación como lo son, fd en posgrados, fd desde la gestión, fd de maestrxs de escuela básica y media; así mismo, en este estado de la cuestión se encontrarán otras categorías que valga la pena analizar desde los estudios abordados.

Dando inicio con este entramado de estudios y construcción de diálogos con otros investigadores frente a la fd, se hace la aclaración que este estado de la cuestión no es abordado de forma temporal y espacial, es decir, no tiene una secuencia por años ni una secuencia de estudios por regiones. Su construcción es a partir de las posturas generadas por los investigadores, por eso se llama entramado, construcción de saberes y análisis investigativo que refleja posturas, nuevos saberes, discusiones, construcciones epistemológicas y aperturas a la formación docente.

Una de las investigaciones realizada de mi autoría, titulada: "La formación docente inicial en cuatro décadas a partir de historias de vida de maestrxs colombianos (2009-2011)" (Rico, 2011) 11 tuvo como propósito comprender la fd inicial desde las experiencias de nueve maestrxs del contexto colombiano, para

\footnotetext{
11 Tesis de maestría realizada para optar el título de magíster en docencia de la Universidad de la Salle, Colombia entre los años 2009 y 2011.
} 
ello, se utilizaron las historias de vida codificadas en tres categorías que fundamentaron la fd inicial, la primera fue fd; prácticas docentes como la segunda; y, la última, experiencia en investigación docente. A partir de este estudio y análisis detallado de cada uno de los relatos, se logró caracterizar la fd inicial y se evidenciaron las continuidades y discontinuidades en las experiencias significativas de lxs maestrxs que participaron en el estudio.

Una primera conclusión que emergió de este estudio y que se relaciona con mi tesis está centrada en la experiencia de lxs maestrxs participantes sobre investigación, lo cual significó un factor importante para el proceso formativo como licenciadxs en una de las áreas de educación. Gracias a la articulación de sus prácticas docentes y los contextos en donde se desarrollaron se potenció la investigación dentro de su formación. Al respecto, Calvo (2004) dice que la formación de maestrxs es un acto práctico - reflexivo que transforma el escenario de la educación, y que enseñar es aprender a investigar a partir de experiencias valiosas dentro de la fd.

Esto sucede en la fd inicial, y es una mirada desde la perspectiva de maestrxs colombianxs de diferentes épocas, si bien es un estudio de la fd en grado, los resultados de esta investigación no dista mucho de los intereses que se tienen en la actual, sale a relucir la preocupación por la investigación en el proceso formativo, suceso que se replica en el formación posgradual, la investigación se convierte en un pilar para conformar saberes, re-pensar otras formas de hacer las prácticas docentes y actuar, "quizás" de otra forma ante lo que se enseña en el aula de la educación básica y media. 
Claro está que en la fd inicial aún se está conociendo, haciendo unos acercamientos desde la teoría y otros hacia la práctica docente, sin embargo, estos primeros pasos son los que anidan el interés por continuar conociendo, descubriendo el ser docente. Es continuar en la permanente formación.

Desde otra mirada, Nocetti y Medina (2017, p. 2) en un estudio consideraron que "los futurxs profesorxs que no tuvieron una experiencia reflexiva durante su formación tienden a examinar de modo superficial su trabajo docente y desarrollan un ejercicio profesional de carácter técnico". Esta afirmación resultó de una investigación realizada en Chile con estudiantes de pedagogía y sus formadores sobre la reflexión docente, resultado que se articula con la intencionalidad directa de mi investigación mediante el cuestionamiento: ¿Qué sentido tiene recibir una serie de conocimientos, saberes, descubrir nuevas prácticas si no se ahonda en ello, no se tratan desde una postura reflexiva? ¿Cómo enseñar sin comprender y cómo comprender sin reflexionar?

Es por ello por lo que uno de los supuestos que inciden en esta investigación es la necesidad de continuar con la fd y más cuando en sus trayectorias como maestrxs, los espacios e intereses de formación han sido intermitentes, quiere decir que para retomar la fd ha pasado un tiempo promedio de 6 a 15 años luego de obtener el título de grado (en este caso un título de licenciado en alguna disciplina del campo de la educación). Retomando esa necesidad por continuar o iniciar un nuevo trayecto en su vida docente, es lo que permite estudiar lo "forastero", lo que se comprende y se articula con la novedad, la apertura por emprender un nuevo proyecto, justamente, son de las "aperturas" que se ocupan 
la mayoría de las historias de vida de lxs maestrxs "narrantes" de esta investigación.

Son tramas ${ }^{12}$ las que van configurando la fd, Alliaud (2010, p. 148) en una de sus investigaciones finalizadas en Argentina, realizó un estudio sobre "el saber de la experiencia", en el que el propósito principal fue "identificar relatos de quienes dejaron testimonio de su hacer, de aquellxs que consideraron tenían algo para decir, contar o transmitir acerca de lo que protagonizaron en sus prácticas docentes cotidianas".

Emprender una investigación sobre las experiencias de lxs maestrxs, se convierte en un suceso entrelazado con distintas situaciones, de orden social, familiar, profesional, personal, económico, entre otros, $x l x$ docente que se forma en un posgrado adquiere un nivel más reflexivo de su quehacer, lo cual genera un discurso más robusto y la necesidad permanente de querer contar e interactuar con sus colegas, amigos, familias y estudiantes. Martínez, et al. (2015, p. 72) en sus análisis, consideran que la formación tiene tres umbrales, el primero, de la cualificación; el segundo, de formación posgradual o avanzada; y, el tercero, de actualización, y manifiestan que, en el segundo umbral, "la reflexividad es un proceso de reconocimiento y explicitación del territorio, de la posición del hecho educativo y de los modos de ser maestrx". Además, esta consideración conlleva a la recuperación de trayectorias. Quiere decir que xlx maestrx retoma el sentido del diálogo y lo hace manifiesto en las comprensiones y prácticas adquiridas en la formación posgradual.

\footnotetext{
12 Trama: término usado en esta investigación para referirse a argumentaciones, cuestiones, "costuras" dialécticas, teóricas o reflexivas que "confeccionan" un problema de investigación.
} 
Retomando el estudio de Alliaud (2010, p. 149) desarrolló la idea de tener ciertos criterios para el abordaje de las narrativas de lxs maestrxs, siendo su finalidad principal el interés con que produzca su telar de experiencias. Uno de estos criterios, son los "relatos significados, marcados"; otro, "que contengan reflexiones producidas a partir del curso de los hechos y de las acciones"; y, "que puedan servir para orientar acciones y decisiones de otros".

De esta exploración queda visible que un aspecto para rescatar, "trazar" y renarrar narrativas parte de las buenas prácticas y experiencias con que cuentan Ixs maestrxs participantes del estudio, y son estas las que van tejiendo el sentido de la fd en posgrados. De por sí, para hacer análisis interpretativos de la fd se anudan a lo anterior las ideas desarrolladas en la Universidad de la Salle, Colombia, por Londoño (2010) quien emprendió un estudio sobre los retos y exigencias de la fd en Colombia y que lo condujo a reflexionar sobre el valor agregado que esta transfiere al desarrollo profesional de lxs maestrxs.

Los retos pedagógicos y los didácticos, como un componente indispensable que busca acercar a lxs profesorxs a las posibilidades que ofrece la reflexión pedagógica y didáctica para la cualificación de los procesos de enseñanza y aprendizaje; y las estrategias para la formación que permiten ubicar una variedad de alternativas y mecanismos para tener en cuenta en las propuestas de desarrollo y actualización profesoral. Xlx maestrx en cualquiera de los lugares de labor (colegio o universidad), requiere de procesos de formación, encontrará un discurso más construido desde los mismos escenarios de formación y actualización. Al respecto, Londoño (2010, p. 29) considera que 
En tal sentido, la formación docente no es una estrategia para enseñar a enseñar, sino un asunto de mucho más fondo: los cambios en las teorías y enfoques pedagógicos y didácticos que siempre tienen algo que aportarnos; la masificación del mundo escolar; el nuevo tipo de estudiante, dados los cambios generacionales y culturales; las nuevas generaciones de profesorxs; las estructuras institucionales y retos frente a nuevas formas de ver la universidad; entre otros muchos aspectos, nos hacen ver que la formación es una necesidad no solo de actualización, sino de atención a todos estos retos y exigencias.

Efectivamente, no se habla de formación como un mecanismo para logros personales o beneficios salariales, este escenario permite comprender las lógicas cambiantes del entorno escolar, las nuevas formas de enseñanza y de aprendizaje, los nuevos modos didácticos y las alternativas para transformar el hacer dxlx maestrx. Son algunos de los lugares en donde muy posiblemente “agujeree" la fd. Incluso, bien lo dice el autor, las nuevas generaciones requieren de otras formas y estrategias de enseñanza, donde la fd a nivel posgrado y continua, brinda su construcción y entendimiento.

Otra línea de análisis sobre la fd la propone De Lella (2003, p. 23) quien considera que uno de los ejes fundamentales para su estudio son las prácticas docentes, abordadas desde la reflexión, que

Parte de las situaciones concretas (personales, grupales, institucionales, sociopolíticas), que intenta reflexionar y comprender con herramientas conceptuales, y luego vuelve a la práctica para modificarla. Se dialoga con la situación interpretándola, tanto con los propios supuestos (prácticos, teóricos) como con otros sujetos reales y virtuales (alumnxs, colegas, autoridades, autorxs). 
Postura que se relaciona con las ideas propuestas por Nocetti y Medina (2017), dado el carácter reflexivo con que se mira la fd y su principal escenario, las prácticas de lxs maestrxs. Quisiera ahondar unas líneas en este trazo ${ }^{13}$, y más, cuando encuentro un estudio que realizó el Instituto para la Investigación Educativa y el Desarrollo Pedagógico -IDEP- bajo la orientación de Martínez, et al. (2015, p. 27), relacionado con la fd en Colombia, y una de sus disertaciones alude al hecho que xlx maestrx carece de confrontaciones pedagógicas con sus pares y unos mecanismos específicos para hacer visible su saber, además "la propuesta de desarrollo profesional docente, afirma la condición dxlx maestrx como funcionarix acríticx al servicio del sistema y no su condición de profesional de la pedagogía”.

Este es otro de los supuestos que aborda esta tesis y que líneas atrás se mencionó, haciendo referencia al fuerte cuestionamiento que se hace a las políticas neoliberales que configuran los escenarios educativos en Colombia. A esto se le suma que la fd para el gobierno ha sido sinónimo de "capacitación", argumento que desarrolla el estudio del IDEP, cuando asevera con franqueza que la fd "se diluye o se materializa en acciones de capacitación" (Martínez, et al., 2015, p. 23). Sumado a esta forma de asumir la $\mathrm{fd}$, es atravesada por las intenciones de "calidad educativa" que manifiesta el gobierno, reflejadas en mediciones y acumulaciones de conocimientos por parte de lxs estudiantes; y asumidas por lxs maestrxs como tecnicismos y reguladores mecánicos para

\footnotetext{
${ }^{13}$ Al referirse al "trazo" se habla de lo que se quiere resaltar, delinear. Se toma la definición del latín tractus que quiere decir arrastrado, camino, recorrido. El trazo o los trazos en el contexto de esta investigación se refiere a los recorridos epistemológicos, metodológicos construidos. Hace referencia, también a lo que delinean lxs maestrxs en sus trayectorias formativas y de experiencia. Es trazar las palabras para relatar estas trayectorias.
} 
“calificar" el desempeño y el desarrollo fugaz de competencias técnicas y propias para agudizar la "constelación obrera” del país.

Hago un retroceso breve para decir que es en este punto álgido del discurso polarizado y politizado, que la fd debe (categóricamente) asumirse desde la reflexión crítica y las intenciones propositivas dxlx maestrx que continua su formación posgradual. A esto se entrelaza la imperante necesidad de reflexionar sobre la práctica docente, como lo propone De Lella (2003, p. 23), iniciar un proceso de familiarización con lo que hace, dice y plantea desde la condición propia dxlx maestrx,

Unx docente abierto, con competencias polivalentes; entre otras, y muy especialmente, con la capacidad de partir de la práctica en el aula, institucional, comunitaria, social; y de identificar, explicitar, poner en cuestión y debatir tanto sus principales supuestos, rutinas y estereotipos.

Es movilizarse y modificar la configuración de "función docente" a "ser maestrx" (Martínez, et al., 2015, p. 27), esto implica generar un carácter reflexivo desde la fd inicial y avivarla en la fd posgradual, acción que se hace sencilla, ya que, por lo general, el total de lxs estudiantes que ingresan a las maestrías en educación son maestrxs en ejercicio, sea de colegios públicos o privados. Este factor incide en que xlx maestrx tiene una comprensión, sea prematura o de expertx de las dinámicas y tramas que se configuran en los ambientes escolares. Y muchos han vivido las "tempestades" de las políticas públicas en educación y su carácter inflexible. 
Posición que le permite al docente en formación posgradual hacer aperturas en su modo de actuar y abordar las condiciones, prácticas y normativas que rigen los escenarios educativos de modo crítico y propositivo. A estas aperturas analíticas sobre la fd, Fernández (2012, p. 13) en las discusiones generadas en su estudio sobre la fd y una aproximación biográfico-narrativa en Argentina, considera que estamos en un tiempo donde se ve la necesidad de estudiar la fd desde el "foco del reconocimiento y las posibilidades de transferencia de las buenas prácticas docentes".

Indiscutiblemente, el objeto principal de la fd es aportar a las prácticas docentes, desde perspectivas disciplinares como lo pedagógico y didáctico; y, también desde miradas de análisis como áulico y escolar. A partir de estos procesos es que xlx maestrx fortalece y re-nueva sus prácticas, genera otros escenarios reflexivos para el desarrollo de sus enseñanzas, es decir, permite que lo enseñable se asuma desde otras posturas (propositivas, argumentativas, críticas, sociales) incrustadas en el mismo contexto donde habita el docente y sus saberes.

En esta línea de abordaje de la fd, hay un estudio desarrollado en Argentina por Alliaud, et al. (2008) en el que resaltan la importancia de adentrarse en las experiencias de lxs maestrxs para revisar con detalle sus prácticas, cita a Schön quien considera que el mejor inicio para indagar por las prácticas de lxs maestrxs es iniciar con la pregunta “¿Qué podemos aprender a partir de un detenido examen de la práctica?” (Schön, citado por Alliaud, et al., 2008, p. 1). Y luego, continúan diciendo estos investigadores "la práctica es formadora solo 
en la medida en que sea objeto de una práctica reflexiva y de un diálogo productivo con referentes teóricos, formalizados, de la pedagogía” (p. 3).

Sin embargo, la trama y la tendencia que emerge con esta pesquisa es que desde el análisis de las prácticas que desarrollan lxs maestrxs se puede hablar de fd. Consideran que la "escuela, en tanto lugar de trabajo, suele ser reconocida por la mayoría de lxs maestrxs como el ámbito que más influencia tiene sobre su formación para el desempeño profesional concreto" (Schön, citado por Alliaud, et al., 2008, p. 1). Aquí conviene detenerse un momento para decir que cuando unx maestrx decide dar continuidad a su formación, necesariamente, involucra todos los entramados que acontecen en su cotidianidad docente.

Uno de estos entramados son sus prácticas, las que suceden en su cotidianidad docente, y en este aspecto, el estudio realizado por Camargo, et al. (2007, p. 5) cuyo propósito fue indagar por las realidades y necesidades formativas de lxs maestrxs de primaria y bachillerato de Colombia, centró su atención en lo que hace xlx maestrx en la escuela, razón para emprender la investigación y "a partir de su visión, vivencia y experiencia de trabajo en las instituciones escolares y en el aula de clases", comprender la fd o como ellos lo llaman "realidades formativas".

De este modo, uno de los hallazgos de esta investigación está determinado por lo que hace xlx maestrx en su cotidianidad, es decir, en sus prácticas, partiendo de que estas están configuradas desde diversos ámbitos, son "trazadas" desde lo social, cultural, político, escolar, profesional y educativo. Prácticas que son atravesadas por el carácter pedagógico del ser maestrx y que "consolidan un 
pensamiento crítico, de modo que se convierta en transformadorx de su ser, hacer y conocer [...] unx maestrx que pueda fijar la mirada en el aula y las distintas relaciones emergentes de ella" (Calvo, et al., 2008, p. 35).

Pero volvamos al asunto sobre los entramados que atraviesan la fd $d x l x$ maestrx, en efecto, hablar de sus prácticas, es solo una parte de sus atributos; otro aspecto que se convierte en parte de ese entramado cuando el docente se está formando en posgrados es la aparición de la investigación atada al primer trazo: las prácticas; y, suscrita a la naturaleza misma de la fd, que es su carácter reflexivo y manifestada en lxs maestrxs desde la reflexión espontánea de su quehacer. La investigación en la fd se caracteriza por su singularidad, incertidumbre, puestas en escena, alteraciones y su condición artística; frente a ello, el estudio en Colombia realizado por Martínez, et al. (2015, p. 73) aseveran que la formación posgradual se trata de un "proceso cuya columna vertebral es la formación investigativa que vincula directamente al sujeto-maestrx, con la posibilidad de incorporar prácticas investigativas a su quehacer".

Por eso puede decirse que la investigación es el trazo más notorio en la fd, y es el que conlleva a re-trazar otras formas de ser, hacer y conocer dxlx maestrx. En líneas anteriores, se asumió la idea que la investigación parte de la re-visión y reflexión de lo que sucede al interior de las prácticas dxlx maestrx, y aquí Martínez, et al. (2015, p. 73) en uno de sus hallazgos y resultados consideran que No se trata de que un maestrx se convierta en investigadorx y no quiera volver a hacer maestrx, sino que asuma la investigación como el lugar donde se pueden poner 
a prueba la configuración de su experiencia como maestrx, donde objeto su quehacer y se producen otras experiencias de subjetivación.

Estas derivaciones discursivas que emanaron de este estudio realizado en Colombia dan lugar a un pequeño trazo del relato de una maestra participante en la investigación que se está escribiendo y que encuentra el significado conveniente para "investigar":

La formación exige esfuerzo, disciplina, entereza de uno como persona, exige hacer priorizaciones, cambios en el estilo de vida, horarios, en fin, es toda una organización de los tiempos y tareas a desarrollar. El cumplimiento de ello le garantiza éxitos. Profesionalmente, la maestría me ha permitido transformar mi cosmovisión de la labor docente, entender con mayor claridad los sistemas y subsistemas que coexisten en la escuela, resignificar mi labor, empezarle a dar valores agregados y a seguir reflexionando sobre ella, pero sistematizando los hallazgos. (Adela Ortiz ${ }^{14}, 2017$. Historia de vida. Valledupar, Colombia)

Investigar para xlx maestrx en ejercicio que se está formando en un posgrado, necesariamente debe equipararse en su quehacer, estar en sintonía con las prácticas y el desempeño institucional, no solo lo áulico sino la generalidad de lo que acontece en la escuela, por ello, la maestra Adela hace referencia a un ejercicio que en la mayoría de lxs maestrxs es difícil de hacer, y se trata de "sistematizar los hallazgos". No es muy común encontrar maestrxs que realicen bitácoras, diarios de campo de sus prácticas, y los que lo hacen, se adscriben en ese mundo idealista dxlx maestrx reflexivx, que se cuestiona, no para ser crítico "depresivo" de lo que hace, sino para desarrollar mejores prácticas.

\footnotetext{
${ }^{14}$ Se usarán nombres ficticios a solicitud de Ixs participantes.
} 
Frente a ello, de la investigación desarrollada por Camargo, et al. (2007, p. 6) con docentes colombianxs, surgió otra conclusión que hace referencia a la necesidad de una fd dirigida a estudiar lo que acontece en su cotidianidad, específicamente, sus prácticas pedagógicas, consideran ellxs que "en ese sentido, es posible entender la solicitud recurrente de una formación más práctica”.

Con esto se quiere decir que, al encontrar un punto de equilibrio entre la fd y la vinculación directa con las prácticas docentes, se logran consolidar investigaciones in situ, que sean una manifestación de lo que hace y conoce $x \mathrm{~lx}$ maestrx en la escuela, y por supuesto, se incremente el número de maestrxs interesadxs en hacer bitácoras de su quehacer y prácticas pedagógicas. A estas ideas se les suman los postulados de la investigación que realizó Vergara (2017, p. 47), que se centró en ahondar sobre la práctica cotidiana dxlx maestrx mexicanx, desde los procesos de fd en posgrados. Y uno de los hallazgos que emergen al hacer un estudio sobre esta práctica, tiene que ver con que la fd "tiene una finalidad innovadora".

Lo innovador tiene que ver con las nuevas aperturas que se pueden lograr en las prácticas cotidianas, dice la investigadora,

No se pretende solo poner al día xlx profesorx en el contenido de su asignatura, sino también en el dominio de los métodos y técnicas que ha de emplear. La formación es un ascenso de lo particular a lo general; esto es, de ir logrando cada vez una mayor autonomía en la toma de decisiones sobre las acciones adecuadas a realizar (Vergara, 2017, p. 47). 
Ese es el vínculo que se genera con mi investigación, uno en el que la fd en la maestría se configura de tramas desde la reflexibilidad y la inserción directa de las prácticas pedagógicas y escolares que realiza xlx maestrx en la escuela. Estas tramas son visibles en las posiciones investigativas que se establecen en los escenarios de formación con lxs maestrxs en ejercicio; y que los primeros acercamientos son basados en un diagnóstico preliminar sobre lo que se hace en las escuelas y colegios para rastrear algunas situaciones que requieren ser investigadas. Estas tramas parten necesariamente de volver hacia las prácticas cotidianas dxlx maestrx.

De otro lado, Parra, et al. (2010) en el artículo resultado de la investigación "Rutas de formación docente en la universidad colombiana", hacen un estudio descriptivo-explicativo a nivel nacional en 44 universidades colombianas, acerca de las estructuras, métodos, estrategias y procedimientos de las rutas de formación de Ixs profesorxs universitarixs en las universidades privadas colombianas.

Dando respuesta a cómo están formando las universidades privadas a sus profesorxs y proponer criterios y lineamientos generales para el diseño de rutas de fd. Esta investigación llegó a la conclusión de que hay una aceptación generalizada de que la buena labor ${ }^{15}$ docente es un factor determinante para el reconocimiento de la buena labor institucional; no obstante, esto no se refleja adecuadamente en el ámbito institucional, ya que los factores son insuficientes y no del todo pertinentes a las rutas de formación docente. Llegando a una

\footnotetext{
${ }^{15}$ La "buena labor" hace referencia a las buenas "prácticas" o a lo que se hace bien desde la docencia o la institución. Término emergente de esta investigación.
} 
afirmación certera "la formación de lxs profesorxs es una tarea todavía pendiente en la universidad privada colombiana" (Parra, et al., 2010, p. 421).

Este estudio confirma la necesidad de continuar indagando por la fd y en avance que ha tenido en el ámbito universitario del país, no solo pensar en lxs maestrxs que laboran en este sector, sino que revisar otras esferas, como lo son Ixs maestrxs que laboran en instituciones de primaria y bachillerato. Es así que la investigación de lxs autorxs mencionadxs llega a la conclusión que con las nuevas políticas de educación y con la implementación de proyectos macro que permiten la formación de maestrxs a nivel de posgrado por parte del gobierno, las miradas se modifican, pensando que es importante analizar la fd en el país a nivel posgrado, haciendo interrogantes en el siguiente orden: cómo están formando en las universidades, cuáles son los criterios de formación y cómo desde las maestrías en educación están formado maestrxs para responder acertadamente a las dinámicas y transformaciones socioeducativas actuales del país.

Gaviria, Delgado y Rodríguez (2009) destacan los elementos constitutivos de la identidad profesional de lxs maestrandxs en Colombia, que se desempeñan como maestrxs universitarixs, a partir de la identificación, análisis e interpretación de tres factores: el sentido de sí mismo, el reconocimiento de sí mismo, y el conocimiento de lo que piensa y siente xlx profesorx universitarix sobre su quehacer pedagógico. 
De estos factores emergieron los relatos de lxs maestrxs que constituyen la identidad profesional docente, desde un contexto social amplio que sobrepasa las mismas prácticas pedagógicas; la consideración de tales factores dio cuenta del impacto en la definición que tienen lxs maestrxs de sí mismxs, definición que necesariamente implica una resignificación. Por lo cual, se vincula a la investigación en la medida en que estudia la fd desde la narrativa y cómo lxs mismxs maestrxs se ven reflejadxs en su quehacer y en lo que les permite construirse permanentemente desde la práctica, todo esto vinculado a la formación como maestrandxs del campo de la educación.

Díaz y Santamaría (2009) profundizan sobre las reflexiones de lxs maestrxs colombianxs en torno a sus procesos de formación, interpretando las concepciones y reflexiones acerca de la formación de lxs profesorxs presentes en las narrativas de lxs cursantes de la Maestría en Docencia de la Universidad de La Salle durante el segundo semestre del año 2007.

Igualmente, reconocen que la formación de lxs profesorxs incluye: la formación inicial y la formación continua; y dentro de cada uno de estos procesos intervienen elementos tales como las instituciones y espacios orientados hacia la fd; el desarrollo de la teoría y la práctica pedagógica y el fortalecimiento de la investigación en el campo pedagógico y el saber específico. Los autorxs tuvieron en cuenta la investigación biográfica narrativa, porque se interesa por reconocer y comprender la voz de lxs profesorxs, posibilitando el acceso a la información para conocer de manera profunda las concepciones de lxs maestrxs sobre el tema investigado. 
De este recorrido por diversas posturas investigativas sobre la fd, que compaginan con los propósitos investigativos de esta tesis, se procura hacer una relación entre estas posturas y sus aportes como antecedentes a esta pesquisa en la tabla 1.

\section{Tabla 1}

Sinopsis de las tendencias emergentes en el estado de la cuestión (antecedentes)

\begin{tabular}{|c|c|}
\hline Tendencias & $\begin{array}{l}\text { Reflexión que vincula lo rastreado en los antecedentes } \\
\text { con los propósitos investigativos de la tesis }\end{array}$ \\
\hline $\begin{array}{l}\text { El acto práctico-reflexivo } \\
\text { de la fd }\end{array}$ & $\begin{array}{l}\text { La fd en posgrados como escenario para desaprender, se } \\
\text { convierte también, en un escenario para re-conocer de } \\
\text { nuevo las prácticas propias, desarticular lo que se ha } \\
\text { tornado mecánico, convertirlo en discusiones, diálogos, } \\
\text { otros aprendizajes, aperturas a nuevos saberes y la } \\
\text { manifestación de otros conocimientos. } \\
\text { La reflexibilidad conlleva a crear nuevas aperturas } \\
\text { pedagógicas, escolares, formativas que permiten xlx } \\
\text { maestrx en ejercicio hacer de lo mismo un nuevo trazo, un } \\
\text { "re-trazo }{ }^{16 ” .} \text {. } \\
\text { Aquí, se retoman las agudas palabras de Freire (2004, p. } \\
\text { 11) } \\
\text { El acto de cocinar, por ejemplo, supone algunos saberes } \\
\text { concernientes al uso de la estufa, cómo encenderla, cómo } \\
\text { graduar para más o para menos la flama, cómo lidiar con ciertos } \\
\text { riesgos aun remotos de incendio, cómo armonizar los diferentes } \\
\text { condimentos en una síntesis sabrosa y atractiva. La práctica de } \\
\text { cocinar va preparando al novato, ratificando algunos de aquellos } \\
\text { saberes, rectificando otros, y posibilitando que se convierta en } \\
\text { cocinero. La práctica de navegar implica la necesidad de saberes } \\
\text { fundamentales como el del dominio del barco, de las partes que } \\
\text { lo componen y de la función de cada una de ellas, como el } \\
\text { conocimiento de los vientos, de su fuerza, de su dirección, los } \\
\text { vientos y las velas, la posición de las velas, el papel del motor y } \\
\text { de la combinación entre motor y velas. En la práctica de navegar } \\
\text { se confirman, se modifican o se amplían esos saberes. } \\
\text { La reflexión crítica sobre la práctica se torna una exigencia de la }\end{array}$ \\
\hline
\end{tabular}

16 Término utilizado para hablar de la deconstrucción. Hace referencia a lo nuevo que se puede hacer con los trazos. Lo que hay por hacer con algo. Derrida (1989). La deconstrucción en las fronteras de la filosofía. Barcelona: Paidós. 


\begin{tabular}{|c|c|}
\hline & $\begin{array}{l}\text { relación Teoría/Práctica sin la cual la teoría puede convertirse } \\
\text { en palabrería y la práctica en activismo. } \\
\text { La fd no solo se manifiesta en el acto de reflexión, ella } \\
\text { también brinda aprendizajes, teorías, sin embargo, xlx } \\
\text { maestrx en formación con sus trayectorias ya construidas } \\
\text { puede movilizar lo estático, y esto lo logra al generar una } \\
\text { acción vinculante entre teoría - práctica - reflexión. } \\
\text { Antecedentes: De Lella (2003); Calvo (2004); Alliaud (2010); } \\
\text { y, Nocetti y Medina (2017). }\end{array}$ \\
\hline $\begin{array}{l}\text { La investigación como eje } \\
\text { "natural" de la fd }\end{array}$ & $\begin{array}{l}\text { Por lo general, la fd en posgrados está atravesada por } \\
\text { entramados investigativos, lxs maestrxs en formación } \\
\text { suelen desviar su atención hacia lo que traerá este nuevo } \\
\text { estudio en términos de teorías, pautas para enseñar, } \\
\text { operaciones de orden metódico y con frecuencia } \\
\text { "recetario" de [enseñar] a enseñar. } \\
\text { Sin embargo, las nuevas apuestas formativas, incluso } \\
\text { asumidas para las maestrías en educación acreditadas de } \\
\text { alta calidad por el Consejo Nacional de Acreditación de } \\
\text { Colombia, han relegado los contenidos densos y } \\
\text { disciplinares, y las grandes teorías sobre educación desde } \\
\text { los griegos hasta la actualidad por los discursos inclusivos y } \\
\text { contextualizados, atrayendo xlx maestrx en formación por } \\
\text { "comprender sus prácticas docentes" "ahondar en sus } \\
\text { experiencias" y "volver a la investigación in situ". } \\
\text { Escenarios que se han vuelto comunes en la fd posgradual y } \\
\text { que tienen que con lá } \\
\text { [teoria]+[práctica]+[investigación]. Dinámica en su forma y } \\
\text { contenido, porque no se trata de quedarse en lo anecdótico } \\
\text { de la práctica, sino ir más allá, pensar los hechos de la } \\
\text { práctica desde lo problémico, lo investigativo, para que de } \\
\text { esta forma se logre teorizar y generar nuevos/otros } \\
\text { saberes/conocimientos, pero esta vez situados y vinculados } \\
\text { con las realidades próximas dxlx maestrx. } \\
\text { De esta forma, es que la investigación se manifiesta a } \\
\text { primera vista como el "monstruo" de lxs maestrxs en } \\
\text { formación posgradual, la razón, es que no es fácil hacer } \\
\text { investigación, y tampoco quiere decir que se deje de ser } \\
\text { maestrx para hacerla, al contrario, el lugar dxlx maestrx, } \\
\text { su saber es lo que alimenta la investigación, tarea no muy } \\
\text { sencilla, ya que implica movilizar creencias, lugares } \\
\text { arraigados, memorias, contenidos instalados que ha } \\
\text { establecido xlx maestrx en sus prácticas. } \\
\text { La investigación va irrumpiendo los lugares dxlx maestrx en }\end{array}$ \\
\hline
\end{tabular}




\begin{tabular}{|c|c|}
\hline & $\begin{array}{l}\text { la medida que se lo permita, es xlx maestrx quien decide el } \\
\text { momento preciso para emprender este trayecto como } \\
\text { "viajero en sus propios trazos”. } \\
\text { Antecedentes: Parra, et al. (2010); Londoño (2010); } \\
\text { Martínez, et al (2015); y, Vergara (2017). }\end{array}$ \\
\hline $\begin{array}{l}\text { El quehacer docente } \\
\text { Las prácticas cotidianas } \\
\text { dxlx maestrx } \\
\text { Continuar formándose }\end{array}$ & 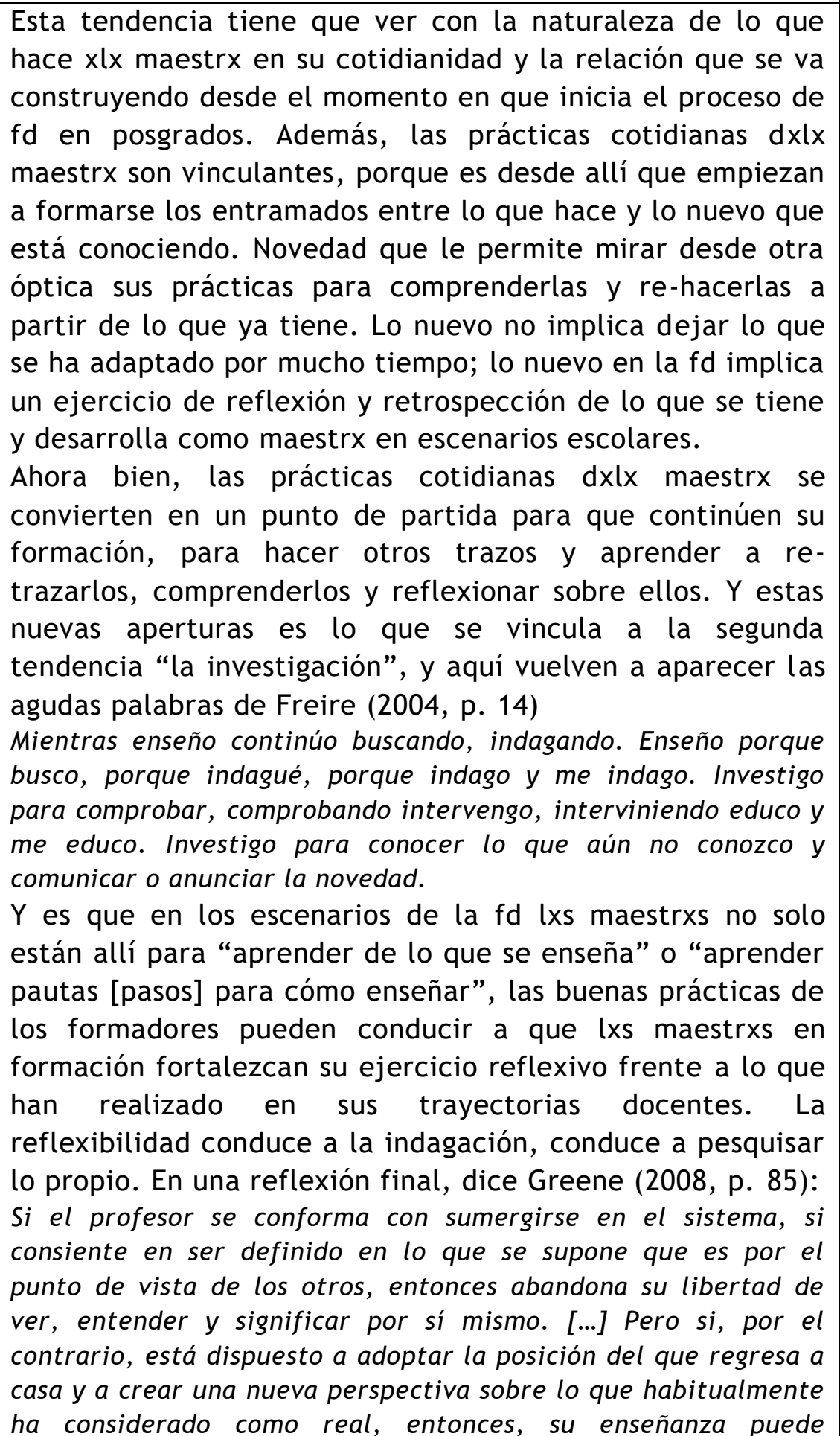 \\
\hline
\end{tabular}




\begin{tabular}{|c|c|}
\hline & $\begin{array}{l}\text { convertirse en parte del proyecto de una persona vitalmente } \\
\text { abierta a sus estudiantes y al mundo. } \\
\text { Antecedentes: De Lella (2003); Alliaud (2010); Nocetti y } \\
\text { Medina (2017); Martínez, et al. (2015). }\end{array}$ \\
\hline $\begin{array}{l}\text { Articulación de la fd con } \\
\text { la cotidianidad de las } \\
\text { escuelas. } \\
\text { El sentido innovador de la } \\
\text { fd. Las nuevas aperturas. }\end{array}$ & 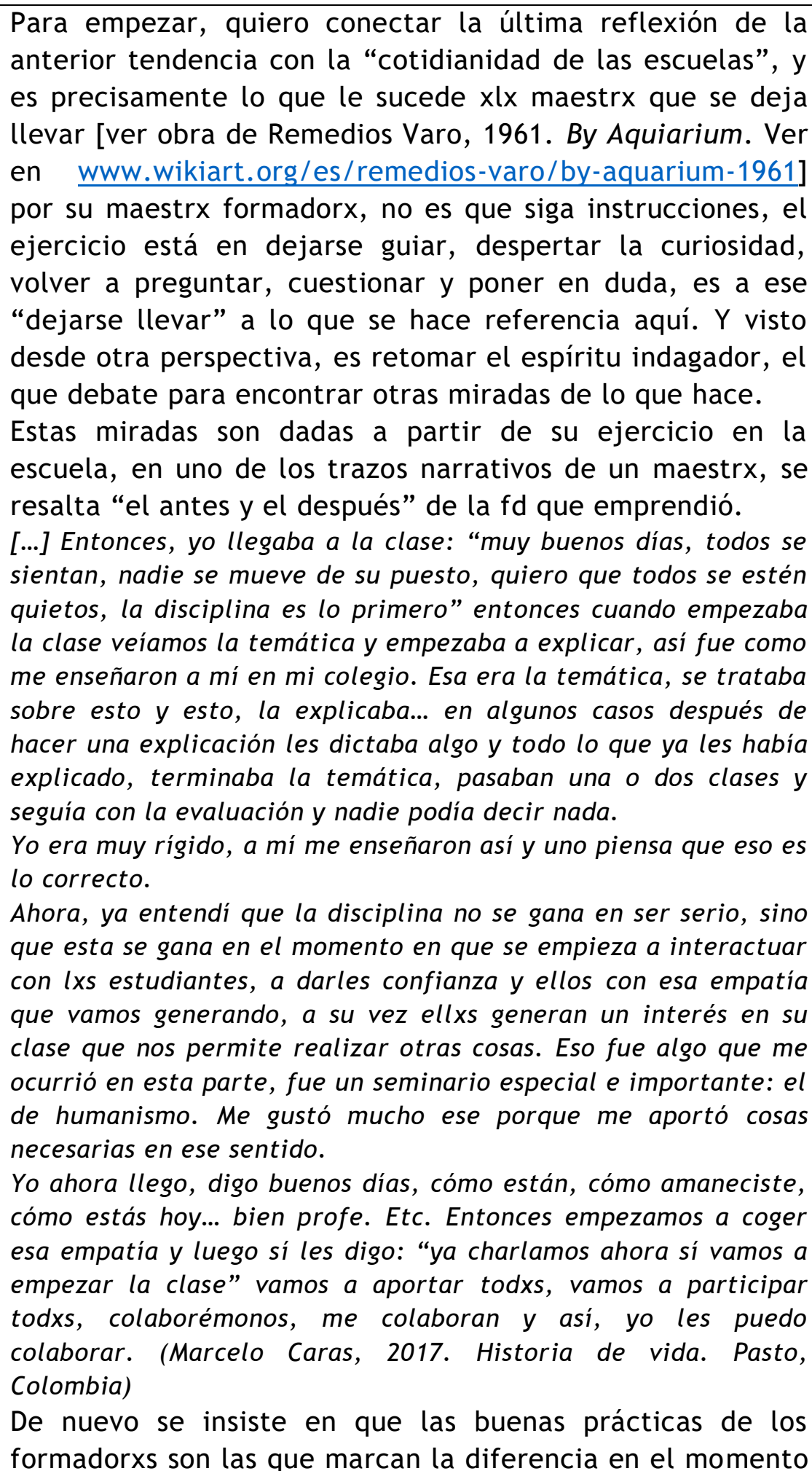 \\
\hline
\end{tabular}




\begin{tabular}{|l|l|}
\hline enenseñar en espacios de la fd posgradual. Las buenas \\
enseñanzas no están marcadas únicamente por contenidos \\
temáticos, grandes teorías o descubrimientos universales: \\
estas son espacios para establecer nuevos diálogos sobre los \\
acontecimientos que circulan en la cotidianidad de lxs \\
maestrxs, en los entornos escolares, en los contextos \\
cercanos de lxs estudiantes y colegas. Se diferencian por el \\
contenido versátil y reflexivo con que se mire la enseñanza \\
y el ser/hacer dxlx maestrx. \\
Por otro lado, de aquí se desprende también, el sentido \\
innovador que tiene la fd posgradual, entre más se \\
devuelva la mirada hacia lo propio [las prácticas cotidianas] \\
más será la actitud de reflexibilidad que fomente entre lxs \\
maestrxs en formación, y, desde luego, los trazos \\
investigativos se tornarán robustos y generadores de nuevas \\
aperturas, en prácticas docentes renovadas de enseñanza y \\
escolares. \\
Antecedentes: Vergara (2017); Camargo, et al. (2007); \\
Martínez, et al. (2015); Gaviria, et al. (2009).
\end{tabular}

Fuente. Suceso producido por la investigadora. 


\section{SEGUNDA PARTE}

\section{Análisis hermenéutico desde la diversidad teórica sobre la fd}

La segunda parte de la pesquisa narrativa hace un recorrido por algunas posturas sobre la $\mathrm{fd}$, centrando la atención en lo que conforma la fd, es decir, entendiéndola como escenario dinámico que convergen diversas formas de aprendizajes, metodologías, rutas, didácticas, saberes, experiencias, modos de enseñar, investigaciones, proyectos, pedagogías y otras manifestaciones que a lo largo del capítulo cuatro son explicadas con más detalles.

El contenido de esta parte conduce xlx lectorx a emprender un recorrido por miradas de expertxs en la fd, ahondando en asuntos como la práctica del docente, las experiencias y las trayectorias que configuran el oficio $d x l x$ maestrx. Las comprensiones que se logran desdibujar en estos capítulos son el pretexto para conocer la vertiente por donde se re-traza la fd en este estudio, que no es solo como proceso de capacitación o configuración de aprendizajes para aplicarlas en los contextos escolares. La fd que se aborda aquí tiene que ver con la necesidad de repensar lo que se hace y lo que es xlx maestrx, es una fd en movimiento, dinámica y pensada desde la reflexión e investigación de la cotidianidad dxlx maestrx.

Quiere decir que es una fd que conduce a los cuestionamientos sobre el oficio de ser maestrx, no es el "recetario" de fórmulas para enseñar, sino que es considerada como la apertura a otras posibilidades de re-trazar el oficio dxlx maestrxs. Todo conduce a que en el quinto capítulo se aborde la noción del 
“maestrx emancipadx", tratándose de aquellx maestrx que constantemente cuestiona lo que acontece en su cotidianidad, conduciéndolo a la reflexión constante de lo que hace, comprende y enseña a lxs estudiantes. La emancipación dxlx maestrx lo conduce a pensar en otros escenarios de formación, ver la necesidad de salir de la zona de confort para crear otras formas de vinculación directa con su profesión y oficio.

En suma, esta parte desglosa al detalle lo que configura la fd desde la participación dxlx maestrx en escenarios de formación y discusiones sobre sus prácticas, y, también, desde los abordajes teóricos que se han consolidado en los últimos veinte años, especialmente, en el contexto latinoamericano. 
Capítulo IV. Fd: Tramas discursivas, tramas teóricas vinculantes

Una primera compresión de la fd es ahondando en sus raíces etimológicas, y desde allí emprender un rompecabezas analítico. Formación proviene de la palabra latina formatio, que significa dar forma a alguna cosa, hacer de la integración de las partes un todo. Esta definición invita a pensar que la formación involucra necesariamente, conceptos como desarrollo, preparación, práctica, experiencia, teoría, avance, transformación.

Centrando esta definición de formación al ámbito educativo, se puede decir que implica algo más que dar forma a algo, va más allá de "moldear”, formación se convierte aquí en un proceso permanente en el que la clave es la experiencia, en palabras de Alliaud (2010, p. 143) "para enseñar no alcanza con saber el contenido a ser enseñado; era necesario, además, conocer las formas apropiadas para su transmisión".

La formación es un proceso que se construye a partir de la práctica, la experiencia, no basta con acumular gran cantidad de información y contenidos, hay que aprender a transmitir todo ese cúmulo de datos y es allí donde se consolida una verdadera formación. Eso no es solo aplicado hacia la educación, en todos los ámbitos de la vida hay que vivenciar para formar, construir cualquier conocimiento, Freire (2004, p. 7) dice que "formar es mucho más que simplemente adiestrar”. 
Vásquez (2011, p. 33) refuerza afirmando que "la formación no es algo que podamos imponer, sino más bien un proyecto personal, inalienable". La noción de formación es aún algo primitiva, entendida como el acto únicamente de formar algo, moldear, ajustar a un molde "querer dar forma a aquello que en su esencia está deforme" (Vásquez, 2011, p. 33), de este modo, es que la formación, específicamente la docente, no solo se consagra en la universidad, teorizando el conocimiento, aprendiendo de otros formadores por medio del oído, la formación requiere de praxis, experiencia, aprender a ser formadorx formando a otrxs, la formación es la práctica del saber.

El otro término es docente, del latín docere, su significado es hacer que alguien aprenda, enseñarle a alguien. También, docente deriva del verbo decet, que quiere decir decente, apropiado, culto. Quiere decir que se podría definir docente como aquella persona que enseña a ser virtuoso, "apropiado" a alguien.

A lo largo de la historia se le ha otorgado numerosos significados al sujeto que enseña, que transmite algún conocimiento, si se recurre a la época de los clásicos, existieron dos tipos de educadorxs, el primero era el pedagogx, su labor principal era acompañar, guiar al niño en su formación, el segundo era xlx maestrx, persona sabia, respetada por lxs ciudadanxs y reconocido por su magno conocimiento sobre las cosas del mundo, eran los dueños del ágora, lugar en donde estaban rodeados por discípulos que querían aprender de ellos.

Aquellxs maestrxs sabixs no solo transmitían conocimiento, sino que su labor principal era generar reflexión y discusión en torno a ese conocimiento, es el caso de Sócrates. Los términos de pedagogx y maestrx, con el paso del tiempo 
fueron modificándose, por razones sociales, culturales, políticas e incluso religiosas. En el caso del periodo medieval, la educación giraba en torno al clero, los educadores estaban regidos por el monasterio, y normalmente eran los mismos miembros de la iglesia quienes se otorgaban el título de educadorxs. Se puede decir que en este periodo el pedagogo hacía las veces de evangelizador.

En otro periodo de la historia, la modernidad se rescata en gran medida el concepto de maestrx de la época clásica, con lxs grandes pensadorxs y sus obras que condujeron a numerosas reflexiones sobre lo que acontecía en el mundo. En este periodo vuelve la preocupación por xlx pedagogx, pensadores como Rousseau, Pestalozzi, Comenio, San Juan de la Salle y más adelante, Piaget, Dewey y otros, quienes no solo hablaron de la educación en general, sino del quehacer del educadxr, llamado en otras ocasiones, docente, profesorx, pedagogx, maestrx.

Mas, sin embargo, todos estos grandes maestrxs, definían al educadorx, como aquella persona que transmite conocimiento, pero también enseña y forma sujetos, la gran mayoría percibió al docente desde la experiencia, la capacidad que tiene de formar desde la práctica y la relación con el contexto. En palabras de Meirieu (2006, p. 15)

Unx profesorx tiene una manera especial de mirar el mundo, una manera de situarse en un proyecto de transmisión que hace que considere a lxs niños y los conocimientos de forma original. Cuando $x l x$ artista pretende conmover, el político convencer, $x l x$ profesorx se dedica a enseñar. 
Si se acude un poco a la historia dxlx maestrx en Colombia, la fd, que está reflejada en cada época, se ve que lo que se pretende es formar maestrxs para las dinámicas sociopolíticas del orden del sistema del momento. Saldarriaga (2003) concibe tres modos de pensar xlx maestrx desde finales del siglo XIX hasta el nuevo milenio, clásico, moderno y contemporáneo; el primero, se ubica desde 1886 hasta 1930, en donde xlx maestrx era un personaje público, autorizado por la iglesia, quien debía ser una persona creyente, católica, con intachables principios morales y, sobre todo, obrar de buena fe, enviado como un mensajerx de dios para salvar las almas terrenales. En este periodo la formación dxlx maestrx estaba dirigida hacia la ciencia y el arte de educar al hombre como creatura de dios, disciplinar el cuerpo, los valores humanistas y católicos y la transmisión de conocimientos. La formación se impartía por las escuelas del clero y las normales formaban maestras para la educación de los niños.

El segundo tipo de maestrx es el moderno, entre 1930 a 1946, se enmarca en unx docente políticx e industrializadx, el objeto de la formación dxlx maestrx es el humanismo liberal, "que piensa a los sujetos en relación con la nación-Estado" (Saldarriaga, 2003, p. 262). Se forman maestrxs para generar moldes industriales, productivos y acomodados en la lógica de la nación, para que capacite a las clases sociales populares, erradique el analfabetismo por medio de la técnica, memorización y la instrucción.

El último tipo de maestrx es el contemporáneo, cuyo principal objeto es generar conciencia ciudadana y consolidar valores colectivos entre sus educandxs, este es el tipo de maestrx "ideal" que pretenden formar las 
universidades, buscando acercamientos a unx maestrx criticx de su labor y lo que acontece en sus contextos inmediatos.

Sin embargo, existe un cruce inminente entre lo que proponen las universidades en cuanto fd y lo que pretende el Estado que sean lxs maestrxs formando ciudadanxs en las escuelas de todas las regiones. Esta pretensión dista sustancialmente del tipo de maestrx que se forma para generar conciencia ciudadana y social, construir comunidad y velar por la diferencia, unx maestrx que se arma de conocimiento para generar espacios de reflexión en los escenarios escolares.

El Estado en su afán por robustecer la mano de obra barata, hace su gran labor en conformar escuelas técnicas para que lxs jóvenes bachilleres le sean útiles a la sociedad y no se resguarden en saberes enfocados a la crítica, la reflexión y la conciencia ciudadana, más bien se esperan jóvenes tecnificados que sigan edificando el emporio del Estado, situado en bajos salarios, pruebas estandarizadas y recursos financieros deficientes y contrarios a las necesidades de las comunidades.

Es en este punto en el que $x l x$ maestrx formadorx puede llegar a cuestionar su labor, en términos de su papel como maestrx que quiere transformar escenarios y personas para que tengan otras perspectivas del oficio de ser maestrxs. Al respecto, Terigi (2013, p. 9) considera que es necesario reconocer

La complejidad del trabajo docente, su carácter político y su naturaleza institucional y, de suyo, colectiva. Esta conceptualización es solidaria de concebir a la educación como un derecho, lo que supone entender a la escuela como uno de los ámbitos 
sociales donde la humanidad produce la transmisión sistemática a las generaciones jóvenes, un ámbito que debe ser disputado y puesto al servicio de la producción y distribución igualitaria y colaborativa de la cultura, y respecto del cual cabe a los Estados responsabilidad principal; supone también concebir al trabajo docente como una actividad colectiva y transformadora.

Evidentemente, la idealización de la fd va dirigida a ser reconocida como un pretexto para erradicar la ignorancia y consolidar escenarios de pensamiento cultural y social en pro del desarrollo del país. Es en el periodo dxlx maestrx contemporánex en donde las universidades públicas y privadas compiten por la formación de maestrxs, por tener en sus sedes programas de alta calidad, avalados por Consejo Nacional de Acreditación -CNA-, pero que sean programas reconocidos por su alto impacto social, educativo y transformador y que sean coherentes con las necesidades territoriales en política educativa y de formación profesional (incluidas las licenciaturas).

Además, este se periodo caracterizó por el auge de tener certificados de acreditación institucional de alta calidad, las universidades emprenden la creación de programas posgraduales en el campo de la educación, especializar maestrxs para que sean "mejores maestrxs". Sin embargo, y siguiendo las ideas de Terigi (citada en Russell, Fuentealba, Hirmas, 2016) que se cuestiona por la responsabilidad que se autoproclaman las universidades con la formación de docentes, que aquí no queda en cuestionamiento, sino que pasa una frontera, considerando como debilidad los irrisorios planes con que cuentan estas instituciones en la formación de formadorxs de futurxs maestrxs. 
Debilidad que en la década de los noventa no representaba una amenaza ya que la formación de formadorxs se centraba en la cualificación profesional más allá que en la reflexión e investigación del quehacer. Su centro estaba dedicado al ascenso de escalafón en la carrera docente del Estado. Dice Terigi (citada en Russell, Fuentealba, Hirmas, 2016, p. 12)

Quienes trabajamos como tales llegamos a esta función por una combinación variable de titulaciones académicas que nos avalan para el desempeño en educación superior. Para acceder a este trabajo, la experiencia en las aulas del sistema escolar no constituye un requisito generalizado, así como tampoco se exige u ofrece alguna otra clase de antecedente formativo específico que justifique, bien sea el pasaje de maestrx y profesorx a formadorx de futurxs docentxs, bien sea el pasaje de la academia y la investigación a esa misma función.

En resumidas palabras, xlx maestrx desempeña su labor según la época y la finalidad del Estado, las entidades formadoras y la escuela. Xlx maestrx en su faceta de formadorx de maestrxs se ve en la necesidad de vincular discursos diversos, como la apuesta de educación que conforma cada gobierno, los anhelados discursos de calidad que permean las universidades, el discurso globalizado que satura al campo de la educación, las manifestaciones culturales y atípicas que se presentan en la escuela como escenario socioeducativo, centro de contenidos, pruebas estandarizadas y disminuido en humanización. Además, xlx maestrx formadorx debe garantizar suficiencia en su disciplina, generación de contenidos apropiados para la fd, investigación, titulaciones y otros requisitos que le permitan ser formadorx de maestrxs. Aunque, queda el sinsabor: ¿cómo formarse para formar docentes?, ¿quién lo hace?, ¿desde qué perspectiva? Habría 
que recurrir a lo que sostiene Terigi (2013) en sistematizar las prácticas, para recuperar el saber y la pertinencia de la fd.

Por otro lado, la fd se reconfigura desde la combinación precisa de teoría y práctica, aprendizaje y enseñanza y la docencia, según Davini $(2008$, p. 7) "se expresa en una práctica profesional específica que pone en funcionamiento los medios adecuados para la transmisión educativa conforme determinadas finalidades e intenciones". La fd es el lugar en donde xlx docente puede adquirir las herramientas necesarias para continuar edificando su práctica docente, es también donde puede repensar y re-significar su quehacer, su actuar como docente.

A propósito, Messina (2008, p. 84 ) propone una fd en movimiento, en la que se cambie la noción de que aún formar es continuar en un recinto cerrado recibiendo instrucciones o continuar pensando "en ese esquema, hay uno que sabe -la institución que realiza la formación- y otro que no sabe, el participante de la formación. La relación es desigual". La fd, teniendo en cuenta esta perspectiva, necesariamente es dinámica, favorecer la relación entre la teoría y la práctica, o mejor construir nuevos e innovadores medios que permitan comprender un ejercicio formativo desde la misma experiencia, Messina (2008, p. 84) considera que

Una formación que recupera la experiencia de los sujetos y crea condiciones para su transformación. Una formación así concebida permite la autonomía de los participantes, la constitución de una capacidad crítica, la comprensión de que las cosas no son inmutables, sino que pueden ser "así o de otro modo". Una formación de este tipo se realiza en comunidad, el otro es mi espejo, mi fuente de aprendizaje 
y el grupo potencia las capacidades de cada uno y del todo. Una formación así abordada se libera de la idea de metodología, de entregar un manual de procedimientos. Al mismo tiempo, la formación deja de estar al servicio del control, de la recentralización, del exclusivo cumplimiento de metas institucionales.

Esto es clave para entender la fd e identificarla desde la propia mirada de lxs maestrxs, para develar la pretensión de su fd y el significado que le puede asignar siendo docente en ejercicio, pero también docente estudiante. La definición de Messina permite estructurar adecuadamente la fd, partiendo de la misma experiencia de su quehacer, hacer que $x l x$ maestrx se defina no desde un centro educativo donde recibe su formación, sino desde su propio actuar, desde sus trayectorias que ha construido como docente.

Si bien es cierto que el centro de esta perquisición ${ }^{17}$ es la fd en posgrado, no hay que descartar la necesidad de pensar la biografía académica del docente, siendo este aspecto el elemento para comprender las manifestaciones de su propio relato y así re-trazar aquellas expresiones teniendo en cuenta las transformaciones socioeducativas que transversalizan su quehacer, hacer y ser como docente.

En palabras de Alliaud (2011, p. 93) para comprender desde dónde se aborda la fd y cuál su intencionalidad, esas manifestaciones,

Son esas narraciones, esas voces, esos relatos producidos que trascienden lo que aconteció (pero que toman el acontecimiento vivido como materia prima del relato), las que tienen un alto poder formativo tanto para quienes los producen, como para sus posibles oyentes.

\footnotetext{
${ }^{17}$ Sinónimo de pesquisa, indagación, investigación.
} 
Esta primera trama discursiva sobre la fd tiene que ver con lo que rodea a la fd partiendo de aquellas narrativas formativas y académicas que tienen lxs maestrxs. Narrativas que se van forjando en distintos acontecimientos de su quehacer docente, escolar y pedagógico que no solo están presenten en las experiencias formativas, como docente o como aprendiz, sino que están entrelazadas en diferentes sucesos. Al respecto, Alliaud, et al. (2008, p. 3) consideran que "la formación entendida como narración, como relato de experiencias marcadas con la huella del que narra y experimenta, podría ser más convocante, más marcadora, atractiva e impactante".

La formación está vinculada directamente con los que narran, aquellxs maestrxs que logran re-hacer sus relatos formativos y permiten que sean vueltos a re-trazar, es desde los trazos narrativos ${ }^{18}$ que emerge el carácter reflexivo del hacer dxlx maestrx. Vergara (2017, p. 43) considera que

Estimular la capacidad de juicio crítico de lxs profesorxs es una de las aspiraciones más ambiciosas en el ámbito de la formación, pero es importante señalar que una auténtica cultura crítica depende de factores complejos y difíciles de producir; en primer lugar, de un conocimiento amplio y riguroso de los objetos sobre los cuales se ejerce el juicio; en segundo lugar, de formas de ejercicio intelectual que exigen la coherencia, la contrastación y la demostrabilidad de los saberes y de las valoraciones sobre ellos.

Estos trazos narrativos tienen que ver con la capacidad de cuestionamiento, criticidad y reflexividad que desarrolle $x l x$ docente no solo en los espacios de formación sino en la cotidianidad docente de hacer sus prácticas. Los trazos

18 Termino creado en esta investigación, desde ahora usado para hablar de construcciones narrativas, experiencias contadas. 
suceden, no son forzados a ser. Por eso la metáfora dxlx maestrx como artesanx, este último se vale de su ingenio para hacer sus artesanías, hace de su oficio un arte. Así mismo, pasa con el oficio dxlx maestrx, se vale de su profesión para enseñar. Hace de los contenidos aprendidos en escenarios de formación lo enseñable, es un arte en el cual xlx maestrx re-pinta, re-traza lo que ha sucedido en las experiencias formativas y académicas.

Cabe ahondar un poco más en esta fabulosa metáfora "maestrx como artesanx", lo que convoca a Alliaud (2017, p. 85) cuando dice "llegar a saber hacer algo bien lleva tiempo". $Y$ es justo ello, que posee xlx maestrx: la vocación.

La vocación dxlx maestrx hace referencia al gusto por la enseñanza, al verdadero sentido que tiene ser maestrx, que es enseñar lo que sabe a otrxs, Meirieu (2006, p. 34) hace ver esta "vocación" como el acto "de hacer vivir a los demás la alegría de descubrir lo que nosotros mismos hemos vivido". La vocación dxlx maestrx implica "enseñar porque sí", sin ninguna represalia social, política, estatal, institucional, económica, se enseña porque xlx otrx lo necesita. "Y así es como acabamos por quedarnos solos, al final de la clase, esperando en vano la frase que justificaría, en definitiva, todo nuestro esfuerzo: [todavía no, profesor, mejor nos quedamos a charlar de lo que acabamos de decir]" (Meirieu, 2006, p. 38).

La vocación dxlx maestrx se refleja en el acto puro de ser maestrx, de ver su clase como un brote de una flor o un acontecer repentino de su cotidianidad, es volver a ser maestrx, sin prejuicios, notas en el observador, reuniones de áreas, 
pagos, servicios, ni políticas. Ser maestrx es escuchar ese "llamamiento" a enseñar sin “fraudes”,

No puedo ser maestrx sin ponerme ante lxs alumnxs, sin revelar con facilidad o resistencia mi manera de ser, de pensar políticamente. No puedo escapar a la apreciación de lxs alumnxs. Y la manera en que ellxs me perciben tiene una importancia capital para mi desempeño. De allí, pues, que una de mis preocupaciones centrales deba ser la de buscar la aproximación cada vez mayor entre lo que digo y lo que hago, entre lo que parezco ser y lo que realmente estoy siendo. (Freire, 2004, p. 44)

En definitiva, la vocación a la que hago referencia es aquella que tiene que ver con su declinación latina vocare "llamar", "llamamiento", evocado a emprender un oficio, profesión. Y es precisamente este llamado que se devela en el ser maestrx, como aquello que Freire llama "enseñar exige compromiso", y que se hace alusión en las líneas anteriores, a mostrar el ser maestrx en consonancia con lxs estudiantes, entre lo que se dice y hace, es tener el compromiso para hacer, ser y pensarse como maestrx.

Aquí, retomando el carácter artesano dxlx maestrx, dice Alliaud (2017, pp. 8788)

Los que forman a otros ayudan, acompañan y también enseñan no solo las competencias técnicas, sino también las competencias sociales y capacidades de adaptación a escenarios laborales diversos y cambiantes. En este caso se trata no solo de que lxs docentes tengan una mejor preparación en términos de desarrollo personal, sino de lo que implica luego el ejercicio de su trabajo. Además de saber hacerlo, a lxs formadorxs les gusta lo que hacen, y pueden mostrarlo y ofrecerlo 
porque están orgullosxs de ello. El oficio los define y están dispuestos a dar lo máximo de sí, con la esperanza de que lo suyo sirva de base para el despegue de los otros.

Xlx maestrx formadorx es quien enseña a "enseñar", es decir, enseña el oficio, precisamente, es aquello que procura xlx maestrx, brindar las condiciones y herramientas necesarias para que el aprendiz "aprenda el oficio". La fd es entonces, una manifestación de poder continuar re-trazando las prácticas, es un entramado en el cual se hilan una diversidad de acciones, situaciones, contenidos. Precisamente, Vergara (2017, p. 52) considera que la

Formación de profesorxs implica promover su desarrollo profesional y personal, urgir su intervención en el ámbito más concreto del ejercicio de su práctica, con la pretensión de reconstruirla y recuperarla. $\mathrm{Y}$, sobre todo, la idea de que toda formación implica una revisión y una crisis, romper con premisas ya instituidas, y abrirse a nuevas formas de pensar y hacer, con la consecuente conmoción que provoca la ruptura de esquemas que muchas veces están ya consolidados.

Hay un punto por destacar de la intervención de Vergara, cuando dice “implica una revisión y una crisis" en cuanto que la fd conlleva a "desaprender" y volver a aprender desde otros lugares epistemológicos, pedagógicos, formativos y vivenciales. Es pertinente comprender esta revisión y esta crisis desde una voz, desde una escena de los trazos narrativos:

Realmente ha habido cambios en la forma de ver y de actuar como docente, no es tan fácil decir cómo ha cambiado la forma de actuar, pero realmente sí, porque cuando uno antes llegaba solamente con un saludo: "buenos días, por favor su cuaderno, vamos a hacer la siguiente presentación y ustedes me recuerdan lo que vimos la clase pasada" esa podía ser siempre la rutina. Pero el hecho de que usted antes de entrar a clase trate de motivar absolutamente a lxs estudiantes y tenerlxs en un espacio donde todxs se sientan concentradxs. Dejar unos cinco 
minutos para hablar de un tema en el que todos se sientan identificadxs y que eso le llegue al tema... ya puedo hacer eso [...]. (Adolfo Calles, 2017. Historia de vida. Pasto, Colombia)

En la fd se entretejen variedad de actos, motivos, logros, desintereses, cumplidos, aprendizajes, enseñanzas, disgustos que van modificando a lo que se aferra xlx maestrx, van desmontando lo que es estático y lo hacen fluir, tomar otras tonalidades, ser visto desde otras posturas, hacer que se manifieste en nuevos trazos, nuevas prácticas.

Aunque no siempre hay rupturas y nuevas aperturas, y a esto hace referencia Alliaud (2006, p. 9) considerando que hay unas características comunes de la fd, Una, dejan de lado el carácter situacional propio de la enseñanza, considerando que es en el "afuera" donde se van a encontrar las respuestas para solucionar aquello que no sale "adentro" (el aula). Dos (relacionada con la anterior), siempre son otros quienes definen lo que lxs maestrxs tienen que aprender y les enseña lo que suponen necesitan para enseñar. Hay una tercera, pensándolo mejor, y tal vez sea la más importante: ambas posturas conciben la formación como "brindar conocimientos o información" a quienes se cree no la tienen.

Por lo general, xlx maestrx que emprende estudios de posgrado llega con la idea de "aprender cómo enseñar", está seguro de que en los espacios de fd se van a dar algunas "recetas" para enseñar "mejor", sin embargo, surgen cuestionamientos ¿desde qué lugar enseñar a unx maestrx que ha enseñado durante más de dos décadas?, ¿qué quieren aprender?, ¿por qué el temor de resaltar lo que hacen? Xlx maestrx percibe la fd como ese lugar para "aprender de nuevo". Dice Alliaud (2006, p. 9) 
Por más formación, capacitación, actualización o perfeccionamiento que reciban, lxs maestrxs parecen resistentes (¿impermeables?) a la hora de plasmar en las aulas qué "aprendieron" en los espacios de formación. Así, lo que prima en las situaciones prácticas suele ser que sabían, producto de que alguna vez aprendieron, lo que les resulta o resultó a lo largo de su carrera o simplemente lo que les "sale" como mezcla de todo ello.

Lo que está presente aquí es una realidad en los escenarios de fd, y da paso a una segunda trama discursiva, las motivaciones e intereses de lxs maestrxs en formación posgradual: ¿qué esperan aprender?, ¿en qué esperan profundizar?, ¿cómo y cuáles son sus imaginarios sobre la fd en posgrado?, cuestionamientos que no solo surgen del que se forma, sino del formadorx. Del primero, porque llega con grandes expectativas; y, el segundo, porque se encuentra con diversidad de pensamientos y razones para hacer un posgrado, gran parte de mantener en pie "las expectativas" recae en xlx docente formadorx. De cómo y qué enseña a maestrxs con trayectorias amplias para narrar y trazar.

Frente a estas circunstancias, desde el lugar que ocupa xlx maestrx formadorx, aquella persona que tiene el rol de enseñar algo, convertir los conocimientos científicos en enseñables, de hacer que el que se está formando comprenda lo que aprende, lo transfiera a un contexto, lo ponga en práctica. Vásquez (2011, p. 23) considera que "ser maestrx cuenta con sus propias lógicas, particularidades y destrezas. Ser maestrx es más que tener conocimiento o vocación”. 
En este punto se puede destacar que no basta con memorizar contenidos para enseñar, y más cuando se trata de un curso de maestría, lxs maestrxs que ingresan a este nivel de formación ya tienen un cúmulo de saberes, nociones previas de cómo enseñar, de sus conocimientos específicos, ya tienen la experiencia de ser maestrxs, así que el que forma debe llegar con la capacidad de enseñar desde unos lugares comunes. Una alternativa con que puede iniciar es con la necesidad de hacer investigación desde las prácticas propias. Continúa Vásquez (2011, p. 24) diciendo que la investigación "renueva nuestra profesión, nos hemos conformado con los exiguos resultados de lo repetitivo o lo ya conocido, dejando de lado la riqueza y el reto de todos esos nuevos eventos educativos que no comprendemos o nos negamos a asumir desde la duda y la pregunta".

Por lo general, xlx maestrx que "va a aprender" en un escenario de maestría, se sitúa en un aprendizaje básico, reglas, instrucciones, pasos, más contenidos disciplinares, insumos para "hacer bien su trabajo". Es por ello por lo que, xlx maestrx formadorx emprende la tarea de modificar el inicio del que está aprendiendo, lo lleva a aprender a desaprender, a ver otras formas de ser maestrx, esta vez desde la reflexión y puesta en escena de su práctica, aunque, al forjar un ejercicio reflexivo no implica un cambio profundo en lo que se hace, ya que cuando se refiere a la reflexión, se alude a ver con más detalle lo que realiza xlx maestrx en su cotidianidad, y el mismo término, como lo manifiesta Edelstein (2013, p. 67) lo reflexivo se masifica, pensando que es una acción que solo tiene como objeto la práctica, "el saber docente no se conforma solo desde 
la práctica; se nutre también en las teorías que dotan a los sujetos de variados puntos de vista y perspectivas de análisis que le permiten una acción contextualizada".

La idea aquí está centrada en que en los procesos de fd en posgrado xlx maestrx que está "aprendiendo", vuelva a re-trazar sus prácticas, pero esta vez lo haga desde una postura más compleja, partiendo de lo que hace y sus connotaciones políticas, sociales, culturales e históricas en el contexto que se desempeña. En el lugar del docente "aprendiz" se espera que como sujeto reflexivo "da valor a una especial estimación de los saberes, lo que implica la consideración de lxs profesorxs como intelectuales capaces de producir conocimientos, de participar en las decisiones y gestión de las instituciones en las que desarrollan su trabajo" (Edelstein, 2013, p. 68).

Lo cierto es que desde el lugar dxlx maestrx formadorx las intenciones de enseñar están centradas en que se re-tracen las prácticas, se re-escriban. Sus enseñanzas nunca van a estar centradas en olvidar y empezar, lo que quiere es que xlx maestrx que se está formando re-reflexione ${ }^{19}$, vea al interior y por ahí se sitúe en otros lugares de su propio ejercicio. Es por ello por lo que la formación va más allá de la mera transmisión de contenidos,

El reto está en dejar de creer que nuestra única tarea consiste en impartir clases. Nuestra función primordial, la que nos constituye y se asemeja tanto al oficio del médico, es la de cuidar el desarrollo del otro. La formación supera la transmisión del conocimiento. El conocimiento es un pretexto para jalonar otras fuerzas, para

\footnotetext{
19 Término emergente de la investigación, tiene que ver con lo nuevo que puede conocer desde una segunda o tercera reflexión del ejercicio docente, es situarse en una reflexión más profunda y delicada de las prácticas, del hacer, ser y saber.
} 
esculpir un carácter [...] el reto, es descubrir los rostros que hay entre la masa informe de estudiantes; es dotar de nombre propio eso que llamamos el grupo o el semestre. (Vásquez, 2011, p. 29)

Quisiera exponer aquí un auto-trazo, de eso que se puede considerar como el "relato oculto" 20 y que tiene que ver con lo que hace xlx maestrx formadorx en los escenarios de $\mathrm{fd}$ en posgrado. Tiene que ver con lo que observa y va construyendo en ese nuevo manifiesto de su experiencia, también, hace alusión

a lo que es enseñar.

Ese primer día de clase continuó su rumbo, cuando somos nuevos, siempre procuramos esperar a recibir las instrucciones para poder dar el siguiente paso, pero lo que no les advirtieron es que esos pasos eran de gigante y ellxs los gigantes, aquí la teoría se va dando en la medida que se da la práctica, ique golpe tan terrible! Cuando les empezamos a explicar que ellos iban a ser los investigados en su propia investigación, que su práctica era el motor de su proyecto, quedaron aún más asustadxs, algunos intervinieron y dijeron "pensamos que la investigación iba a ser teórica...íbamos a tener un tema y desde allí partíamos la búsqueda de información". -No- aquí hacemos investigación investigando. En ese otro momento, tuve la impresión de que los veinticinco se preguntaban cómo vamos a hacer de lo nuestro, investigación, cómo funciona, qué hacemos, por qué nuestra práctica y no la de otros.

$[\ldots]$

Ser formadorx de maestrxs es formarse uno mismo, a estxs maestrxs no los veo como estudiantes sino como personas que enriquecen mi quehacer en varias dimensiones, profesional, formativa, laboral, emocional...y otras... una de las definiciones que tengo sobre formación se orienta hacia la diversión, como docente me divierto demasiado, me gusta compartir con los estudiantes y lograr construir ese vínculo, que necesariamente debe ir más allá de la mera clase, la formación se hace en otros escenarios, con distintas herramientas y vinculando a otras personas. Conozco sus hogares, voy a ellos cuando me lo permiten, hablamos de nuestras vidas, experiencias a lo largo de su labor docente, salimos a compartir un almuerzo, una cena...Estos espacios permiten que lxs maestrxs en formación se salgan de esos espacios rígidos que en varias ocasiones es lo académico, no hay como la espontaneidad, las risas, tratar de descubrir nuevas formas para interactuar con lxs maestrxs en formación. La formación de maestrxs se vive desde la experiencia de ellxs mismxs, desde lo que son y lo que hacen, es allí donde habita la esencia de lo

\footnotetext{
${ }^{20}$ Término forjado en la investigación, se trata de relatar por atrás de lo que se está relatando, son las tramas del
} investigadorx como narradorx, es relatar desde el "resguardo", re-relatar sobre el relato. 
que es formar, es decir se forma en y para la vida, y desde la vida misma es que se emprende la búsqueda por conocer más y lograr otros sucesos que fortalezcan la labor docente. (Alejandra Rico, relato personal, 2018)

Si volvemos a las palabras de Vásquez, cuando dice el reto está en dejar de creer que nuestra única tarea consiste en impartir clases, es precisamente lo que por lo general lxs maestrxs formadorxs hacen, "dar clases", "poner en el tablero otros contenidos"; pero: ¿es esto lo que están buscando lxs maestrxs en formación? ¿Es esta la forma de dar continuidad a la formación? Desde la óptica de esta pesquisa, la respuesta es no. La formación es concebida como otra manera de actuar en contexto, es otro sentido de la cotidianidad docente, $x l x$ maestrx que busca seguir configurando trayectorias nuevas, muy seguramente no quiere encontrar algo de lo mismo, de lo que ya conoce. Xlx maestrx en formación querrá explorar océanos desconocidos, tener acercamientos con lo que le es desconocido y arriesgarse a cambiar algo de sí mismo, algo de su cotidianidad escolar.

Y el reto está en concebir la fd como la novedad para el que se forma, xlx docente formadorx es quien, mostrando otra faceta de lo que implica y significa hacer enseñable algo, debería ir a "pesquisear", más que ir a "impartir" ese algo. Es preciso considerar que ese reto está en ser unx maestrx, en hacer manifiesto el ejemplo, Alliaud (2006, p. 11) en una de sus investigaciones expone una forma interesante en que lxs maestrxs pueden enseñar compartiendo sus experiencias o como ella lo dice, lo que hacen, 
Unx maestrx actual le puede contar a otro u otros cómo lo hizo. Puede narrar su experiencia acerca de cómo abordó una clase, un tema o un problema puntual que se le haya presentado. Las narraciones podrán ser orales o escritas. Es probable que esos relatos sean de utilidad también para quienes los producen. Sabido es que narrar, contar acerca de lo que se hizo, puede tener en sí mismo un componente formador o reflexivo, en tanto aleja al protagonista de la situación vivida y lo pone en una situación distinta, la de contar o de dar cuenta (para otrxs, ante otrxs) de lo que hizo y cómo lo hizo.

Precisamente, esa es la cara que se quiere mostrar del papel dxlx formadorx, que logre enseñar a partir de sus propias trayectorias docentes, que conduce a la tercera trama discursiva, de lo que sabe hacer, desde luego, no es tarea fácil, enseñar desde las propias trayectorias, incluso resulta más sencillo hacerlo desde lo disciplinar, estableciendo un modo de enseñanza pasivo y rutinario, en el que todo está sujeto a un plan de contenidos diseñado previamente, y que salirse implicaría no dar cumplimiento con lo ofertado. Esta es la cotidianidad, lo que se frecuenta en escenarios de fd posgradual, seguir lo ya planeado. Sin embargo, de esto hay las suficientes investigaciones, teorías, críticas, estudios, entre otros, no se trata de repisar en lo que ha estado bajo el carácter normal de la enseñanza, se trata aquí de hacer "tramas teóricas vinculantes" como dice llamarse este apartado. Se muestra lo vinculante en la siguiente ilustración. 


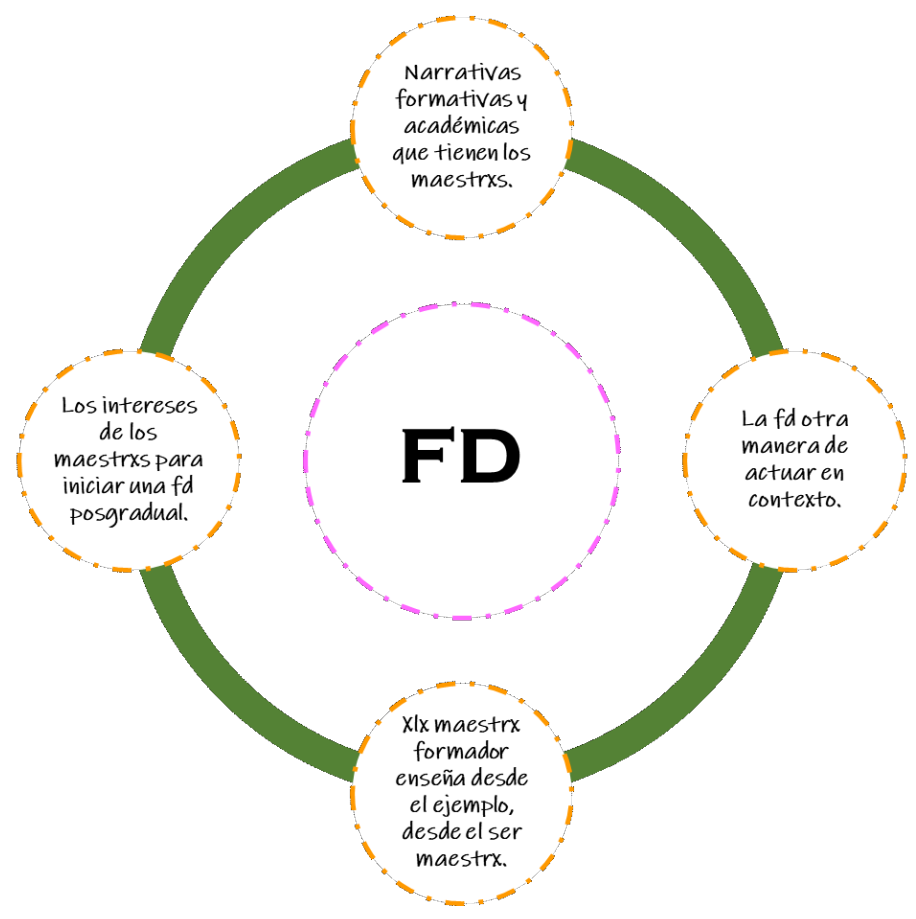

Ilustración 1. Tramas discursivas/vinculantes sobre la fd. Fuente. Suceso producido por la investigadora.

Para concluir, lo vinculante está en no repetir y direccionar al mismo discurso, sino en generar aperturas relacionadas al entramado teórico sobre la fd y que se adapten a la perspectiva narrativa desde donde está siendo abordada. La fd, es, por tanto, un entramado de experiencias que en su conjunto pueden conducir a las buenas prácticas de lxs maestrxs asociadas a lo que enseñan, al carácter pedagógico de su saber y a lo global de la educación, xlx maestrx que se forma, lo hace con la finalidad de desenvolverse mejor y tener otras posibilidades de circular en los contextos escolares y los sucesos que de estos surgen frecuentemente. 
Capítulo V. Maestrxs emancipadxs: la fd desde una perspectiva reflexiva y participativa

El anterior capítulo permitió tener una trama significante de la fd, partiendo de diversos factores como lo son, la formación en su conceptualización propia, el sujeto formado (docente), lo que hace, la práctica, experiencia y las manifestaciones emergentes de su biografía académica para definir la razón de formarse como magíster en educación. Asunto que conduce a esbozar la segunda mirada desde donde se visibiliza la $\mathrm{fd}$, como un proceso consolidado y emancipado que permite xlx maestrx acentuar su profesión y su práctica, desde la formación brindada por otrxs formadorxs en el recinto universitario, teniendo en cuenta todas las dinámicas académicas, pedagógicas, investigativas que se facilitan en el contexto académico de la formación en posgrado.

Lxs maestrxs emancipadxs son los que constantemente reflexionan y re-trazan sus prácticas, manifiestan interés continuo por estar actualizados, cuestionar y proponer políticas públicas en educación coherentes con el quehacer dxlx maestrx y su actuar en la sociedad. Hablar de una emancipación, por lo general, es pensar en liberarse de algo que sujeta al ser humano, Freire (2004, p. 19) considera que $x l x$ docente que se forma permanentemente, precisa un ejercicio de reflexión crítica de su propia práctica.

Es por eso por lo que el momento fundamental en la formación permanente de lxs profesorxs es el de la reflexión crítica sobre la práctica. Es pensando críticamente la práctica de hoy o la de ayer como se puede mejorar la próxima. El propio discurso 
teórico, necesario a la reflexión crítica, tiene que ser de tal manera concreto que casi se confunda con la práctica.

Es justamente, la definición de emancipación que se quiere abordar en este capítulo, lo cual se constituye en la reflexión permanente de las prácticas, y ese ejercicio reflexivo, no es emancipador por sí mismo, sino que conlleve a cambios o nuevas miradas de lo que se hace como maestrx y el vínculo directo con lo que se piensa. Day (citado por Porta y Martínez, 2015 p. 37) considera que la función emancipadora de la "enseñanza apasionada, aludiendo a la influencia que ejerce en la capacidad de lxs estudiantes para entusiasmarse con el aprendizaje y ayudarlos a elevar su mirada más allá de lo inmediato”.

Esto, precisa que hay que decir que los contextos en donde se desenvuelve xlx maestrx cada día están permeados por inflexibles políticas educativas, lineamientos instrumentalizados, evaluaciones impuestas y estandarizadas para “medir" los desempeños dxlx maestrx, las cuales están alejadas de cuestiones académicas, investigativas y pensadas para la mejora constante de las prácticas. Situación que se marca en el rastreo de los tres tipos de maestrxs, mencionados por Saldarriaga y enfatizando, Giroux (1998, p. 173) considera que

El actual énfasis en los factores instrumentales y pragmáticos de la vida escolar se basa esencialmente en una serie de importantes postulados pedagógicos. Entre ellos hay que incluir: la llamada a separar la concepción de la ejecución; la estandarización del conocimiento escolar con vistas a una mejor gestión y control de este; y la devaluación del trabajo crítico e intelectual por parte de profesorxs y estudiantes debido a la primacía de las consideraciones prácticas. 
Al respecto, Edelstein (2013, p. 33) manifiesta que la fd de maestrxs se hace necesario que enfatice en tres aspectos, esto con la finalidad de comprender y actuar desde las prácticas reflexivas que tiene xlx maestrx. El primer aspecto tiene que ver con el bagaje cultural que posee xlx maestrx "de una clara orientación política y social, en el que las disciplinas de las ciencias humanas son consideradas parte central de los contenidos en el currículo de formación".

El segundo aspecto es la capacidad de reflexión con que cuenta xlx maestrx, esto le permite tener claras sus posturas ideológicas y concebir unas prácticas de enseñanza propias de un contexto, además "para desenmascarar la influencia de la ideología en las prácticas cotidianas de la escuela, en el currículo, la vida escolar, en los sistemas de evaluación”. (Edelstein, 2013, p. 33). Y, finalmente, el tercer aspecto se relaciona con la capacidad, la apropiación y compromiso intelectual que tiene $x l x$ maestrx para generar transformaciones en los contextos escolares. Entre otros asuntos "actitudes de interés, iniciativa y búsqueda, de experimentación y crítica”. (Edelstein, 2013, p. 33)

Es en este punto en el cual vale la pena considerar que xlx maestrx emancipado parte de la reflexión crítica de su quehacer y ser que conlleva a generar prácticas elocuentes y coherentes con los contextos escolares donde habita y que se permite en sus enseñanzas áulicas configurar reflexiones y posicionamientos discursivos en lxs estudiantes. Precisamente, la fd desde la perspectiva participativa y reflexiva permite orientar xlx maestrx en formación y mostrar otras posibilidades de generar prácticas emancipadoras. 
Para ilustrar mejor el asunto sobre Ixs maestrxs emancipadxs, me gustaría abordar un tema básico de emancipación en la fd y aquí me valgo de las comprensiones de Vásquez (2011, p. 19) quien considera que es hacerse responsable con los quehaceres [tareas] asignados por lxs maestrxs formadorxs. “Así como el deber dxlx maestrx es preparar su clase, de igual manera el deber de alumno es hacer la tarea". Y es que este es uno de los inconvenientes más frecuentes que lxs maestrxs formadorxs enfrentan en escenarios de $\mathrm{fd}$ posgradual. Frente a ello, unx maestrx se haría la pregunta: ¿Qué pasa, por qué no presentan sus tareas?

Y son válidas las preguntas porque al ser maestrxs en formación se espera un alto grado de responsabilidad y compromiso, este hecho resulta oportuno mencionarlo, porque es desde allí que se empieza a formar el sentido reflexivo y crítico con la fd.

Cuando xlx alumnx hace la tarea, cuando se enfrenta a aquella actividad que $x \mathrm{~lx}$ maestrx ha pensado, lo que en verdad sucede es que tiene la oportunidad para tomar la palabra, para adueñarse particularmente de su aprendizaje, la tarea es el momento en que xlx estudiante se apodera de su propio proceso, dice o expresa cómo ha tenido sentido para él un tema, una teoría, un procedimiento. (Vásquez, 2011, p. 19-20)

$Y$ es que cuando se toma en serio lo que acontece en los procesos de $f d, x l x$ maestrx como estudiante puede aprehender un bagaje robusto de contenidos que le van a permitir adentrarse en sus propias prácticas e iniciar con la configuración de vínculos entre la teoría y las prácticas. Esto se logra en la medida que se da la relación educativa, porque el proceso formativo [enseñanza 
+ aprendizaje] es compartido y colegiado. "Quien no hace la tarea, no sale del territorio de la enseñanza, no logra acceder a las fronteras del aprendizaje. Dejar de hacer la tarea es permitirle xlx maestrx seguir hablando, es condenar la relación pedagógica al monólogo”. (Vásquez, 2011, p. 20)

Aquí es donde el papel dxlx maestrx que se forma cobra sentido en los lugares de fd, es quien decide cómo abordar sus procesos e involucrarlos en su cotidianidad docente. Edelstein (2013, p. 35) considera que más que espacios de estricta formación académica, se buscan espacios que legitimen la "preparación para intervenir en procesos de investigación de las prácticas, reflexionar sistemáticamente sobre ellas y utilizar los resultados en la mejora continua”.

La fd por sí sola no es emancipadora, reflexiva ni crítica, son los actores involucrados que hacen de esta un lugar de reflexión y apertura para posibles transformaciones en contexto. $Y$ no solo $d x l x$ maestrx que se forma es responsabilidad una fd reflexiva, se trata del involucramiento de todos Ixs participantes que es posible generar este tipo de escenarios. Y con esto, se hace referencia, en primer lugar, a las posturas formativas que proponen los gobiernos en cuanto a fd posgradual se refiere. En segundo lugar, a la universidad y la propuesta curricular que tiene frente a la fd posgradual; y, por último, a lxs maestrxs formadorxs con que cuenta la universidad.

Como se puede ver en esta cadena, xlx maestrx que se está formando viene permeado de distintas tonalidades y posturas, y a ellas se incluyen las que va conociendo [universidad y maestrxs formadorxs]. Al respecto, Vezub (2007, p. 10) considera que no existen las suficientes garantías para que $x l x$ maestrx en 
formación consolide prácticas vinculantes entre lo que enseña y aprende. "Las prácticas de formación presentan una escasa reflexión acerca del sentido de la enseñanza en los contextos actuales [...] Paralelamente se aumentan las exigencias de la sociedad a lxs maestrxs, se les pide que asuman nuevas y más responsabilidades".

Frente a ello, no quiere decir que la fd no pueda ser emancipatoria y generar una actitud reflexiva y crítica en lxs maestrxs, por eso se decía en líneas anteriores que es un proceso compartido y que se consolida en un trabajo colegiado que, además, parte de las buenas enseñanzas emitidas por Ixs maestrxs formadorxs.

Las buenas enseñanzas tienen que ver con las formas adecuadas para conocer algo, mejor dicho, las maneras en que xlx maestrx desde sus prácticas conecta al estudiante con los contenidos aprendidos. Bain (2012) considera que las buenas enseñanzas se reflejan en el modo en que Ixs estudiantes perciben lo aprendido, es decir, en la forma en que lxs maestrxs conducen a lxs estudiantes a cuestionarse lo que saben y poder incluir en sus reflexiones epistemológicas otras formas de ver lo que ya sabían. Considera el autor que no se trata de aglutinar de bloques de contenidos a lxs estudiantes sino en revisar la forma en que ellos aprehenden estos contenidos y si es necesario desglosarlos para extraer mejores resultados. Bain (2012) en sus estudios considera que sí es posible hablar de lxs buenxs profesorxs y de sus buenas enseñanzas.

Xlx buenx profesorx es el que está al tanto de sus estudiantes: cuestiona, indaga, alude a los contextos para enseñar los contenidos, hace experimentos, se 
sale de las cuatro paredes de un salón de clases hacia fuera, manifiesta interés de cómo aprenden lxs estudiantes y para qué les sirve en sus cotidianidades. Lo cual conduce a buenas enseñanzas en su quehacer, más allá de la vocación es el interés $\mathrm{dxlx}$ maestrx por generar conocimientos apropiados y situados, aunque son elementos que se rescatan desde la vocación. Dice Bain (2012, p. 72) que

Con una amplia sonrisa, un enorme sentido del humor y una actitud positiva que indica "pienso que ustedes pueden hacer esto", levanta la figura de papel y dice a sus estudiantes “Esta es el área debajo de una curva. ¿Cómo podemos calcularla?” Mediante preguntas socráticas y en una atmósfera amistosa, el profesor los incita para que construyan una forma de resolución del problema... No obstante, no es el carácter absurdo lo que hace que su clase funcione. Es la habilidad de ocupar a lxs estudiantes en algo que les resultará fascinante porque es tan inesperado y porque alguien los considera con seriedad.

Es desde esta idea que se hace referencia a las buenas enseñanzas, en la medida que lo bueno no es bueno porque se transmiten unos contenidos dentro del aula y siguiendo un plan de estudios predeterminado, lo bueno, tiene que ver con que esos conocimientos ya establecidos, sean también, transferibles, es decir, que no se queden anclados a ejercicios mecánicos del aprender, sino que sean vinculados con las realidades posibles que conoce el estudiante. Es xlx maestrx aquella persona que hace posible la enseñanza de conocimientos transferibles, críticos y reflexivos, ya que los conocimientos por sí mismos, no cumplen estas acciones. 
En resumidas cuentas, las buenas enseñanzas no están marcadas por el volumen de contenidos que xlx maestrx logre transmitir a lxs estudiantes, por los resultados cuantitativos que consiguieron lxs estudiantes o por el tipo de evaluaciones que implementó xlx maestrx para medir lo aprendido. Estas buenas enseñanzas se traducen en las formas de aprender y aprehender los contenidos enseñados y las apropiaciones que logren lxs estudiantes en el momento de vincular estos aprendizajes con las acciones generadas en sociedad, es decir, las posturas críticas que se construyan desde sus saberes, experiencias y conocimientos. En donde la apropiación conceptual, metodológica, epistemológica, social, cultural que poseen estos actores, puede generar trazos significativos entre los que aprenden. Trazos que posibilitan el cuestionamiento y la reflexibilidad de la cotidianidad y prácticas docentes.

Al respecto, Sandoval (2000) considera que la fd en Colombia parte de la necesidad de reconstruir los sistemas educativos trabajando de la mano del desarrollo intelectual, cultural y los lineamientos integrales de éstos. Él desglosa el interior de la fd haciendo un análisis del quehacer de la educación y de la escuela, de sus protagonistas, modelos, aprendizajes y enfoques pedagógicos puestos en práctica, es decir, ¿qué hacen?, ¿cómo lo hacen?, y ¿por qué lo hacen? Esto quiere decir que una razón de la fd es formar maestrxs que transformen sus prácticas y deriven otras nuevas experiencias.

Es así, que la fd contiene varios factores, el primero, es una vía hacia la permanente construcción investigativa; el segundo, es el continuo cambio que afronta xlx maestrx y que se da desde él mismo, teniendo como objetivo 
permanente la preparación inicial hasta la práctica, para que de esta forma se convierta en unx maestrx activo de formación de valores y principios claros para la sociedad, que impulse la valorización de la enseñanza coherente dentro del aula y su aplicabilidad fuera de ella, de tal manera que fomente una cultura más humana y autónoma.

Bajo los argumentos anteriores, la fd es entendida como un proceso social, político y cultural que encierra diversas transformaciones dentro de nuestro contexto, una de estas transformaciones parte de que lxs maestrxs y las instituciones están llamados a participar de la proyección y renovación de la educación y las concepciones educativas, gestionando alternativas que permitan un desarrollo armónico, bajo aspectos, como la academia, la investigación, reflexión y modos de aprender vinculados con la innovación y el aporte social desde la escuela.

En otras palabras, los modos de emancipación de la fd es que se asuma como colectiva y colegiada relacionada con el ejercicio docente innovadorx que permita un acercamiento sistémico con xlx estudiante, posibilitando descubrir cualidades, actitudes y aptitudes que generen el diálogo académico dentro y fuera de la realidad educativa (Calonje, 1999, Rico, 2011).

Teniendo en cuenta lo anterior, la fd no solo es aquel proceso en el que se capacita o instruye, sino que va más allá de la mera trasmisión o profundización de conocimientos mecanicistas, este proceso está comprometido con posturas reflexivas y aperturas propositivas de otras prácticas docentes. La fd se relaciona con la realidad social, xlx maestrx además de ser [instructorx] o guía 
de los aprendizajes, necesita consagrarse como unx gestorx activx de su saber, es decir de su dominio conceptual teniendo en cuenta en todo momento la relación que construye con el contexto y las personas [estudiantes] a quien hace llegar sus conocimientos (Camargo, et al., 2007).

Igualmente, la fd no se enmarca únicamente en el institucionalismo o normatividad que rige al interior del sistema educativo, se debe tener en cuenta la formación de unx docente autónomx [emancipadx], con las suficientes capacidades intelectuales, investigativas y humanas para intervenir los contextos escolares y sociales, que genere posibilidades y transformaciones en su práctica pedagógica y visibilice sus conocimientos de una forma innovadora para el desarrollo colectivo.

De esta manera, formar maestrxs es dirigirse hacia la emancipación, en el caso de la formación como magíster de la educación, no se trata de retomar contenidos ya vistos en la formación inicial de grado como licenciadx, lo que se trata es de aprender cómo los contenidos instaurados en sus trayectorias producen sentidos entre los que enseña y entre sus pares colegas. Es poder reflexionar sobre la práctica docente, qué herramientas son las más adecuadas para generar buenas prácticas o mejorar las instauradas desde la investigación y las prácticas compartidas con lxs maestrxs que se están formando (Camargo, et al., 2007, Calvo, 2004).

Debo agregar que la $\mathrm{fd}$ emancipa en la medida que logre propagarse entre $\mathrm{xlx}$ maestrx que se forma y xlx maestrx formadorx, optando por una mirada crítica e interdisciplinaria de los diferentes contextos educativos y formativos. De tal 
manera que pueda producir y referenciar desde su misma práctica aquellos intereses intelectuales que le permitan fortalecer su oficio y carácter docente investigativo. La fd se presenta como un campo de transformaciones permanentes que suscitan la investigación y la revisión teórico - práctica del quehacer y vivir formativo.

Puede verse como un campo estratégico de la educación actual, el cual crea espacios para la metamorfosis de la práctica docente, creando un vínculo entre la pedagogía aplicada y los lineamientos de las políticas educativas. El desarrollo de este campo es compromiso de todas las personas que se relacionan con la educación, ya que de esta forma se generan nuevas investigaciones las cuales inspiran nuevos avances en cuanto a ideales, principios y propuestas que fundamentan la fd. (Sandoval, 2000, Messina, 1999)

Otro de los aspectos que logra fundamentar el tema de investigación, es el significado que tiene la fd para la consolidación del campo de la educación, ya que, la figura dxlx maestrx como actor central de este proceso, agencia la necesidad de generar espacios de formación continua, que le permitan actuar profesional, ética e integralmente desde su rol, haciendo que tensiones como la relación entre teoría y práctica sea más estrecha y exprese su idoneidad y generación de nuevo conocimiento.

De esta manera, se define que lxs maestrxs son lxs representantes más importantes dentro de los cambios educativos, son los que pueden tomar decisiones favorables frente a los procesos que se generan dentro de su ámbito 
profesional, es decir son profesionales de cambio y desde luego, de renovación e innovación en la fd.

Una fd desde una visión emancipadora promueve la cultura de cambio, el desarrollo investigativo y la exigencia en la práctica docente, partiendo desde la construcción de conocimientos actuales y pertinentes con la dinámica social y global de los contextos escolares. Lo que se propone es que la fd sea dinámica, genere transformaciones en el hacer y ser $\mathrm{dxlx}$ maestrx, indagar y re-significar aquellos relatos silenciados y a menudo olvidados por la sociedad y por los mismxs maestrxs, las concepciones sobre la formación que están haciendo, pero, también ver qué es lo novedoso de esa formación, cómo se están preparando lxs maestrxs para asumir los retos sociales, $x l x$ docente es quien transmite saberes $y$, define el rumbo de una sociedad. En este paraje, se hace pertinente presentar en la ilustración 2 las principales características dxlx maestrx emancipadx a partir de los procesos de fd posgradual.

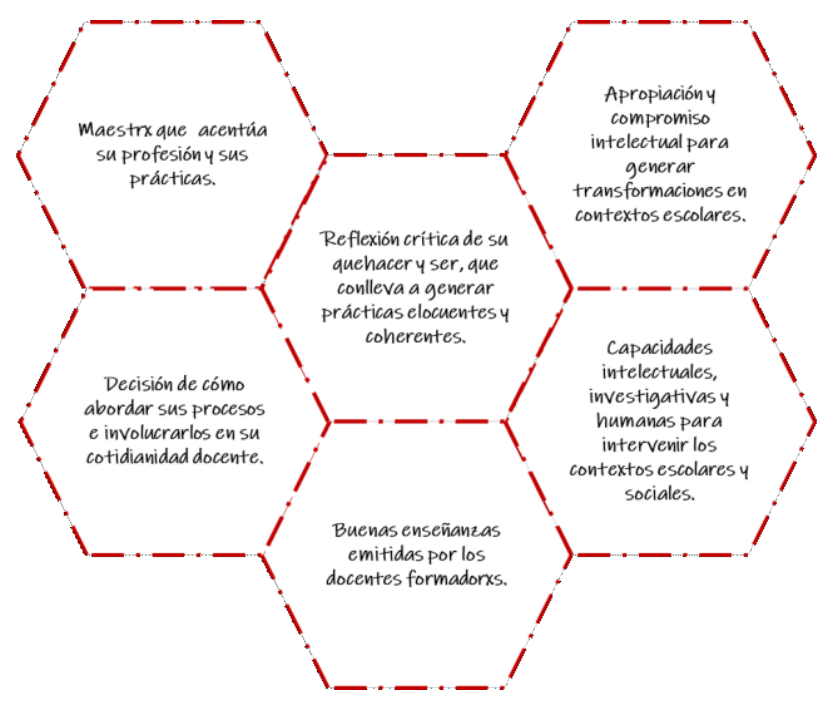

Ilustración 2. Características dxlx maestrx emancipadx a partir de los procesos de fd posgradual. Fuente. Suceso producido por la investigadora. 
Para concluir, la fd es un proceso permanente en el que se facilitan aspectos pedagógicos, sociales, políticos e investigativos con el fin de fomentar una formación idónea, crítica, re-novada e innovadora, con miras no solo a un mejor ejercicio docente y tampoco a una mejor remuneración económica, sino enfatizada a un cambio social e intelectual. Es así como se enmarca en una renovación continua que puede lograr nuevas aperturas tanto en la práctica docente como en los modos de percibir el ser maestrx en lo social y cultural. (Torres, 1996, 2001).

A partir de los relatos de lxs autorxs investigadxs es posible extraer trazos significativos, los cuales forman parte de la investigación en fd, permitiendo no solo dar cuenta de las voces de lxs maestrxs, sino hacer una contribución teórica-práctica dentro de la gran teoría sobre la formación docente y la manera de hacer y de vivir su proceso formativo. 


\section{TERCERA PARTE}

\section{El uso de la narrativa para pesquisar: El despertar de las voces}

\section{narrantes sobre fd posgradual}

Frecuentemente se hace referencia en todas las investigaciones de la ruta metodológica a ser implementada para dar cumplimiento con los objetivos propuestos desde el inicio de toda investigación. Esta parte, efectivamente, da cuenta de este enunciado, sin embargo, se manifiesta en una serie de comprensiones teóricas y analíticas sobre el uso de la narrativa para estudiar la $\mathrm{fd}$ posgradual. Ruta metodológica que no solo es eso, sino que es lo que pone en movimiento esta tesis. La narrativa como efecto y causa de lo que se pesquisea, es lo que da vida a la fd posgradual, lo que puede trazar y re-trazar las palabras y los acontecimientos de esta investigación.

El uso de la narrativa como método, enfoque y técnica permite ver que no solo son entrevistas o datos obtenidos de las personas, sino que es el análisis hermenéutico que sustenta la tesis y que permite comprender la fd desde otros lugares, desde el acercamiento a las voces, a los relatos, las emociones y experiencias de lxs maestrxs participantes. Desde luego, también, re-traza la teoría y la pone en discusión con los aconteceres de lo narrado.

Todo ello, da apertura al capítulo VI, titulado “Acercamientos narrativos: Disertaciones teóricas narradas" en donde se hace un acercamiento a distintas teorías sobre la investigación narrativa y su uso en el campo de la educación. Desde luego, en este capítulo se construye un panorama general donde se ubica 
la investigación narrativa, ahondando un poco la perspectiva cualitativa, para así emprender con detalles las comprensiones de la narrativa. En el capítulo VII, titulado "El relato dxlx maestrx de escuela rural: Narraciones periféricas (del pueblo)" se adentra en el análisis del uso de la narrativa en lugares distintos, en este caso en la recuperación de historias de vida de maestrxs de escuelas rurales, pensadas en la cotidianidad del campo, las calles de piedra y las escuelas con paredes blancas. El relato dxlx maestrx rural cuenta la historia del campo colombiano, del campesino y el arraigo cultural que hace dxlx maestrx un personaje público y reconocido entre la comunidad.

Es de esta manera que el relato cuenta historias, con inicios felices, nudos de asombro y finales melancólicos. En suma, el uso de la narrativa conduce a lo que será la interpretación de los hechos vividos y contados por lxs maestrxs, transporta al lector a ser partícipe de lo que viven lxs maestrxs y construyen cada día. 
Capítulo VI. Acercamientos narrativos: Disertaciones teóricas narradas

El proceso [metodológico] cuenta con un componente teórico que parte de la investigación cualitativa y desemboca en la investigación narrativa. Aquí, se hace necesario hacer referencia desde dónde se parte para tratar la investigación cualitativa, con autorxs como Creswell (1994); Martínez (2008); Vasilachis (2006), teniendo claro que de este tema abunda la literatura, sin embargo, en esta ocasión se trata, a partir de estos investigadorxs de conjugar lo cualitativo como el gran paraguas que cubre los primeros pasos de narrativa y que desde las concepciones cualitativas se pueden comprender otras razones para emprender pesquisar narrativas.

Para iniciar esta sencilla narración sobre la investigación cualitativa, Vasilachis (2006, p. 25) citando a Mason considera que este tipo de investigación está "basada en métodos de generación de datos flexibles y sensibles al contexto social en el que se producen". El carácter cualitativo permite adentrarse en los contextos, conocer en profundidad a lxs participantes, e incluso, ser un investigadorx investigadx. El involucramiento y cercanía que se generan en las investigaciones cualitativas tienen que ver con la necesidad de comprender los significados que las personas les otorgan a las realidades inmediatas que circulan en los contextos investigados.

Al respecto, Creswell (1994, p. 13) la considera como una "indagación que explora un problema social o humano. Xlx investigadorx construye un panorama complejo y holístico, analiza discursos, refiere visiones detalladas de lxs 
informantes y lleva a cabo el estudio en un entorno natural". De este modo, las configuraciones de análisis se basan en las reacciones propias de las personas sobre el tema a explorar, bien lo dicen lxs autorxs, este tipo de investigación se produce en entornos naturales, sensibles a las percepciones propias y a las de lxs investigadorxs.

Hacer investigaciones cualitativas tiene que ver con los sentidos y cuestionamientos que surjan de los contextos y personas investigadas, implica conocer el contexto, hacerlo manifiesto a partir del análisis interpretativo que se realice. También implica hacer devoluciones comprensivas y de nuevos aprendizajes a las comunidades con que se trabaja. Esta investigación no es de un solo lado, da cuenta de los dos lados [xlx participante] + [xlx investigadorx], frente a ello, Vasilachis (2006, p. 26) considera que

Es una amplia aproximación al estudio de los fenómenos sociales, sus varios géneros son naturalistas e interpretativos y recurre a múltiples métodos de investigación. De esta forma, el proceso de investigación cualitativa supone: a) la inmersión en la vida cotidiana de la situación seleccionada para el estudio, b) la valoración y el intento por descubrir la perspectiva de (xs participantes sobre sus propios mundos, y c) la consideración de la investigación como un proceso interactivo entre xlx investigadorx y esxs participantes, como descriptiva y analítica y que privilegia las palabras de las personas y su comportamiento observable como datos primarios.

Algo que cabe resaltar es que la investigación cualitativa "es un proceso interactivo", y es este aspecto que se entrelaza con la narrativa; para hacer pesquisas narrativas, es necesario actuar con los otros, es decir, integrarse a las realidades de lxs participantes [maestrxs], comprenderlas antes de buscar 
narrantes, en la medida que xlx investigadorx se vincule en estas realidades, en Ixs narrantes seleccionadxs habrá un nivel de confianza alta para relatar sus trazos, se logra un lazo fraterno en el momento de narrar, xlx investigadorx hace parte de los relatos, se privilegia el relato y se comprende desde una postura de investigadorx y otra, como participante del mismo relato.

Iniciando con las disertaciones sobre el método narrativo, Ricoeur (2006) insiste en que narrar es conectar el relato con la vida, es por ello, que no se narra la vida sino la historia que hay dentro de ella. La narrativa es una práctica que constituye las relaciones sociales que se dan entre las personas, las cuales son internalizadas y personalizadas, permitiendo así, descubrir e interpretar diversos acontecimientos en el relato narrado.

Sin embargo, no es tan fácil hacer una investigación con este método, ya que no se trata de hacer historias de vida con el pretexto de averiguar o entrevistar a lxs participantes de la investigación; se trata de preguntarse qué es lo que se busca en/con la narrativa, si los hechos encontrados allí sirven en su totalidad o hay que hacer una discriminación para así determinar lo que se pretende dentro del margen de la pesquisa.

De este modo, cuando se buscan datos con los relatos narrados, es importante seleccionar varios de ellos, ya que se pueden emplear como método para rescatar, reconstruir, confirmar, ampliar, entre otras la investigación. Desde otro punto de vista, lo relatado puede ser usado para explorar, comprender e interpretar significados que den cuenta de la realidad del contexto de la investigación. Por eso, las narrativas permiten describir la vida de unas 
personas, en este caso maestrxs, teniendo en cuenta lo que se quiere indagar dentro de ellas.

Las narrativas son las historias de las personas, las cuales se focalizan en determinadas experiencias humanas que pueden ser un foco para pesquisar. Un relato narrativo es una práctica de vida, entre las relaciones sociales del contexto de las personas y que son interiorizadas y exteriorizadas al mismo tiempo, lo cual hace posible que se pueda descubrir con el relato de vida una descripción específica o una situación social.

Quiere decir que con las historias de vida se logra tener una visión universal a través de lo singular, mediante la indagación con relatos es importante tener en cuenta aquello que se busca en ellos o a dónde se quiere llegar con lo que sucede en alguna parte de la vida de las personas, ya que los datos deben tener claridad investigativa y una destinación objetiva dentro del marco de los propósitos de lxs investigadorxs. (Connelly y Clandinin, 2008).

Cuando se emprende una indagación entre las historias de vida, se intenta esbozar las tramas que constituyen cada parte de esta historia, se escudriña lo que constituye el relato, considerando las experiencias vitales y los momentos que trascienden en la persona. (Mallimaci y Jiménez, 2009) Aquí, la otra parte del relato [investigadorx] puede detectar en lo narrado otros aspectos para hacerlos visibles en su re-relato, en sus re-trazos.

En efecto, las personas que narran sus historias son autónomas de lo que cuentan y tienen control sobre los detalles de ella, quiere decir que la gran variedad de significados que se le otorgan a las historias depende de lo que la 
persona cuenta a la investigadora. La historia de vida guarda el significado total de algún aspecto social y lo que trata de hacer la investigadora es descubrirlo, es decir, la función de la investigadora es relacionar lo relatado con el contexto en el que transcurre y lograr profundizar en los aspectos más significativos de la narración "prestada" por la persona.

Es así como los datos manifiestos se obtienen mediante encuentros conversacionales con las personas que decidieron participar de la pesquisa y que logran ser interpretados por parte de la investigadora. Cuando se recurre a historias de vida [narrativas] Ixs investigadorxs no solo deben hacer el papel de oyentes, es importante construir una relación en donde ambas partes comprendan y sean parte de la historia. Se entiende entonces que no solo resulta una narración sino la agrupación de dos narraciones, la del participante [xlx maestrx] y la de la investigadora. Y que gracias a la integración de esta relación se logra hacer una construcción y re-construcción de lo narrado. Lo narrado es un encuentro de significados, de modo tal que se integran sentimientos, perspectivas, razones, elogios, controversias que la persona tenga desde lo relatado. (Connelly y Clandinin, 2008, Taylor y Bogdan, 2006).

Las historias comprenden diversos aspectos, sensaciones, expresiones, gestos, imprecisiones, modos, que toman matices diferentes cuando la investigadora los escucha, transcribe, analiza, reconfigura, interpreta. De todas formas, los primeros aspectos no pueden perder su esencia, no se pueden "desordenar" ni quitar su sentido único y es tarea de la investigadora hacer que esta esencia 
permanezca en la medida que vaya abriendo, escudriñando cada una de las palabras narradas por los otros [maestrxs].

"Xlx transcriptorx se convierte en intérprete, como xlx actorx de una pieza clave, [...] el análisis es montar un rompecabezas (en donde) las piezas no están dadas, sino que deben ser determinadas" (Bolívar, Domingo y Fernández, 2001, pp. 192-193). La tarea de la investigadora para construir el análisis de los datos inicia con la transcripción textual y fiel de las entrevistas, es necesario hacer una primera transcripción sin omitir detalle alguno, no solo se transcriben palabras, hay que transcribir el acto de hablar. En esos detalles es que se encuentran las fichas más difíciles para armar el puzzle (análisis), desde luego, es un ejercicio denso e incluso desconsolador ¿Cómo saber transcribir el gesto, la mirada, la expresión de reflexión?

Allí es donde se ve el trabajo de la investigadora, su rol no es solo escuchar, grabar y asentir con la cabeza mientras el otro habla, es investigadorx aquellx que muestra interés, se desprende de su marcado papel de angustia académica y cientificista, es aquel que se asombra, admira, interioriza y presupone que es parte de la historia que está construyendo el otro. Es desde este ejercicio que parte el sentido propio de la narrativa, si como investigadora entiende cuál es su papel antes, en y después del relato, el ejercicio de entramar, resignificar e interpretar será más sencillo y sin correr el riesgo de perder la esencia de la historia en sí. 
La investigadora debe estar consciente que es una parte de la historia de vida que está construyendo el otro, de lo contrario, se limitará a recortar un sinnúmero de fragmentos de las historias de vida y pegarlas a su conveniencia en un informe final, fragmentos que pierden su esencia por completo, se convierte en texto sin vida, sin significado ni re-significación por parte de la investigadora, ella misma se convierte en un agente pasivo, sin capacidad de asombro por lo que narra el otro. La historia es vida, porque son hechos en y con contexto, no pueden ser parte de un aparte sin más, no pueden quedar en letra cursiva sin darle paso a ese otro que narró, no pueden quedar relegados al acto operativo del investigador.

Investigar, conseguir, reconstruir, analizar e interpretar historias no es fácil, es menester saber hacer el ejercicio y en especial para qué se está haciendo, es algo así como cuidar los pasos en hielo quebradizo. De esta manera, es que hay que darle paso al relato, pero sin dejar de hacer un análisis riguroso, y analizar sin ocultar el relato. Supone una contradicción necesaria y que la investigadora es quien hace esta cadena, si está trabajando con historias de vida, es porque sabe lo que significa hacerlo y reconoce el valor de la voz del otro.

"La tarea de quien informa y analiza la información no puede limitarse a tomar nota” (Bolívar, Domingo y Fernández, 2001, p. 201). Se requiere de una postura holística de análisis, en la que se les dé significado a los componentes del relato de vida, y que también se ubique en un contexto para que tome un significado más amplio. "superar el mero collage de fragmentos, implica que $x l x$ investigadorx se adentre en el complejo conjunto de símbolos que la gente usa 
para conferir significado a su mundo y a su vida" (Bolívar, Domingo y Fernández, 2001, p. 201).

El trabajo investigativo con narrativas implica hacer otra narrativa, implica estar sujeto no de las historias de vida, pero sí de la razón de ser, hacer y rehacer los relatos de otros [lxs maestrxs].

De este modo, cuando se hace la entrevista (encuentro presencial con la persona) no es solo la recolección inerte de datos, va más allá de la relación insípida entre investigadora-investigadxs, la entrevista es un "relato biográfico que construye humanamente -sentir, pensar, actuar- una realidad" (Bolívar, Domingo y Fernández, 2001, p. 205). Es que la investigadora debe hacer todo lo posible por mantener el relato, y también [transgredirlo], en la medida que pueda re-construir, re-significar, re-trazar, que pueda hacer investigación narrativa, pensar en el relato desde el propio, adentrarse en él, sin agredir, procurando una transformación, una interpretación de un relato individual a un relato social.

En suma, es preguntarse: ¿Cómo re-presentar esas voces? ¿Cómo volver a narrar los relatos? Es hacer la tarea de ser narradora-investigadora. Dice Alliaud, 2011, p. 95,

Estos saberes constituyen un conjunto de representaciones y referencias a partir de las cuales Ixs profesorxs interpretan y comprenden su entorno de trabajo, otorgan sentido a su tarea y orientan su enseñanza y práctica cotidiana. De allí la importancia de recuperarlos y trabajarlos, con la finalidad de incorporarlos a las instancias formalizadas de formación y desarrollo profesional docente. 
Igualmente, Hernández (2011, p. 20) considera que

Lo que constituye la característica principal de la perspectiva metodológica de las historias de vida es su finalidad, que no es otra que conectar las narrativas personales y biográficas de profesorxs e investigadorxs con su contexto sociocultural, histórico e institucional. Esta conexión es la que hace posible que lo individual se convierta en colectivo, desde una doble dimensión: en relación con la posición que se construye, y en la proyección que estas formas de subjetividad adquieren en relación con la experiencia de ser maestrx.

Siendo así, pesquisar narrativamente comprende una parte esencial del trabajo con maestrxs en formación posgradual, ya que permite indagar por sus intereses, reacciones, vivencias, manifestaciones de su acontecer pedagógico y formativo. Frente a esta connotación, Vásquez (2011, p. 65) se refiere a la incorporación de la narrativa en el oficio de maestrxs, y para ello alude a "una decena de razones", para que el ejercicio narrativo se adentre en la cotidianidad dxlx maestrx, aquí se mencionan tres razones que se acoplan a las intenciones propias de esta pesquisa:

La primera razón "la narrativa afecta no solo nuestra dimensión cognitiva sino también nuestra emocionalidad" (Vásquez, 2011, p. 65). Efectivamente, en el momento de escuchar los relatos de vida de lxs maestrxs se atraviesan emociones que son difíciles de controlar tanto para xlx relatorx como xlx que lo está escuchando, esos difuminados recuerdos cobran vida en esos instantes que narramos, nos sentimos vulnerables y en ocasiones incapaces de seguir narrando, aunque, xlx relatorx siente la necesidad de avivar ese momento y expresarlo en relato, considera que sin ello, aquello que cuenta está incompleto, queda 
inconcluso. Quiere decir que las emociones son las que intensifican los significados del relato de vida, esto implica que tanto narradorx como oyente son seres de palabras, son seres de emociones, el uno recuerda; y el otro abriga el recuerdo, por eso es por lo que el buen relato se teje entre dos vidas.

La segunda razón "la narrativa no moraliza, sino que presenta, sin un afán doctrinal, ciertas acciones o determinados discursos" (Vásquez, 2011, p. 66). Narrar lleva consigo a la apertura, cuando xlx maestrx narra hechos de su vida, recuerda acciones que le permitieron ser, hacer y conocer en su labor, traer de nuevo acontecimientos propios de su quehacer docente a los que, probablemente, no pensó narrar jamás. Narrarse es posibilitar nuevas acciones desde lo vivido, desde lo re-relatado, y, por eso mismo no tiene implícita la acción dogmática, porque genera apertura para la introspección y, en lo posible, perpetuar en lo que se hizo desde otras narrativas, otras perspectivas.

La tercera razón, "la narrativa hace de la experiencia la mediación fundamental para el conocimiento" (Vásquez, 2011, p. 66). Aquí se hace referencia a lo dicho por Larrosa (2008, p. 192), estamos conformados por un cúmulo de historias, "quizás los hombres no seamos otra cosa que un modo particular de contarnos lo que somos". Hace referencia a que "mediante la narración, la experiencia cobra visibilidad, cobra existencia y esa existencia nos constituye" (Alliaud, 2011, p. 99).

La narración de las experiencias desemboca en asignarle un sentido a lo que aconteció y que posiblemente se tenga algo más que escribir al respecto en la propia biografía docente. El rescate del pasado puede llenar vacíos del presente, 
conformar unas maneras alternativas de generar conocimientos propicios para el desarrollo del acontecer dxlx maestrx en escenarios escolares. En otras palabras, la narrativa es en sí, conocimientos y saberes que posee $x l x$ maestrx y que configuran sus experiencias, sus historias. En la ilustración 1 se muestra que no son los momentos los que configuran las narraciones, son los puntos fugaces, las intersecciones lo que hacen las narrativas.

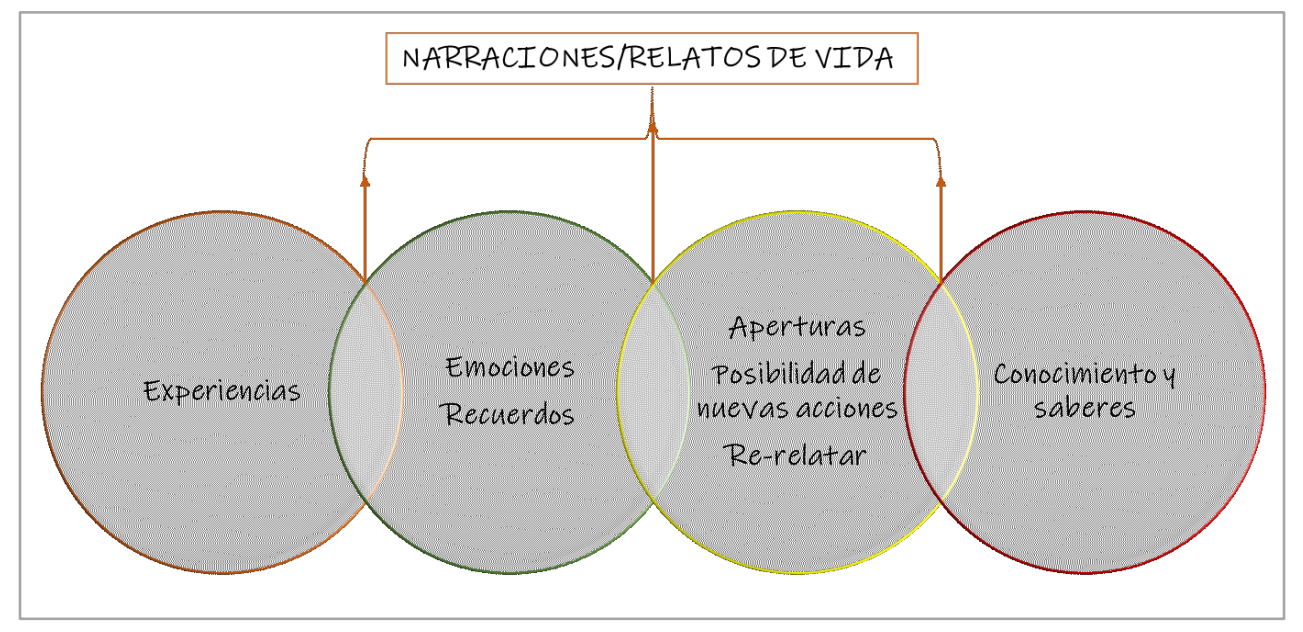

Ilustración 3. Las intersecciones narrativas. Fuente. Suceso producido por la investigadora.

La investigación biográfico - narrativa desde su lado más teórico, y atendiendo a lo mencionado por Bolívar, Domingo y Fernández (2001) cuenta con un colectivo de cuatro postulados, los cuales se refieren a este tipo de investigación como una perspectiva propia: El primero, es narrativa, las experiencias no tienen otra forma de ser representadas, son relatadas. El segundo, contextual, las historias cobran vida en la medida que estén dentro de un contexto, llámese social, cultural, escolar, familiar. El tercero, es dinámica, las narrativas son temporales y se hacen y deshacen frecuentemente. El cuarto, es integral, lo que 
es narrado se ve holísticamente, cada uno de los aspectos personales interactúan entre sí para configurar la vida de las personas.

Para resumir, la investigación narrativa permite adentrarse en lugares poco comunes a los indagados por la investigación "tradicional". Se puede decir que pesquisar narrativamente es entramar desde otras comprensiones epistemológicas y metodológicas, ya no es una mera metodología ni un paso a paso, sino toma el rigor de ser una perspectiva propia para hacer investigación en contextos educativos e involucrarse en la vida de los que hacen posible este escenario: Ixs maestrxs. Bolívar y Domingo $(2006$, p. 6) se refieren a la investigación narrativa como:

Compartir la vida, los significados y las comprensiones dialécticamente mediante un relato de vida posibilita la creación y mantenimiento de una comunidad discursiva. En este sentido, la investigación narrativa permite reparar y representar un conjunto de dimensiones relevantes de la experiencia (sentimientos, propósitos, deseos, etcétera), que la investigación formal deja fuera. Pero no solo expresa importantes dimensiones de la experiencia vivida, sino que, más radicalmente, media la propia experiencia.

En el caso concreto de las narrativas con maestrxs en formación posgradual, se refleja la necesidad constante de recordar experiencias para configurar la vivida en los escenarios de formación como magíster en educación, poner en el tapiz vivencias con cierto grado de significación y que logran caracterizar y re-trazar las específicas del acontecer formativo. Es adecuado decir “¿Qué forma se le impone a la realidad cuando le damos los ropajes del relato?" (Bruner, 2013, p. 19). 
Capítulo VII. El relato dxlx maestrx de escuela rural: Narraciones periféricas (del pueblo)

Este capítulo aborda los modos en que la investigación narrativa incursiona en los entramados de lxs maestrxs que emprenden un proyecto posgradual, no solo como proyecto profesional sino de vida. Maestrxs cuya principal característica es que sus voces provienen de las entrañas de regiones rurales de Colombia, en donde las grandes urbes colombianas se conocen por las franjas de noticias y los lugareños que han dejado huérfanas sus raíces en busca de un mejor futuro.

La narrativa se consagra como aquella aliada para hacer emerger las experiencias del silencio, hacer que estos maestrxs se permitan escuchar y volver a sentir el paso de las trayectorias ya vividas, volver a los trazos y hacer con lo que fue, otros entramados manifiestos en el relato. El que narra autoriza al que escucha, ir con él y explorar en sus trayectorias, también hacer un rerelato. Dicen Porta y Martínez (2015, p. 29) que la "reconstrucción y reorganización de la experiencia a través de la narrativa permite atribuir significados al pasado con referencia al presente y a las concepciones personales".

Es por ello por lo que la pesquisa narrativa no es estrictamente método, es un modo de interpretación y reinterpretación de acontecimientos relatados por personas [maestrxs] que se entrelazan y forman tramas desde el presente, pero re-narrando el pasado. Es justamente, lo que sucede con los acontecimientos de Ixs maestrxs participantes de esta pesquisa narrativa, van relatando lo que han 
sido algunos trazos de sus historias de vida en cuanto a la formación como maestrxs, cómo ha sido ese devenir formativo, cuál fue el impulso inicial para hacerse maestrx.

Quizás, para algunos fue por las necesidades de salir adelante, progresar, ayudar a la familia y no tener que pasar necesidades de carencia, hambre, no volver a vivir lo que vivieron sus ancestros o sus padres. El ser maestrx se presentó por azares del destino y el amor por este arte se fue tejiendo a medida que se fue aprendiendo de la labor. Leamos un trazo:

(...) Esa parte de que yo no tuve, la oportunidad y que hubo muchos inconvenientes en el momento de terminar, el bachiller, porque mis papás no tenían los recursos. Por sugerencia, a mis papás les dijeron que me mandaran a una normal porque veían una mejor salida.

Eso fue en 1991, cuando fui a octavo grado de colegio. Ya bachiller pedagógico. Yo no sabía que la normal era exclusivamente para lxs profesorxs, yo pensaba que este era un colegio normal, entonces cuando ya empezaron las prácticas, pues eso no me importaba, me empezaron a llevar a observar lxs profesorxs, cómo se daban las clases y todo eso, y uno iba y ya los niños le decían a uno "profe".

$[\ldots]$

Yo no veía que mi responsabilidad o que mi trabajo iba a ser la docencia. Yo lo único que quería era salir del contexto y trabajar en una oficina. (Berta Robles, 2017, p. 6. Historia de vida. Pasto, Colombia)

La narrativa consiste en dejar ver lo que no es visible a primera vista, consiste en desdibujar el ser con palabras narradas, con relatos que desnudan el pasado. A propósito, Hernández, Sancho y Rivas (2011, p. 17) consideran que el propósito de recuperar relatos

De maestrxs ha sido construir una metodología de investigación (unas gafas para mirar la realidad y actuar sobre ella) que sea más sensible al contexto, que nos ayude a comprender algo tan intensamente personal como es la enseñanza y su contexto social, tecnológico, económico, político y cultural. 
Es por ello por lo que la investigación narrativa se vincula íntimamente con las experiencias formativas de lxs maestrxs, que para el caso de esta investigación son maestrxs de regiones apartadas de las grandes urbes de Colombia, en este caso maestrxs participantes de Pasto y Valledupar. Aunque las dos son ciudades, se caracterizan por ser pequeñas, aún con arraigos culturales muy marcados y propios de cada región. La tradición es importante para lxs habitantes de estos lugares: las reuniones familiares, los bazares, las fiestas del barrio, los carnavales. En Pasto, lxs maestrxs enseñan en escuelas y colegios de municipios aledaños a la ciudad, lugares distanciados, entre dos a tres horas, en donde sus lugareños visten de ruana y sandalias ${ }^{21}$, Ixs niñxs llevan saco de lana y botas de caucho por si acaso llueve o hace frío.

Y, por el otro lado, Valledupar, conocida en Colombia como la ciudad del vallenato, género musical compuesto por el paseo, merengue, puya, son y tambora. Esta tierra, con una temperatura no inferior a los 28 grados, se caracteriza por el son alegre del acordeón, que se enseña en las escuelas y colegios. Xlx maestrx por lo general relata al son de un vallenato o en el fondo unas notas de acordeón. En la escuela, Ixs niñxs caminan con pantalones cortos y remeras frescas que no los sofoquen al inicio de las clases ni al medio día cuando van de regreso a casa. Andan luego, con sandalia baja y remeras por las calles de algún barrio de la ciudad.

\footnotetext{
${ }^{21}$ Se hace alusión a su vestimenta, como parte de su cultura, de lo que caracteriza el "buen vivir" de Ixs lugareñxs, lo autóctono y original de sus costumbres. La ruana de lana y las sandalias de fique son oriundas de las tierras del sur, en este caso de Nariño, son elaboradas a mano, tanto la ruana como las sandalias, costumbre que se quiere resaltar en esta tesis, como lo hermoso de ser culturalmente arraigado a lo que es nuestro, a lo que pertenece al pueblo.
} 
Dos ciudades de contrastes diferentes, entre el frio del páramo y el sofocante calor del río Guatapurí o la Plaza Alfonso López. En cada una, las historias son manifestadas desde las circunstancias propias del contexto y las condiciones socioculturales que han marcado el ser de cada maestrx. La nostalgia de sus experiencias los hace recabar a profundidad en sus historias, recordar cómo llegaron a ser maestrxs y cómo es que se han formado para dar lo mejor de sí cada día con sus prácticas, la energía de hacerlo mejor es lo que los ha llevado a continuar su formación docente, especializarse, aprovechar las oportunidades de fortalecer su ejercicio.

La narrativa se trabaja desde las voces periféricas de maestrxs que han enseñado en escuelas rurales por más de 20 años, que van pasando por el centro o llegando a la plaza de mercado y son saludados con alegría por sus estudiantes y sus familias, tienen un reconocimiento entre la comunidad. Se visten de traje y vestido para ir a sus clases, demuestran dominio al hablar y silencian a su público con sus palabras, en ocasiones con dureza, otras con sencillez y maestría.

Estas voces son escogidas por lo que han cultivado, por el poder del relato que está a la espera de ser develado, de ser escuchado. Solo basta el encuentro personal, la pregunta inicial y xlx maestrx hace de su voz el principal atractivo para la investigadora, para él, la voz del que relata, del que teje palabras debe ser fantástica. El que está escuchando no cumple un papel insensible, a medida que escucha necesariamente siente las palabras, se adentra en ellas, siente la 
emoción del que narra, de los trazos, se vale de su imaginación para ir entrelazando hechos.

Bruner (2013, p. 38) considera que la "gran narrativa es una invitación a encontrar problemas, no una lección acerca de cómo resolverlos. Es una profunda reflexión sobre la condición humana, sobre la caza más que sobre la presa”. De por sí, encontrar maestrxs narrantes no es tarea sencilla, en esta investigación se realizó el siguiente proceso:

1- Escenario de confianza: Adentrarse en los contextos de lxs maestrxs de escuela implica llevar un discurso novedoso, que genere entre ellos curiosidad, saberes que los sitúen en un lugar de cuestionamiento y reflexión sobre lo que hacen, lo que han construido en sus trayectorias como maestrxs, incluidas en ellas, la enseñanza y formación. Xlx docente formadorx de maestrxs y a la vez investigadorx, es el que genera ambientes de confianza entre ellos, es anecdótico y a la vez, es académico, no descarta enseñar desde la experiencia e involucrar a sus [estudiantes]+[maestrxs] en la escena de enseñanza. Preguntar, indagar, rastrear y ser maestrx al igual que los que están formándose es lo que permite ir perfilando a sus participantes narrantes.

2- Involucramiento en la investigación educativa: Xlx docente formadorx e investigadorx emprende la tarea de envolver a lxs maestrxs en la investigación, o mejor, hacer de sus prácticas un lugar para hacer investigación, esto permite que se vaya descifrando quiénes tienen habilidades para investigar, quienes lo hacen por el cumplimiento del plan de estudios posgradual o un grupo que no esté interesado en participar de la investigación. Esto no quiere decir que no 
haya interés de todxs por hacer investigación, lo que sucede es que a unxs se les facilita más y muestran más curiosidad por hacerla. El hecho de ser maestrx no quiere decir que se dé por hecho el ser investigadorx. El carácter investigador puede darse en el momento menos esperado y en el escenario de enseñanza que xlx maestrx no se esperaba. Sin embargo, para algunxs maestrxs el ser docente se hace más sencillo de involucrar en su cotidianidad. Acostumbra a registrar lo que hace, trabaja por medio de preguntas orientadoras y genera pequeños debates con sus estudiantes de lo que están aprendiendo. A esto se le llama, involucramiento en la investigación y es lo que busca la investigadora en sus narrantes.

3- Acercamiento a los contextos de Ixs narrantes participantes: La invitación de la investigadora se consolida cuando $x l x$ maestrx permite que se adentre en su contexto, lo conozca y se establezca un diálogo sobre lo que acontece en sus prácticas. Hay interés de ambas partes por generar investigación, por conocer más dxlx maestrx y que este quiera conocer más de lo que hace, de sus trayectorias. Esto lo genera la investigadora cuando empieza el ejercicio de pesquisar narrativamente, de hacer que xlx otrx [maestrx] narre, descubra sus trazos, teja sus palabras.

A continuación, en la ilustración 4 se recapitula el proceso metodológico de la narrativa, implementada en esta investigación, con el fin de encontrar lxs maestrxs narrantes y recuperar su narrativa. 


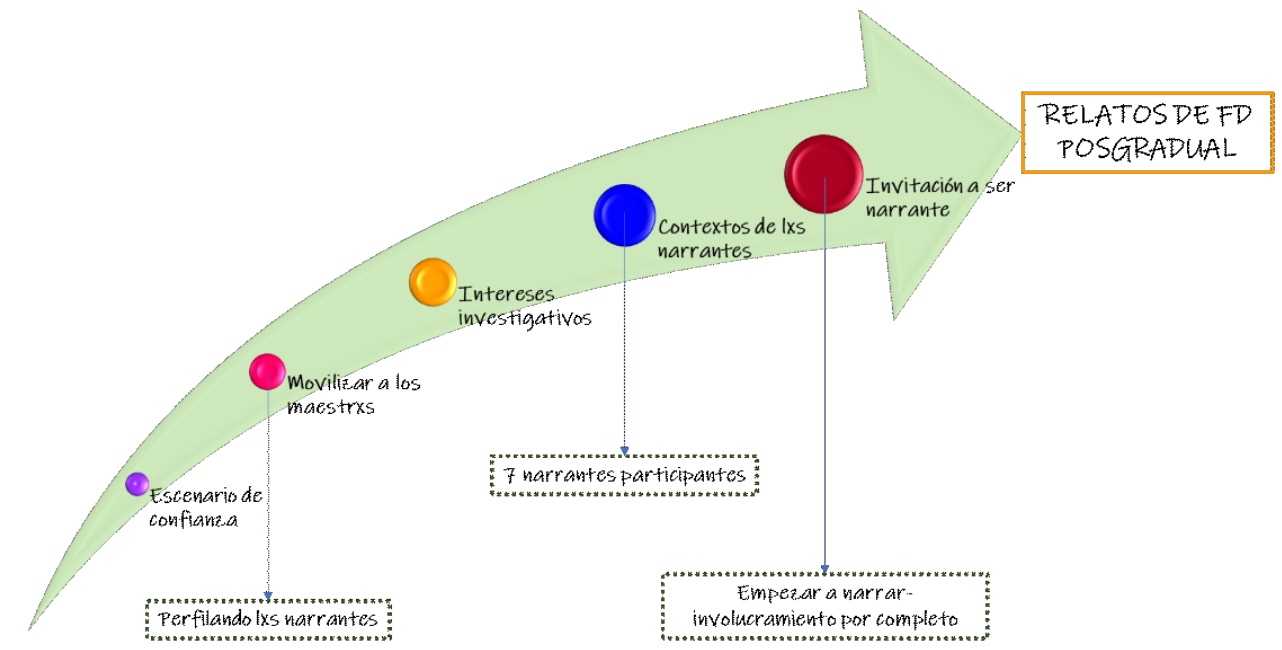

Ilustración 4. Proceso metodológico de la narrativa: maestrxs narrantes. Fuente. Suceso producido por la investigadora.

La buscadora de maestrxs narrantes emprende esta labor partiendo de las intenciones primarias de la pesquisa, perfilando a lxs participantes, cuestión que no se hace con rapidez, se necesita despejar el camino, (quitar los matorrales), o sea, conocer a lxs narrantes, adentrarse en su contexto, vivencias, trayectorias vividas y por hacer. La buscadora es la que explora más allá de su investigación, comprender otras realidades, aquí, se puede vincular con xlx investigadorx etnógrafx, el que se adentra, aprende a hacer lecturas precisas de los acontecimientos y las personas, es el que descubre diferentes tonalidades, los entramados.

Justamente, xlx investigadorx narrativx empieza a ser narrante de su historia, de su pesquisa desde el momento que emerge la trama que vislumbra el problema de la investigación, quiere decir, desde el instante mismo que decide hacer entramados con sus trazos y los trazos de otros. Y, cuando llega a la fase de buscar narrantes, es aún más cuando se adentra en la narrativa, la 
interacción directa, el contacto dialógico con sus posibles narrantes lo lleva a indagar más sobre la teoría de la narrativa, cómo hacer investigación narrativa con maestrxs de escuelas rurales.

Bruner (2013, p. 34) considera que para que haya relato, "algo ha de estar alterado, de otro modo no hay nada que contar", y en este sentido, "la acción del relato describe los intentos de superar o llegar a una conciliación con la infracción imprevista y sus consecuencias. Y al final hay un resultado, algún tipo de solución".

De esta circunstancia nace el hecho que es la buscadora [investigadora] quien, de cierto modo, genera esa alteración, manifiesta a través de su experticia investigativa un punto de partida para empezar a recuperar narrativas y tejer sus significados. Al respecto, Bolívar, Domingo y Fernández (2001, p. 97) citando a Bruner, consideran que la narrativa es una construcción de las realidades, "es un modo de ordenar la experiencia, de construir la realidad".

De este hecho es que la investigadora se interesa por el vínculo directo que puede consolidar con lxs participantes narrantes, al haber un cierto grado de confianza, es seguro que las intenciones de las narrativas se traducen en análisis e interpretación de sus significados. Lxs narrantes buscan la forma de relatar con tranquilidad, pero, también de hacerlo pensando en las intenciones de la pesquisa de la que hacen parte. Sigue Bolívar, Domingo y Fernández (2001, p. 97) citando a Bruner, con que

Los modos de hablar y de conceptualizar lo que hacemos han llegado a ser tan habituales, que son ya formas dadas de estructurar la experiencia misma, no solo 
para guiar el presente sino para proyectarla al futuro. La vida es llevada de modo inseparable a cómo es contada.

Esto lleva a decir que la búsqueda de narrantes requiere de un tiempo lento, para esta investigación este ejercicio tardó un año, en este periodo la buscadora se interesó por conocer a dos grupos de estudiantes de la maestría en educación a los cuales les dictaba clase, interactuó con cada uno de ellxs, conoció sus lugares de trabajo, sus modos de enseñanza, los espacios fuera de la escuela, sus formas de aprender, escribir, hablar, analizar, trabajar en grupos de estudio, sus momentos de angustia laboral, académica, los deseos de querer saber más de lo que han aprendido y otras situaciones que lxs estudiantes le permitieron conocer. Desde ese entonces, la buscadora inició con la construcción de un perfil, qué quiere que cumplan Ixs participantes narrantes. La ilustración 3 muestra los criterios de selección.

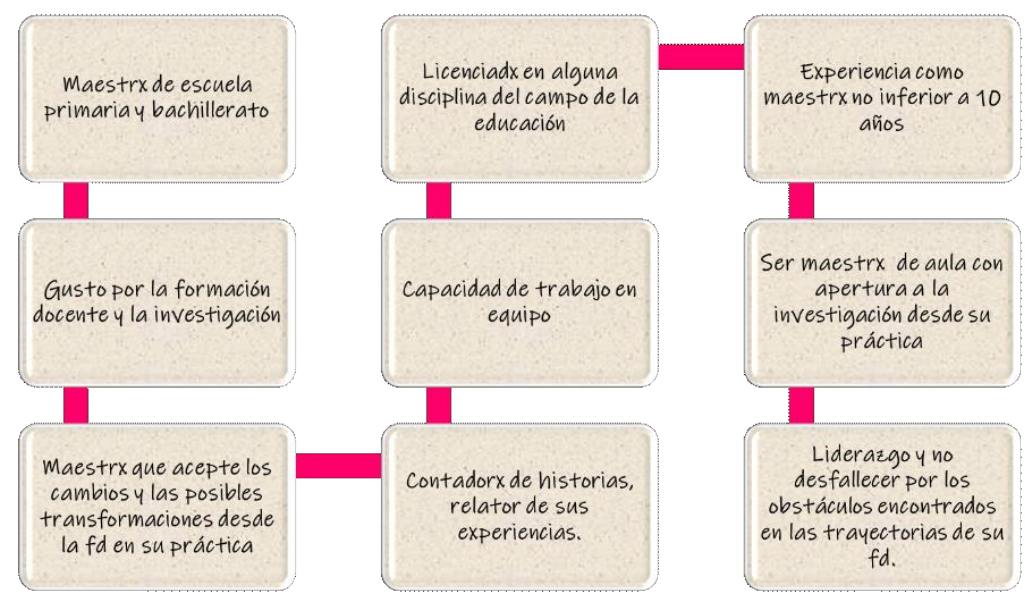

Ilustración 5. Criterios para el perfil de lxs maestrxs narrantes. Fuente. Suceso producido por la investigadora. 
Los criterios de selección surgen de observaciones realizadas al interior de las sesiones de clase de maestría, en las ciudades de Pasto y Valledupar, estas observaciones se realizaron durante un año, tiempo en el que se tuvo en contacto con todxs lxs maestrxs en formación como magíster en educación, en parte para conocer sus intenciones de formación en posgrados, cómo llegaron a la maestría, las proyecciones que tenían con respecto a esa etapa formativa. Indagación que dio como resultado la creación de estos criterios y la selección asertiva de Ixs participantes. No todos Ixs que estaban haciendo en ese momento la maestría tenían intenciones de aprender o de mejorar sus prácticas, varios de ellos tenían una única función que cumplir con la obtención del título como magíster: ascenso de escalafón docente.

$Y$ es cierto que un estudio de posgrado para un maestrx conduce a mejorar las condiciones salariales, no debería ser lo único porque estar dos años haciendo este estudio. Se tendría que pensar en para qué más me puede servir ser magíster en educación. Asunto que se logró rastrear en lxs seis maestrxs elegidos. Maestrxs con proyecciones a ser investigadorxs, sistematizar sus experiencias, enseñar a sus pares lo que aprendieron en la maestría, líderes de comités en la escuela, entre otros aspectos que identifican a estxs maestrxs y el interés en ser parte de una investigación doctoral.

De esta manera, en un estudio que desarrollaron Álvarez, Porta y Sarasa (2010, p. 165) en donde utilizaron el método biográfico y narrativo, consideran que el espacio narrativo se distingue porque da paso a contar de distintas maneras una historia o las experiencias. Se refieren a ello, reconociendo que 
La indagación acerca de la vida de lxs maestrxs involucra aspectos biográficos personales de cada individuo y aspectos interpersonales y culturales de sus trayectos profesionales. El enfoque biográfico y narrativo puede ser entendido como un espacio de indagación con características propias en la investigación cualitativa o como un enfoque específico con identidad particular y derecho propio. Las historias de vida y la investigación narrativa constituyen un campo de investigación que apunta a la dimensión personal de las ciencias sociales.

Lo cierto es que la narrativa como opción para la investigación se caracteriza por la indagación en profundidad de las trayectorias construidas por Ixs participantes [maestrxs narrantes] en alguno de los entramados que las conforman, en este caso el entramado es la fd en posgrado, y se parte de los trazos de los intereses singulares para formarse como magíster en educación, los aprendizajes investigativos y las posibilidades que brindan las nuevas enseñanzas de la fd para cambiar o generar transformaciones en la cotidianidad de sus prácticas como maestrxs de escuela primaria y secundaria.

Se trata desde luego de caracterizar la pesquisa narrativa, de verla como enfoque específico con identidad particular y derecho propio, que por supuesto, parte de los orígenes de la investigación cualitativa, ese gran parasol epistemológico y metodológico que se manifiesta en el estudio de lo particular, de los contextos, las realidades y las percepciones, ideas, sentidos y significados que le otorgan las personas a las realidades cercanas, las cuales son objeto de investigación. 
Esta caracterización se puede establecer en los siguientes criterios, más que metódicos, reflexivos y vinculados con el estudio de la fd posgradual desde la narrativa:

1- Acercamiento. La narrativa permite a la investigadora el acercamiento íntimo a los sucesos de lxs participantes, se manifiesta en el vínculo significante que se desarrolla en la aprehensión de los relatos de vida. Se adentra en los sentidos, en las tramas que van narrando lxs participantes, el relato pasa de ser una voz a ser la integración de dos voces.

2- Lugares de confianza. En el momento de iniciar la narración es impredecible que la investigadora haya "ganado territorio", es decir, se convierta en una persona cercana para xlx narrante, de esta forma, el relato fluye, la voz de la investigadora es mínima, xlx narrante toma la palabra, se deja guiar, se convierte en un espacio de confianza dialógica, hay risas, anécdotas, preguntas mutuas, historias. Todo ello es permitido, en la medida que se tenga claro el horizonte investigativo, porque de lo contrario xlx narrante puede relatar mucho, dispersarse del objeto de indagación, y es en este punto en el que el investigador debe pausar, interferir y traer de vuelta al narrante. Esto puede generar dos reacciones, la primera, xlx narrante pierda confianza, porque siente que lo pausan y no lo dejan terminar sus relatos; la segunda, que el encuentro personal se torna extenso y al finalizar no se cumplió con el objeto propuesto. Lo que implicaría que un segundo encuentro sea retomar lo que se desvió en la conversación. Por ello, los lugares de confianza son base fundamental para que los relatos cobren vida y se articulen con la pesquisa, no 
solo la investigadora es quien debe estar dentro de la pesquisa, xlx participante, también, y esto se logra con los vínculos de confianza que se consoliden antes de iniciar la narrativa.

3- Conocimientos teóricos y metodológicos. La investigadora requiere conocer la teoría sobre la narrativa, sus lugares epistemológicos, metodológicos; los usos en el campo de la educación, las técnicas para hacer investigación narrativa y las posibilidades de análisis que se usan. Antes de iniciar es necesario documentarse, indagar en investigaciones recientes, locales e internacionales, qué se ha hecho y cómo, cuáles son sus alcances y cómo se hace en términos prácticos la narrativa. Todo ello, para que la investigadora adquiera una postura teórica sobre el tema, pero, además, transmita la suficiente confianza de empoderamiento a lxs narrantes, esto permite afinar el segundo criterio -lugares de confianza- e iniciar las narrativas. Lo teórico siempre será visto como un lugar de empoderamiento conceptual, académico y metódico para emprender cualquier pesquisa.

4- Construcción de rutas y guiones. Para hacer las historias de vida se hace necesario tener claro qué se va a hacer en el encuentro con xlx participante, cómo iniciar, cuál será el punto de encuentro, el lugar que favorecerá el desenvolvimiento dxlx narrante al hablar, expresarse, al narrar. Por lo general, se hace en el lugar elegido por xlx narrante -conocido previamente por la investigadora-, este lugar puede ser el lugar de trabajo, la casa, un parque, un 
salón de onces ${ }^{22}$, una biblioteca. En este caso, lxs maestrxs narrantes eligieron

sus hogares, al lado de sus familias.

Hoy voy hacia San José de Alban, en el departamento de Nariño, allí vive y trabaja la maestra. Toda su familia es de allí, viven en una vereda ${ }^{23}$, rodeados de cultivos de café, mango, trapiches y gallinas. Ella, además de ser la maestra de la escuela es cultivadora de café, herencia de familia, junto a su esposo e hijxs cultivan la tierra. Es respetada por lxs lugareñxs, Ixs niñx la quieren mucho. Llego sobre las 9.00 am y para empezar me hace un recorrido por su casa y la casa de sus padres. Allí, hay desayuno lugareño: arepas de maíz, una taza de café recién molido, arroz con huevo y tajadas de plátano maduro. Sin decir mucho, hay que comer a gusto. Luego, vamos por un tramo del bosque, en un lugar donde ella decide iniciar su relato. Con la vista sobre el río y el canto de los pájaros. Hicimos un primer intento, pero ella solicitó no continuar, íbamos bien, paramos la narración, hubo un momento muy sentimental, ella recordó su vida de infancia y no pudo continuar. Decidí dar un tiempo y seguir en la tarde, luego de un almuerzo campestre con gallina criolla y frito pastuso. (Alejandra Rico, relato personal, 2018).

Para las rutas y guiones, es sugerente diseñar una serie de preguntas que orientarán la entrevista, que serán la ruta por seguir tanto para la investigadora como para xlx narrante. En esta ocasión, el guion fue construido por bloques, un primer bloque, hace referencia al contexto $d x l x$ narrante, esto se hace para tomar la suficiente confianza y generar soltura en xlx narrante al momento de hablar. El segundo bloque, tiene que ver con preguntas sobre la formación de grado, los años de ser maestrx, cómo ha sido la formación inicial. Y el tercer

\footnotetext{
${ }^{22}$ Lugar donde se reúnen las personas para tomar café, té o alguna bebida caliente, acompañado de un pastel, torta, pasaboca o galleta. Se encuentran en zonas residenciales o galerías comerciales. Son comunes por sus ambientes cálidos y hogareños en donde sirven café o infusiones con ingredientes naturales y los pasabocas son preparados de forma casera. Estos lugares son más frecuentes en las ciudades del sur de Colombia. Aunque, en algunas ciudades cálidas hacen presencia las grandes cadenas de los "salones de onces" como "Juan Valdés", "Oma".

${ }^{23}$ En Colombia existe una división administrativa, empezando por el departamento, municipios u otros, los cuales son: vereda: lugar rural, en donde residen campesinos que labran la tierra, se cultiva papa, café, frutal, hortalizas, hay ganadería, galpones y otra crianza de animales domésticos. En todas las veredas de los municipios se encuentran las escuelas rurales que están adscritas a la institución educativa municipal.
} 
bloque se centra en la formación docente posgradual, su vinculación, la investigación, los trayectos como magíster, los aportes.

La construcción de guiones permite a la investigadora enrutar la conversación, y cuando se hace necesario volver a traer al narrante con algo de la misma pregunta o abordarlo con otra que tenga que ver con lo que está contando, para no pausarlo bruscamente y que se sienta coartado de seguir su relato.

Al respecto, Álvarez, Porta y Sarasa (2010, p. 166) dicen que en los últimos tiempos la entrevista ha sido la técnica cualitativa mejor diseñada para obtener información de lxs participantes, para ello, la describen como

La manera de escribir al mundo, como forma de ponerlo en acción. [...] Los significados de las entrevistas son contextuales e improvisados y performativos y así deben ser tomados en su interpretación. La entrevista es un texto activo, un lugar donde el significado es creado y actuado. Durante la realización, el texto de la entrevista crea el mundo, dándole una significación situada.

5- Analizando las narrativas. Justamente, para empezar el análisis es prudente tener claro que la "entrevista crea el mundo... le da una significación situada", y es a lo que se refieren Bolívar, Domingo y Fernández (2001, p. 192) cuando manifiestan que en el análisis la investigadora hace las veces de una intérprete. "Hace como xlx autorx de una pieza teatral. No estamos ahora ante la comunicación interactiva entre personas sino ante un corpus textual, objeto de interpretación”.

El análisis de narrativas es, precisamente, emprender el rumbo de los retrazos. Es la re-construcción de la narrativa, el papel que desempeña la investigadora es vital, se entrelazan dos relatos, se escribe otra historia. Aunque 
también, no se trata de convertir las narrativas [texto con vida] en retazos combinados simultáneamente para generar resultados operativos y planos. De lo que se trata es de narrar a través de la interpretación textual y hacer nuevo conocimiento a partir de las voces de maestrxs. Frente a esto, Suárez (2007, p. 9) señala que la investigación narrativa

Pretende ser un enfoque específico de investigación que reclama su propia validez y legitimidad para construir conocimiento en educación, y que altera algunas certezas de los modos asentados de investigar, haciendo de esta práctica algo más accesible, natural y democrático. Relatar historias en las que los actores educativos se encuentran involucrados a través de la acción, e interpretar dichas prácticas a la luz de los relatos que éstos narran, se erige de esta forma en una perspectiva peculiar de investigación educativa que disputa legitimidad con el naturalismo, objetivismo y funcionalismo que estructuran y definen la ortodoxia epistemológica, teórica y metodológica.

El análisis implica hacer nuevo algo, involucra las aperturas de las narrativas, no se trata únicamente de recolectar voces e interpretarlas, más allá de este ejercicio, lo interesante de la investigación narrativa es dar lugar a una buena historia, la investigadora como poseedorx de las voces hechas textos, es la encargada de generar vínculos entre las distintas piezas, y así generar significados y nuevos re-significados de las narrativas. (Bolívar, Domingo y Fernández, 2001)

Para resumir, en la ilustración 6 se muestra la caracterización de la investigación narrativa creada desde esta investigación. 


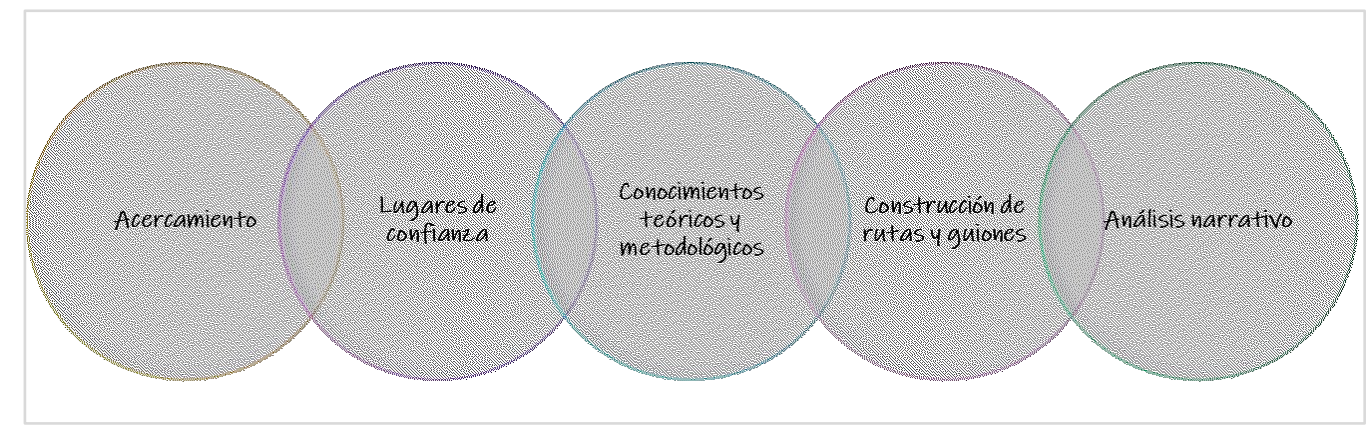

Ilustración 6. Características de la investigación narrativa. Suceso producido por la investigadora.

Llegando a este punto, se puede ahondar en un primer desenlace sobre la investigación narrativa y los abordajes metodológicos implementados para el estudio de la fd posgradual de maestrxs de primaria y bachillerato. Tiene que ver con las tramas que se configuran en las trayectorias originadas desde las experiencias y prácticas formativas de lxs maestrxs, no solo en los escenarios de fd, también, desde la cotidianidad docente que se manifiesta en su formación, como lugar de partida de los sucesos investigativos que emprenden en la fd.

Aquí, la investigadora hace uso de la narrativa para recupera las historias de vida que se han constituido a lo largo de la historicidad dxlx maestrx en formación posgradual, es decir, de los trazos que derivan de algunos episodios de las trayectorias formativas. Estos trazos son expresados a través de la palabra contada, los gestos, los silencios, recuerdos, sentidos que han hecho de ellos significativos y que requieren ser narrados, re-trazados desde el presente, para así, volverlos texto escrito y poder ser analizados e interpretados por la investigadora. En otras palabras, darles apertura a otros nuevos trazos [re-trazos narrativos]. 
Un segundo, y último desenlace sobre la metodología implementada en esta pesquisa, tiene que ver con lxs participantes seleccionados como narrantes, asunto que se abordó en el segundo capítulo. $Y$ que, sin embargo, requiere puntualizar algunos aspectos de cierre, partiendo de la premisa presentada en el título de este capítulo [narraciones periféricas, del pueblo], es justamente, la intención de este trazo metodológico, la participación de maestrxs de escuelas situadas en las periferias regionales [Pasto y Valledupar] en la investigación, que con sus narrativas logran ahondar en un colectivo, xlx narrante es símbolo de colectividad en la medida que representa un lugar, unas experiencias, representa el oficio dxlx maestrx como artista de la enseñanza, como poseedorx de saberes y de su formación.

Lxs narrantes son maestrxs que han decidido recuperar sus historias y permitir a la investigadora adentrarse en una parte de sus vidas como suceso de investigación, para tomar el papel de intérprete de sus palabras, construir aperturas narrativas sobre la fd posgradual y la personificación epistemológica y pedagógica que dan las experiencias docentes a ella. Finalmente, investigar narrativamente es pensar narrativamente, lo que implica comprender contextos, voces y sentidos que circulan en las trayectorias de lxs maestrxs como participantes narrantes de una nueva historia. 


\section{CUARTA PARTE}

\section{Palabras de maestrxs sobre las trayectorias de fd posgradual en Colombia: Tramas narrativas desde la experiencia}

Esta parte de la tesis tiene que ver con el análisis, interpretación y las discusiones sobre las trayectorias formativas construidas por lxs maestrxs en ejercicio y los fundamentos (razones) que emergen de sus sentidos para continuar su fd en posgrado, y así habilitar cambios en sus prácticas docentes.

Igualmente, se espera analizar y consolidar discusiones en torno a las historias de vida de lxs maestrxs sobre la fd, de tal forma que se reconstruyan las trayectorias y sentidos que circulan en la fd posgradual, relacionados con el oficio de ser maestrx, teniendo en cuenta sus prácticas docentes y su experiencia formativa. Para, finalmente, llevar las nuevas narraciones de esta tesis al descubierto, es decir, descubrir y reconocer las transformaciones y manifestaciones emergentes de los procesos de $\mathrm{fd}$ desde los aprendizajes en investigación, los nuevos conocimientos situados en la práctica, el acto educativo, pedagógico y social que construye $x l x$ maestrx en la cotidianidad escolar.

Es así como se abordan las voces de lxs maestrxs, traducidas en palabras desde el análisis narrativo, teniendo en cuenta una postura holística, es decir, “emplea la historia de vida completa del individuo y se centra en el contenido que presenta, analizando el significado de cada parte" (Bolívar, Domingo y 
Fernández, 2001, p. 195). Anudado a esto, es necesario que la investigadora se adentre al mundo $d x l x$ narrante, se aventure en sus palabras y los significados que de él emanan, "y es que las entrevistas no hablan por ellas mismas; si se las quiere comprender, es preciso que xlx investigadorx las retraduzca y analice" (Bolívar, Domingo y Fernández, 2001, p. 199).

En este escenario es necesario hacer una aclaración de orden metodológico, que consiste en definir el tipo de narrativa usado en esta pesquisa, la cual es la life history, que

Investiga sobre un individuo determinado donde se incluye su propio relato y es complementado por xlx investigadorx con otros documentos. Se basa en un amplio recorrido en la vida de una persona donde los hechos cronológicos son el hilo conductor. Interesa más el acontecimiento que la historia de vida (Mallimaci y Giménez, 2006, p. 1).

Esto conduce a definir que las narrativas de lxs maestrxs son historias de vida que se centran en un acontecimiento situado de sus experiencias construidas, es decir, estas se manifiestan en la reconstrucción de sentidos, que en este caso se hizo de una forma cronológica, llevando xlx maestrx a narrar los hechos más representativos de su fd, para llegar al punto álgido de la narrativa que es la fd en posgrados y su relación directa con las trayectorias consolidadas como maestrx en ejercicio, basando su relato en aquellas significaciones que dieron lugar a unos posibles cambios en sus prácticas docentes.

Teniendo claridad al respecto, se prosigue, afirmando que "xlx investigador aborda el análisis del material a partir de una pluralidad de perspectivas, 
organizando las historias en temas centrales que han ido transformando esa vida" (Denzin, citado en Mallimaci y Giménez, 2009, p. 201).

$\mathrm{Y}$, por otra parte, "se recomienda ordenar el material alrededor de núcleos temáticos. Estos ejes surgen de la pregunta que guía la investigación” (Sautu, citado en Mallimaci y Giménez, 2009, p. 201).

Todo ello conduce a la investigadora hacia un análisis que permita evidenciar las palabras de lxs narrantes y, a la vez, resaltar la labor que hace, en términos de cómo re-construye las historias de vida, ya que "no estamos ante textos informativos, sino ante relatos biográficos que construyen humanamente (sentir, pensar, actuar) una realidad” (Bolívar, Domingo y Fernández, 2001, p. 205).

Esto conlleva a configurar un análisis detallado y hermenéutico sobre las historias de vida de fd de lxs maestrxs, partiendo de la reconstrucción de hechos que anteceden a las experiencias de fd en posgrados. Lo que se trata es de emprender un recorrido por los relatos que resaltaron la vida dxlx maestrx para ser "maestrx". Quiere decir que,

Realizar la historia de vida de una persona supone sumergirse en una otra existencia, y esto exige tiempo y disposición por parte $\mathrm{dxlx}$ investigadorx, así como una constante revisión de los temas, y una ida y vuelta permanente entre el material obtenido y el diseño, para enriquecer el resultado del proyecto (Mallimaci y Giménez, 2009, p. 186).

Es en el análisis narrativo y hermenéutico que se develan los significados de los datos obtenidos con las historias de vida, estos datos son en sí mismos narrativos, se basan en la remembranza de sucesos sobre un acontecimiento específico, que en este caso son las "trayectorias de fd". De por sí, abordar 
temas como la fd implica, más allá de la teoría, encontrar sus significados en las narrativas de lxs maestrxs, y, los análisis de narrativas suponen, Introducir cambios en la formación docente a partir de la generación de diarios de la experiencia de formación, de manera especial en la escuela, la práctica de enseñanza y en la tutoría. De esta manera, se abría una nueva agenda para la formación inicial y continuada en la cual lo personal pasa a ocupar una parte fundamental del territorio de la formación (Thomas, citado en Hernández, 2011, p. 14).

En definitiva, el análisis de la narrativa se basa en estudiar en profundidad los sentidos y significados de un tema específico, por lo que "considerar el papel reciente que se la ha otorgado a las emociones y los afectos como un componente fundamental a la hora de explicar...la propia actuación docente, particularmente, en un momento histórico de profundos cambios sociales y culturales" (Hernández, 2011, p. 15). Es decir, de ahondar desde los inicios, o sea, desde las primeras incursiones de la investigadora a las historias de vida de Ixs maestrxs en la búsqueda permanente de estos significados, en este caso es de la fd posgradual, que, para ello, se hizo necesario hacer un rastreo temporal de la constitución de experiencias como maestrxs, o, mejor dicho, recorrer la vida por los momentos que marcaron las decisiones para "ser maestrxs".

Con estas notas preliminares y aclaratorias sobre el tratamiento, análisis e interpretación de las narrativas, lo que se va a desarrollar en esta parte, se divide en tres capítulos; el octavo, "reconstruyendo narrativas pasadas sobre la fd para develar los acontecimientos presentes de lxs maestrxs" tiene que ver con la recuperación de las historias de vida de seis maestrxs y que configuran los 
hechos que marcaron su labor docente. En varias de las historias concurren afirmaciones que parten del hecho de "no pensar jamás en ser maestrxs", y que bajo esta premisa se encuentran relatos que avistan a definir que son maestrxs no por vocación sino por los diferentes y, en ocasiones, "forzados" sucesos que vivieron estxs buenxs maestrxs. Es por ello, la necesidad de conocer la vida pasada para comprender la vida presente de estxs maestrxs.

En el noveno capítulo "trayectorias y sentidos dxlx maestrx en ejercicio sobre la fd", se abordan dos categorías: la primera, la práctica docente, desde el interrogante ¿de qué forma las experiencias formativas en posgrado fortalecen y se manifiestan en "re-trazadas" prácticas docentes?

La segunda tiene que ver con la experiencia formativa adquirida en el desarrollo de la maestría. Esta categoría hace referencia a los aprendizajes que se manifiestan a lo largo del periodo de formación posgradual y que consolidan un bagaje teórico, conceptual, metodológico, didáctico y pedagógico en $x l x$ maestrx en formación posgradual, que para el caso de esta tesis se hace una defensa fundamentada en los relatos, sobre las transformaciones y cambios que producen estas experiencias formativas en las prácticas y la cotidianidad docente.

El décimo capítulo “manifestaciones emergentes de la fd posgradual para reflexionar el acto pedagógico y educativo dxlx maestrx". Aquí, las narrativas se analizan desde dos categorías: la primera se centra en los aprendizajes adquiridos sobre investigación, partiendo del hecho que en todas las historias de vida se hace referencia al acto investigativo de la propia práctica docente, 
suceso que incursiona como novedad en la cotidianidad docente. La segunda, xlx maestrx como sujeto social, pedagogo, artesano y humano.

Es así como, en esta categoría se hace un abordaje concluyente sobre el papel dxlx maestrx que se forma como magíster en los contextos que se desenvuelve y con las personas que en ellos transitan; o sea, ¿qué le permite a este maestrx fomentar mejores prácticas, proporcionar mejores aprendizajes y ser parte del cambio social de su contexto inmediato?, ¿qué lo hace, no mejor, pero sí más consciente de generar prácticas situadas desde el diálogo, el afecto y la integración de saberes? 
Capítulo VIII. Reconstruyendo narrativas pasadas sobre la fd para develar los acontecimientos presentes de Ixs maestrxs

Martínez (en Porta y Martínez, 2015) comienza una entrevista a Roberto Kuri sobre las buenas prácticas de lxs maestrxs, para adentrarse en la historia de Roberto sobre cómo se hizo maestrx y cómo fue su formación docente. En la primera respuesta, Roberto dice "hace un tiempo, tuve un alumno en cuarto año que estuvo un tiempo enfermo, un día llamé a la casa para saber de él y hablé con los padres. Ellos me dijeron: “Ay, Kuri, usted no sabe, qué gusto conocerlo, ¿sabe que mi hijo tiene locura con usted? Pregunta ¿qué día es hoy? Y si es lunes dice: ¡qué suerte, mañana tengo diseño!” (Porta y Martínez, 2015, p. 46).

Esto conduce a entrelazar lo anterior con lo que dice Alliaud (2018, p. 10), Todxs podemos llegar a ser -artesanxs de la enseñanza-; pero para lograrlo hace falta contar con cierta preparación. Una preparación que no disocie el pensamiento de la acción, pero que tampoco deje afuera el sentimiento; que nos convoque a saber y poder hacerlo; que nos acompañe, que nos conduzca, que nos enseñe a enseñar. Y a enseñar hoy, es decir, en los escenarios educativos del presente, con los desafíos y particularidades que los caracterizan.

Tejido de argumentos que se manifiesta en el momento que lxs maestrxs trazan sus narrativas sobre lo que ha marcado su labor docente, al respecto, en una entrevista que realizaron Álvarez y Sarasa (en Porta y Martínez, 2015, p. 39) a Cristina Piña sobre lxs maestrxs memorables, y, específicamente, sobre poner de manifiesto "que las prácticas de aula de los docentes están vinculadas con los afectos, la vida y la profesión". Cristina en su primera intervención dice "enseño 
porque me gusta comunicar lo que me pasa [...] yo enseño única y exclusivamente por el entusiasmo, porque me apasiona la literatura, me apasiona la teoría y el pensamiento".

Estos dos maestrxs entrevistadxs tienen algo en común, hacen buenas prácticas por gusto a lo que son. Se enfocan en generar otras formas de contemplar las realidades desde sus enseñanzas y modos de trazar lo enseñable a sus estudiantes. Sin embargo, para llegar a este punto de "perfección" sobre el ser maestrx es necesario forjar trayectorias de formación, tejer experiencias y apropiarse de lo que en verdad es ser maestrx.

Se ha referido a dos situaciones que son la columna vertebral dxlx artesanx maestrx; la primera tiene que ver con el contexto $d x l x$ maestrx, siendo esta situación uno de los trazos conformado por lxs maestrxs narrantes, y que resulta relevante para ellxs, narrar cómo es el lugar donde viven y se han desempeñado como maestrxs de primaria o bachillerato en algún colegio o escuela de la ciudad. En este re-trazo hermenéutico se recurre a las voces de maestrxs, para que ellas sean las que narren y tejan esos entramados de lugares, testigos de sus trayectorias como maestrxs.

Adela Ortiz: Vivo hace trece años, voy a cumplir trece años de vivir aquí, y he visto crecer la ciudad de manera impresionante, el tema de la ruralidad, el tema de la cultura, logra enamorarlo a uno definitivamente y hace que uno se quede aquí. Hay un adagio popular que dice que "el que se baña en el rio Guatapurí, queda absolutamente enamorado de estas tierras y se queda", y si no se queda vuelve. Éste es el caso mío volvió, pero volví para quedarme.

Los 13 años que he vivido aquí en Valledupar, los primeros cinco años los trabajé en el sector privado, en los últimos años, de esos cinco alternaba sector privado y sector oficial en la misma institución donde me encuentro, siempre he estado en 
esta institución y trabajaba en un colegio privado de estrato socioeconómico 3 y $4^{24}$, y las condiciones eran totalmente diferentes, de formación soy profesora normalista, soy licenciada, recientemente magíster en didáctica, y toda esta formación me ha permitido mirar poco a poco y transformar mí quehacer pedagógico y descubrir nuevas situaciones en lxs estudiantes, me han abierto los ojos, es un nuevo panorama, que realmente veo.

Al comienzo, fue muy difícil el tema del sector privado a lo público, a lo oficial, yo llegué con una perspectiva, muy diferente sobre todo por el nivel socio económico en el que estaba trabajando, a aterrizar a una institución con niveles socio económicos estrato 1... yo dije “ipor Dios, aquí qué pasa, ¿esto qué es?!” (Risas) yo veía que eran totalmente dos esferas distintas y ahora cómo hago, cómo arrastro toda esa disciplina cómo la manejo yo, en un estrato como este, las mismas estrategias que asumía allá, no me daban los mismos resultados acá... inclusive, el discurso pedagógico, el discurso didáctico, el discurso disciplinario me tocó empezar a transformarlo.

Bertha Robles: Hay algo que yo hago con ellxs cuando algunxs estudiantes no entienden al momento, muchas veces me desplazo a las casas de ellxs en horas de la tarde y les explico.

Entrevistadora: Eso es otro trabajo. Ahí es donde me nace la idea de cómo han sido esos vínculos con la comunidad, porque me imagino que el reconocimiento con la comunidad es bastante. Porque hacer esa labor de ir a las casas después de la jornada a explicarles, y hagas unas clases. Yo me imagino que la comunidad lo valora mucho.

Bertha Robles: Sí. Ellxs son bastante gratos. Lo que pasa es que hay casas muy distantes y es preferible yo ir donde ellos a que ellos vengan a mí.

Entrevistadora: ¿Cómo así distantes? por ejemplo.

Bertha Robles: Distante: de la escuela al sitio donde viven, por ejemplo, hay algunxs estudiantes que se gastan una hora de salida y las casas están cerca al río. La escuela está muy lejos y son niñxs pequeñxs. La distancia de lxs niñxs que salen de allá es muy lejos, entonces, pues, un sábado, yo me traslado a donde ellxs.

Entrevistadora: ¿Además vas un sábado?

Bertha Robles: Si, porque entre semana tengo que preparar la clase y con los que viven relativamente cerca, si les digo que vengan a mi casa y yo trabajo desde las 4.30 hasta las 5:30 p.m.

Entrevistadora: ¿En la escuela?

Bertha Robles: No, en mi casa. Sí, porque lo de la escuela se trabaja normal, pero ya después, los invito a mi casa.

\footnotetext{
${ }^{24}$ La estratificación social en Colombia según el Departamento Administrativo Nacional de Estadísticas -DANE- se divide en 1. Bajo-bajo 2. Bajo 3. Medio-bajo 4. Medio 5. Medio-alto 6. Alto. Para ampliar la información sobre el tema ver página del DANE: 
Entrevistadora: ¿Y si hay niñxs que van? ¿A ellxs les gusta ir a tu casa?

Bertha Robles: Sí claro, porque yo les doy café o galletas.

Entrevistadora: $Y$ ¿Qué hacen aparte de la jornada? Por ejemplo, el sábado que vas hasta la casa dxlx niñx que vive más retirado ¿Qué haces en ese día?

Bertha Robles: En ese día, ellxs desarrollan sus tareas, juegan y aprovechamos ese espacio, ya que el sábado no hay tanto trabajo para los padres de familia, porque el sábado ese es "día del mercado" aquí, entonces, ellxs van al mercado y más o menos llegan a las 10:00 a.m., a esa hora yo ya estoy con lxs niñxs. Y mire que esto me ha dado mucho resultado porque me enfoco en xlx estudiante que tiene más necesidad de explicación y de que yo le profundice más el tema. Yo sé que hago una "clase personalizada".

Sí, y como docente de la comunidad todo gira en torno al docente, no solamente son labores académicas sino también son otras las que uno hace, por ejemplo, dígase ya en diciembre que es la novena, en semana santa también.

Entrevistadora: $O$ sea que la comunidad ya sabe que tú eres la que lidera ese tipo de celebraciones. $Y$ is te apoyan? ¿La comunidad es agradecida?

Bertha Robles: Sí la comunidad es bien agradecida. Lo tienen en cuenta a uno. Por ejemplo, cuando es día dxlx maestrx me dan detalles en nombre de la comunidad, en nombre de la familia. Uno no espera eso, pero son detalles bonitos. Todos estos de detalles y este cariño me motivan para seguir haciendo esta labor y esta lucha. Porque la educación rural es compleja, no es lo mismo que lxs estudiantes de la ciudad, ellos lo tienen todo. En cambio, aquí tenemos que rebuscar los recursos del medio, la señal del internet es demasiado lenta, el internet es muy escaso y regular. Antes trabajaba en otra vereda, muy lejos de mi casa, casi a hora y media. Tenía que madrugar mucho. Luego me casé y quedé embarazada, en ese entonces, tenía mi nombramiento por contrato y tuve que pedirle al alcalde que por favor me contratara nuevamente, una vez hablé con el alcalde y le pedí el traslado a mi vereda, porque había bastante estudiantes en ese entonces. En esa época había cuatro profesorxs, eran 76 estudiantes y daba para tener cuatro docentes, ahora la población ha ido disminuyendo y a estxs docentes los han ido trasladando a otras escuelas, y ahorita estoy con otro compañero, pero con el temor a quedar sola.

Adela y Bertha, maestras narrantes, la segunda, residente de una vereda del municipio de San José de Alban en Nariño; la primera, residente en la ciudad de Valledupar, reflejan en sus relatos algunos trazos de la experiencia en cada lugar. Adela hace un primer acercamiento a las tonalidades culturales de su tierra, ella no nació allí, sin embargo, gran parte de su trayectoria como maestra la ha tejido en Valledupar, su cultura folclórica, que entre acordeones y aires 
musicales del paseo y el merengue se mezclan con los aconteceres pedagógicos en las escuelas y cotidianidad dxlx maestrx. Dibujando su cotidianidad, hace un acercamiento a la vida docente desde dos perspectivas, el trabajo docente en colegio público y en colegio privado.

Este pedazo de relato permite ampliar el análisis, haciendo hincapié en el trabajo dxlx maestrx, y, más aún, dxlx maestrx que ha explorado los dos sectores de la educación colombiana, lo privado y lo público. Adela cuando se graduó de la Normal trabajó en un colegio privado, diseñado para infantes con ciertas condiciones óptimas, entre ellas, libros textos, uniformes de calidad, horarios flexibles, tutorxs, transporte puerta a puerta, cuadernos, útiles escolares de mayor calidad. Y, para lxs docentes, materiales de trabajo, recursos físicos, bibliográficos, tecnológicos y pedagógicos, transporte, salario adecuado, espacios formidables para la enseñanza, espacios verdes para enseñar en mejores condiciones, infraestructura adecuada según el clima de la ciudad.

Estas situaciones son altamente marcadas en Colombia, los colegios privados cuentan con las condiciones necesarias y en muchas ocasiones, las superan para que maestrx y estudiante, enseñe y aprenda en ambientes apropiados para hacerlo, cuenta con recursos privados que logran mantener estas condiciones y mejorarlas.

Adela cuando pasó al sector público, se encontró con un escenario muy diferente al que se imaginaba, y no hay que pensarlo porqué, sin embargo, aquí algunas consideraciones. La educación pública en Colombia es desigual, en las grandes urbes se localizan gran parte de los recursos destinados para la 
educación primaria y secundaria. Cuando se refiere a los recursos destinados para los corregimientos, veredas y resguardos indígenas ${ }^{25}$, estos se ven afectados por la indiferencia política y las presiones gubernamentales. En una porción considerable de las escuelas de las ciudades pequeñas y sus periferias las condiciones básicas se relegan a "lo que se pueda hacer".

No se cuenta con textos escolares, las bibliotecas son remotas, las condiciones de desplazamiento para lxs estudiantes son limitadas, Ixs maestrxs cuentan con pocos recursos didácticos, lúdicos y tecnológicos, son ellxs quienes deben asumir su material, en muchas ocasiones. A estas condiciones se suma la inseguridad social, las dificultades de contar con mejores salarios docentes, las constantes exigencias por parte de los gobiernos por ver resultados favorables en las pruebas estandarizadas nacionales e internacionales.

Todo ello hace parte de la cotidianidad dxlx maestrx en el sector público, agregado a ello, las oportunidades en fd son escasas para las regiones apartadas de las ciudades centrales, lxs maestrxs licenciadxs tienen dos opciones, la primera no aspirar a ninguna opción de fd posgradual; o la segunda, salir de sus regiones para profesionalizarse y formarse en posgrados. Adeudando créditos con entidades públicas o privadas para lograr una mejor formación que conduce a mejores condiciones salariales.

\footnotetext{
${ }^{25}$ Lo resguardos indígenas son una comunidad de origen colonial, legalmente constituida, todos los resguardos en Colombia son de propiedad colectiva y comunitaria, tiene una legalización especial regida por sus principios y tradiciones culturales. Los resguardos más reconocidos están ubicados en La Sierra, Santa Marta, La Guajira, Vichada, Nariño, Leticia, Quibdó, Tierralta, Guaviare, Tumaco. Consultar resguardos indígenas en http://buritaca.invemar.org.co/siam/tesauro_ambiental/anex/Resg.htm
} 
Los dos sectores de la educación son regidos por los mismos lineamientos ministeriales y se ajustan a la normatividad colombiana desde Ley General de Educación 115 de 1994 hasta los lineamientos disciplinares y las pruebas estandarizadas. Sin embargo, así como ambos sectores traen sus bondades, así mismo tienen sus dificultades, y una que más caracteriza al sector privado es la inestabilidad laboral que año tras años pone en riesgo xlx maestrx. Mientras que al ser maestrx estatal se cuenta con seguridad laboral por nombramiento público. Desde luego, tomando como condición inicial contar con un ingreso fijo durante todo el año, pero asumiendo los retos que conlleva ser parte de la educación pública en Colombia.

Así como Adela se encontró de frente con otra realidad, se hizo necesario modificar su discurso, sus condiciones pedagógicas y afrontar un reto de enseñar a infantes con variedad de problemáticas sociales, familiares y académicas. Ella lo resalta "inclusive, el discurso pedagógico, el discurso didáctico, el discurso disciplinario me tocó empezar a transformarlo."

Por otro lado, Bertha es una maestra campesina que nació, se crió y ahora trabaja en la escuela de su vereda, la dedicación que tiene por su oficio abarca la mayoría de su tiempo, se desplaza a las casas de sus estudiantes para hacerles refuerzos escolares o para hablar con los padres y las madres. Labor que hoy en día es escasa, pero que las condiciones del contexto lo permiten y más cuando se tiene la ventaja de vivir en el lugar donde labora, con las personas que la aprecian y colaboran en su labor de maestra. 
En el relato de Bertha se logra evidenciar parte de los rasgos distintivos dxlx maestrx artesanx, que forjan su oficio desde el sentir de su ser, son maestrxs de hechos y vínculos estrechos con las comunidades, a pesar de las condiciones para enseñar, falta de recursos, familias que no alcanzan a devengar un salario mínimo, pero que sin importar llevan a lxs hijxs a la escuela y más cuando saben que cuentan con una maestra preocupada porque sus estudiantes tengan buenos aprendizajes y que les sirva en sus labores cotidianas. En otras palabras, el contexto de esta maestra se marca en condiciones regulares, desde las que debe tomar lo mejor para ejercer su oficio y empoderar a sus estudiantes para que logren perspectivas más amplias de sus contextos y condiciones.

Esto conduce a conocer los trazos sobre el lugar de Mateo Símil,

El Peñol es una región de personas trabajadoras, campesinxs humildes que trabajan el campo y quieren salir adelante, que luchan porque sus hijxs cambien de vida. Porque les ha tocado muy duro, entonces, es un lugar en el que hay mucho por hacer por la niñez, es una parte donde viví mi infancia, nací, crecí allá y ya por cuestiones profesionales salí de allá. Pero estoy ejerciendo mi profesión en este momento acá en el Peñol, también. Entonces, es un lugar en el que tengo muchos recuerdos de infancia, muchas experiencias de vida en este corregimiento de San Francisco, donde está la institución, que me impulsan a mí a hacer de mi labor algo para apoyar y aportar a esos jóvenes y a esas señoritas, que de pronto por sus situaciones económicas se les dificulta salir adelante. Entonces, trato de hacerles ver que todos estuvimos en algún momento en esta situación y que, con el esfuerzo y la voluntad, pudimos seguir adelante y ahora quisiera contribuir a que otrxs puedan lograr esas oportunidades que yo no tuve. Quisiera ayudar a esxs muchachxs, entonces, este es un corregimiento (San Francisco) que me impulsa y que me da muchas razones para ejercer mi profesión.

Cuando yo estudié no existía este colegio. Era el colegio que había en la cabecera municipal. Yo estudié en la Institución Jorge Eliecer Gaitán de donde yo residía en ese momento quedaba una hora y quince minutos. Nos tocaba a pie todos los días de 7 a 1 de la tarde. A veces nos tocaba regresar a pie porque en ese tiempo no teníamos transporte, ni desayuno. Eran unas condiciones bien difíciles, pero el apoyo de nuestros padres y madres fue fundamental. Nos impulsaban a que teníamos que estudiar y teníamos que seguir adelante y aunque había unas condiciones difíciles, íbamos a estudiar porque pensábamos que el estudio nos permitiría 
mejorar nuestras condiciones. Así lo hacíamos todos los días, muchos estudiábamos allí. Éramos como 50 jóvenes, señoritas en ese momento, pero si nos tocaba viajar mucho.

Una anotación inicial, como se resalta en la voz dxlx maestrx tiene que ver con las grandes dificultades que enmarcan los contextos de estxs maestrxs, los cuales se encuentran en zonas retiradas de las principales urbes y que su acceso es difícil, esto genera que un gran porcentaje de los jóvenes que logran ser bachilleres no continúen con sus estudios profesionales por las condiciones en que están, partiendo del desplazamiento hacia las ciudades y la renta que esto genera. Por lo que deciden seguir los pasos de sus padres de labrar la tierra o emplearse como recolectorx de café o frutales.

Se vería que esto está aislado del campo de la fd, sin embargo, este es el contexto y sus condiciones que lxs seis maestrxs convocadxs para esta investigación han tenido que vivir al largo de sus trayectorias como maestrxs. Su formación está marcada no solo por las bondades que ésta genera sino por las dificultades que han tenido que superar para lograr posesionarse como maestrxs en escuelas o colegios de primaria y bachillerato.

Más allá de lo que constituye el contexto dxlx maestrx, es identificar los sentidos que circulan por estos, los tres relatos anteriores, en donde se resalta parte de la cotidianidad dxlx maestrx y las labores que no solo están reducidas al escenario escolar, sino que va más allá, la vida de un maestrx supera los límites de la escuela, "los referentes de nuestras biografías familiares han dejado una huella profunda en nuestro sentido vocacional, nuestro amor por la enseñanza [...] esa huella nos mueve y conmueve" (Porta y Martínez, 2015, p. 36). 
$Y$ son justamente las reacciones encontradas en lxs maestrxs narrantes, su oficio es en todo lugar, en todo momento, hasta en sus hogares son maestrxs. Van dejando enseñanzas por el camino que transitan. Es el caso de Bertha, ella, la maestra de la vereda, a la que la generación de sus padres y abuelxs vieron crecer, y ahora, su generación y la de sus hijxs, ven como la maestra y la que lleva enseñanzas y bondades a sus hogares, donde sabe que la posibilidad de acercamiento es mayor y más receptiva. 0 , al contrario, su casa se convierte en otro lugar de enseñanza.

Las huellas que se marcan en las trayectorias como maestrxs son memorables, es esto lo que ocurre cuando la vida dxlx maestrx permea todos sus ámbitos, sus trayectorias están conformadas de sentidos, localizados no solo en xlx maestrx, sino en las personas que lo rodean. Lo cual se puede percatar fácilmente en los contextos donde se desenvuelve $x l x$ maestrx, sean en la escuela o en el vecindario; los contextos marcan los modos de enseñanza y actuación de lxs maestrxs. En resumen, la conjugación entre el quehacer y las posibilidades de fd en parte se definen por el contexto en donde ejerce xlx maestrx, las connotaciones teóricas y epistemológicas de la fd solo cobran sentido si xlx maestrx actúa con apropiación y acogida en el contexto donde hace su oficio.

Todo ello conduce a la segunda situación de este capítulo que se resalta en xlx maestrx artesanx y que se presenta en las remembranzas de lxs maestrxs y que vinculan directamente con sus pasos por la $\mathrm{fd}$, teniendo que ver con las experiencias en la formación de las Normales y su paso por la universidad como estudiantes de licenciatura. Sus primeros acercamientos fueron en la Normal, en 
el caso de lxs seis maestrxs, cuatro mujeres se formaron como normalistas y los dos hombres se formaron como bachilleres académicos.

Uno de los argumentos que trazan las seis historias de vida es el hecho de nunca imaginarse ser maestrx, las mujeres que se formaron en las Normales no imaginaron ser maestras al punto de vivir para enseñar. Lulo Corrales cuenta en uno de sus trazos que ser maestra no estaba entre sus planes, de hecho, no sentía gusto por enseñar:

Lulo: Mi pregrado fue en educación básica con énfasis en ciencias naturales, estudié en la Universidad de Nariño. Fuimos el primer grupo con la extensión de la universidad en Túquerres y mi formación fue semipresencial, teníamos clase aquí en Túquerres y los fines de semana, cada 15 días trabajábamos en Pasto.

Fueron 5 años, fue una experiencia muy chévere, porque a mí siempre me ha gustado las ciencias naturales y la biología y fue interesante el proceso, aunque, prácticamente lo hice porque ya estaba metida en el cuento de la docencia, pero mis ideas y mis metas estaban encaminadas por otro lado.

Entrevistadora: ¿Tenías otros intereses? ¿Tú no pensabas ser docente?

Lulo: No, yo no quería ser docente, lo que pasó es que yo estudié en el Teresiano, en la Normal, aquí en Túquerres, me gradué con la promoción de 1991 y cuando uno estudia en la Normal, lógicamente uno no tiene definida la misión. Yo estudié en un colegio de monjitas y allá lo preparan a uno para ser docente, pero yo no sentía que esta fuera mi vocación, no me atraía ni me llamaba la atención. A mí me matricularon en ese colegio, porque era un colegio privado, en el que la familia piensa que uno aprende más, que lo cuidan más, incluso, yo hice desde la primaria allí. En ese tiempo era solo femenino, pero ahora es mixto.

Me metieron allá como para estar mejor. En ningún momento a mí me llamó la atención ser docente, es más, cuando en bachillerato teníamos que hacer las prácticas docentes, para mí era una tortura tener que ir a dictar clases a lxs niñxs, aunque no lo hacía mal.

Haciendo un primer análisis del anterior relato, ser maestrx no necesariamente implica "nacer" con la vocación para enseñar, esta cualidad distintiva de lxs maestrxs va surgiendo con el paso del tiempo y de las experiencias construidas. Al respecto, Alliaud (2018) hace referencia a que la 
enseñanza se puede comparar con una artesanía, en la medida que la artesanía no es en sí misma, sino que necesita de la experticia dxlx artesanx para ser. $Y$ es justamente, lo que pasó con Lulo, al estar involucrada previamente con los andares de ser maestra optó por hacerlo de la mejor forma posible, a pesar de no tener gusto por lo que estaba haciendo, ya que todo proceso requiere de formación y de la experiencia adquirida en los trayectos consolidados.

Al recuperar las historias de vida de lxs maestrxs, en sus voces se reflejan las eventualidades que los condujeron a ser maestrxs, no siempre se llega a la profesión que se ejerce por voluntad propia o porque ese era el destino que correspondía. Para ellxs, llegar a ser maestrxs fue por necesidades de la vida y alteraciones propias de los contextos. Dice Mateo Símil que él no pensó nunca en ser maestrx, pero las dificultades que tuvo que transitar al salir del colegio graduado de bachiller lo condujeron a tomar decisiones drásticas para su futuro.

Porque yo donde viví, soy campesino de nacimiento, trabajé el campo, trabajé la tierra, me gradué de 15 años y me fui a estudiar medicina a Ecuador, estuve 8 meses, pero por problemas de salud me tocó regresarme, no quise saber más nada del Ecuador, me vine aquí otra vez y dije: "mejor yo me quedo trabajando en el campo" empecé a cultivar cebolla, tomate y así lo hice tres años, hasta los 18, cuando yo estaba en un momento de trabajo en un día de esos soleados, me puse a analizar y dije esto no va conmigo, desde hoy no quiero volver a trabajar en el campo, no porque me demeritara, sino porque era muy duro. Al día siguiente dije: mañana me inscribo a la universidad y así fue, me inscribí, afortunadamente, tenía un buen puntaje en el ICFES ${ }^{26}$, pasé a la universidad de Nariño a estudiar y pues, continué mi carrera y ahora estoy acá. No ejerciendo la profesión que estudié. Porque mi profesión es química pura, no es el perfil del docente, pero ingresé al concurso docente del 2005 por una oportunidad laboral. Soy sincero, y digo, "por una posibilidad laboral". Ya cuando llegué a laborar en este campo, sentí que, aunque no era la vocación mía, es un trabajo que tiene mucha responsabilidad y que

\footnotetext{
${ }^{26}$ Instituto Colombiano para el Fomento de la Educación Superior, es una entidad autónoma adscrita al Ministerio de Educación Nacional de Colombia. Ofrece servicios de evaluación de la educación en todos sus niveles y apoya al Ministerio de Educación en la realización de los exámenes de Estado.
} 
de mi dependen muchas vidas y el futuro de muchos jóvenes que están en las mismas condiciones que yo estuve. Toda esa experiencia de vida que yo tuve me ha permitido enriquecer para poder hacer mejor mi labor.

[...] Yo cuando ingresé al pregrado en química, fue en un momento de decisión y de decir quiero cambiar este nivel de vida, este trabajo tan fuerte que es el campo y me inscribí. Incluso yo diría que son las cosas que a veces Dios le pone a uno en el camino. [...] Yo lo único que quería era estudiar, no estaba por ingeniería de sistemas, entonces, empecé a estudiar química. Cuando hice el primer semestre, realmente me iba a retirar, ya había pasado tres o cuatro años fuera del sistema educativo y perdí el hilo del estudio.

(cinco años después) [...] En ese tiempo tenía 28 años. Salió el concurso docente, yo me inscribí. Como una posibilidad de trabajo y me fui. Pasé el concurso, salí y entré a trabajar... entonces miren que la parte laboral me fue llevando por otro camino, tuve otras oportunidades de trabajo y fui dejando a un lado la parte del estudio. Ya cuando estuve en Policarpa, pensé en retomar nuevamente lo del estudio del doctorado, porque el ambiente allá era un ambiente complicado y difícil [...] resulta que, entre julio, cuando ya tenía un cupo, surgió el proceso de la reubicación docente y me trasladaron acá (El Peñol). Entonces, llegué a mi tierra, me dije estoy trabajando, estoy con mi gente y no me fui a estudiar. Me quedé acá, aunque económicamente la remuneración era mínima, porque irme para Cali, implicaba dejar a mi esposa, irme solo y mi esposa también se iba a quedar sola. En cambio, acá tenía trabajo y me quedé. Afortunadamente, empezaron los procesos de ascenso, de reubicación salarial en concursos y en evaluaciones que hemos presentado, afortunadamente, he pasado muchas de ellas y económicamente ya mejoré y no he tenido la opción de irme por ese lado, me enamoré de la enseñanza y de la docencia.

Este trazo, remite directamente a Meirieu (2006, p. 121) “hacerse profesorx es invertir en el futuro, ya que significa trabajar todos los días en los aprendizajes". Y, desde luego, el que decide ser maestrx está destinado a aprender algo nuevo cada día, las condiciones dxlx maestrx novel lo remiten a cultivarse permanentemente. Analizando el relato de Mateo es claro que sus intenciones iban por otro lado, las pretensiones profesionales y laborales nunca fueron ser maestrx de escuela, y menos de retornar a su tierra a ser xlx maestrx 
de lxs hijxs de sus hermanxs, amigxs y vecinxs que lo vieron crecer y cultivar la tierra al lado de sus padres.

La elección de la carrera tampoco fue una decisión de su interés, fue porque necesitaba estudiar lo que fuera para no hacer el trabajo duro de cultivar la tierra, esta necesidad lo condujo a enfrentar un reto y cumplir una meta, ser profesional en alguna carrera y poder ejercerla. Sin embargo, los avatares de la vida lo llevaron por otros caminos, él mismo dijo que las casualidades no existen y que por algo fue conducido hacia la docencia, oficio, del que terminó enamorado y cimentando una vocación.

Xlx maestrx que narra sus trayectorias vividas es aquel que manifiesta su realidad, no se es lo que se quiere ser, se es lo que las condiciones de vida le permiten ser. Y queda evidenciado en el relato de Mateo, todo comenzó por salir de su tierra y correr el riesgo de conocer lo nuevo, situación que lo impulsó a seguir adelante, obtener buenos resultados y encontrarse en el camino el oficio de ser maestrx. Oficio que hasta el momento ha realizado con empeño, compromiso y enfatizando en la responsabilidad de enseñar a otros.

Mateo: Yo cuando ingresé, ya nos exigieron a nosotros un curso de pedagogía, es un curso que hicimos en cinco meses, porque éramos profesionales no licenciadxs, entonces nos exigían eso para hacer el nombramiento en propiedad, hicimos eso, pero realmente para yo irme a dictar esas primeras clases yo no sabía qué hacer, yo pedí los cuadernos de una prima que apenas se había graduado del once y le pedí el favor de que me los prestara y con esos cuadernos yo empecé a enseñar porque en realidad yo no sabía cómo hacerlo ni qué enseñar, en el colegio Policarpa. Cogía los cuadernos y empezaba dictar y a tratar de explicar. Eso era lo que yo hacía, yo no sabía que más hacer. No tenía conocimiento de plantear estrategias o de una planeación de clases mucho menos, entonces, llegaba a la clase miraba el cuaderno, y a veces con ese mismo les dictaba. Luego, poco a poco empecé a hablar con mis compañerxs docentes, para saber qué es lo que hay que planear, lo que teníamos 
que hacer, pero realmente yo podría decir que todo lo que aprendí fue de manera empírica que fui aprendiendo mi trabajo docente.

Es claro que Mateo, en sus primeros rasguños en el oficio de ser maestrx, la inexperiencia era la principal fuente del miedo, no estudió para lo que estaba ejerciendo, y lo que le valió fue recordar las enseñanzas de sus maestrxs junto con otros elementos que iba obteniendo en el camino. En este relato, Mateo reconoce que ser maestrx no le fue sencillo, tardó por lo menos dos años en aprender, haciendo cursos que llevaba el MEN al colegio donde laboraba, realizó una especialización en pedagogía, estableció diálogo con otros colegas para reforzar su quehacer.

Frente a ello, Alliaud (2018) considera que el oficio de enseñar lo integra el ser propio de cada maestrx y las condiciones que él forja a lo largo de sus trayectorias, la perspectiva que se tiene del oficio está vinculada directamente con las tramas construidas y recorridas que xlx maestrx realiza.

Cuando se hace un oficio se está aprendiendo permanentemente algo, se vuelve a la metáfora dxlx artesanx, cuando elabora sus artesanías, él se permite conocer qué nuevo puede hacer para crear, es decir, aprende desde su propio arte, diseña diferentes moldes, con diversas formas y muy seguramente ninguna artesanía es igual a otra. Algo similar sucede con el oficio de ser maestrx, hace enseñable lo que sabe y los resultados en todos sus estudiantes son diferentes. En este punto, de nuevo se narran los trazos de Lulo, teniendo en cuenta que ella, al igual que Mateo en sus intenciones iniciales no estaba destinado ser 
maestrx, sin embargo, quizás, debido a las enseñanzas recibidas; y Lulo en

particular, a las enseñanzas de su madre fue que tomó el rumbo de ser maestra:

Lulo: [...] Luego uno tenía que hacer su preparador de clases, lo presentaba a la directora de práctica docente, luego a la directora de curso y ahí le indicaban lo que uno tenía que hacer.

Entrevistadora: ¿Tu cuántos años tenías ahí?

Lulo: 16 años, me gradué a los 18. Entonces, uno aprende allí, pero no se enamora de la profesión. Yo tenía algunas compañeras que sí les encantaba y sí querían ser maestras, pero a mí no me nacía, es más, trabajar con niñxs me parecía durísimo y terrible y, a uno, por ejemplo, cuando están en sexto, séptimo, octavo y noveno lo llenaban de mucha teoría, entonces, recuerdo que dictaban muchas clases, había profesoras de administración educativa, de psicología, comportamiento y salud. A uno le decían que teníamos que hacer todo esto porque íbamos a ser profesorxs. Nos hacían repetir las cosas y nos hacían grabar, me acuerdo de que tenía una profesora de administración educativa y ella, nos hacía memorizar todo, códigos, leyes y a mí me parecía odioso eso. A uno le decían que cuando sea profesor, debía llevar unos libros reglamentarios. El registro de asistencia, de notas, seguimiento. Lo ponían a grabar eso y nunca me llamaba la atención hacer eso, pero se debía hacer todo eso en las prácticas, pero como para cumplir el requisito para graduarme.

Nunca me llamó la atención, porque me parecía mucha presión. Yo hacía estas prácticas, pero como para cumplir el requisito, como para graduarme.

Cuando yo tenía 20 años, mi mamá adoraba ser maestra, ella era muy consagrada y también la querían mucho donde estaba. Para ella dejar la docencia era dejar su vida. Yo no sabía qué decirle, y mi mamá me dijo que ella me dejaba porque el ingeniero Luis Eduardo, nos iba a ayudar para que yo siguiera trabajando. Me pareció feo decirle que no, porque prácticamente, ella me estaba dando su herencia y su vida. Entonces, le dije que sí, y desde ahí en adelante me he metido en la docencia. Entonces, pensé en ahorrar y volverme a presentar en la universidad para empezar a estudiar derecho. Trabajé un año, se terminó el contrato, y luego de eso, el alcalde me dijo que ya se me había terminado mi contrato, pero que como mi mamá ya había cumplido el tiempo de jubilación, que eran los 50 años; ella me dice un día -mija, yo ya me jubilé, ya recibo mi pensión, le voy a dejar la plaza para que usted siga trabajando como maestra-.

Está claro en este fragmento que ser docente no implica tener el gusto por este oficio desde siempre, es posible que sean las enseñanzas vividas o el afecto obtenido luego de un tiempo lo que permita xlx maestrx valorar y encontrar el sentido de su oficio. De la misma forma, el que decide ser maestrx, sea por los 
avatares de la vida o por sentir el llamado de enseñar a otrxs, ve reflejado ese significado cuando está frente a sus estudiantes y decide convencerlxs de la posibilidad de un futuro diferente, a pesar de toda fatalidad que se presente y todos los obstáculos existentes, muy seguramente en ese momento, el oficio de ser maestrx cobre el sentido que se ha estado buscando por un tiempo.

Lulo vio la opción de seguir los pasos de su mamá, a pesar de no sentir el gusto por el oficio de ser maestra, sin embargo, con el tiempo, se profesionalizó en el oficio, desarrolló habilidades para enseñar y encontró el sentido de ser maestra en los colegios de su región. Poder conducir a otras personas a lograr sus propósitos y encauzarlos a seguir formándose es lo que tiene viva la chispa de su oficio, el agradecimiento, el legado de su madre, los momentos de compartir con sus colegas, los estudios realizados y todos los lazos afectivos y sociales que ata el llamado de ser maestrx, bien lo considera Meirieu (2006, p. 121) "hacerse profesor es invertir en el futuro", y las razones no bastarían para explicar esa inversión no solo profesional, sino de un alto contenido social y político, porque implica adentrarse en los demás "futuros", en las vidas de las otras personas.

Alrededor de las historias de vida analizadas, el aspecto que se ha venido trabajando sobre "no pensar en ser maestrx" tiene un significado notorio, en la medida que esas situaciones recuperadas en las trayectorias conllevaron a estos maestrxs narrantes a consagrar sus vidas como maestrxs de escuela, enseñando y formando personas con posibles y mejores futuros. Todo ello conduce a analizar un fragmento de la historia de vida de Adela, que el destino ya le tenía asegurada su labor en la sociedad: ser maestra. 
Adela: En la Normal Sincelejo, la educación era muy académica y pedagógica pero también muy humana y a uno le enseñaban a hacer de todo un poco. Yo aprendí a tejer, a bordar, a hacer bolsitos en cuerina, a cocinar, a pegar botones, porque era una educación también pensada en todos los aspectos de la vida, en este caso de la mujer, porque era femenino el colegio. Pero también había una exigencia desde el punto de vista pedagógico y desde las prácticas, y eso también tenía mucho incentivo. A las mejores estudiantes, siempre había alguien que los recomendaba en los mejores colegios que podían asistir en la ciudad, en ese momento. Eso le daba realce y prestigio al colegio y los padres y las madres de familia decían: yo quiero que mi hija esté allá, porque le están asegurando un futuro laboral. Pero, lo pensaban en todo lo que eso significaba.

Por ejemplo, yo que me gradué en el 93 y en el 94 me consiguieron un trabajo en un colegio donde eran doble jornada, privado, con doble jornada, yo entraba a las 8 de la mañana y me desocupaba a las 11 del día, luego entraba a las 2 pm y me desocupaba a las $4 \mathrm{pm}$ de la tarde con los mismos muchachitxs, y de remate me dan una transición con aproximadamente 48 estudiantes, y me dicen que han tenido problemas y no hemos conseguido quién te haga el acompañamiento, un soporte para mí y mientras tanto me tocó trabajar con todos ellos. Yo decía i48 cuadernos! Llenar de planas, revisar.

Entrevistadora: ¿Qué edad tenías en el 94?

Adela: 18 años. Yo decía... yo lloraba cuando veía esa "cuadernera", le decía a mi mamá: "porque no te hice caso, me hubiera ido mejor para la universidad" en cierto modo fue traumático y al otro año dije no más...me voy, yo hice tres semestres de ingeniería industrial. Le dije a mi mamá, te lo suplico, envíame a la universidad, yo voy a estudiar otra cosa que no tenga que ver con esto.

Entrevistadora: 0 sea, ¿tú inicialmente no querías saber nada de docencia?

Adela: No

[...] Ese mismo día, había un paro terrible en la universidad del Atlántico, porque soy egresada de allí. Me inscribí, pensé que de todas maneras no perdería nada, ya llevaba tres semestres sin ir a la universidad porque no tenía los medios económicos, entonces no perdía nada.

Me inscribí, ya trabajaba, ya había conseguido un trabajito. Me habían pasado para el segundo semestre de la mañana, porque yo empecé en la autónoma de noche. Entonces había conseguido un trabajito en un colegio de barrio privado, de esas "escuelas de garaje”. Dije, bueno, me voy a inscribir allá. Cuando aparecen las listas, soy como la tercera en las listas de ciencias sociales, y dije: idefinitivamente "el que nació para limonero del cielo le caen limones y el caldero"! así que dije, me tocó, ya no hay nada que hacer.

Entrevistadora: ¿Pero era licenciatura en ciencias sociales?

Adela: Sí. Yo me acuerdo de que llegaba llorando a la universidad, decía el misma Karma, la misma cosa. Pero igual pensaba que no me iba a ir para allá, yo estudio cualquier cosa. Así fuera una licenciatura. Ya yo lo veía como lo peor, pero tenía que estudiar. 
Pero me pasó también, algo significativo y muy bonito, yo llegué como al segundo o tercer semestre y conocí a un profesor de antropología, de avanzada edad y ya cansado con el tema de la educación. Él me decía: "Ochoa, vea, yo tengo una clasecita en la noche este es el tema, prepárelo". Ya él sabía que yo era normalista y me dijo eso que usted sabe y todo lo que ha aprendido póngalo en práctica, estúdiese el tema. Lo miraba y con antelación, lógicamente me decía "estúdiese el tema" y me muestra qué es lo que va a decir. Yo hacía un guión de la clase, y me decía, bueno, hágase un acetato o una cartelera, y esto que tiene aquí, está muy bien, hágalo.

Aquí entra un elemento que persiste en el relato de Adela, que tiene que ver con la formación centrada y definida de las Normales, teniendo como finalidad que desde los primeros años de escuela de las niñas que ingresaban a ella, en aquel entonces, que tenía que ver con la ineludible función de ser maestras, de ejercer el oficio, finalidad que ha pasado por generaciones para optar por una única opción y es el oficio docente.

En Colombia, las 137 Escuelas Normales Superiores (en adelante ENS) están en 30 departamentos del país, llevando la formación y preparación pedagógica a las regiones más apartadas de las capitales, para formar maestrxs para los niveles de preescolar y básica primaria, Ixs maestrxs normalistas se encuentra en su mayoría en escuelas localizadas en las veredas y corregimientos del país. La formación de los maestrxs está regida por el artículo 112 de la Ley General de Educación y el decreto 1075 de 2015, que establece que las ENS pueden formar maestrxs para el nivel de preescolar y primaria.

La labor de las ENS ha generado que varias personas opten por la profesión de ser maestrxs y seguir con la formación profesional como licenciadxs en alguna disciplina específica del campo de la educación en su mayoría gracias a los convenios con algunas universidades donde cuentan con facultades de educación, 
y así, ser maestrxs de bachillerato y/o universidad. De esta forma, es que las trayectorias recorridas por la formación como normalista, en el caso de Adela, fue fundamental para que ella se diera cuenta que requería formación como licenciada para poder enseñar a niveles avanzados en el bachillerato. Todas las experiencias que vivió siendo maestra de primaria la condujeron a tener buenos resultados y permitirse explorar otros campos del oficio $\mathrm{dxlx}$ maestrx.

Esto conduce a pensar en que la formación dxlx maestrx está sujeta no solo a los contenidos disciplinares que adquiere, sino en los múltiples caminos que recorre para adquirir la experticia del oficio. La instrumentalización de los saberes no es suficiente para encontrar el sentido de ser maestrx, como bien se ha visto no solo en la historia de Adela, sino en otras, hay que tropezar, festejar, aprender, llorar, olvidar, comprender y proyectar cada una de las experiencias que conforman la formación como maestrxs. Bien lo acentúa Davini (2015) el oficio de ser maestrx no se refleja en el cúmulo de experiencias de los años de servicio, este oficio se configura desde la reflexión constante del quehacer, la actualización permanente de cómo enseñar, en la recuperación de estrategias que en algún momento dejaron buenos resultados, y otros elementos que se manifiestan a lo largo de toda la formación.

Lo anterior define que desde los inicios como maestrxs se dan diferentes situaciones que definen el oficio, el primer trabajo, la dedicación, la frustración por no querer estar en algún lugar, los logros que van llegando en la medida que se avanza en la misma formación como maestrx y que precisa los lugares más acogedores para ejercer el oficio, y es justamente, lo que sucedió con Adela, en 
su formación universitaria pudo encontrar el sentido de la profesión e ir encontrando por sí misma las habilidades y destrezas como maestra para enseñar en un lugar determinado y con estudiantes adolescentes, no únicamente limitarse a ser maestra de primaria.

Esa definición de ser maestra y poder toparse el sentido, para Adela fue en principio una situación de frustración y desencanto de la profesión docente, pero que luego se encontró con otro camino y pudo consolidar nuevas trayectorias no solo de formación sino de experiencias. Los primeros pasos para unos suelen ser más difíciles que para otros, y es el caso de Tita, que, al contrario de Adela, su experiencia en la Normal la marcó de por vida. Desde luego que persiste el común denominador en no querer ingresar a la Normal, porque los intereses eran otros, y que, sin embargo, ingresó y logró excelentes resultados en sus inicios de su formación.

Entrevistadora: Bueno Tita, devolvámonos un poquito a que me cuentes cómo es el proceso de la Normal ¿Cómo es estudiar en una Normal y salir normalista?

Tita: ¡Espectacular! Inicialmente, mi mamá siempre me decía y lo recuerdo mucho... que yo tenía vocación para ser maestra porque lxs niñxs se la iban mucho conmigo, pero yo le decía: -mami, pero es que a mí no me gusta, yo no me veo en un salón con una "muchachera" ${ }^{27}$ " pidiéndome cosas.

Entonces yo le dije que quería estudiar en un colegio en Sincelejo que se llama ITI, Instituto Técnico Industrial. Porque a mí me gustaba el dibujo técnico, la mecánica y ella me dijo: - no, usted no va a estudiar eso, usted va a estudiar en la Normal.

Fue una experiencia que, a pesar de ser difícil en ese momento, después de tanto tiempo uno se da cuenta de que aclaró muchas cosas, siempre me encuentro por ahí a un profesor que ya está jubilado, y eso de encontrarte con ese profesor que te quería rajar, eso a mí me parece muy bonito.

También si había reuniones de profesorxs no se perdían clases. Xlx estudiante a partir de noveno estaba totalmente habilitado para cuidar una actividad que dejara algunx maestrx. Cuando se podía hacer, cuando eso se podía hacer, porque

\footnotetext{
27 Varixs estudiantes.
} 
actualmente lxs estudiantes no se pueden quedar como un encargado, jamás. Pero en ese momento sí se hacía. Entonces, nosotros desde noveno comenzamos a hacer prácticas. Así nosotros no planeáramos las clases, teníamos que explicarles a lxs niñxs lo que ellxs no entendieran, y si uno no entendía entonces uno iba hasta las salas de profesorxs, le preguntaba xlx profesorx, xlx profesorx le explicaba y luego uno regresaba al salón, a continuar con la actividad y eso era más o menos unas tres o cuatro veces al mes, y ya cuando una llega a la práctica del ciclo complementario, uno ya sabía lo va a hacer al aula, solamente que hay unos requisitos para preparar clase, unos proyectos de aula, a interactuar con ese proceso, que no se hace en noveno, décimo y once.

En mi experiencia de práctica en la Normal, hice un proyecto de aula, sobre el aprendizaje colaborativo, con unxs niñxs de cuarto de primaria que estudiaban en un colegio que quedaba al lado de la cárcel de Sincelejo y todo ese sector eran invasiones. Entonces, Ixs niñxs tenían muchas habilidades y la idea mía era hacer que todas esas habilidades se unieran e hicieran un producto conjunto, entonces, el trabajo se hizo a través de la lectura y la expresión corporal, ellxs tenían unos textos y debian representarlos a través de su expresión corporal. En drama o en bailes. Llegaron a la comprensión de un texto a través de ejercicios de expresión corporal.

Lo que se encuentra en las trayectorias de lxs maestrxs narrantes es historia, son acontecimientos que se recuperan a partir del recuerdo contado, hablado. Los que relatan sus experiencias las documentan, dice Ferrer (2008, p. 167) que “la narración otorga comprensión a la realidad, lo escrito explica la vida. Reparar un texto antiguo significa revivir, recordar". Y es justamente, lo que sucede con lo que lxs maestrxs narrantes cuentan, porque son experiencias que se recuerdan, que son parte de la vida, de la formación como maestrxs y la constitución del oficio de ser maestrx.

Tita revive sus experiencias de formación en la Normal desde las bondades que esta le dejó, para seguir adelante con su formación docente, en donde se sitúa desde las primeras prácticas que desarrollaron, en donde más allá de la "vigilancia” a lxs niñxs de primaria, su deber estaba orientado a explicar los 
contenidos que se estaban viendo en ese momento. Estas circunstancias condujeron a Tita a generar acciones a lo largo de su formación que definían su perfil docente y enriquecían las bases de los gajes del oficio. Tanto así, que este interés la condujo a ser parte de proyectos pedagógicos y participación en los concejos académicos de la institución, proponer acciones de mejora entorno a la planeación curricular y pedagógica de lo que significa la formación como normalista.

Más allá del contenido del relato, en el momento de hacer el relato, es decir, cuando Tita iba contando sus historias, fue notoria la emoción y compromiso que tenía con lo que decidió hacer a lo largo de su vida, muchos episodios de su relato la emocionaban al contarlos, pareciera que se hubiera situado en este momento y aun estuviera allí viviendo, sus palabras evidenciaban lo feliz y relevante que fue esta etapa de su formación, y lo mucho que aprendió para dar continuidad a su formación profesional como licenciada. En este punto, quiero hacer un acercamiento a unas palabras de Sarasa (2012, p. 171) que reflejan la necesidad de relatar lo que se ha vivido, la narrativa en educación permite irrumpir en lo cotidiano dxlx maestrx, "El transcurrir de una carrera docente constituye una historia -una trayectoria- que está plagada de satisfacciones, frustraciones, penas, compromisos, pasiones, elecciones, vínculos y capacidades".

Tita, maestra de bachillerato, con formación como normalista, se ha situado en el oficio, afirmando que hacerlo es alentar cada día a ser algo mejor, se están formando personas que alojan gran parte de sus añoranzas en unx maestrx, y por 
ello, la gran responsabilidad de enseñar y educar para la vida, no se trata de memorizar contenidos sino de situarlos en el contexto donde está ese estudiante.

En resumidas cuentas, las trayectorias recorridas por las ENS o por la universidad marcan el camino de lo que constituye ser maestrx. $Y$ es justamente lo que muestran los relatos de lxs maestrxs narrantes. Todas la experiencias recogidas son las que configuran ese oficio y conducen a forjarlo cada día, y es allí, en donde posiblemente se logra encontrar el sentido de ser maestrx, en el acercamiento con Ixs estudiantes, en ver que, ese sentido y ese llamado se encontró un día que lxs estudiantes resaltan la labor dxlx maestrx, el reto es continuar la formación como maestrx, en los encuentros con lxs colegas de oficio; todo constituye no solo el oficio de ser maestrx sino representa la cotidianidad y labor social que configura enseñar a otrxs y lograr la transferencia de lo enseñado.

La formación en las ENS y en la universidad marca el primer trayecto del camino que recorren lxs maestrxs, como lo indican los relatos seleccionados, sin imaginar que estos trayectos los llevarían a ser maestrxs de por vida, con la resistencia de no querer serlo, y con la curiosidad de ver qué puede pasar, o por la necesidad de tener un ingreso económico fijo se vieron involucrados en este oficio y sus aventuras cotidianas. Lo aprendieron en medio de la formación y las primeras y arriesgadas experiencias in situ en contextos escolares. Encontraron el sentido de este oficio, porque es un oficio que además de transmitir contenidos planos, el ser maestrx precisa un cúmulo de valores, que conducen la 
enseñanza y forjan la vocación, esta última no es innata, pero sí se configura en la medida que se tejen experiencias y se hacen trayectorias. "La vocación hay que procurarla día a día y se requieren recursos y destrezas" (Alliaud, 2017, p. 30), para hacerlo posible. 
Capítulo IX. Trayectorias y sentidos dxlx maestrx en ejercicio sobre la fd

Este capítulo tiene que ver con el abordaje directo de la experiencia formativa adquirida en el desarrollo de la maestría y su relación con las prácticas docentes, desde el siguiente interrogante ¿De qué forma las experiencias formativas trazadas en posgrado fortalecen y se manifiestan buenas prácticas? Haciendo referencia al sentido que cobran los aprendizajes de orden epistémico y pedagógico que se manifiestan a lo largo del periodo de formación posgradual y, que para el caso de esta tesis se hace una defensa fundamentada en las historias de vida sobre las transformaciones y cambios que producen estas experiencias formativas en las prácticas y la cotidianidad del docente en ejercicio.

Dando inicio al análisis, quiero traer al escenario a Vergara $(2017$, p. 52) quien manifiesta que la fd implica "promover su desarrollo profesional y personal. Y, sobre todo, la idea de que toda formación implica una revisión y una crisis, romper con premisas ya instituidas, y abrirse a nuevas formas de pensar y hacer". Es justamente la intención de recabar en las historias de vida de lxs maestrxs, buscar en todo ese telar de narraciones, los acontecimientos que permiten fortalecer su formación, y, más profundo, manifestarse en sus prácticas. Para ello, busqué en las narrativas esos lugares comunes que conducen a develar el sentido más profundo de lo que ha vivido cada maestrx a lo largo de sus trayectos, aquí, la intención es que lo relatado sea lo que lleve de la mano el 
análisis, la historia de vida dxlx maestrx narrante es lo que versa entre el sentido y la interpretación de lo que hace cada unx por fortalecer su oficio.

Dando paso a las primeras intervenciones de Adela,

Llevo 8 años trabajando en la institución educativa Alfonso Araujo Cotes de Valledupar, que está ubicada en la zona sur, tiene un número aproximado de 2200 estudiantes y 76 profesorxs. La institución brinda la educación en todos los niveles, el preescolar, primaria, bachillerato, y también, tiene la educación por ciclo los sábados, como una manera de ayudar a la comunidad, y a aquellos adultos que no tienen la posibilidad de estudiar en los horarios regulares.

He visto también, cómo ha venido surgiendo la institución, desde que estoy allí han pasado tres rectores en estos años y cada uno ha venido con diferentes intenciones, uno, de que la institución crezca en infraestructura; $y$, los dos últimos rectores que hemos tenido, sobre todo este último, muy preocupado por la organización y la orientación de la institución de la parte académica, la construcción de un nuevo horizonte institucional, eso ha permitido que poco a poco la institución avance en el ámbito local como una institución de prestigio.

Entrevistadora: ¿Cómo es tu labor en la institución? ¿Cómo la describes?

Adela: Hago parte del comité de liderazgo en la institución. Somos la mano derecha del rector en toma de decisiones. No significa que él no tenga en cuenta a los demás compañeros. Pero el equipo que él llama inicialmente para concertar sobre algunas decisiones somos nosotros. Somos los replicadores de información, estamos en el tema de un proyecto que va de la mano con Terpel que se llama "escuelas que aprenden"; es un proyecto interesante, que ellos han formulado en el cual buscan que las instituciones públicas crezcan como institución, y mejoren los procesos a nivel de estas. Entonces, nosotros somos participantes activos de esos talleres, somos replicadores de esas estrategias, según la situación soy secretaria del consejo directivo ya hace varios años.

Yo doy clases a los de decimo y once. Ahora estoy con el tema de decirle al rector, iprofe, por favor...! Porque hace poco me dijo que me necesitaba en grados de octavo a noveno. Pero yo le dije "es que yo soy profesora de la media" pero quiero la posibilidad de estar en cursos inferiores, porque me estoy quejando de un tema en la educación, que es bastante complicado; y es que siempre se les echa la culpa a Ixs profesorxs que vienen de atrás. "la culpa es del de primaria" "la culpa es de lxs docentes sexto y séptimo" entonces, cuando estamos en décimo y once pensamos, ¿iQué hicieron estxs docentes abajo!? Entonces, yo quiero saber realmente qué pasa allá. Y me llama poderosamente la atención el tema de la investigación en la educación, yo quiero empezar a hacer investigación en ese lugar, quiero saber, cuáles son esas competencias en que lxs muchachxs tienen más habilidades. Cómo lo hago, tengo que empaparme bien de ese tema. De cómo se trabaja allá. 
Si se hace un recuento de la historia de vida de Adela, más arriba cuenta que ella no quería ser docente, aunque por un destino marcado, aprendió el oficio y por la naturalidad de lo que acontece a diario, es ahora una maestra entregada y preocupada por conocer mucho más lo que sucede en este mundo de la docencia, su preocupación la ha llevado a continuar con su formación continua y que esta sea un peldaño para adentrarse en otros lugares de su misma profesión como maestra. Un poco lo que narra arriba son los otros espacios en donde xlx maestrx se desenvuelve, y algo, de gran interés, es el hecho involucrarse en la gestión institucional, en muchas ocasiones, "el campo indeseable" de lxs maestrxs.

Ella, con su espíritu curioso y comprometido, quiere que sus prácticas se vean reflejadas en toda la institución, es de este modo que xlx maestrx, al adentrarse en los otros escenarios que tiene la escuela, permite ampliar su experiencia y tener una mayor perspectiva de cómo son sus prácticas, es decir, xlx maestrx que desarrolla un modo holístico de su labor, considera permanente poder reflexionar desde lo que hace, y, a la vez, inculcar la reflexión en sus compañerxs maestrxs. Un tanto, que Adela, no solo fortalece su oficio, sino que aprende de sus experiencias, a este argumento se involucra Alliaud (2011, p. 94) quien considera que se aprende de las experiencias propias y de la de los otros en la medida que esos aprendizajes "promuevan la imaginación, el descubrimiento de nuevos problemas, la creación". 
Al momento de preguntar por la labor que desempeña en la institución donde es maestra, su interés inicial es contar lo que hace por fuera del salón de clases, contar lo que pasa en otros contextos donde también es maestra. Esto conduce a hacer referencia a que el oficio dxlx maestrx no está ligado permanentemente al salón de clases, estudiantes y contenidos. Es claro que el ser maestrx lo conforman diversos modos y funciones al interior de la escuela. Incluso, está el modo social, el aporte sustancial que genera xlx maestrx a la sociedad y los desarrollos culturales, sociales y políticos que su oficio forja. Aunque aquí, el centro del discurso se sitúa en la práctica dxlx maestrx, que en este caso se representa en lo institucional, pero que las discusiones, productos y decisiones se ven reflejadas en las prácticas pedagógicas que realiza en su cotidianidad.

Este primer acercamiento narrativo de las prácticas docentes es sin duda el inicio de correspondencia que los trazos de la fd permiten xlx maestrx explorar en otros lugares y ver distintas formas de fortalecer y empoderarse de su oficio. Este segundo relato, se manifiesta en el entusiasmo, más acercase al compromiso y la pasión con que se ejerce el oficio.

Tita: Cuando llegué a Valledupar me nombraron en el 2012, llegué al colegio Institución Educativa de Patillal, llegué con mucha expectativa, me recibió el coordinador, me dijo -usted va a hacer la directora de un salón, aquí tiene estos documentos, este es el observador, esta es la programación de la clase... ¿algo más? "todo claro"-

De entrada, el colegio me presentó a mí una organización como tal, y yo dije: -aquí hay que hacer las cosas mejor que como las vengo haciendo porque aquí es una organización, que en las dos instituciones en donde yo ya había trabajado.

Efectivamente cuando uno llega nuevo uno quiere mostrarse, lo que uno sabe de una manera muy respetuosa, ;claro! Y obviamente el coordinador y el rector se dieron cuenta de eso, que le digo y llegar aquí fue una superación personal, porque me tenían en cuenta; por ejemplo, si tenían una dificultad me decían: qué podemos 
hacer, tenemos que planear un acto cívico para esto, qué debemos hacer... cuando hacíamos reuniones de área buscábamos planes de mejoramiento, yo dirigía la cuestión de planes de mejoramiento con los compañeros de primaria, y eso me ayudó mucho a "encarretarme" con Valledupar y con Patillal, más específicamente de querer. Yo sacaba tiempo, después de clase me quedaba en el colegio a hacer refuerzos con lxs niñxs, les hacía actividades lúdicas, me invitaban los sábados, entonces como que me querían tanto que yo empecé a querer esta comunidad.

Hice un proyecto en donde yo puse a lxs niñxs a entrevistar a los juglares de la música vallenata que vivían en Patillal, ellos exponían qué fue lo que hicieron. Algo como lo que normalmente se hace en clase "léame ese cuento y explíqueme que entendió", en este caso ese cuento era real y vivencial, entonces, xlx niñx tenía más propiedad para hablar de lo que se estaba preguntando, porque $x l x$ lo vio, $x l x$ lo vivenció y tuvo la oportunidad de preguntar lo que quería. Luego de eso nació una propuesta de hacer un semillero de decimeros, con un decimero de Patillal porque a pesar de que tiene un gran reconocimiento, este se está perdiendo. Ya no hay niñxs que componen, hay pocxs niñxs que tocan un instrumento. Entonces, esta es una preocupación de la comunidad y yo quise aportar a eso.

[...]

En esos tres años, Patillal me dio la oportunidad de hacer la ejecución de ese proyecto que venía haciendo en la especialización. Y esto dejó ver a lxs directivxs que yo andaba pilosa trabajando, y la comunidad si decía, por ejemplo, vimos a la profe Tita en casa de Chiche Maestre. Vimos a la profesora en la casa de José Vélez. Entonces, ya las personas me conocían a pesar de que llevaba tres meses en el pueblo, empezamos a hacer capacitaciones en deporte, ese mismo año llevé a dos estudiantes a las finales de las pruebas nacionales "supérate con el deporte", aunque yo no era la maestra de educación física. Al otro año, pasaron dos niñas a las finales de las pruebas "supérate con el saber" y estamos hablando de las dos áreas que se evalúan en las pruebas de "supérate con el saber" que era lenguaje y matemáticas.

Este relato condensa un elemento que Porta y Martínez (2015, p. 41) trabajan en su investigación, y es la pasión. Justamente, en la entrevista que le realizan a Cristina Piña, cuando en una de sus afirmaciones dice: "a mí lo que me mueve es absolutamente el entusiasmo, a mí nunca se me ha hecho una carga enseñar". Es lo que pasa con Tita, su entusiasmo la hace superar lo que tiene a su cargo, se involucra humanamente con toda la comunidad, hace parte del compromiso social de lo que es ser maestrx, se adentra en la vida de lxs estudiantes y 
permite que sus experiencias sean parte de sus prácticas. Va más allá de lo que se "debe hacer", no espera indicaciones, sino que propone acciones. Es una maestra activa y que comprende el sentido dinámico del oficio.

De nuevo, hay una afirmación bella de Cristina Piña "la pasión en el trabajo es un disfrute, es de pronto como de una obra de arte, un paisaje" (Porta y Martínez, 2015, p. 61). Es lo que reflejan las palabras de Tita, cuando en su labor como maestra, se queda un rato más con lxs estudiantes para reforzar algunos aprendizajes o en otras ocasiones para convocarlos a eventos fuera de la escuela. La pasión de sus prácticas es emancipadora no solo para ella sino para sus estudiantes, ellxs ven el interés de su maestra porque aprendan y, a la vez, se sienten motivadxs por hacerlo. Las acciones que se realizan en las prácticas cotidianas del docente son transferibles, en el sentido de que se contagia el interés, en entusiasmo por hacerlo mejor.

Tita no solo asume esta postura y desarrolla buenas prácticas en la escuela, sino que se despliegan hacia la comunidad, participando, dándose a conocer por las personas y convocando a sus estudiantes que partan de sus contextos para lograr aprendizajes significativos y propios desde los lugares donde se encuentran. De estas buenas prácticas se desprenden factores que se vinculan entre sí, uno de ellos está relacionado con lo que xlx maestrx hace para que sus estudiantes vayan más allá de lo que están aprendiendo. Cristina Piña en su entrevista dice que "el sentido de la enseñanza es dar herramientas para que después ellos puedan multiplicar, ir más allá, es decir, abrir el apetito del saber" (Porta y Martínez, 2015, p. 71). 
El hecho de hacer buenas prácticas no necesariamente se centra en que Ixs estudiantes aprendan contenidos o conozcan libros del tema, estas buenas prácticas se ligan con las buenas enseñanzas que están conectadas con los contextos, los lugares donde habitan Ixs estudiantes, las comunidades donde interactúan. Xlx maestrx dedica sus buenas prácticas a lo que pueden hacer sus estudiantes, Cristina tiene una afirmación precisa para esto: “porque de pronto, vos les enseñas una cosa que les abre el panorama y eligen otra cosa por allá...pero no importa, yo no quiero réplicas" (Porta y Martínez, 2015, p. 71).

Tita hace prácticas de enseñanza para la vida, consagra su oficio en lo que puede ser mejor para lxs estudiantes y la comunidad en donde se encuentra, desde luego, también, ella ve sus logros, los cuales la llevan a forjar aún más su labor. Todo ello estrechamente relacionado con los aportes que le ha brindado su fd, las nuevas perspectivas que ha ido descubriendo con lo que aprende al formarse continuamente, las prácticas están ligadas a lo que va aprendiendo en su trayectoria, a los trazos formativos que puede vincular a su oficio, y de esta manera consolidar buenas prácticas, no solo en el aula de clases sino en cada uno de los lugares que se entrelazan con la escuela.

Hasta este punto del análisis narrativo, se evidencia que Ixs maestrxs narrantes parten de la necesidad formativa para que sus prácticas tengan sentido en los contextos donde se encuentran. Los aprendizajes y la experiencia formativa llevan xlx maestrx a desenvolverse de forma diferente, a ver su entorno desde otras perspectivas, que posibilitan transformaciones en sus prácticas y los conducen a realizar un ejercicio reflexivo de su quehacer. Señala 
Alliaud et al (2008, p. 3) "la práctica es formadora sólo en la medida en que sea objeto de una práctica reflexiva y de un diálogo productivo con referentes teóricos, formalizados, de la pedagogía".

Los sentidos que tiene la fd en las prácticas de lxs maestrxs son tejidos por las experiencias que tienen en los contextos escolares en donde desarrollan su labor, adicional, las experiencias de formación cobran vida en el momento que se adicionan a las prácticas y se definen algunos cambios que permitan otras buenas prácticas. Quiere decir que no en vano lxs maestrxs buscan formarse, es el caso de Adela, a quien se le dio la oportunidad de realizar un estudio de posgrado, no solo por la necesidad, sino ella quería seguir aprendiendo:

Y ahora ¿Qué hago? Le dije un día a mi esposo: -ya me aburrí, quiero estudiar y esto no es suficiente, porque a veces están hablando de educación y no entiendo de dónde lo sacaron, todavía me falta estudiar eso y quiero investigar más sobre esto. Definitivamente, toca seguir estudiando.

Aquí se mezclan situaciones de orden pedagógico, profesional y algunas manifestaciones emotivas, de la pasión por saber qué más se puede aprender. Cuando xlx maestrx va más allá de cumplir unas funciones, y empieza a despertarse el interés por ampliar sus conocimientos y mejorar lo que hace en su cotidianidad, piensa en formarse, en realizar un estudio que le brinde la seguridad profesional y formativa que está buscando. Un estudio de posgrado, como una maestría en educación, permite xlx maestrx profundizar sus aprendizajes y ampliar sus experiencias. Lo conduce a ver desde otras perspectivas lo que ha venido realizando en su quehacer. Vásquez $(2011$, p. 16) considera que hacer una maestría "pone a nuestro hacer en la balanza del 
sopesamiento: contamos con la riqueza de discernimiento. $Y$ en adelante lo que hagamos o digamos tendrá que ser pasado por el cedazo de la reflexión, del cuestionamiento".

La fd conduce al reconocimiento de lo que se hace, es el peldaño que xlx maestrx sube para emanciparse profesional y socialmente, la educación es lo que otorga sentido a las trayectorias y práctica de lxs maestrxs. Formarse es dar un paso hacia el descubrimiento de otras posibilidades de ser maestrx, permite fortalecer lo que está y proveer de nuevo conocimiento a otrxs maestrxs, formarse como magíster indica que "ya se está legitimado para esa tarea de ayudar a parir, para acompañar a otrxs en sus propias búsquedas, para servir de tutorxs a aquellxs que aún temen dar el paso, o para enseñar ciertos conocimientos anhelantes de ser sabiduría” (Vásquez, 2011, p. 16).

El paso por la fd de posgrado genera en xlx maestrx inquietud por comprender ampliamente lo que hace y poderlo robustecer con más conocimientos y experiencias. A ello, Davini (2008, p. 7) manifiesta que el oficio dxlx maestrx requiere de un acervo de conocimientos y prácticas que le permitan tener una apropiación permanente de lo que realiza. "Una buena parte del "oficio" de enseñar se desarrolla en las experiencias prácticas: actuar en contextos concretos, trabajar sobre distintos contenidos, elaborar alternativas prácticas, aprender de la propia experiencia, de la capacidad de reflexionar y decantarla".

Todo ello amplía el análisis narrativo teniendo en cuenta que el principal elemento de las trayectorias de fd son los relatos de lxs maestrxs narrantes, son sus historias las que develan los sentidos de la fd en los escenarios escolares y se 
reflejan en las prácticas que realizan, además, estos sentidos cobran fuerza cuando se manifiestan en los re-trazos que hagan lxs maestrxs a las propias prácticas. De este modo, como el relato es inacabado, siempre hay algo más por contar, parte de la historia de Mateo se entrelaza con lo que se ha venido narrando:

En el colegio llevo trabajando 10 años. Llevo de docente 11 años, estuve primero un año en el municipio de la Policarpa, zona de la cordillera, era muy lejos de la capital del departamento, tuve la posibilidad de que me trasladaran al Peñol y precisamente a mi tierra y a mi casa.

Antes de ser docente yo vivía acá, en el municipio del Peñol y era una situación bastante difícil en cuanto a lo social por la propagación de los cultivos ilícitos en toda la cordillera. Eso generó muchos problemas de tipo social y mucha violencia, en ese momento yo no era docente. Ya cuando yo ingresé a la docencia, ya estaba en esos procesos de erradicación de los cultivos ilícitos, aunque las secuelas y todo eso todavía quedaban allí. La violencia todavía seguía, menos acentuada, pero había.

[...]

Entrevistadora: Tú eres docente ¿De qué grados?

Mateo: Yo soy docente del área de ciencias naturales, en los grados noveno, décimo $y$ once. También doy clases a veces en el grado séptimo u octavo de ciencias naturales.

Puedo decir que este proceso formativo (la maestría) ha cambiado mucho mis clases. Veamos, como profesional de la química tiene una formación científica y uno cree que lo importante es que $x l x$ estudiante se aprenda ese contenido y yo enseñaba tal y como a mí me enseñaron, con una disciplina rígida. Yo pensaba también que la disciplina era mostrarse con una "cara de bravo" y que nadie le pueda decir a uno nada.

Entonces, yo llegaba a la clase: "muy buenos días, todxs se sientan, nadie se mueve de su puesto, quiero que todxs se estén quietxs, la disciplina es lo primero" entonces, cuando empezaba la clase, veíamos la temática y empezaba a explicar, así como me enseñaron a mí en mi colegio. Esa era la temática, se trataba sobre esto y esto, la explicaba... en algunos casos después de hacer una explicación, les dictaba todo lo que ya les había explicado, terminaba la temática, pasaban una o dos clases y seguía con la evaluación y nadie podía decir nada.

Yo era muy rígido, a mí me enseñaron así y uno piensa que eso es lo correcto. Ahora, ya entendí que la disciplina no se gana con ser serio, con ser bravo, la disciplina se gana en el momento en que se empieza a interactuar con lxs estudiantes a darles confianza y ellxs con esa empatía que vamos generando, a su vez ellxs generan un interés en la clase que evita que realicen otras cosas. Eso fue algo que me ocurrió en 
esta parte, fue un seminario especial e importante que fue el de humanismo. Me gustó mucho ese porque me aportó cosas necesarias en ese sentido.

Digo la temática y empiezo a preguntar, a ver qué saben ustedes de esto o con qué lo relacionan. Ahí es donde yo aprovecho lo que ellxs me dicen y empiezo a encarrilarlo de tal manera. Eso me ha cambiado bastante, las clases han sido más amenas.

Entrevistadora: Tú aprendiste a enseñar química de manera empírica. Con tus compañerxs y con la práctica.

Mateo: Yo empecé a mirar qué puedo hacer aquí para cambiar un poco, no dictarles. Fue así, que con otro compañero que también es químico, empecé a hablar, en el colegio donde trabaja, los capacitaban mucho para la enseñanza. Empezamos a hablar bastante y él me decía que hiciera esto, o lo otro. Me prestaba unas cartillas, donde decía la preparación de la clase. Entonces, empecé a hacer eso, a implementar el trabajo en grupo, el trabajo en guías. Eso empezó más o menos hace unos cinco años y en el colegio yo no miraba a otro docente que hiciera más que dictar y explicar. Me fue hablando de eso, fui empapándome e incluso empecé a meterme por ese lado en el trabajo de la institución y después el rector se dio cuenta, y dijo que todxs lxs docentes empezaran a implementar eso. Por decir algo yo empecé a innovar en la institución por mi propia cuenta, metiendo algunas cositas diferentes y ya con la maestría me aportó más.

En el relato de Mateo se encuentran elementos que reflejan la búsqueda del sentido por la fd y la puesta en práctica, son elementos como la manera de acercarse a sus estudiantes, situación que reconoce entre un "antes" y un "después" de la realizar la maestría. Sin afecto, basado en la rigidez disciplinar y el silencio por parte $d x l x$ estudiante, era lo que priorizaba en sus clases, no permitir la interacción entre las partes, lo veía desde el factor orden y en cierta medida, el poder ser xlx maestrx.

Yendo un poco más allá, lxs maestrxs que ingresan a realizar un estudio de posgrado, por lo general, tienen concepciones limitadas de su misma profesión, partiendo del supuesto que la enseñanza se centra estrictamente en el conjunto de contenidos transmitidos a lxs estudiantes en un escenario plano y sin discusiones académicas o debates entre estudiantes. El oficio dxlx maestrx se 
centra en el conocimiento que tiene y en lo que puedan memorizar lxs estudiantes en sus clases. Asunto que no dista de la realidad expresada por Mateo, la preocupación mayor de él estaba focalizada en que lxs estudiantes repitieran los contenidos de la química y luego poderlos evaluar a través de un examen o quiz, que permitiera ver lo que asimilaron de determinados contenidos.

Ahora, la otra cara del relato, en el que expresa que él sí ha visto los cambios que ha tenido en sus clases, característico de poder pensar un ejercicio de autorreflexión de sus prácticas. Quiere decir que los sentidos, en este punto, son vinculados a la reflexión y a la acción del oficio dxlx maestrx. Vásquez (2011) considera que, al obtener el título de maestría, xlx maestrx está recibiendo una invitación a la renovación y al cambio, a que su quehacer sea la pauta para generar espacios de reflexión y participación sobre lo que se hace de maestrx en los escenarios escolares. "Se trata de [un más] que invita a seguir con el propio proceso de formación. Los procesos de formación requieren de aquellos que los comandan una tarea previa: la de conocerse, la de perfeccionarse, y la de avanzar" (Vásquez, 2011, p. 17).

Para Mateo dar continuidad a su fd no era algo nuevo ya que desde que obtuvo el título de químico su proceso de continuar formándose se quedó en pausa por otros asuntos de la vida, así que retomar el proceso de formación le resultó alentador, aunque su concepción era otra y sus expectativas iban por otro camino. Él tiene la idea de que la maestría es para enseñarles a lxs maestrxs cómo deben hacer sus clases, algo así como un "recetario" o algunas 
indicaciones que puedan aplicar en sus prácticas. Algo que no sucedió ya que desde el inicio había un enfoque bien marcado para formarse como magíster, este estaba dirigido a la investigación intervención, sus prácticas eran el centro de la investigación, la reflexión, discusión y propuesta aplicada en el contexto escolar. Así que, para maestrxs como Mateo, del enfoque positivista, entrar en la esfera de una investigación social y de intervención no fue tarea fácil ya que estaba muy marcado por las acciones determinadas y los resultados exactos desde su disciplina.

Esta cuestión en la que se basa este análisis narrativo me transporta a ese primer día de clases de lxs maestrxs narrantes:

Estaba en frente de 25 maestrxs de diferentes colegios públicos de la ciudad de Pasto, allí sentadxs esperando alguna indicación de nuestra parte, [nuestra parte] éramos dos, Carlos y yo. Pero volviendo a los 25 maestrxs, cada unx mostraba algo, algunos quizás emoción, otrxs, curiosidad, Ixs de más adelante expresaban alegría, Ixs de atrás, no todxs, tenían sueño, claro... después de una jornada laboral y estar en un salón de clase a las 13 horas del viernes, el agotamiento de la semana y la alegría de que era fin de semana, eran dos emociones que en ese momento estaban en un choque desmedido. En otrxs estaba la pregunta ¿Qué hago aquí? Pero no estaban dispuestos a responderla por ahora. Simplemente estaban allí, sentadxs y a la espera de algo, lo que fuera, pero pronto.

"Bienvenidos a la Maestría en Educación de la Universidad Santo Tomás, hoy inician el recorrido para formarse como magíster en Educación, hoy comienza su formación de posgrado, van a aprender, investigar, des-aprender..." algo así dijo Carlos. Quizás dijo algo más, pero no estaba muy concentrada en sus palabras sino en lo que pasaba allá, en los susurros y gestos que emergían en el momento que él habló. Hubo un momento que él dijo "además de la formación y de recibir un título de magíster, es un trayecto que se debe formar, hay que trabajar fuerte, comprometerse, actuar y construir colegiadamente. Es una maestría en donde cada unx edifica su formación, somos tutores, orientamos un proceso, pero los actores principales son ustedes". Esta frase causó por un momento asombro, luego, inquietud, algo de desesperación y el acercamiento a la pregunta ¿Cómo lo vamos a hacer? Estando frente a ellxs, me salió una sonrisa inesperada, esta sonrisa emergente fue de los fugaces recuerdos de mi primer día al iniciar mi maestría, atenta como ellxs, con altas expectativas, y algo típico cuando iniciamos una maestría en educación, estamos allí bajo el 
presupuesto que nos van a enseñar cómo ser maestrxs o quizás nos darán algunas indicaciones para serlo. Lo que sí me quedó claro es que lxs 25 maestrxs en formación estaban "asustadxs". (Autorrelato Alejandra Rico, 2017)

Todo acontecimiento nuevo en nuestras trayectorias genera un choque de emociones, entre ansiedad y curiosidad, temor y alegría. Esto pasó con Mateo y el grupo en el que se encontraba en ese entonces, la ansiedad los abrumó de pensar que lo que se avecinaba era algo que ni les pasaba por la mente en ese momento, desde el primer día se inició con el trabajo de indagación y hacerlxs autorxs de su proceso de formación. Xlx maestrx formadorx bajo el enfoque de la intervención hace parte del proceso desde la mirada de un guía y orientadorx de lo que realice xlx estudiante.

Lo que se ha dicho hasta este punto, tiene que ver con las diversas perspectivas que tienen las trayectorias de la $\mathrm{fd}$, desde la narrativa dxlx maestrx en formación, y desde la narrativa dxlx maestrx formadorx. De este modo, se consolidan los sentidos, en dos órdenes, lo epistémico y lo pedagógico, que va a desembocar en la generación de prácticas situadas. Tratándose las buenas prácticas desde la concepción de Bain abordada por el Grupo de Investigaciones en Educación y Estudios Culturales de la Facultad de Humanidades, Universidad Nacional de Mar del Plata aludiendo a lo conceptual, puntualmente, por Sarasa (2012) quien considera que las buenas prácticas están relacionadas con la creación de escenarios y la preparación de sus clases.

Estas buenas prácticas son parte de un telar de acciones acorde con un acto reflexivo y colegiado, en donde lxs maestrxs se permiten auto-referenciarse y a la vez, integran sus saberes para generar prácticas versátiles y encauzadas a la 
apropiación de conocimientos pertinentes y contextualizados, y que se manifiestan en aprendizajes alejados de la inmediatez y el facilismo. Aprendizajes situados, coherentes con las realidades de lxs estudiantes y propicios para generar espacios de discusiones y reflexiones propias de las buenas prácticas logradas por lxs maestrxs.

En este orden de ideas, hablar del vínculo directo que tienen los trazos formativos posgraduales y las prácticas $d x l x$ maestrx, se articula con lo que $x l x$ maestrx en formación ha recibido en esa etapa de estudios posgraduales, es decir, conocimientos que le pueden brindar herramientas para re-trazar sus prácticas, quiere decir, que no es que genere nuevas, sino que se da la oportunidad de hacer mejor lo que ha venido realizando a lo largo de sus trayectorias como maestrx.

Estos nuevos conocimientos recibidos le permiten xlx maestrx "una nueva tarea: ser más propositivos, responsable, cuidadoso frente a lo que implica formar o tratar de educar a otrxs" (Vásquez, 2011, p. 15). Para situarlo en el relato, Adolfo, maestrx narrante, cuenta lo que viene:

Yo estoy trabajando en la Institución Educativa San francisco de Asís, queda en el municipio de lles. Esa amabilidad con que uno se encuentra, y desde que usted va en la vía, sin conocerlo lo saludan, eso me parece maravilloso. A mí me parece fascinante, todo el mundo se salude así nunca se haya cruzado palabra. Desde el primer día en que llegué fue lo más maravilloso que, aunque nadie me conocía todo el mundo me saludaba. Lo otro, el espacio social también permite ver muchos valores en las personas... y de hecho la próxima semana reanudo mis visitas a las familias, tengo dos compromisos...ya me están esperando. Entrevistadora: ¿Cuál es tu labor visitando a las familias? Adolfo: Simplemente es dialogar. Es un diálogo con ellxs, de personas. En el que yo les digo cómo veo a sus hijxs dentro de ese espacio académico, cómo visiono en ellxs su futuro, cómo quiero que integren la familia en el proceso escolar y que no lo 
dejemos solamente con un espacio donde él únicamente pueda ir a hacer sus estudios y en la tarde volver sin preguntarle qué es lo que hizo, cómo le fue, qué de nuevo aprendió, qué le pasó, que pueda socializar con los papás.

Entrevistadora: ¿Cuántos años llevas trabajando en esta institución?

Adolfo: En esta institución llevo trabajando 17 años, el 18 de octubre del 2005, me "arrecuerdo" mucho, porque fue una fecha demasiado especial para mí, el hecho de haber ingresado a allá con una resolución en propiedad que me decía: usted ahora es docente de esta institución. Eso también fue maravilloso, de llegar ese día yo dije, de aquí no me muevo. Porque anteriormente, mi labor era por contratos, entonces, lo removían a uno de un lugar a otro y no se era parte de la dinámica del ejercicio docente en rigor de las instituciones.

Entrevistadora: ¿Cómo describes tu labor aquí en este colegio? ¿Gustas de la labor que haces aquí en esta institución?

Adolfo: Sí. Alguien comentó una historia en algún momento y utilizó una frase, dice: "estoy en un trabajo, que me fascina hacerlo, que me encanta, que me divierte, encuentro todo lo que necesito en ese espacio y además me pagan”, decía.

Entrevistadora: Entonces, íbamos en que te pregunto ¿Cómo describes tu labor en esta institución?

Adolfo: Es una actividad en la que me fascina estar. La docencia es un espacio, que desde que he tenido la posibilidad de encontrarme en este espacio, me ha fascinado y cuando uno empieza a dialogar con las personas y que ellas vean que uno puede tener elementos para compartir, orientar y visualizar, la labor que uno hace se vuelve más enriquecedora. El hecho de ver en ellos una sonrisa, esa satisfacción, unas gracias, a uno lo hace sentir bien, tengo, por ejemplo, estudiantes que han egresado y ellxs me hablan, yo lxs llamo y siempre con gratitud. Es muy gratificante, describo mi labor como donde yo sé que día a día hay muchas cosas para disfrutar, para compartir, para conocer y estructurar con ellxs y eso me hace sentir muy bien. No me imaginaría en otro espacio en el que tendría que trabajar. Tendría que evaluarlo desde muchos aspectos, pero lo que en estos momentos estoy haciendo me parece que es una gran labor.

La profundidad con que narra Adolfo es de aquellos relatos que estremece al otro, su pasión es reconfortante, "volver sobre los afectos, las emociones, las pasiones, nos coloca en el centro de la relación pedagógica” (Porta y Martínez, (2015, p. 31). La expresión de fascinación por ser maestrx permite ver in situ que sus prácticas son situadas y procura hacerlas de la mejor forma posible, extiende su labor a la comunidad, se involucra en la vida de sus estudiantes, 
para que puedan llegar un poco más lejos con sus estudios, concentra su atención en repasar sus prácticas y ver cómo pueden ser mejores para que sus estudiantes comprendan los conocimientos enseñados. En su relato, lo que más se resalta es que la dedicación a sus estudiantes es generosa, para él no pasa desapercibido aquellx estudiante que tiene dificultades en comprender una temática, busca el espacio por fuera de la jornada escolar para hacer refuerzos y que el estudiante alcance los logros.

En el relato de Adolfo es marcada la labor como pedagogo, se llega entonces, al segundo orden, que es lo pedagógico. Saber que está de más, aunque, aquella labor no se debe reducir a lo que hace xlx maestrx en el salón de clases, esa labor de ser pedagogx va más allá, se transporta hacia la comunidad, acompaña al estudiante en su proceso educativo, procura llevarlo de la mano, con afecto, con la esperanza de que aquellx aprendiz se llevará consigo, además del conocimiento, las formas de cómo su maestrx le enseñó y se preocupó por xlx.

Cuando Alliaud (2010) se refiere a la enseñanza, considera que es una actividad que necesariamente debe producir algún tipo de transformación sobre las personas. Y continúa diciendo que cuando se tiene evidencia de que lo enseñado efectivamente sí produjo algún cambio, el sentido del oficio de enseñar se potencia y magnifica. Algo así pasa en el relato de Adolfo, su sentimiento por lo que hace es porque a lo largo de sus trayectorias ha encontrado momentos que enaltecen y proclaman su labor, ha evidenciado que sus buenas prácticas han hecho parte del progreso de otrxs. Por lo cual, se expresa de su ser maestrx con emoción y pasión, al respecto, Cristina Peña, 
finalizando una entrevista relata lo siguiente: “...pensar que lxs alumnxs que yo les dije les hicieron bien y me recuerdan...entonces que a mí me recuerden, es una cosa conmovedora y emotiva" (Porta y Martínez, 2015, p. 77).

Revivir el oficio de ser maestrx a través de las narrativas, es la manifestación más emotiva que se pueda hacer, recabar en los trazos vividos constituye una manera de toparse con las realidades inmediatas de lxs maestrxs y las escuelas, es incorporar desde la palabra otras formas de hacer teoría, de hacer análisis y configurar nuevos modos de comprender las dimensiones del oficio, que en este caso hace referencia a la formación dxlx maestrx y las maneras de articular lo nuevo con lo que realizado en la cotidianidad de la escuela.

En resumidas, adentrarse en las trayectorias de maestrxs que al inicio sus pretensiones no eran estar en el lugar donde se encuentran ni mucho menos viendo en el oficio de enseñar, sin embargo, la vida se encargó de ubicarlxs estratégicamente en ese lugar, en donde poco a poco se fue cultivando y enriqueciendo el oficio, se vieron envueltxs en los avatares de ser maestrx, y, quizás, con pocos beneficios económicos, pero sí con la certeza del reconocimiento permanente de sus estudiantes y los logros cumplidos, entre ellos, poder continuar con su fd, conocer, comprender y empoderarse de su labor, lo que me conduce a replicar un fragmento de mi auto-narrativa como docente formadorxa:

Ser formadora de docentes es formarse uno mismo, a estxs maestrxs no los veo como estudiantes sino como personas que enriquecen mi quehacer en varias dimensiones, profesional, formativa, laboral, emocional y otras, una de las definiciones que tengo sobre formación se orienta hacia la diversión, como maestra me divierto demasiado, me gusta compartir con lxs estudiantes y lograr construir ese vínculo, que 
necesariamente debe ir más allá de la mera clase, la formación se hace en otros escenarios, con distintas herramientas y vinculando a otras personas. Conozco sus hogares, voy a ellos cuando me lo permiten, hablamos de nuestras vidas, experiencias a lo largo de su labor docente. Estos espacios permiten que lxs maestrxs en formación se salgan de los rígidos que en varias ocasiones es lo académico, no hay la espontaneidad, las risas, tratar de descubrir nuevas formas para interactuar con los maestrandos. La formación de docentes se vive desde la experiencia de ellxs mismxs, desde lo que son y lo que hacen, es allí donde habita la esencia de lo que es formar, es decir, se forma en y para la vida, y desde la vida misma es que se emprende la búsqueda por conocer más y lograr otras cosas que fortalezcan el oficio $d x l x$ maestrx.

Ir a formar docentes a las regiones es descubrir los diversos significados que emergen en el diario acontecer de la vida de cada uno de ellos, quizás como docentes tutorxs decir que los comprendemos es arriesgado, pero sí los percibimos y muchas veces en las sesiones presenciales logramos atrapar esos significados, puede ser cuando algunos de ellos afirman que "estar haciendo una maestría les ha cambiado varios aspectos, no solo en su ser como maestrx sino en su ser persona", o, "vemos con otros ojos nuestra propia práctica docente". Esas expresiones espontáneas generan satisfacción, pero también preocupación, pues para algunos ha sido difícil destinar tiempo para los encuentros del grupo de trabajo, han tenido que quitarles tiempo a otras ocupaciones, entre ellas, las familiares, para poder hacer los trabajos, las reuniones o demás "obligaciones" que tienen con la maestría. Digo obligación, pero siempre he tratado de que estén convencidos que más que una obligación es un logro que están cumpliendo, es un trazo más que están dibujando para enseñar o simplemente ser mejores personas y ver los contextos desde otra perspectiva. Me arriesgo a decir que hacer una maestría en educación, es cortar "otro retacito de ese gran telar y poderlo agregar a ese telón que diariamente construimos..." (autorrelato Alejandra Rico, 2017). 


\section{Capítulo X. Manifestaciones emergentes de la fd posgradual vinculadas al}

\section{oficio dxlx maestrx}

Aquí las narrativas se analizan desde dos categorías: la primera se centra en los aprendizajes adquiridos sobre investigación, partiendo del hecho que en todas las historias de vida se hace referencia al acto investigativo de la propia práctica docente, suceso que incursiona como novedad en la cotidianidad docente.

Y, la segunda, partiendo del análisis de la primera, cómo la investigación conduce xlx maestrx a pensarse desde su rol como sujeto social y artesanx. Aquí, es más que pertinente hacer referencia a las palabras de Hernández (2011, p. 15),

El análisis del fracaso de las reformas centradas en la consideración dxlx docente como un mero aplicadorx de las visiones y propuestas de lxs expertxs, y la importancia que, derivada de estos análisis hacia la apertura de focos de interés en la investigación como las creencias y pensamientos de lxs profesores, las biografías e historias de lxs docentes, las trayectorias profesionales.

Es así como se hace un abordaje concluyente sobre el papel dxlx maestrx que se forma como magíster en los contextos donde se desenvuelve y con las personas que en ellos transitan; o sea ¿Qué le permite a este maestrx fomentar buenas prácticas, proporcionar mejores aprendizajes y ser parte del cambio social de su contexto inmediato? ¿Qué lo hace, no mejor, pero sí más consciente de generar prácticas situadas desde el diálogo, el afecto y la integración de saberes? 
Para iniciar con esta última trama de la pesquisa narrativa, pensando en el lazo que sujeta el oficio dxlx maestrx con las prácticas de investigación. $Y$ esta relación comienza cuando xlx maestrx en formación despierta su curiosidad por ir más allá de lo que tiene y lo que hace en su cotidianidad. Quiero señalar aquí un re-trazo de Adela al inicio de su formación como magíster en educación:

Me enamoré desde el primer día en la maestría y ver a profesorxs como María Ester, a tutorxs como ustedes, de ver al profesor Cogollo, dije esto es importantísimo. De todas las cosas que aprendía, yo tomaba nota. Yo escribía todo, punto a punto, porque no me quería perder ningún detalle y cuando llegaba a mi casa volvía a retomar las notas, ampliaba lo que decían, buscaba lxs autorxs que se habían trabajado y decía: - esto me interesa para llevarlo al curso 1001, que es donde tengo dificultad para esta situación. Ya sé qué es lo que está pasando en once. Ya sé cómo trabajar esto, asunto resuelto. Entre otras deliberaciones sacaba del inicio de mis estudios.

Es a este aspecto que se hace referencia, el interés, los lugares comunes que se empiezan a entrever entre lo novedoso de la formación y las prácticas $d x l x$ maestrx. Cómo xlx maestrx en medio de sus aprendizajes va reflexionando su acontecer diario, Vásquez (2011, p. 16) ante esta actitud dxlx maestrx considera que iniciar un estudio de posgrado es ir más allá de lo dado, "es un deseo por la búsqueda permanente o por el anhelo de convertir nuestras labores en escenarios para la incertidumbre".

Esa búsqueda no es iniciar desde el origen, sino que está localizada al interior de las trayectorias que ha construido xlx maestrx, esto sucede con Adela cuando expresa que los conocimientos nuevos son útiles para su labor. La acción investigativa comienza en el momento que xlx maestrx re-torna a sus prácticas, tiene la necesidad de revisar el interior de su hacer, y para ello, reconoce la 
investigación como la ruta más dinámica para considerar su ejercicio y re-pensar sus prácticas de forma contextual, pedagógica e hilada con las condiciones sociales en donde se desenvuelve como maestrx. Continúa Adela con su relato, al considerar que el ingreso a la maestría y los aprendizajes en investigación fueron un suceso representativo en la conformación de sus trayectorias como maestra.

Desde el primer día toda la fundamentación teórica y la manera de cómo se conceptualizaban las cosas, no solamente quedaban en esa teoría, sino que había una clara explicación de la relación con lo que se hacía en el aula. Entonces, la posibilidad que yo tenía de traer al aula, a mi propio contexto y esa posibilidad de poder reproducir esas experiencias y ver no solamente que yo las reproducía, sino que había un impacto positivo en lxs estudiantes y que ellxs... se podían transformar cosas y ellxs mismxs se transformaban en ese ejercicio. Yo dije: -claro, esto es lo que yo he buscado siempre, entonces, veía y sigo viendo algunas normas y reglas que son fundamentales y que son columna vertebral en el proceso didáctico, metodológico y en todo el quehacer docente, entonces, por eso en estas experiencias que tengo con los grupos "escuelas que aprenden" me enriquezco y también tengo la posibilidad de replicar lo aprendido en la maestría.

La incursión en los avatares de la investigación, para la mayoría de lxs maestrxs de primaria y bachillerato es algo nuevo, ellxs están habituadxs a ser maestrxs de aula, sin ver la necesidad de ahondar en otros escenarios como lo es la investigación, la tendencia es considerar esta ruta como algo denso y que requiere de un tiempo adicional para ser maestrxs que investigan. Sin embargo, el paso por la maestría trae una perspectiva nueva y asequible para incorporar la investigación en el quehacer cotidiano dxlx maestrx, para que las prácticas sean las que conduzcan a la indagación, y, posterior, a la reflexión del ejercicio. No se trata de que xlx maestrx se convierta en unx investigadorx senior o que deje de ser maestrx de aula, la verdadera razón para vincular la investigación al 
quehacer es procurar otras maneras de hacer enseñable lo que conocemos desde nuestras disciplinas. "No se habla de grandes y complejas investigaciones, sino de pequeños proyectos nacidos del trabajo cotidiano, de nuestra docencia habitual” (Vásquez, 2011, p. 24).

Todo ello conduce a re-trazar la fd del magíster, desde luego, sujeto a la filosofía y la intencionalidad pedagógica que tiene la universidad, sin embargo, para precisar, se hace referencia a la fd de la maestría en educación de la Universidad Santo Tomás, la cual está marcada por hacer del futuro magíster en educación unx profesional que reflexione su hacer y proponga en su quehacer, lleve la teoría a los hechos y realice investigación desde su labor. Y puntualmente, Ixs maestrxs narrantes se formaron bajo la premisa de que una de las maneras adecuadas para procurar transformaciones en las prácticas es por medio de la investigación situada, es decir, poniendo en el tapiz lo que se hace para luego, revisarlo, analizarlo y proponer otras maneras de hacer las prácticas, pero partiendo de lo que está.

Esto conlleva, no solo reflexionar sobre el lugar dxlx maestrx: qué hace, cómo, para qué lo hace, sino que xlx maestrx, luego de un profundo estudio de su oficio, tiene la capacidad de desplazar su ejercicio de indagación a otro lugar, que es el aprendizaje, es decir, sus múltiples reflexiones lo llevan a ver cómo se pueden mejorar los modos de aprender que tienen sus estudiantes, es una invitación abierta a compartir saberes y experiencias con otrxs colegas, para que desde el rol de maestrxs se establezcan propuestas en donde lxs estudiantes se apropien de aprendizajes situados y que sean transferibles en la sociedad. 
Esto se puede interpretar que xlx maestrx tiene la capacidad de enseñar a desaprender, sabiendo que él ha pasado por un proceso de conocer y desconocer lo establecido, es decir, sus lógicas de aprender son percibidas desde la creación de ecosistemas de conocimientos y nuevos aprendizajes. "xlx maestrx vive elaborando permanentes hipótesis sobre su propio trabajo, en el espacio de su cotidianidad las valida o invalida, y con base en esos resultados modifica o reafirma sus acciones" (Vásquez, 2011, p. 163).

Otra de las narrativas re-trazadas en esta pesquisa legitima lo anterior, tener una comprensión que $x l x$ maestrx debe formarse permanentemente y que las buenas prácticas son el resultado de una permanente reflexión, validación y covalidación entre el grupo de maestrxs que se encuentre. Bertha relata sus trazos:

Entrevistadora: ¿Qué experiencias han impulsado que tú continuaras con tu formación en ejercicio?

Bertha: Te voy a contar toda la realidad, resulta que cuando me dijeron que hay una maestría en educación, pero solamente son tales estudiantes, me hubiese gustado hacerla, entonces, me tomé el atrevimiento de llamar al rector e informarle que había una convocatoria para las maestrías, le dije que no estaba en el grupo por algunas razones, pero le dije que me inscribiera. Él me dijo que, sí me inscribía, pero que me rechazaban no era su culpa.

Me gusta actualizarme, me gusta estar al día, si hacen un curso yo soy la primera que levanto la mano para ir. Entonces, pasé (a la maestría) y mis compañerxs se enteraron.

Al comienzo de la maestría, todxs pensábamos que nos iban a decir todo lo que teníamos que hacer, resulta que no. Todo lo teníamos que descubrir poco a poco. Uno se tenía que ir documentando. Y a través de los diferentes autorxs, uno se daba cuenta que la cosa era diferente. Ustedes lxs tutorxs cada vez que teníamos clase de investigación, había momentos en los que parecíamos que íbamos bien, pero otros en los que no, siempre lo mirábamos de otra manera. Hasta que llegó el momento en el que nos dimos cuenta de que estar en la maestría es investigar, eso me ha servido mucho en mis prácticas.

Entrevistadora: ¿Esa formación que tú recibiste cumplió con tus expectativas? Tú me dices que esas expectativas iniciales, eran yo voy a hacer una maestría y me van a dar, lo que me decía un profesor un día una receta para ser mejor docente. Lo que 
yo le decía era que ustedes ya son maestrxs y que no necesitamos darles ninguna receta porque ya están ejerciendo y construyen su práctica.

Bertha: Sí, bastante, mis prácticas han mejorado en un $100 \%$, porque yo antes hacía de una manera no tan buena, ahora hago diferente y busco otra forma de llegarle mejor al estudiante para que entienda y comprenda mejor cualquier tema. Cada vez que voy dando alguna clase, un tema, siempre me acuerdo de mis tutorxs y trato de buscar algo nuevo para que xlx estudiante le agrade, como nuestro proyecto de investigación es de lectura comprensiva, eso enlaza todas las áreas y busco que mis estudiantes lean porque les guste y no porque les toque. Y a ellxs ya les gusta leer mucho, mis estudiantes son muy especiales, por ejemplo, hay dos niñas que nunca van al recreo, sino que siempre se quedan leyendo, me piden libros.

He implementado algunas estrategias, como la de la biblioteca de aula que ha sido el eje para que lxs niñxs lean con más amor y sientan más interés. Todos los días lxs niñxs llevan sus libros a casa para que lean con sus papás, quienes saben de esta maestría y las nuevas estrategias que implemento, además me han apoyado mucho, preguntándoles a lxs niñxs sobre las cosas que ellos leen. Los resultados se notan en las pruebas que uno les hace. Han mejorado bastante sus resultados

Uno crece enormemente, para mis prácticas algunos compañeros me han dado recomendaciones, porque uno ya entra en confianza con ellos y ya entra a ser parte de esa familia, somos una familia en la universidad, ya nos conocemos muy bien, han pasado muchos meses en los que hemos compartidos juntos, entonces eso me ha formado bastante.

Otra parte es en la formación académica siempre, recuerdo que lxs autorxs me enseñan, así ellxs no estén aquí presentes, pero a medida que uno va leyendo, va contextualizando esas lecturas y eso hace que cada vez uno enriquezca más sus prácticas pedagógicas.

[...]

Yo antes no leía mucho. No era muy fanática a los libros. Solo leía porque las especializaciones que yo hacía me lo obligaban y pues no me nacía a leer como ahora, entonces, me doy cuenta de que el cambio comenzó en mí para yo poder cambiar a mis estudiantes y que el saber y el conocimiento lo tiene uno allí, sino que hay es que apropiarse de ese conocimiento y agarrarlo, cada vez leer más, para aportarle a mis estudiantes nuevas estrategias.

Como se puede ver en lo que cuenta Bertha, modificar o no las acciones que realiza xlx maestrx tiene relación directa con la fd posgradual, lo cual tiene que ver con los nuevos conocimientos adquiridos, las enseñanzas recibidas por los tutores, la incursión en la investigación situada, el intercambio de saberes con otros maestrxs, las discusiones grupales en las sesiones de clase, las nuevas 
lecturas que incorpora en su quehacer, entre otros aspectos que conducen a la reflexión del hacer y ser $\mathrm{dxlx}$ maestrx, es decir, se retoma la pregunta por el oficio dxlx maestrx y su contenido pedagógico y social que lo permea.

Las palabras de Bertha conducen a lo que dice Alliaud (2017, p. 68) referente a lo que significa una experiencia, considerando que no es un acumulado de años y de contenidos, sino que es lo que ha de generar algún cambio ya sea del poseedor de la experiencia o del que la recibe.

Es decir, de situaciones cotidianas que por alguna razón revisten un carácter extraordinario y así se distinguen de lo que meramente sucede. Son vivencias que portan un significado especial para quienes las protagonizaron, ya sea por lo que produjeron o también por sus implicancias en el modo de ver y pensar lo educativo por parte de quienes las experimentaron. Es el sentido que le otorga Dewey (1949) a la experiencia al decir que no es mera actividad, sino una fuerza en movimiento que supone cambio y constituye la base del pensamiento reflexivo, investigativo.

Lo que experimentó Bertha supone una indudable modificación en sus prácticas y en el modo de hacerlas, la interacción con lxs estudiantes y la emoción con que los anima a alcanzar los logros no solo hace parte de las buenas prácticas sino de la conformación de un cambio de actitud sobre el quehacer y la vinculación de la reflexión e investigación de su hacer. En un documento de investigación de Suárez y Ochoa (2005, p. 17) consideran que las instituciones de formación docente, en este caso las facultades de educación deben tener una relación directa con las dinámicas de las escuelas, con el fin de generan mayor inclusión de estudiantes de zonas alejadas de las grandes ciudades. "Las 
instituciones formadoras necesitan acercarse aún más, de forma sostenida y sistemática, al amplio universo de la vida pedagógica de las escuelas”.

Justamente lo que sucedió con la fd recibida en la maestría en educación, la incursión directa a zonas retiradas de donde se ubican las universidades que ofrecen programas de posgrados, fue un proyecto que surgió en el 2015 desde el MEN para garantizar mejores procesos de enseñanza y aprendizaje. Lxs maestrxs de veredas y corregimientos se vieron beneficiados en formarse como magíster y así poder profundizar sus conocimientos, prácticas y rutas de enseñanza para optimizar su labor al interior de la institución.

Esto es lo que sucede con Bertha, ella vive y trabaja en una vereda de un municipio llamado San Juan de Albán en Nariño, la ciudad más cercana es Pasto, a tres horas, y allí es donde se ubican algunas universidades donde podía continuar su formación, sin embargo, fue seleccionada para ser parte del grupo de estudiantes del programa de maestría en educación de la Universidad Santo Tomás. Situación que la motivó a emprender esta nueva aventura de sus trayectorias como maestra de escuela veredal, al lado del río y escondida entre bosques, caminos artesanales y un sinnúmero de cultivos frutales y café colombiano.

Ella no imaginó poder formarse como magíster, pero sus intenciones se realizaron y esto le permitió transformar sus ideas frente a sus propias prácticas. Logró enlazar sus acciones con lo aprendido en la etapa de formación, y no solo eso, sino que incursionó en los avatares de la investigación situada, escudriñan do en el interior de su ejercicio para convertirlo en objeto de estudio y propuestas 
encauzadas a la generación de buenas prácticas y aprendizajes contextualizados y universales entre sus estudiantes.

Para aprender a enseñar, podríamos decir, es necesario abordar la enseñanza concentrándose en la tarea, en lo que se hace, y no solo en su definición. Las prácticas mejoran y llegan a convertirse en artesanía cuando la información y la acción se convierten en conocimiento. Para poder mejorar la calidad, las personas necesitan de esa ancla de saberes de donde agarrarse, como así también de procesos reflexivos que implican la puesta en diálogo de esos saberes entre sí y con los conocimientos formalizados (Alliaud, 2017, p. 78).

Xlx maestrx en formación se concentra en desarrollar habilidades que le permitan hacer de mejor forma su labor, encontrar otras alternativas para desarrollar mejores prácticas y encontrar otros lugares que favorezcan la enseñanza, y a la vez, alentar a sus estudiantes para aprender. Las buenas prácticas son en doble vía y permiten a ambas partes comprender de mejor forma los conocimientos enseñados y aprendidos. Esto desemboca en un relato trazado por Tita, quien desde que salió de la Normal, ha procurado formarse y encontrar alternativas para mejorar su labor como maestra, incluso, luego de tener el título de licenciada en ciencias sociales, se enfocó en la fd como eje principal para perfeccionar y profundizar en la teoría pedagógica, la vida escolar y los nuevos elementos que se requieren para ser maestra de escuela en estos tiempos. Asunto que lo consiguió al ingresar en la maestría y ver que no era algo de lo mismo, sino que estaba en un escenario que le presentaba otras formas de ser maestra. 
Entrevistadora: Bueno, entonces arrancas en 2015 la maestría. ¿Cómo arranca esto?

Tita: Bueno el rector nos llama. Nosotrxs ya estábamos enteradxs de que el Estado estaba tratando de buscar unas políticas para ayudarles a lxs maestrxs para profundizar en su formación. Pero al colegio no le había llegado ninguna convocatoria, solo la de ciencias naturales y química que era con la Universidad Nacional. Entonces esa no aplicaba para nosotrxs y los que empezaban en Patillal. Cuando nos llaman y nos dicen que estaban habilitadas para lenguaje y matemáticas, yo no lo dudé y más con las condiciones, que lo único que iba a necesitar era mi disposición y mi trabajo, no lo dudé en ningún momento. Entonces, este proyecto empezó. Yo estaba muy optimista y nerviosa cuando me llamaron a la entrevista de la universidad Santo Tomas, no sabía qué contestar o qué me iban a preguntar. Yo realmente no sabía y estaba bastante impaciente.

Entrevistadora: ¿Cómo es que inicia ese proceso de la maestría?

Tita: Entonces empezamos el proceso de la maestría, llegan nuestrxs tutorxs, todxs con la expectativa de decir cómo era eso, porque si sabíamos que era de un nivel bastante alto, pero no sabíamos cómo íbamos a reaccionar a ello. Lo primero que nos dijeron era que pensáramos en una idea y algunas necesidades que tuviera nuestra institución educativa y frente a eso algunas ideas para empezar a trabajar. Todxs nos quedamos mirando y nadie se atrevió a preguntar nada. Todxs éramos desconocidxs, entonces la tutora nos dijo: -es que la investigación y el proyecto lo vamos a iniciar ya.

Entonces, empezó el proceso, teníamos incógnitas y preguntas, no entendíamos muchas cosas. Cuál fue la primera impresión, decíamos, por ejemplo, el problema de lectura, inventábamos una solución y cuando las mostrábamos a nuestrxs tutorxs, ellos decían ¿Cómo sabes que esa es la que va a funcionar si todavía no has hecho un trabajo de campo o una observación? Entonces, qué nos toca hacer, otra vez hacia atrás. Entonces, qué tenemos que hacer... miren, deben hacer un diagnóstico y ahí colocábamos las necesidades de nuestra institución educativa.

[...]

Un día nos sentamos en mi casa, los cuatro compañeros, y yo dije: hasta dormida creo que estoy pensando en eso, quién maneja la didáctica, xlx maestrx, entonces la investigación debe estar basada en xlx maestrx, pero que proyecte un resultado en Ixs estudiantes. No debemos hablar de lxs estudiantes. Todos me quedaron mirando, se preguntaban ¿será que es así y yo les decía: -claro que sí, así es que hay que montarlo.

Empezamos a montar las ideas, qué estrategias didácticas podría utilizar unx profesorx para mejorar.

Entonces frente a esa situación, cuando uno tiene ese dominio conceptual, hablando de la didáctica, uno ve las cosas totalmente diferentes a como se veían antes, para uno antes todo era un complique, por cualquier recurso. La idea no es buscar el problema la idea es buscar la solución. Y bueno, ese más que todo en líneas generales fue el proceso de la maestría.

Cuando regreso a mi colegio, en básica primaria, yo me dije, aquí hay una meta que muchxs no habían cumplido, y con este dominio conceptual que tengo ahora de ya no 
ver problemas sino soluciones, voy a lograr este año, que estxs niñxs me vayan a sacar a mí los mejores resultados de las pruebas saber, empecé un proyecto en donde lxs niñxs hacian actividades para las pruebas saber e identifiqué desde mi experiencia cuál era la principal necesidad de lxs niñxs, y empecé a trabajar.

Eso es otra cosa que conseguimos con la maestría, la reflexión de la práctica. Si no hay una reflexión de la práctica no hay un proceso formativo, y si no hay un proceso formativo xlx maestrx lo único que está haciendo en el aula es llevar una cantidad de actividades para mantener ocupados a lxs estudiantes. No hay más nada.

Yo creo que con el posgrado mejora la forma de ver la profesión, saber que desde ese dominio conceptual que yo tengo, todas las transformaciones que puedo hacer y todas son posibles si me lo propongo y eso se refleja en el ámbito familiar, cultural y social. Uno se convierte en una persona totalmente crítica de las cosas que pasan alrededor de uno, uno no se queda con lo primero que le dicen, más bien conversa, pregunta. Si hay una experiencia en $X$ lugar: oye yo quiero saber de eso. Es como no quedarse en esa mecánica de voy para el colegio, trabajo, pero me voy para mi casa y me siento a ver televisión.

La formación de maestrxs no es de una sola vía, también hace parte de esta trayectoria xlx formadorx de formadorxs, en el sentido que es quien orienta el proceso y facilita las pautas para emprender esta experiencia. Es quien enruta al que está aprendiendo. Sin estas orientaciones en el proceso, xlx maestrx en formación puede desviarse del camino y confundirse al querer aprender algo diferente. $Y$ es que, en el relato de Tita, se muestra lo oculto que hay en él, lo que vio en sus primeras sesiones, las asesorías, tener que retomar una, dos o tres veces para consolidar un tema, hace parte de las orientaciones dxlx maestrx formadorx.

A este aspecto, lo llama Vásquez (2011) “el arte del cuidado”, considerando que es el tiempo de lo impersonal, los medios de comunicación y la sociedad de consumo han agotado las formas sustanciales de interacción con xlx otrx, las nuevas tecnologías se encargan de corroborar la presencia o ausencia de las 
personas, dejando de lado el carácter de preocupación y detalle por los que conforman el grupo o semestre.

Sin embargo, al ser parte de una apuesta de formación no solo diluida en contenidos disciplinares y resultados mercantiles, sino que es una apuesta por pensar en el otro, ver y sentir sus necesidades y preocupaciones, los espacios de formación de la maestría se caracterizaron por nombrar al otro, "descubrir los rostros que hay entre la masa de estudiantes" (Vásquez, 2011, p. 29). Ese espacio de formación es el que consolida experiencias, es aquel que permite ser narrado. Los modos de pensar, actuar y sentir de los que se forman hacen parte de las intenciones de formación del que enseña. El hecho de preguntar por el otro, por notar la ausencia de unx estudiante, el rostro de preocupación o de cansancio, ver que además de una lista de estudiantes, estamos frente a personas con el anhelo de cumplir una meta, ser mejores o aprender algo que no sabían.

Todo ello se refleja en el modo de cómo ellxs se apropian de lo que aprenden, el acto de enseñar implica compasión por el que aprende, implica afecto, comprensión, contacto visual, diálogo compartido. Una etapa de formación es entendida como un suceso de vida, el cual marca o no la diferencia, es recordado u olvidado, esto está atado no solo a la persona (maestrx) que se forma sino al formadorx.

Tita, en su relato, se refiere a las enseñanzas de sus maestrxs, asumidas desde los momentos de aprendizaje y otros de corrección, los dos entrelazados para dar continuidad a la formación. El primero, para conocer y comprender; y, el 
segundo, para desaprender y re-comprender. Aquí, de nuevo dirijo este análisis desde la obra de Remedios Varo "hacia el acuario", dejarse llevar es la forma más acertada para conocer el camino, y luego, poder caminar solo.

Precisamente, enseñar, aprender e investigar, son tres acciones que se tejen a lo largo del proceso de formación como magíster, el que enseña, lo hace desde el carácter pedagógico, el que conduce a otro; el que aprende, lo hace desde el lugar de la curiosidad, de saber a dónde está siendo conducido; y el acto de investigar es el resultado de este binomio, se abren nuevos caminos para la indagación pedagógica, para que hayan aperturas sobre la labor dxlx maestrx, en donde el ejercicio de reflexión es el puente para que se encuentre la teoría y la práctica instalada en el quehacer y ser dxlx maestrx.

Siendo así, el primer sentido que se le otorga a la fd posgradual tiene que ver con las prácticas investigativas y su vinculación con el obrar dxlx maestrx. Este sentido se destaca por dejarse conducir, poder re-mover lo que se ha realizado, no se habla de desechar, aquí, hay que re-tomar para re-mover. Xlx maestrx en formación es quien decide qué transforma y cómo lo hace, es quien concede sentido a su formación, y parte de ello, se instala en la indagación, en precisar cómo puede investigar lo que está haciendo.

El trabajo de enseñar se va construyendo artesanalmente en el día-a-día, paso a paso. En tiempos en que la enseñanza se complejiza, si bien es necesario sumar a la formación nuevos conocimientos formales, dotarlos de mayor complejidad y profundidad, también se requiere poner en valor, recuperar y poner a dialogar aquellos saberes (de la experiencia) que aluden a lo particular, a la producción, a la creación y a la experticia en lo que se hace (Alliaud, 2017, p. 165). 
Al incorporar las experiencias de formación docente obtenidas en la labor dxlx maestrx, se genera una mayor apreciación por lo que hace, es decir, xlx maestrx se da cuenta que lo que ha venido realizado desde hace varios años es el material más importante que tiene para transformar sus propias prácticas. Partiendo desde el involucramiento de algunas teorías sobre pedagogía, evaluación, educación, investigación, y revisando qué le pueden aportar a las prácticas establecidas para robustecerlas y lograr otras nuevas en lo posible. Este es el ejercicio que arroja la fd en posgrados, no hay recetas de cómo enseñar, la mayor pretensión se centra en la autorreflexión de lo que hace $x l x$ maestrx en la cotidianidad escolar. Desde allí es que parte la acción investigativa educativa.

El cúmulo de conocimientos, experiencias, saberes, teorías, acciones didácticas, entre otros elementos que encierran la labor dxlx maestrx, por sí mismos no permiten la reflexión o como lo dice Alliaud, todo ello es necesario que se ponga en diálogo, se entrelace para fortalecer el oficio dxlx maestrx, para llegar al lugar del artesano, quiere decir que

Lxs artesanxs se dedican a hacer bien su trabajo por el simple hecho de hacerlo bien. $Y$ esa dedicación o compromiso es con lo que se hace y no necesariamente instrumental. Cuando la artesanía se desarrolla en alto grado supera la actividad mecánica, permite sentir más plenamente lo que se está haciendo y pensar en ello con mayor profundidad. Para aprender a enseñar y a enseñar bien, es necesario insertarse en el proceso en que se produce la enseñanza y este posicionamiento implica tanto a quienes se están formando como a lxs propixs formadorxs. (Alliaud, 2017, p. 78). 
Lxs maestrxs narrantes de esta pesquisa quisieron tener la opción de ser mejores en lo que hacen, y no solo ser mejores ellxs, sino llevar lo aprendido a sus lugares de trabajo, que en todas las historias sucedió, la formación recibida se convirtió en el pretexto para reunir al equipo de maestrxs y contarles lo aprendido, incentivarlxs a que se pueden re-pensar las prácticas en la medida que se logre recabar en ellas.

Esto conduce a develar un segundo sentido de la fd posgradual: lo aprendido es un modo de transformar un colectivo de maestrxs. Es la acción pedagógica, social que caracteriza xlx maestrx. En la medida que se obtienen más conocimientos y elementos para mejorar la enseñanza y fortalecer el oficio, xlx maestrx en formación querrá, también, que su entorno laboral, y especialmente, que sus compañerxs se vean beneficiados por sus conocimientos. La nueva formación implica un acercamiento a la reflexión no solo de lo propio sino del otro. Cómo puede aportar para que lxs otrxs maestrxs logren mejores prácticas.

En el siguiente relato de la historia de vida de Mateo, se hace evidente el interés por seguir su formación, y más cuando dejó un proyecto de doctorado atrás. La oportunidad de poderse formar como magíster es la que había estado esperando para hacer mejor su labor y así mismo, replicarlo en la institución.

Mateo: Yo sentía que tenía debilidad en la parte de docencia, siempre había pensado en hacer este proceso formativo, no se me había dado la oportunidad de hacerlo, esto es bastante costoso, pero no tenía las condiciones, afortunadamente, el gobierno sacó el programa de las "becas para la excelencia docente", en el primer corte no salimos y se me bajó un poquito el ánimo. Luego salió el segundo corte. Entonces, le dije al rector que me incluyera porque yo estaba muy interesado en hacer parte de ese proyecto. El rector entró en el juego de conocer a lxs otrxs docentes, porque yo solo no podía ser, debía haber dos, emprender un proyecto de 
formación, la verdad sí llenaba todos esos vacíos que tenía y superaba mis malas clases haciéndolo. Todo eso me llevó a hacer eso.

Entrevistadora: Con este proceso formativo como magíster en educación; ¿Qué práctica ha cambiado? O sea, ya después de que tú dijiste, yo quisiera fundamentar más es práctica que he adquirido empíricamente.

Mateo: Bien ahí podía decir, en cuanto a la importancia de la puesta en práctica, todo este proceso formativo me ha permitido a mí empezar a reflexionar de lo que estoy haciendo en el aula, qué estoy haciendo y para qué lo estoy haciendo. Para qué hago estas actividades...entonces, es empezar a hacer esa reflexión sobre la práctica y ver que no todo está acabado, en el sentido de que yo diseño una estrategia para una clase, esa estrategia me sirve con unxs estudiantes y con un grado, pero de pronto yo tengo que empezar a reevaluar dentro de la misma práctica qué puedo mejorar, qué puedo cambiar, qué me hace falta. Empezarla a alimentar para irla mejorando, eso de cierta manera me ha permitido y me ha hecho ver que cuando yo digo que la química es simplemente experimental y práctica. No solamente lo puedo ver, porque como yo en la universidad solo veía la práctica en los laboratorios, esto me ha permitido que el laboratorio no es simplemente el aula donde están todos los aparatos, sino que este puede estar en cualquier lado, en mi entorno, el contexto rural que está allí es un gran laboratorio. Lxs estudiantes tienen cosas y podemos hacer muchas experiencias con cosas cotidianas que ellxs manejan, experiencias caseras y empiezo a ver que los recursos están allí y que no me puedo limitar porque no tengo laboratorio, pero todo esto lo he podido mejorar porque uno empieza a leer, a mirar y ver experiencias y artículos de otros que han hecho algo así, entonces, uno piensa en hacer lo mismo. Con lxs docentes, compañerxs de otras instituciones y con los que son de la misma área empezábamos a hablar, por ejemplo, con el profe Oscar, empezábamos a charlar, a preguntar sobre las clases. Entonces, uno empieza a hacer esa interacción y empieza a fortalecer esa práctica. Esos vínculos son bien importantes.

Entonces eso me aportó mucho, cuando venían a darnos charlas sobre didáctica yo me imaginaba que nos iban a dar una "receta" para dictar las clases. Entonces, ya comprendí que no eso y que la didáctica la construyo a diario con mis estudiantes, cuando me pongo a analizar y piensas, eso fue algo nuevo.

Algo nuevo, que nos pasó a varios, es ese cambio de mentalidad, en cuanto a la concepción de lo qué es la investigación. Cuando yo entré a la universidad al pregrado, yo vi, la concepción de la investigación como ciencia pura, por el método científico que tengo que partir de una observación, uno mira ese tipo de formación en investigación. Cuando yo llego acá (a la maestría) y empiezo a ver otro tipo de investigación, empieza un choque... yo decía, que así no es investigar.

[...]

Este proceso formativo es necesario para lxs profesionales, sobre todo cuando estamos vinculadxs a una profesión y ya tenemos definido un perfil laboral, nos ayuda a enriquecer mucho, a mejorar el desempeño laboral. En este caso de la docencia es fundamental hacer este proceso que ayuda y contribuye para que nosotrxs podamos hacer una labor en el cual salgan beneficiados lxs estudiantes, que 
muchas veces por desconocimiento y falta de fundamentación, a veces cometemos muchos errores que pueden llegar a perjudicar xlx niñx. Pero cuando uno tiene este proceso formativo da muchas bases para tratar de hacerlo un poco mejor de lo que se lo venía haciendo.

Este segundo sentido de la fd tiene que ver con la manifestación directa que tienen los nuevos aprendizajes en el quehacer dxlx docente, el cual no es solo impartir clases, sino que se dimensiona en otros escenarios del contexto escolar e incluso social en donde labora xlx maestrx. Precisamente, Mateo ha dejado entrever que el diálogo entre maestrxs favorece las buenas prácticas, en la medida que existen consensos y discusiones que conllevan a compartir las experiencias y los saberes, para poder replicarlas en cada institución donde ejercen su labor. Mateo junto con sus compañerxs que estaban haciendo la maestría, tuvieron que llenarse de paciencia para que Ixs demás maestrxs Ixs escucharan, hicieron varias jornadas con ellos, pero la gran mayoría no les interesaba participar porque consideraban que les iban a poner más trabajo y les iban a modificar lo que han venido haciendo. Sin embargo, Mateo y el grupo no desistían de la idea de hacerles saber la importancia de trabajar colegiadamente y hacer grupos de reflexión para contar lo que cada unx hace.

Con tanta insistencia, se logró que varios de lxs maestrxs de la institución lo hicieran y los resultados fueron maravillosos, al conocer la investigación de Mateo, empezaron a participar y preguntar cómo podían hacer de otras maneras sus prácticas, de qué modo. Asunto que motivó a Mateo a dialogar con sus compañerxs y exponerles su experiencia, con todo el material pedagógico que habían creado en su etapa de estudios posgraduales. Lo compartió y maestrxs se 
unieron al proyecto propuesto para fortalecer la enseñanza de las ciencias naturales en la institución vinculando áreas como español, matemáticas, artes, tecnología, entre otras.

Alliaud (2011, p. 94) considera que xlx maestrx que cuenta lo que experimenta genera un nivel formativo elevado no solo propio sino dentro del grupo en que se encuentra. "Son esos relatos que se organizan a partir de acontecimientos, personajes, escenarios y situaciones, pero que también incluyen interpretaciones y reflexiones, los que permitirán no sólo enriquecer las prácticas de sus productorxs, sino también las de quienes los comparten o se encuentran con ellxs".

Bien se ha dicho que el proceso de fd conlleva compromiso, aperturas, transformaciones y nuevas perspectivas del oficio $\mathrm{dxlx}$ maestrx, cuando ese maestrx que se está formando siente que debe compartir lo que ha aprendido, en ese momento ha comprendido el sentido de formarse, ha vinculado en su ejercicio docente la acción investigativa, lo que le permite hacer una indagación en dos lugares: el primero, la cotidianidad de sus prácticas; y, el segundo, lo que sucede en su entorno. Ejercicio que le brinda posibilidades para ser un transformadorx de su ser, hacer y conocer, saliendo de la zona de confort e ir modificando o situando sus prácticas en otros lugares epistemológicos y metodológicos para realizarlas mejor y en coherencia con el ámbito sociocultural en donde se alojan sus estudiantes. 
De este modo, xlx maestrx al situar las experiencias de $\mathrm{fd}$ adquiridas en su cotidianidad, está tejiendo otros saberes, nuevas experiencias y visionando otros conocimientos y teorías que puede articular en sus prácticas, y que, a la vez, puede intentar transferir y comunicar lo nuevo que ha descubierto en el medio en donde labora, es decir, hacer parte de sus trayectorias a otrxs maestrxs. Es decir, "unx maestrx que logra fijar la mirada en el aula y las distintas relaciones emergentes de ella, logrará más acercamientos de su labor con la investigación y encontrará otros sentidos a su quehacer" (Camargo, et al. 2007, p. 35).

En este orden de ideas, me permito integrar los últimos dos fragmentos de las historias de vida de Adolfo y Lulo, en donde sobresale la idea que la fd es algo que $x l x$ maestrx debe hacer para estar actualizado y conocer otras formas de hacer enseñable lo que sabe.

Adolfo: Ver esa situación desde un mundo mucho más cualitativo y ver una sociedad que juega en muchos espacios en la construcción de un conocimiento y de una historia, de un proceso, entonces, hace de que uno ya vea la estructura de la docencia desde otra percepción, no a los números sino a los elementos que hacen parte de esos resultados, incluso, mis valoraciones son distintas, a pesar de que soy docente de matemáticas, ya no lo veo tan cuadriculado, y hay espacios diferentes y de flexibilidad, y de conocer a lxs estudiantes desde otras facetas, me hace de que yo también pueda valorar esos elementos que han hecho crecer a lxs estudiantes.

Entonces, sí ha cambiado totalmente, incluso mi actitud como docente en un área que realmente cobija unas expectativas distintas en términos de hacerla más asequible a lxs estudiantes. Porque llenar el tablero con una serie de fórmulas y de números, parece no interesarle mucho a lxs estudiantes, el tratar de contextualizar eso y hacer que esos elementos se vuelvan cotidianos, que $x l x$ estudiante los pueda recrear en algo que ve todos los días, eso es lo que ahora mi tablero trata de decir, cada vez algo distinto.

Realmente ha habido cambios en la forma de ver y de actuar como docente, no es tan fácil decir cómo ha cambiado la forma de actuar, pero realmente sí, porque cuando uno antes llegaba solamente con un saludo: "buenos días, por favor su cuaderno, vamos a hacer la siguiente presentación y ustedes me recuerdan lo que vimos la clase pasada" esa podía ser siempre la rutina. Pero, el hecho de que usted 
llegue antes de entrar a clase, y trate de motivar a sus estudiantes y tenerlos en un espacio donde todxs se sientan concentrados.

Gracias a esto, lo que he tenido en mi docencia, creo que eso es lo importante, porque a veces uno se llena la boca diciendo que es magíster. Lo mío no es eso, para mí es un reto mucho mayor donde yo pueda demostrarme con hechos de que puedo estar en posición distinta, que puedo compartir, contribuir y colaborar.

Lulo: Yo, por ejemplo, ya estoy en el último grado del escalafón, la 14 y se supone que no tengo que hacer ninguna formación,

En una entrevista de ingreso yo respondí, que hacía la maestría porque necesitaba aprender, formarme y tener más experiencias para dar más de lo que he dado a mis alumnxs, que está era la entrega que yo sentía por mi carrera.

Ese es mi sentido de formación, si yo por ejemplo termino la maestría y me dan la posibilidad de hacer un doctorado lo hago, no por el hecho de ser doctora, sino solo por el hecho de que voy a aprender más y voy a fortalecer más mi práctica. Sé que eso me va a dar resultado con lxs muchachxs.

Yo estaba segura de que la maestría era una formación más grande y amplia, uno a veces comete el error de pensar que allí a uno le van a decir cómo tiene que dictar las clases o cómo va a trabajar, uno se va como en ese sentido. En mi caso mis expectativas eran muy grandes, porque yo sabía que en la maestría iba a conocer mucho más en otro nivel.

Uno piensa que se está quedando mucho en el proceso. Entonces, lo importante en un docente no es el título, sino la capacitación y la formación que recibe. Para mí esto fue muy impactante, encontrarse con gente que sabe y que exige, que le dijera, vaya y busque esto... lea esto... busque en las fuentes...es bueno y es lo que uno como docente debe de hacer todo el tiempo.

Aquí, aprendí que tengo que leer para saber cómo definir lo que es enseñanza y didáctica, uno empieza a centrar las cosas, y en la parte formativa, pues más aun, porque uno, por lo general dicta sus clases desarrolla el tema y ya. Aquí, uno aprende otras maneras, por ejemplo, con las profundizaciones en ciencias, el profesor Guillermo dijo algo muy bonito que yo recuerdo siempre, decía, que nosotros no debíamos enseñar un concepto sin haberlo trabajado, abordado su historia ni su epistemología, entonces, no enseñamos bien el concepto, solo lo damos por el momento, pero nunca indagamos antes, ni consultamos las experiencias que se han trabajado con ese concepto. Es decir, uno solo llega y enseña, pero no hace un recuento sobre esto. 
El último sentido de la fd posgradual tiene que ver con el desinterés de formarse, hacerlo no por ostentar un título de magíster sino por el simple hecho de aprender, de conocer otras formas de enseñanza, poder enriquecer las propias prácticas y contribuir al progreso de la institución en donde labora cada maestrx. Adolfo y Lulu, tiene algo en común y es que ellos ya están en el úl timo nivel de escalafón docente según el decreto 2277, en donde el nivel 14 es el más alto, y para llegar allá, xlx maestrx debe hacer una especialización de un año o publicar un libro. Los dos hicieron la especialización años atrás antes de iniciar la maestría, así que cuando ingresaron a los estudios de maestría no tenían necesidad de hacerlo. La razón más sencilla que ellxs dan en sus relatos es que querían aprender otras cosas.

Cuando unx maestrx emprende un estudio de posgrado bajo esas condiciones, sin la preocupación del ascenso salarial, se está permitiendo escalar a otros niveles, los cuales tienen que ver con los aprendizajes desinteresados y la lectura que hace de su experiencia es más profunda. Ve en la formación el punto de partida para consagrarse en su labor y destinar más tiempo en leer, conocer las experiencias de otrxs maestrxs, indagar en estudios locales e internacionales. Estx maestrx se da la oportunidad de hacer de la formación un disfrute.

Una frase que dice Lulo en su relato "para dar más de lo que he dado a mis alumnxs", es una apreciación libre de prejuicios, preocupaciones y desligarse de lo mercantilista que puede llegar a ser la fd en un escenario como lo es Colombia. Todo lo contrario, sucede con xlx maestrx que ingresa con la única intención de presentar el "cartón" ante el MEN para subir de escalafón, sin el 
interés de aprender o estimular sus conocimientos establecidos para así reflexionar sobre su acción. El facilismo y el conflicto es el derrotero del interés mercantilista, buscan siempre la inmediatez, lo efímero y la ley del poco esfuerzo. La ligereza de sus palabras choca con la reflexión profunda que acarrea el oficio dxlx maestrx, desatinan con el ejercicio de otrxs maestrxs, incluso con el que xlx maestrx formadorx realiza.

Estas dos lógicas hacen parte de la cotidianidad de la fd posgradual, xlx maestrx que se forma como magíster se le presentan numerosas posibilidades de ascenso profesional, no solo el que imponen los decretos del MEN, sino un trabajo alterno, clases de cátedra, ofertas laborales. Sin embargo, bien lo dice Adolfo, el título pasa a segundo plano si no hay una verdadera apropiación de los conocimientos aprendidos. Xlx magíster en educación se otorga ese título cuando empieza a obtener experiencias en el campo de acción. Cuando es reconocido por las posturas que fomenta entre sus estudiantes y colegas, la circulación real de la fd surge cuando se hacen trayectorias que reafirmen el oficio de ser maestrx.

Al ser magíster “inmediatamente se comienza a pertenecer a un grupo especial de artesanxs ocupadxs en esto de tallar el espíritu, darle forma al carácter, forjar pensamientos y voluntades” (Vásquez, 2011, p. 17). Y con esto no quiere decir que $x l x$ maestrx sin formación posgradual no tenga sus experiencias y trayectorias consolidadas, a lo que se quiere llegar es a considerar que la formación posterior al pregrado permite matizar aún más los conocimientos adquiridos y comprender mejor el cúmulo de experiencias 
adquiridas. No es la cantidad ni los años de oficio, sino es la pertinencia y lo memorables que pueden llegar a ser esas experiencias para la consolidación de nuevas e incluso ser replicadas por otros maestrxs.

Dice Alliaud (2011, p. 96) "una experiencia sería aquello que alguien considera "valioso" de contar, de recuperar, por el significado proporcionado. Aquello que nos conmovió, nos transformó, en tanto produjo algo diferente. La experiencia en este sentido se une al cambio". Es justamente lo que sucede cuando se hace referencia al sentido del desinterés por formarse, no quiere decir que no haya interés, lo que sucede es que se está allí, pensando en generar transformaciones en las prácticas propias, y no solo por el cumplimiento de tareas. A este tipo desinterés se hace referencia, la despreocupación de cumplir, más bien, está la preocupación por aprender y ampliar lo aprendido.

Lo que concluye este análisis narrativo tiene que ver con lo que se escribió al inicio, partiendo del interrogante ¿Qué le permite a estx maestrx fomentar mejores prácticas, proporcionar mejores aprendizajes y ser parte del cambio social de su contexto inmediato? ¿Qué lo hace, no mejor, pero sí más consciente de generar prácticas situadas desde el diálogo, el afecto y la integración de saberes?

Lo que conlleva a decir que estxs maestrxs narrantes hacen parte de contextos rurales, que deben viajar por carreteras artesanales para llegar a su lugar de trabajo, otrxs se van a vivir en las veredas de lunes a viernes y retornan a sus hogares el sábado. Son maestrxs entregadxs a su oficio, que a pesar del viaje que debieron hacer todas las semanas para formarse como magíster, valió cada 
sacrificio, son más conscientes de lo que hacen, hay mayor interacción con Ixs estudiantes y más agudeza en el momento de hacer enseñable lo que saben. No buscan la perfección de sus clases, aunque se esfuerzan porque sean recordadas y que sus compañerxs puedan tomar algo de ellas para llevarlo a sus prácticas. Vale la pena resaltar las palabras de Porta y Martínez (2015, p. 109) quienes consideran que Ixs maestrxs memorables "son Ixs hacedorxs de un tejido basado en el interés genuino por el que aprende, el dominio del campo disciplinar y la vocación por compartirlo".

Lxs maestrxs que cuentan sus historias y permiten que estas sean investigadas, hacen parte de un grupo selecto de maestrxs narrantes, de maestrxs que persiguen afianzar constantemente su oficio, exploran y escudriñan en lo propio, han superado el temor a ser parte del cambio, a narrar y re-trazar su quehacer. Estxs maestrxs de territorios colombianos, azotados por la violencia, los cultivos de coca, el narcotráfico y el desplazamiento forzado, son lxs verdaderxs artesanxs de la enseñanza. Aún recorren con romanticismo sus trayectorias vividas. 


\section{QUINTA PARTE}

\section{CONCLUSIONES: Las aperturas de lo que se narró}

Este último apartado concluye la pesquisa narrativa y se compone de dos aperturas: la primera, tiene que ver con el uso de la narrativa para encontrar una definición de la fd posgradual; y, la segunda, con el reconocimiento en las narrativas del sentido que tiene el oficio dxlx maestrx y el vínculo generado a partir de los procesos de fd posgradual.

Para iniciar es preciso hacer una aclaración con respecto al orden estructurado en que se presentan las dos aperturas, que no necesariamente serán tomadas en rigor bajo el orden presentado, ya que para hablar de la definición que se construyó de la fd es necesario que se haga un recorrido por los sentidos emergentes de las narrativas sobre su oficio y los procesos fd. Uno de estos sentidos nace en el momento que xlx maestrx retoma su formación posterior a la recibida en las Normales y en la carrera de grado, esta decisión se ve reflejada en todas las narrativas por diferentes motivos, el que más resalta es la necesidad de mejorar las prácticas docentes y robustecer su labor en la institución donde labora.

Incluso, en una de las historias de vida xlx maestrx considera que formarse como magíster "va a hacer que mejoren sus malas prácticas", es un poco duro con lo que ha conformado, aunque él dice que se requiere de una formación en teoría pedagógica, didáctica y metodológica para organizar lo que ha realizado a lo largo de sus trayectorias como maestrx. En otra voz considera que la fd 
permite generar procesos con mayor profundidad y poder brindarles a lxs estudiantes lo que requieran para su formación. Son razones que van tejiendo este primer sentido, retomar la fd para varios de estxs maestrxs fue un proceso nuevo, a pesar de que todos pasaron por la universidad, esto fue tiempo atrás y la enseñanza universitaria se ha modificado ampliamente.

Ellxs se encontraron con un escenario en donde sus prácticas tienen un lugar en la investigación, ya que las investigaciones centradas en las grandes teorías, reflejadas en cientos de páginas escritas quedaron en el pasado, dando paso a la incursión de la investigación situada y de intervención. Aquí lo que hace xlx maestrx es lo que cobra valor frente a lo que se puede indagar y proponer para diversificar y robustecer no solo la práctica propia, sino la de un colectivo de maestrxs.

Retomar conduce a reconocer que formarse es ir más allá de lo que se tiene y se espera hacer, xlx maestrx que toma esta decisión lo hace bajo la premisa de permitirse conocer más de lo que tiene y dar más de lo que hace en sus prácticas. Es unx maestrx que quiere modificar sus acciones y con ellas hacer de sus prácticas de enseñanza una labor situada y reconocida por sus compañerxs y estudiantxs, no solo desde lo disciplinar y epistemológico, sino desde un enfoque cooperado, social y participativo que permita la integración de las experiencias, saberes y de la comunidad que posiblemente se pueda beneficiar con aquellxs maestrxs que acuden al llamado de la aventura y la decisión de continuar con la fd posgradual para su desarrollo personal, profesional, laboral y colectivo. 
Otro de los sentidos que emergió de las voces de lxs maestrxs tiene que ver con las experiencias encontradas en el periodo fd, las cuales fueron en su mayoría novedosas y complejas de asimilar. Su complejidad se debió a que no había la suficiente apropiación de ellas y hubo que hacer un esfuerzo mayor para poder integrarlas con su quehacer y recorrido teórico alojado en las trayectorias de cada maestrx. Sin embargo, la novedad es la que resalta en medio de la dificultad: para lxs maestrxs en formación posgradual, más allá de lo que tuvieron que estudiar y reaprender, estas complejidades teóricas y formativas no fueron obstáculo para que lograran proyectos investigativos en educación, pedagogía y didáctica articulados con las prácticas y contextos en donde son maestrxs.

La novedad de fd posgradual se manifiesta desde el inicio, Ixs maestrxs narrantes en sus historias relataron que desde el primer día de clases los aprendizajes captados les permitieron descartar los supuestos y nociones erradas de lo que era emprender un estudio posgradual. Entre esos supuestos se encontraba dar por hecho que la investigación era teórica y sin lugar para lo que acontecía en la cotidianidad dxlx maestrx. Situación que los llevó a repensar sus prácticas y asimilar otras formas de hacer investigación y despojarse de considerarla una labor exclusiva de los docentes universitarios o de grupos académicos particulares.

Xlx maestrx de escuela debe ser un actor activo en los procesos investigativos, incursionar en este lugar le permite "promover su desarrollo profesional y personal, urgir su intervención en el ámbito más concreto del 
ejercicio de su práctica, con la pretensión de reconstruirla y recuperarla" (Vergara, 2017, p. 52). Transitar por la fd posgradual le brinda herramientas teóricas, metodológicas y profesionales xlx maestrx que se encuentra en estos lugares, en la medida que con estas puede indagar en su ejercicio, ser y hacer como maestrx, teniendo en cuenta que al recuperar sus experiencias desde la investigación de su quehacer va a consolidar nuevos entramados en su oficio, entre ellos, se encuentra la consolidación del ejercicio reflexivo, no solo hacer por hacer, sino buscar las razones de ese hacer.

Schön (1998) expone que hacer reflexión no es un acto de hablar de lo que hace, esto va más allá, es la comprensión holística de las prácticas, de la labor como maestrxs, cómo se entienden, es alejarse de la perspectiva mecánica y lineal que se tiene del oficio dxlx maestrx, la cual ha llevado a entender por años que la teoría y el conocimiento es un ejercicio de orden científico y que las prácticas que realiza $x l x$ maestrx están sujetas a este ejercicio y su desarrollo es lineal. Schön (1998) propone que el oficio dxlx maestrx se debe ver como una actividad reflexiva y artística; reflexiva en términos de ahondar en lo que hace xlx maestrx; y, artística desde una postura de contemplar los sucesos, ir al trasfondo de lo que hace, poder ver más allá de la pintura, ver la obra de arte en su totalidad, tanto el interior como el exterior y sus periferias.

El sentido de ver la fd desde lo novedoso, lleva a las aperturas que pueden obtenerse. Desde luego, se encuentra el lugar de lo complejo de este escenario, y es que, desde este lugar xlx maestrx pone al descubierto su oficio; estar situadx en lo complejo lo ubica en el desconocimiento de lo propio y es 
allí donde inicia por re-conocer su labor, sus acciones y la esencia de sus prácticas. Es decir, lo complejo es la manifestación primaria para la reflexión y encontrar el sentido único de la fd.

En este orden de ideas, el reconocimiento encontrado en las narrativas del sentido que tiene el oficio dxlx maestrx y el vínculo generado a partir de los procesos de fd posgradual está centrado en las experiencias que lxs maestrxs pudieron construir a lo largo del proceso de formación, las cuales le permitieron generar acciones como: la reflexión de sus prácticas; la incursión en la investigación desde su propio quehacer; las confrontaciones epistemológicas derivadas de la diversidad teórica vista en los cursos de posgrado; las transformaciones y asimilación de otras prácticas para fortalecer su oficio como maestrxs $y$, finalmente, comprender que la fd hace parte de las trayectorias que consolida xlx maestrx a lo largo de su quehacer y que estas son resultado de re-pensar y reflexionar en sus propias prácticas. Con ello es que se teje lo que pueden ser unas buenas prácticas.

El segundo bloque de conclusiones tiene que ver con el uso de la narrativa para encontrar una definición de la fd posgradual emergente de las voces de lxs maestrxs narrantes. Esta definición se logra teniendo en cuenta la incursión de la narrativa como ruta para descubrir otro modo de analizar los acontecimientos de la fd posgradual. Alliaud (2011, p. 100) considera que las narraciones de lxs maestrxs deben ser entendidas como aquello que se quiere contar, que nace de la cotidianidad dxlx maestrx y que deja rastro al ser transmitida. "Ellas suscitan cursos de acción, abren interrogantes y promueven 
respuestas diversas. Proponen, provocan, intrigan, sorprenden y dejan pensando al lector u ocasional oyente. Son, de este modo, potencialmente ricas para producir prácticas, pensamientos y reflexiones".

Xlx maestrx que narra lo que le ha sucedido en alguna de las trayectorias formativas o de su labor, permite conectarse con lo que hace, incursiona en las tramas reflexivas de sus prácticas y recupera las experiencias de su labor. Esto quiere decir que la narrativa cobra sentido cuando el narrador incorpora sentimientos, sentires y emociones, son sus palabras las que permiten ver el sentido de lo que está narrando, de ese relato vivo que se manifiesta en experiencias y tramas de su formación como maestrx. Al igual que no solo es el relato cerrado, sino que este trae consigo diversas aperturas, xlx maestrx que narra vincula sus experiencias de formación con su quehacer, sus prácticas, los sucesos y la cotidianidad de la escuela.

La narrativa pone al descubierto los hechos vividos, es una forma de comprender lo que se hace y profundizar en ello. Xlx que se narra re-traza su vida, y la vida dxlx maestrx es un hecho social que transcurre en diversos escenarios, principalmente, en la escuela, como lugar de escolarización, acontecer social y generación de vínculos entre los que transitan en ella. Estos hechos vividos son fenómenos sociales que al ser narrados se convierten en textos interpretados y reinterpretados no solo por los que investigan sino por Ixs dueñxs del relato, el primer momento de hacer un ejercicio hermenéutico parte de volver texto los hechos, las historias (Porta, 2010). 
De este modo, dice Alliaud (2006, p. 17) que las narrativas de lxs maestrxs cobran sentido en la medida que sean hechos y experiencias que "proponen, provocan, intrigan y produzcan prácticas, pensamientos y reflexiones" en su quehacer y en el colectivo de maestrxs del escenario escolar donde labora. Y es justamente lo que sucedió con las narrativas de lxs maestrxs participantes en esta pesquisa: contaron parte de sus trayectorias de formación, la enlazaron con lo vivido en la fd posgradual y pusieron de manifiesto la necesidad de participar en estos espacios de formación, no solo como un logro profesional sino para el fortalecimiento de lo que hacen.

Lo dicho hasta aquí remite a definir la fd posgradual, desde dos lugares. El primero, el rol que ocupa $x$ lx maestrx en formación y los modos en que asume estas nuevas experiencias. En esta pesquisa, la formación es entendida como el escenario conformado por enseñanzas, estrategias, metodologías, formas de investigación, diálogos colegiados, desaprendizajes y nuevas formas de configurar los saberes y conocimientos obtenidos en esta etapa de formación. En esta formación se fortalecen no solo conocimientos sino prácticas, $x l x$ maestrx la consolida desde su propio hacer y quehacer, esta formación no es configurada desde la teoría sino desde la práctica dxlx maestrx.

La fd posgradual es aquella en donde $x l x$ maestrx retoma lo que ha realizado a lo largo de sus trayectorias, no como un recuento de acontecimientos, sino como un telar de experiencias, las cuales quieren ser recuperadas y profundizar en ellas, integrando otros modos de comprender la labor dxlx maestrx, las teorías y los saberes. La fd posgradual es aquella etapa en donde xlx maestrx 
toma la decisión de conocer más de lo que tiene ya instalado en su labor, decide crear otras formas de comprender lo que hace y cómo lo ha venido haciendo, con la finalidad de poderlo hacer mejor, con más criterio y reflexión. Es la etapa en donde se ponen en el escenario las trayectorias construidas y se toma la decisión de profundizar en ellas, analizarlas y configurar otras maneras de enseñar y construir los escenarios escolares.

El segundo lugar desde donde se define la fd posgradual es desde el rol dxlx docente formadorx, no solo es el que transmite ciertos conocimientos o facilita algunas indicaciones para que el que se forma siga una ruta de aprendizaje. Estx docente es quien hace que la fd sea el escenario para investigar y analizar el oficio dxlx maestrx en formación, da forma a lo que trae estx maestrx para ser estudiado, es decir, para emprender la configuración de nuevas trayectorias de formación y práctica dxlx maestrx.

En la fd posgradual $x l x$ docente formadorx sitúa modos alternativos de considerar las propias prácticas de lxs maestrxs como el principal material de trabajo y estudio para emprender el ejercicio de formación y profundización en el quehacer. $Y$ esto se ve reflejado en las narrativas: estos modos de pensar y reflexionar en lo propio hicieron que lxs maestrxs narrantes diseñaran otras formas de enseñar y dieran apertura a pensar la escuela desde otras perspectivas no solo como el lugar a donde llegan lxs estudiantes y son dirigidos a los salones de clase para que les brinden cierta información sobre algunos temas del plan de estudios, sino que la escuela es aquel lugar para crear e implementar estrategias de enseñanza en donde xlx estudiante sienta interés 
por lo que le enseñan, porque son conocimientos situados y que puede relacionarse con la realidad inmediata que conoce.

En resumidas, la fd posgradual, en este caso ser Magíster en Educación, es considerada desde el compromiso de seguir formándose, continuar las discusiones entre maestrxs, trabajar en equipo, analizar los planes curriculares, vincular la teoría con las prácticas desarrolladas, establecer estrategias didácticas que faciliten los aprendizajes y se articulen con los contextos en donde se encuentran lxs maestrxs y lxs estudiantes. De este modo, la fd posgradual es aquella en la que lxs maestrxs y docentes formadorxs construyen en conjunto diversas formas pedagógicas y epistemológicas de mejorar la labor dxlx maestrx, generando trazos investigativos para desarticular la noción dxlx maestrx transmisorx y reproductorx, y poder pensar $x l x$ maestrx como un artesanx de su oficio. 


\section{REFERENCIAS}

Alliaud, A. (2006). Experiencia, narración y formación docente. Revista Educacao realidade. $31(1), \quad$ pp. 7-22. Disponible en: https://seer.ufrgs.br/educacaoerealidade/article/viewFile/22997/13269 . (2010). Experiencia, saber y formación. Revista de educación. $N^{\circ}$ 1, pp. 141-157. Disponible en: http://fh.mdp.edu.ar/revistas/index.php/r_educ/article/view/11/55 - (2011). Narración de la experiencia: práctica y formación docente. Revista Reflexão e Ação, Santa Cruz do Sul, v.19, n2, pp.92-108. Disponible en:

http://online.unisc.br/seer/index.php/reflex/article/view/2357/1903 - (2017). Los artesanos de la enseñanza: Acerca de la formación de maestrxs con oficio. Buenos Aires: Paidós.

Alliaud, A.; Suárez, D.; Feldman, D. y Vezub, L. (2008). El saber de la experiencia: experiencias pedagógicas, narración y subjetividad en la trayectoria profesional de lxs maestrxs. Universidad de Buenos Aires. Facultad de Filosofía y Letras. Instituto de Investigaciones en Ciencias de la Educación. Disponible en el Repositorio Digital Institucional de la Universidad de Buenos Aires: http://www.filo.uba.ar/contenidos/investigacion/institutos/lice/ANUARIO 2008/textos/32_Andrea_Alliaud.pdf 
Álvarez, Z, Porta, L, y Sarasa, M. (2010). La investigación narrativa en la enseñanza: las buenas prácticas y las biografías de los profesores memorables. Revista de Educación. $N^{\circ}$ 1, (pp. 159-179). Disponible en: http://200.16.240.69/ojs/index.php/r_educ/article/view/12

Bain, K. (2012). ¿Qué es la buena enseñanza? Revista de Educación. N4, pp. 63 - 74. Universidad Nacional de Mar del Plata, Argentina. Disponible en https://fh.mdp.edu.ar/revistas/index.php/r_educ/issue/view/8

Bolívar, A. y Domingo, J. (2006). La investigación biográfica y narrativa en Iberoamérica: Campos de desarrollo y estado actual. Forum Qualitative Sozialforschung / Forum: Qualitative Social Research. Volumen 7, No. 4, pp. 1-33. Disponible en http: / /jbposgrado.org/icuali/La\%20investigacion\%20biografica\%20y\%20narr ativa\%20en\%20iberoamerica\%20\%20\%20.pdf

Bolívar, A., Domingo, J. y Fernández, M. (2001). La investigación biográfico-narrativa en educación enfoque y metodología. Madrid: Muralla.

Bruner, J. (2013). La fábrica de historias. Buenos Aires: Fondo de cultura económica.

Calonje, P. (1999) La Formación continua de maestrxs: otro modo de concebirla. Revista Colombiana de Educación. $N^{\circ} 38$ - 39. 145 - 156. Bogotá: Universidad Pedagógica Nacional. 
Calvo, G. (2004) Digital observatory for higher education in Latin America and the Caribbean, la formación de lxs maestrxs en Colombia. Disponible en: www.iesalc.unesco.org.ve

Camargo, M., Calvo, G., Franco, María C., Vergara, M. y Londoño, S. (2007). La Formación de profesores en Colombia: necesidades y perspectivas. Bogotá: Facultad de Educación. Universidad de la Sabana.

Connelly, M. y Claudinin, J. (2008). Relatos de experiencia e investigación narrativa. En Larrosa (ed.). Déjame que te cuente: Ensayos sobre narrativa y educación. (pp. 11-59). Buenos Aires: Laertes.

Creswell, J. (1994). Qualitative inquiry and research design. Estados Unidos: Sage Pubns.

Davini, M. (2008). Formación de profesores y didáctica: tendiendo puentes hacia el desarrollo profesional y de la enseñanza. B. Téc. Senac: a R. Educ. Prof., Rio de Janeiro, v. 34, n.1, pp. 4-11. Disponible en: http://www.senac.br/BTS/341/artigo-1.pdf

Davini, M. (2015). La formación en la práctica docente. Buenos Aires: Paidós. De Lella, C. (2003). Formación docente. El modelo hermenéutico-reflexivo y la práctica profesional. Desicio. Disponible en: https://cdn.designa.mx/CREFAL/revistas-decisio/decisio5_saber3.pdf

Derrida, J. (1989). La deconstrucción en las fronteras de la filosofía. Barcelona: Paidós. 
Díaz, G. y Santamaría, J. (2009). Concepciones y reflexiones sobre la formación de los profesores a partir de los relatos de vida pedagógica. (Tesis de maestría). Bogotá: Universidad de la Salle.

Edelstein, G. (2013). Formar y formarse en la enseñanza. Buenos Aires: Paidós.

Fernández, M. (2012). Aportes de la aproximación biográfico-narrativa al desarrollo de la formación y la investigación sobre formación docente. Revista de Educación. No. 4 (pp. 11-36). Universidad Nacional de Mar del Plata. Disponible en: https://fh.mdp.edu.ar/revistas/index.php/r_educ/article/view/82

Ferrer, V. (2008). La crítica como narrativa, de las crisis de formación. En Larrosa, J. (ed.). Déjame que te cuente. Ensayos sobre narrativa y educación. (pp. 165-190). Buenos Aires: Laertes.

Freire, P. (2004). Pedagogía de la autonomía. Disponible en: http://www.bsasjoven.gov.ar/areas/salud/dircap/mat/matbiblio/freire.p $\underline{\mathrm{df}}$

Gaviria, C., Delgado, F. \& Rodríguez, G. (2009). Identidad profesional de maestrxs universitarios. Un estudio exploratorio con maestrantes de da Maestría en Docencia de la Universidad de la Salle. (Tesis de Maestría). Bogotá: Universidad de la Salle.

Giroux, H. (1998). Los profesores como intelectuales. Barcelona: Paidós. 
Greene, M. (2008). El profesor como extranjero. En Larrosa (ed.). Déjame que te cuente: Ensayos sobre narrativa y educación. (pp. 81-135). Buenos Aires: Laertes.

Hernández, F. (2011). Las historias de vida en el marco del giro narrativo en la investigación en Ciencias Sociales: los desafíos de poner biografías en contexto. En Hernández, F., Sancho, J. y Rivas, I. (coord.). Historias de vida en educación: biografías en contexto. Disponible en: http: / /hdl.handle.net/2445/15323

Herrera, M. e Infante, R. (2004). Las políticas públicas y su impacto en el sistema educativo colombiano. Una mirada desde los planes de desarrollo 1970-2002. Nómadas. N. ${ }^{\circ}$ 20, pp. 76-85. Recuperado de http://nomadas.ucentral.edu.co/index.php/inicio/29-produccion-deconocimiento-hegemonia-y-subalternidad-nomadas-20/419-las-politicaspublicas-y-su-impacto-en-el-sistema-educativo-colombiano-una-miradadesde-los-planes-de-desarrollo-1970-2002

Larrosa, J. (2008). Las paradojas de la autoconciencia. En Larrosa, J. (ed.). Déjame que te cuente. Ensayos sobre narrativa y educación. (pp. 191219). Buenos Aires: Laertes.

Londoño, G. (2010). La formación y el desarrollo profesional docente. Colección Documentos Institucionales No 37. Bogotá: Universidad de la Salle. Disponible en: http: / / www.lasalle.edu.co/wps/wcm/connect/cd3bd6fe-48ac-41e2-9befbbb2e0212438/Librillo_37.pdf?MOD=AJPERES 
Mallimaci, F. y Giménez, V. (2009). Historia de vida y métodos biográficos. En Estrategias de investigación cualitativa. Vasilachis I. (Coord.). España: Gedisa. (pp. 175-212).

Martínez, M., Calvo, G., Martínez, A., Soler, C., y Prada, M. (2015). Pensar la formación de maestrxs hoy. Bogotá: Serie de investigación IDEP.

Meirieu, P. (2006). Carta a un joven profesor: por qué enseñar hoy. Barcelona: Grao.

Messina, G. (1999). Investigación en o investigación acerca de la formación docente: Un estado del arte en los noventa. Revista Iberoamericana de Educación, Número $19 . \quad$ Disponible en: http://www.rieoei.org/oeivirt/rie19a04.htm

Messina, G. (2008). Formación “docente”: del control al saber pedagógico. Revista Profesión Docente. 34 (78-86). Disponible en: http: //www.revistadocencia.cl/pdf/20100731221204.pdf

Nocetti, A. y Medina, J. (2017). Condiciones que desencadenan la reflexión docente en el futuro profesor durante sus prácticas de formación. $\begin{array}{lllll}\text { Espacios. } & \text { Vol. } & 39 & \text { (15). }\end{array}$ http://www.revistaespacios.com/a18v39n15/a18v39n15p02.pdf

Parra, C., Ecima, I., Gómez, M. y Almenárez, F. (2010). La formación de los profesores universitarios: una asignatura pendiente de la universidad colombiana. Revista Educación y educadores. Vol. 13, No. 3 pp. 421-452. Disponible en: 


\section{http://educacionyeducadores.unisabana.edu.co/index.php/eye/article/vi}

\section{$\underline{\mathrm{ew} / 1733 / 2275}$}

Porta, L. (2010). La investigación biográfico-narrativa en educación. Entrevista a Antonio Bolívar. Revista de educación. Número 1, pp. 201212. Universidad Nacional de Mar del Plata.

Porta, L. y Martínez, C. (2015). Pasiones: Roberto Kuri. Mar del Plata, Argentina: Editorial de la Universidad Nacional de Mar del Plata.

Porta, L. y Martínez, C. (2015). Pasiones: Cristina Piña. Mar del Plata, Argentina: Editorial de la Universidad Nacional de Mar del Plata.

Rico, A. (2011) La Formación Docente Inicial en cuatro décadas a partir de historias de vida de maestrxs colombianos. (Tesis de maestría). Facultad de Educación, Bogotá: Universidad de Salle.

Ricoeur, P. (2006). La vida: un relato en busca de narrador. Pastoriza, J. (trad.). Revista Ágora. Vol. 25, (2) 9-22. Disponible en https://minerva.usc.es/bitstream/10347/1316/1/Ricoeur.pdf

Russell, T., Fuentealba, R., e Hirmas, C. (2016). (comp.). Formador de formadores, descubriendo la propia voz a través del self-study. Santiago de Chile: OEI.

Saldarriaga, 0. (2003). Del oficio de ser maestrx. Bogotá: Magísterio.

Sandoval, C. (2000) El modelo de formación de maestrxs en Colombia. En Formación de formadores en educación básica y media. Bogotá: Convenio Andrés Bello. 
Sarasa, M. (2012). La narrativa biográfica como vehículo para explorar la trazas de la buena enseñanza. Revista de Educación. Número 4, pp. 167182.

Disponible

en

https://fh.mdp.edu.ar/revistas/index.php/r_educ/issue/view/8

Schön, D. (1998). El profesional reflexivo: cómo piensan los profesionales cuando actúan. Barcelona: Paidós.

Suarez, D. y Ochoa, L. (2005). La documentación narrativa de experiencias pedagógicas. Una estrategia para la formación de docentes. Disponible en http://www.bnm.me.gov.ar/giga1/documentos/EL004074.pdf

Taylor, S. y Bogdan, R. (2006) Introducción a los métodos cualitativos de investigación. Disponible en http://books.google.com.co/books

Terigi, F. (2013). VIII Foro Latinoamericano de Educación: saberes docentes: qué debe saber un docente y por qué. - 1a ed. Buenos Aires: Santillana.

Torres, R. (2001). La profesión docente en la era de la informática y la lucha contra la pobreza. Séptima reunión del Comité Regional Intergubernamental del Proyecto Principal de Educación en AL y el Caribe. UNESCO.

Vasilachis, I. -coord.- (2006). Estrategias de investigación cualitativa. Barcelona: Gedisa.

Vásquez, F. (2011). Educar con maestría. Bogotá: Universidad de la Salle. Vergara, M. (2017). La práctica cotidiana de los profesores. Un estudio desde el proceso de formación en el posgrado. México: Universidad de Guadalajara. 
Vezub, Lea F. (2007). La formación y el desarrollo profesional docente frente a los nuevos desafíos de la escolaridad. Profesorado. Revista de Currículum y Formación de Profesorado [en línea] 11, (pp. 1-23). [Fecha de consulta: 19 de abril de 2019] Disponible en: http: / / www.redalyc.org/articulo.oa?id=56711102 


\section{GUIONES PARA EL DESARROLLO DE LAS HISTORIA DE VIDA}

Preguntas de contexto

1. ¿Dónde vives, cómo describes este lugar?

2. ¿Qué hace único este lugar? Sus características

3. ¿Dónde trabajas? ¿Queda cerca de tu casa?

4. ¿Cómo es el colegio donde laboras? ¿Cómo son lxs estudiantes? ¿Qué enseñas? ¿Qué haces en clases? ¿Cuántos años llevas laborando en este colegio? Antes, ¿Dónde trabajabas?

5. ¿Cómo describes tu labor en este colegio? ¿te gusta lo que haces, eres feliz?

6. ¿Cómo son los vínculos que se han construido con la comunidad aledaña al colegio, cómo sientes que estos vínculos impactan tu práctica?

Primera conversación

7. ¿En qué es tu pregrado?

8. Antes de iniciar la formación de pregrado, hubo una formación pre-inicial ¿cursos relacionados con la docencia, talleres, la Normal? ¿cómo fue este proceso?

9. ¿Cómo se fue construyendo esa formación en el pregrado?

10. ¿Cómo es que se llegaste a formarte como docente? ¿Algunos motivos en especial? ¿hubo otros intereses antes de tomar la decisión de formarse para ser docente? Cuáles

11. ¿Cuántos años han pasado desde que te graduaste de licenciada?

Segunda conversación

12. ¿Cuáles experiencias en la práctica han contribuido para continuar con la formación como docente en ejercicio? ¿Qué te impulsó a iniciar una Maestría en Educación?

13. ¿Qué significa para ti recibir una formación estando en ejercicio como docente, en estos dos últimos años? ¿Cómo valoras la formación que recibiste en la Maestría? ¿has encontrado algo nuevo que no esperabas? ¿Ha cumplido tus expectativas? Describe ¿alguna práctica ha cambiado? Me puedes relatar cómo fue el primer semestre de la formación como magister, unos detalles, cómo la relación con lxs compañerxs, Ixs docentes de la Maestría, el contexto, la universidad, las razones para 
estar en ese lugar, retomando la formación en la universidad como magister ¿Cuáles vínculos se empiezan a generar con tu práctica estando en formación como magister?

14. ¿El pasaje por la Maestría en Educación dejó transformaciones en el ser docente? De qué tipo, cómo es.

15. ¿Para qué hacer una Maestría en Educación? ¿Qué sentido tiene para ti y para los que te rodean? Tu familia, colegas, tus estudiantes, otros.

16. ¿Cómo es la relación con Ixs compañeros en el colegio en el que trabajas? ¿Se ven diferencias entre Ixs que no hacen la Maestría y lxs que hacen? ¿hay recelos o situaciones de vínculo personal que se dificultan entre Ixs que hacen la Maestría y lxs que no? ¿se puede compartir en el colegio lo que aprendes en la Maestría? 


\section{HISTORIAS DE VIDA}

1- Adela Ortiz

2- Bertha Robles

3- Tita Manjarrez

4- Mateo Símil

5- Adolfo Calles

6- Lulo Corrales 


\section{Historia Adela Ortiz}

E: Bien, buenas noches. Estamos acá reunidos para iniciar con la historia de vida de la profesora Adela Ochoa. ¡Bienvenida!

Adela: Buenas noches, gracias.

E: Bueno entonces, la primera pregunta va a orientar todo este ejercicio es ¿dónde vives? y ¿cómo describes este lugar?

Adela: Bien, vivo en la ciudad del Valledupar, en el departamento del Cesar, realmente este lugar... es maravilloso, inicialmente porque desde el punto de vista geográfico estamos ubicados en un valle $y$ eso le hace tener características muy especiales, que lo diferencian lógicamente de cualquier otro lugar en el país. Valledupar es una ciudad encantadora porque uno en cualquier momento se sienta en dos ambientes: un ambiente citadino y un ambiente rural, cuando uno, de la ciudad pasa unos cinco minutos, ya se está en el rio Guatapurí, en el balneario Hurtado y esto la da un matiz natural o rural al municipio.

La gente, la cultura, el folclore es otro tinte significativo. Esto me llama la atención porque yo realmente no soy de Valledupar, soy de Sincelejo (Sucre). Soy sabanera dentro del contexto geográfico y el tema del río es escaso. Soy oriunda de Sincelejo, Sucre y desafortunadamente haya tenemos un problema muy difícil con el asunto del agua, entonces ver tantos manantiales y ver tanta agua aquí en Valledupar es encantador, definitivamente es encantador... (Silencio)

E: Culturalmente se distingue a Valledupar por su festival vallenato...

Adela: $\mathrm{Si}$, correcto.

E: Pero primero, antes de que me respondas, ¿hace cuánto vives aquí en Valledupar?

Adela: Vivo hace trece años, voy a cumplir trece años de vivir aquí, y he visto crecer la ciudad de manera impresionante, el tema de la ruralidad, el tema de la cultura, logra enamorarlo a uno definitivamente y hace que uno se quede aquí. Hay un adagio popular que dice que "el que se baña en el rio Guatapurí, 
queda absolutamente enamorado de estas tierras y se queda", y si no se queda vuelve. Este es el caso mío volvió, pero volví para quedarme.

Ya en cuanto al fenómeno cultural en sí, también hay una particularidad, es que a pesar de que se piensa que todos son de aquí de Valledupar, no. Valledupar hay mucha gente de los municipios y de los alrededores.

En un momento fue centro de acopio por el tema del algodón, que fue una de las fuentes de ingreso y de economía solidas del municipio y del departamento, y eso atrajo a muchísima gente, que tras esos sueños de bonanza y de la economía vinieron y se quedaron, y en este momento el tema de las minas de carbón también sigue siendo un atractivo para mucha gente en el país.

E: Bueno Adela ¿Dónde trabajas?

Adela: Llevo 8 años trabajando en la institución educativa Alfonso Araujo Cotes de aquí de Valledupar, que está ubicada en la zona sur, tiene un número aproximado de 2200 estudiantes y 76 profesores, que están distribuidos en la jornada mañana, tarde y sábado. Esta institución cuenta con dos sedes, una sede llamada El Contador y la sede principal que es donde yo me encuentro ubicada. Es una institución que nació de las buenas intenciones de la comunidad y de brindarle a los hijos de esa comunidad un lugar donde estudiar, entonces dentro del pininos de la institución aparecen los conductores como los primeros padres de familia en la institución, y ellos fueron organizando el tema ya de la escuela como tal.

E: ¿Eso hace cuánto fue? ¿Más o menos?

Adela: Ya... con certeza no tengo la fecha, pero sí fue hace más de 45 años. Ellos preocupados por el tema de la educación de sus hijos consiguieron apoyo del gobierno municipal de ese momento y le fueron donando unos terrenos, y con ello se empieza a organizar todo el tema de la institución y de la forma como se encuentra estructurada hasta este momento. La institución brinda la educación en todos los niveles, el preescolar, básica primaria, en básica secundaria, y también tiene la educación por ciclo los sábados, como una manera, también de ayudar a la comunidad, y a aquellos adultos que no tienen la posibilidad de estudiar en los horarios regulares. 
He visto también cómo ha venido surgiendo la institución, desde que estoy allí han pasado tres rectores en estos años y cada uno ha venido con diferentes intenciones, uno, de que la institución crezca en infraestructura; y, los dos últimos rectores que hemos tenido, sobre todo este último, muy preocupado por la organización y la orientación de la institución de la parte académica, la construcción de un nuevo horizonte institucional, eso ha permitido que poco a poco la institución avance en el ámbito local como una institución de prestigio. Pese a que la comunidad que nosotros atendemos son chicos con mucha vulnerabilidad, son hijos de padres de familia, inicialmente disgregados, padres de familia que se dedican a la economía informal y a la venta de la gasolina, hasta el año pasado gracias a los temas del conflicto en Venezuela, y en general a la venta ambulante.

Esto lógicamente tiene un impacto en nuestros estudiantes desde el punto de vista social, quienes se sienten muchas veces desamparados y vulnerados con respecto a otros temas y situaciones de violación, abuso sexual, hay temas de drogadicción, y poco a poco a través de los proyectos institucionales y de la manera de cómo se ha venido organizando este horizonte institucional se le han venido tratando de dar soluciones a esos problemas, sin embargo, estamos allí, en esta situación y tratando de solventarla.

E: Adela, bueno pasando igual al mismo contexto y a la misma situación ¿Dónde trabajabas antes? Llevas 8 años trabajando en la institución... ante...cuéntame un poco tu trayectoria de labor.

Adela: De los 13 años que he vivido aquí en Valledupar, los primeros cinco años los trabaje en el sector privado, en los últimos años, de esos cinco alternaba sector privado y sector oficial en la misma institución donde me encuentro, siempre he estado en esta institución y trabajaba en un colegio privado de estrato socio económico 3 y 4 , y las condiciones eran totalmente diferentes, de formación soy profesora normalista, soy licenciada, recientemente magíster en didáctica, y toda esta formación me ha permitido mirar poco a poco y transformar mí quehacer pedagógico y descubrir nuevas situaciones en los 
estudiantes, me han abierto los ojos, es un nuevo panorama, que realmente veo.

Al comienzo, fue muy difícil el tema del sector privado a lo público, a lo oficial, yo llegué con una perspectiva, muy diferente sobre todo por el nivel socio-económico en el que estaba trabajando, a aterrizar a una institución con niveles socio-económicos estrato $1 . .$. yo dije “ipor Dios, aquí qué pasa, ¿esto qué es?!” (Risas) yo veía que eran totalmente dos esferas distintas y ahora cómo hago, cómo arrastro toda esa disciplina, cómo la manejo yo, en un estrato como este, las mismas estrategias que asumía allá, no me daban los mismos resultados acá... inclusive, el discurso pedagógico, el discurso didáctico, el discurso disciplinario me tocó empezar a transformarlo.

Los ejemplos que daba para las clases totalmente. Yo cómo trabajo el contexto, cómo ellos me van a entender, si yo estoy hablando cosas de un mundo que ellos desconocen totalmente. Entonces, yo ya venía habituada a eso, porque yo me gradué en 1993 y empecé a trabajar inmediatamente en el 94, en Sincelejo. Muy joven. $Y$ he trabajado en los niveles de preescolar.

E: ¿Pero en Sincelejo empiezas a trabajar en privado?

Adela: $\mathrm{Si}$, yo todo el tiempo había trabajado en privado, nunca ni por una licencia, ni por una casualidad, ni por una provisionalidad nunca había estado en un colegio público, es más, el único colegio oficial que yo conocía fue mi normal, de donde yo egresé, pero realmente yo no conocía el tema de la oficialidad, absolutamente nada. Entonces, Había venido haciendo esos pininos, trabajé como docente en preescolar y en primaria, pero solo en colegios privados, con esa perspectiva de la parte administrativa y de cómo funcionan las cosas, con unos seguimientos, con unas normas muy distintas. Inclusive, hasta el tema de las relaciones personales y profesionales dentro de los dos ámbitos son totalmente distintos.

Entonces, fue una experiencia al principio muy dolorosa, dura. Pero también, gracias a la lectura y las conversaciones que surgen entre compañeros y entre padres docentes, uno se va dando cuenta, y esa reflexión permanente que uno 
va haciendo de su quehacer, le permite ir transformando poco a poco esa realidad.

Pero no me quedé ahí, dije: "este es un reto, voy a cumplirlo y no puedo ser inferior a las necesidades, porque aquí toca echar hacia adelante", entonces a eso me comprometí.

Y... de pronto a veces el estudiante tiene una concepción. Yo cuando llegué al sector oficial llegué de remate, en la jornada de la tarde. Es una jornada muy dura. Con jóvenes extra-edad. Con jóvenes que, a nivel institucional, tenían el tema de las drogas, el tema de la agresividad, en esa jornada se vivía aún más, y el sector donde está ubicada la institución, sus barrios aledaños son perfectamente cultivo de todo ese tipo de situaciones; entonces, a cualquier momento a la institución se entraba un grupo de pandillas, se entraba el amigo de lo ajeno, que quería saber si algún docente por ahí estaba "mal ubicado"... y siempre estábamos con ese temor.

E: ¿En la misma institución? ¿Dentro?

Adela: Dentro. Entonces a cualquier momento uno estaba dando una clase y de pronto se colocaba en la puerta alguien con un palo o un machete a decir: "yo te espero a la salida".

Entonces, era muy duro, yo decía y me preguntaba ¿dios, en donde estoy metida? $Y$ con esos temores, pero vuelvo y repito, todo es un proceso y una experiencia muy significativa, y gracias a todo esto que se ha vivido en la institución se ha venido transformando. Ya no tenemos jornada en la tarde entre otras cosas.

E: ¿Ya es jornada única?

Adela: Para lo grados 10 y 11 , es jornada única. Pero este nuevo rector que tenemos, y por eso digo ha habido una transformación, él decidió ubicar todo el bachillerato en la mañana y por la tarde dejó a los niños de primaria. Entonces, eso ¿en que ayuda a la institución?

E: ¿Pero no es más riesgoso para los niños?

Adela: El tema es el siguiente: los chicos de bachillerato salían faltando 10 para las 7:00 pm, en un sector como el que estamos, es peligroso, los buses que 
tienen los niños para el transporte ya a esa hora no querían entrar al colegio. Nos cuidamos de las pandillas y todo este tipo de personas que entraban a la institución. Los chicos de primaria salen más temprano, salen a las 5:00 pm o 5:30 pm, no recuerdo, no tengo la exactitud.

Esa es una hora, todavía razonable. Son niños y el padre de familia se ve obligado a ir por él. En la tarde había niños de primaria y niños de bachillerato, entonces, eso también generaba una gran problemática porque los niños grandes atentaban contra los niños pequeños, entonces, cómo evitar esa situación de agresividad, de robar la merienda, de abusar de los niños más pequeños de alguna manera, entonces el rector dijo: "vamos a quitarnos este dolor de cabeza" y aquí dice la solución y realmente ha funcionado.

El tema que realmente le colocó una extra-seguridad a la institución son las rejas. Desde que uno entra a cualquier lado hay reja acá, reja allá. Y uno se pregunta, ¿Por qué tanta seguridad? Precisamente buscando aislar a la comunidad y al mismo padre de familia de los sectores en que nosotros queremos que nuestros muchachos estén concentrados y no tengan ningún tipo de interferencia, entonces, esto es una logística y una transformación académica que el hombre (rector), está proponiendo y los docentes nos sentimos satisfechos y seguros con ese tema.

E: ¿Cómo es tu labor en la institución? ¿Cómo la describes?

Adela: Sin hacer halagos y sin echarme flores (risas)

E: ¡échate flores!

Adela: Es muy importante, es significativa.

E: ¿En qué sentido?

Adela: Hago parte de un comité en la institución que se llama comité de liderazgo. Somos la mano derecha del rector en toma de decisiones. No significa que él no tenga en cuenta a los demás compañeros. Pero el equipo que él llama inicialmente para concertar sobre algunas decisiones somos nosotros. Somos los replicadores de información, estamos en el tema de un proyecto que va de la mano con Terpel que se llama "escuelas que aprenden"; es un proyecto muy bonito e interesante, que ellos han formulado, en el cual buscan 
que las instituciones públicas, entre ellos nosotros, hay unas 8 o 10 instituciones participantes en el municipio, crezcan como institución, y mejoren los procesos a nivel de estas. Entonces nosotros somos participantes activos de esos talleres, somos replicadores de esas estrategias, según la situación soy secretaria del consejo directivo ya hace varios años. Entonces, he sido activa de estos 8 años indirectamente el resto del tiempo entonces, le genero mucha confianza al rector, y pienso que esa ha sido la clave y un elemento significativo para que tenga un argumento de peso.

Se me confían muchas tareas, entonces, no lo miro como carga, sino que reconozco que debe haber algo interesante para continuar.

E: ¿Pero eso que tú haces que sea más una labor educativa del contexto, ¿cómo transforma y afecta tu labor pedagógica?

A: No, yo pienso que no la afecta para nada, al contrario.

E: Digo que la afecta en términos positivos. ¿Cómo involucra esa labor que tú tienes, educativa con tu labor pedagógica?

(Silencio)

A: Toda vez que nosotros por ejemplo acudimos a un taller o se nos da la responsabilidad; en este diálogo abierto que tenemos puedo ser muy sincera en decir: lo que pasa es que hay compañeros que los envían a estos talleres o a capacitaciones y formaciones y no aprovechan al 100\% esta situación. Sencillamente, utilizan ese tiempo y no asisten. Llegan una hora, media horita, firmaron asistencia y se fueron. Entonces, en esos seguimientos que hacen se detectan quiénes son esos profes que no aprovechan el tiempo y que no son multiplicadores de esa información y que no hacen un uso correcto a favor de la institución para ellos. Entonces, esas veces que siempre me envían y que tengo esas posibilidades, yo aprendo; y cuando veo que tengo esas posibilidades, pero no me invitan, porque estoy en otras cosas, yo voy y le digo al rector, "iprofe mándeme a mi”! y yo respondo por la parte académica y por lo que me toque. No tengo reparo si, por ejemplo, me toca en jornada contraria, el tiempo extra porque pienso que eso es beneficioso para mi 
formación pedagógica y que eso va a redundar en cómo mis estudiantes pueden hacer provecho de esto.

Entonces, yo le digo: -yo quiero que me mande a mí, porque yo quiero aprender. Ahorita estamos trabajando en el grupo "escuelas que aprenden" sobre currículo y ha sido fabuloso, porque toda la experiencia y todo ese conocimiento con lo que me alimenté en la maestría, lo estoy confrontando con todos los procesos que estoy viviendo y con todo lo que se me está presentando, lo estoy poniendo en práctica en la institución y les digo a los profesores aquí tenemos estas tareas, esto sería interesante mirar cómo lo solucionamos, cómo lo adaptamos. En ese reorientar el horizonte institucional se han adaptado muchas de estas ideas, el grupo de compañeras con el que terminamos esta maestría... como dice él, "estamos en deuda y debemos pagar", entonces pagamos con conocimiento. Pagamos con eso aportes significativos que le damos a todos los procesos que hay allá.

E: Claro, volviendo un poquito a atrás, Adela, me dices que tú eres normalista. ¿Cómo es eso de la normal?

A: Bueno, cuando yo estudié, que me gradué en el 93, como ya les decía.

E: ¿Te graduaste de normalista?

A: Si, de normalista. No había esa formación continuada, de esos dos años, creo que, en el 94, empieza el tema de dos años más, para los docentes bachilleres pedagógicos. Porque el título de bachiller pedagógico normalista.

E: ¿Tu título es así?

A: Si, mi título es así.

E: ¿En qué Normal?

A: En la Normal Sincelejo. En ese momento era Normal Superior para señoritas de Sincelejo, un título bastante subjetivo (risas).

La educación, era muy académica y pedagógica, pero también muy humana y a uno le enseñaban a hacer de todo un poco. Yo aprendí a tejer, bordar, hacer bolsitos en cuerina, cocinar, pegar botones, porque era una educación también pensada en todos los aspectos de la vida, en este caso de la mujer, porque era femenino el colegio. Pero también había una exigencia desde el punto de vista 
pedagógico y desde las prácticas, y eso también tenía mucho incentivo. A las mejores estudiantes, siempre había alguien que las recomendaba en los mejores colegios que podían asistir en la ciudad, en ese momento. Eso le daba realce, prestigio al colegio y los padres y las madres de familia decían: yo quiero que mi hija este allá, porque le están asegurando un futuro laboral. Pero, no pensaban en todo lo que eso significaba.

Por ejemplo, yo que me gradué en el 93 y en el 94 me consiguen un trabajo en un colegio donde eran doble jornada, privado, con doble jornada, yo entraba a las 8 de la mañana y me desocupaba a las 11 del día, luego entraba a las 2 pm y me desocupaba a las $4 \mathrm{pm}$ de la tarde con los mismos muchachitos, y de remate me dan un transición con aproximadamente 48 estudiantes, y me dicen que han tenido problemas y no hemos conseguido quien te haga el acompañamiento, un soporte para mí y mientras tanto me tocó trabajar con todos ellos. Yo decía ¡48 cuadernos! Llenar de planas, revisar.

E: ¿Qué edad tenías en el 94?

Adela: 18 años. Yo decía... yo lloraba cuando veía esa "cuadernera", le decía a mi mamá: "por qué no te hice caso, me hubiera ido mejor para la universidad" en cierto modo fue traumático y al otro año dije no más...me voy, yo hice tres semestres de ingeniería industrial. Le dije a mi mamá, te lo suplico, envíame a la universidad, yo voy a estudiar otra cosa que no tenga que ver con esto.

$\mathrm{E}$ : O sea, ¿tú inicialmente no querías saber nada de docencia?

Adela: No, yo soy la mayor de tres hermanas y yo estudié mi primaria. Mi hermana la segunda y yo, nos llevamos un año de diferencia, pero mi mamá nos crio como si fuéramos gemelas, entonces, estudiamos toda la primaria junta y cuando empezamos el bachillerato, ingresamos juntas. Pero ingresamos a un colegio privado y con orientación a la parte comercial, con énfasis en la parte comercial. Pero a mí desde la primaria siempre me había gustado el tema de la docencia y a mí me colocaban como monitora de grupo, explicaba lo que no entendían y me colocaban en otros cursos como ejemplo. Yo me sentía bien, y decía, esto me gusta, esto es lo mío. (Risas) Entonces, yo entré a bachillerato y le dije a mi mamá que me colocara en la Normal y ella me dijo que no. En ese 
momento mis padres tenían una situación económica muy buena, entonces, lógicamente el bachillerato lo debía hacer en colegio privado, porque eso era lo mejor que existía en Sincelejo en ese momento, entonces, mis padres no querían. Mi mamá me decía que yo no tenía necesidad y mejor que le diera ese cupo a alguien que necesite en realidad estar allá.

Entonces, en sexto me fue muy bien, saqué las mejores calificaciones, pero le dije a mi mamá que me llevara a la Normal o si no, no seguiría estudiando. Presioné tanto a mi mamá que me escribió allá y con tan buena suerte que quedé entre los primeros puestos y no hice ni entrevista para entrar al colegio. Mi mamá dijo que sí, que efectivamente esto era lo mío y permitió que yo estudiara allí. Cuando Salí, le dije a mi mamá, que no iba a entrar a la universidad y que iba a trabajar y la señora Olimpia, recuerdo mucho ese nombre, ella era mi tutora de práctica docente en la Normal. Le dije, mami, la seño Olimpia ya me recomendó, yo me voy a trabajar. ¿Cómo así? Si su hermana está pensada que se van a ir las dos... Yo le dije: no, yo quiero ser profesora, entonces ella me dejó quedar.

Me quedé, y me tocó esa experiencia. Yo estaba traumada, mi mamá me decía, usted se metió en esto, usted responde... entonces, pensé en renunciar en mitad de año, a pesar de todo ello, yo me sacrificaba mucho, yo me quedaba allí, hasta que no revisara todos los cuadernos y hasta que no dejara mi material organizado. A mitad de año, yo tenía un tablero que daba la vuelta, entonces para el proceso de lectoescritura, yo me colocaba en una silla, de tal manera que yo pudiera mirar las dos caras del tablero y dividía el tablero en dos partes, de un lado y en dos partes del otro, y colocaba a 4 muchachitos, dos adelante y dos en el respaldo, y desde ahí les hacia el dictado. Porque tenían que salir leyendo y escribiendo los muchachitos, entonces, ahí les hacia el dictado y todos mis estudiantes iban por un fonema distinto, unos iban por la $\mathrm{p}$, otros por la $\mathrm{l}$, etc. $\mathrm{Y}$ tuve en ese momento esa capacidad de hacer ese tipo de trabajo y de decirle e individualizar la educación en ese momento, yo le dictaba a algunos y después me levantaba de la silla y les calificaba en el tablero, entonces decía: bueno, tú ya puedes pasar a otra letra, luego, 
rápidamente les revisaba la tarea y los mandaba a que se sentaran. Cuando llegó mitad de año, yo ya tenía estudiantes que ya habían terminado prácticamente las consonantes, entonces, los padres de familia no aceptaron que yo me fuera. Ellos dijeron: ¡No aceptamos que la profesora se vaya! Dijeron: "los muchachitos van muy bien, ella no se va" entonces, me toco terminar el año escolar, terminé el año y para satisfacción mía, con muchas felicitaciones, con detalles materiales de los padres de familia, con carticas hechas por mis estudiantes, por aquellos que pasaron las combinaciones y leían absolutamente bien. Entonces, traté de llevar todo el grupo y al final, traté de emparejarlo y nivelarlo, pero yo lo hice por un reto personal. Cuando finalizó, yo dije "ya yo cumplí" "ya nadie me obliga y nadie me amarra aquí a esto" "yo me voy". Entonces mi mamá me vio toda esa frustración y todo ese llanto y me dijo: en realidad te vas a volver loca y me dejó ir.

Y me fui, empecé a estudiar, pero en esos vaivenes de la vida a ellos (mamá y papá) les fue muy mal económicamente en los últimos negocios que hicieron, quebraron. En ese momento, ya éramos tres en la universidad y mi mamá dijo: "adivinen quien trabaja..." "La que ya empezó a trabajar y ya sabe qué es trabajar... y si no pues vénganse..." en ese momento estábamos en Barranquilla.

E: ¿En qué universidad?

Adela: En la Autónoma. Yo estudié en la Autónoma de Barranquilla. Mi mamá me dijo: "usted ya sabe trabajar porque usted ya ha trabajado, entonces, tiene dos posibilidades, estudia y trabaja, o se viene y no sigue". Entonces, yo le dije a mi mamá: “no... ya me vine, ya yo estoy aquí... yo no voy a ser la burla de la gente del barrio, no voy a ser la burla de nadie, yo sé lo que es trabajar, voy a trabajar, pero me quedo aquí". Entonces, me encontré con unas compañeras de la Normal, que entre otras cosas no estudiaban licenciatura, sino química y farmacia.

E: ¿Tú?

Adela: Mi compañera. Entonces, ella me dijo: "Adela, tú tienes posibilidades de estudiar derecho o ciencias sociales, tú eres muy buena para eso". De 
pronto en mi bachillerato, yo tenía muy buenos recuerdos de que yo era muy buena en esas materias, entonces, me dijo que me presentara, que estaba segura de que yo pasaría, y más con ese puntaje, sí ¡Tú pasas! Cualquier día, salí de la universidad y me inscribí. Ese mismo día, había un paro terrible en la universidad del Atlántico, porque soy egresada de allí. Me inscribí, pensé que de todas maneras no perdería nada, ya llevaba tres semestres sin ir a la universidad porque no tenía los medios económicos, entonces, no perdía nada. Me inscribí, ya trabajaba, ya había conseguido un trabajito. Me habían pasado para el segundo semestre de la mañana, porque yo empecé en la Autónoma de noche. Entonces, había conseguido un trabajito en un colegio privado de barrio, de esas "escuelas de garaje". Dije, bueno, me voy a inscribir allá. Cuando aparecen las listas, soy como la tercera en las listas de ciencias sociales y dije: ¡definitivamente "el que nació para limonero del cielo le caen limones y el caldero"! así que dije, me tocó, ya no hay nada que hacer.

E: ¿Pero era licenciatura en ciencias sociales?

Adela: Sí. Yo me acuerdo de que llegaba llorando a la universidad, decía el misma Karma, la misma cosa. Pero igual pensaba que no me iba a ir para allá, yo estudio cualquier cosa. Así fuera una licenciatura. Ya yo lo veía como lo peor, pero tenía que estudiar.

Pero me pasó también, algo significativo y muy bonito, yo llegué como al segundo o tercer semestre y conocí a un profesor de antropología, de avanzada edad y ya cansado con el tema de la educación. Él me decía: "Ortiz, vea, yo tengo una clasecita en la noche, este es el tema, prepárelo". Ya él sabía que yo era normalista y me dijo: "eso que usted sabe y todo lo que ha aprendido póngalo en práctica, estúdiese el tema". Lo miraba y con antelación, lógicamente me decía "estúdiese el tema" y me muestra qué es lo que va a decir. Yo hacía un guion de la clase, y me decía, bueno, hágase un acetato o una cartelera y esto que tiene aquí, está muy bien hágalo. En la primera noche llegó a clase y me vio dictar la clase.

E: ¿En la Autónoma? 
Adela: No. En la del Atlántico, ya haciendo la licenciatura. Me vio dictar la clase, en la segunda oportunidad que me dio, se sentó como 5 minutos y luego se salió y se fue hacia la baranda del edificio a fumarse un cigarrillo y me dejó sola dando la clase. Y como a la tercera oportunidad, se apareció con un profesor de geografía. Cuando los veo parados a los dos viéndome dictar la clase, a mí las piernas me temblaban y le daba clase a un primer semestre, entonces, qué me gustó del cuento, que me decía, tome para la gaseosa y para los chicles, (Risas) en esa época me daba como 12 o 14 mil pesos, para mí eso era plata y una ayuda muy grande para el tema de transporte, ya después a él lo pensionaron como al siguiente semestre y hasta allí me llegó el negocio (Risas)

Pero me empecé a enamorar otra vez del asunto y me di cuenta de que me gusta ser profe, pero no de chiquitines sino de personitas más grandes. (Risas) entonces, yo le decía a la profe: ¡no me lleves a prescolar! Los dos primeros años que estuve trabajando allá estuve con primero y segundo, ya después, todo el resto de la carrera me los costeé, uno con las exoneraciones que me ganaba por los primeros y segundos puestos en la universidad, solo pagaba $\$ 35.000$ por semestre y con la exoneración solo necesitaba $\$ 10.000$ pesos al día, luego ya me daban cuarto y quinto, y toda la carrera la terminé trabajando con tercero, cuarto y quinto en mi labor en ejercicio.

Tengo como 5 años, por esas casualidades de la vida de estar trabajando con la media, entonces estoy ahí, en ese rango siempre, de los más grandecitos; en ese proyecto del colegio de los sábados, estoy en ese programa hace como cinco años trabajando con adultos, entonces, me he movido en ese campo y descubrí que ese es el campo que me gusta.

E: ¿De media y adultos?

Adela: Sí. Los más grandecitos. Ahora estoy con el tema de decirle al rector, iprofe, por favor...! Porque hace poco me dijo que me necesitaba en grados de octavo a noveno. Pero yo le dije "es que yo soy profesora de la media" pero quiero la posibilidad de estar en cursos inferiores. Él me dijo -Bueno le voy a proponer un reto, bájeme de la media... porque me estoy quejando de un tema 
en la educación, que es bastante complicado; y es que siempre se les echa la culpa a los profesores que vienen de atrás. "la culpa es del de primaria" "la culpa es de los docentes sexto y séptimo" entonces cuando estamos en decimo y once pensamos, ¿iQué hicieron estos docentes abajo!? Entonces, yo quiero saber realmente qué pasa allá. Y me llama poderosamente la atención el tema de la investigación en la educación, entonces, yo quiero empezar a hacer investigación en ese lugar, quiero saber, cuáles son esas competencias en que los muchachos tienen más habilidades y entonces, pensando, cómo empiezo a descubrir esas competencias. Cómo lo hago, tengo que empaparme bien de ese tema. De cómo se trabaja allá.

E: Ahí ya se mira un poco, el proceso que hiciste en la maestría, de pronto, con que te esté inquietando investigar en cierto modo qué es lo que pasa allá.

Adela: Correcto.

E: Ya te está inquietando. Ya entrando a eso, ya de pronto al grueso de este relato. Empecemos preguntando ¿Qué te impulsó a hacer una maestría? A parte de que sabemos que es un programa del gobierno y de becas por la excelencia, ¿tu si querías hacer una maestría?

Adela: Estaba tan desesperada, pero tan desesperada. Imagínese... le voy a contar "rapidito" la historia en ese tema. Yo dije: - yo me estoy quemando aquí. Cuando yo estaba en colegio, yo decía, uno aquí se quema porque uno aquí qué hace. 0 sea, solo se cumplen normas, es una rutina, una llenadora de contratos y formatos. Es llenar los formatos más que hacer el ejercicio del saber de uno. Entonces, yo decía, que esto me tenía cansada y sentía que no estaba haciendo nada productivo. No sabía que hacer o que más inventarme. Empecé a buscar en internet, estrategias, metodologías, qué hacer con estudiantes de este comportamiento y con esta condición y empecé a ser autodidacta en algunas cosas, muy pocas, por cierto, pero para mí eso era bueno y novedoso.

Luego, empecé en el colegio oficial, mientras que me adapté y seguí el ritmo. Me dije ya estoy ubicada, ya me meto en el cuento y ya sé cómo voy a tratar a mis estudiantes, ya utilizo el contexto de otra manera, ya puedo hacer esto y lo 
otro. Y ahora ¿Qué hago? Le dije un día a mí esposo: ya me aburrí, quiero estudiar y esto no es suficiente, porque a veces están hablando de educación y no entiendo de donde lo sacaron, todavía me falta estudiar eso y quiero investigar más sobre esto. Definitivamente, toca seguir estudiando, entonces, generalmente, había un tema de discusión de pareja, por el tema de estudiar, porque mi esposo es licenciado en ciencias sociales y se graduó junto conmigo de la misma promoción y nosotros nos miramos y decimos, nosotros estamos en la misma situación, no hemos avanzado, aquí nos estancamos y de remate mi esposo no está en el casco urbano, él es de una zona bastante rural. Los estudiantes que él tiene son más de la zona rural que de la zona urbana, conversamos mucho sobre esta temática y él me dijo, bueno vamos a hacer algo. Como tú tienes más afán que yo, yo te voy a impulsar para que lo hagas, empezamos a averiguar el tema de las maestrías en Venezuela, que era lo que más cómodo salía y a lo que teníamos acceso desde el punto de vista económico, yo le dije: -si nos vamos, nos vamos los dos- nos vamos a estudiar juntos nuevamente. Entonces, repetir esa experiencia de universidad, pero ahora en la maestría. Fuimos nos inscribimos, nos presentamos y cuando yo regreso de hacer la entrevista en Venezuela, voy cruzando la frontera para la entrevista. Me aparece un mensaje de una compañera que dice "Adela apareces habilitada para las maestrías que está ofreciendo el programa de Excelencia docente. ¡Te felicito! Me dice “¡Y esto de dónde”!

Enseguida viene el tema, que la maestría no es en Valledupar, sino que hay que trasladarse hasta Cartagena, empezamos nosotros en seguida a sacar cuentas, pensamos que lo que íbamos a pagar en pasajes hasta Cartagena en ir y regresar y la estadía, pagamos lo mismo en Venezuela y nos queda dinero. Entonces, cruzamos la frontera y nos presentamos allá. Fuimos a la entrevista. Cuando estábamos en plena entrevista se dieron cuenta que a mí me hacía falta un documento y suspendieron la entrevista, entonces no me dejaron terminarla. Mi esposo me dijo, sencillamente, si tú no puedes porque te falta ese documento, yo no me presento. 
Aquí lo hacemos los dos. Vengo a Colombia y me dice el rector, preséntate y hay plazo hasta tal fecha. Yo le dije: profe los documentos que yo había sacado están en Venezuela y a mí me toca volver a sacar estos documentos y yo no sé si alcance. Yo voy a dejar eso así, y voy a hacer la maestría con mi esposo, voy a pasear, voy a compartir con mi cónyuge. Él me dice, yo te voy a proponer algo, lleva los papeles así y no cierres esa puerta. Espera a ver qué pasa. Tienes un desespero, cálmate, las cosas te van a salir.

Entonces, inmediatamente levanté el teléfono y comencé a llamarlo, me puse en movimiento y allí en Barranquilla le dije a mi familia, le pedí las actas de grado y lo que no tenía. Todo el mundo se movilizo y llevé mis papeles a la Universidad Santo Tomas y me llaman de Venezuela, me mandan un mensaje de texto y me escriben al correo que las clases empiezan justo el mismo día que empiezan las clases aquí en Valledupar. Yo dije: -Dios mío y ¿ahora? ¿Y si lo de Valledupar no se me da y pierdo todo el proceso allá? ¿Y qué pasa con él (esposo)? ¿Lo voy a dejar botado?

Le dije: amor, que pena contigo, pero yo me voy para la clase aquí en Valledupar, porque me voy para la clase, me queda mucho más fácil acá.

Y me "encarreté" desde el primer día. Porque ya en la entrevista sentí, que había mucha seriedad en el proceso y que estaba frente a gente que realmente conocen el tema de educación, sentí que la oferta que tenía era muy poderosa y con una capacidad de transformar mi quehacer que era la idea que yo tenía en ese momento y que sigo pretendiendo. Entonces, yo llegué y le dije: definitivamente lo de Venezuela no se pudo, ni se va a poder porque me gusto esto, imagínate que dijeron esto, dijeron aquello... No, no. Me caso con eso y con esa me quedo.

Me enamoré desde el primer día en la maestría y ver a profesores como María Ester, a tutores como ustedes, de ver al profesor Cogollo, dije esto es importantísimo. De todas las cosas que aprendía, yo tomaba nota del grupo mío. Yo escribía todo, punto a punto, porque no me quería perder ningún detalle y cuando llegaba a mi casa volvía a retomar las notas, ampliaba lo que decían, buscaba los autores que se habían trabajado y decía: - esto me interesa 
para llevarlo al 1001 que es donde tengo dificultad para esta situación. Ya sé qué es lo que está pasando en once. Ya sé cómo trabajar esto, asunto resuelto. E: Fíjate que ahí me llevas a hacer otra pregunta que quisiera que ampliaras un poco más. ¿La formación que recibiste como magíster efectivamente transformó tu práctica y más que esa formación la recibiste siendo docente en ejercicio? Transformó práctica ¿Cómo fue eso?

Adela: Sí. Indudablemente.

E: Desde el primer día prácticamente.

Adela: Sí. Desde el primer día, porque toda la fundamentación teórica y la manera de cómo se conceptualizaban las cosas, no solamente quedaban en esa teoría, sino que había una clara explicación de la relación con lo que se hacía en el aula. Entonces, la posibilidad que yo tenía de traer al aula, a mi propio contexto y esa posibilidad de yo poder reproducir esas experiencias y ver no solamente que yo las reproducía, sino que había un impacto positivo en los estudiantes y que ellos... se podían transformar cosas y ellos mismos se transformaban en ese ejercicio. Yo dije: -claro, esto es lo que yo he buscado siempre, entonces veía y sigo viendo algunas normas y reglas que son fundamentales y que son columna vertebral en el proceso didáctico, metodológico y en todo el quehacer docente, entonces, por eso en estas experiencias que tengo con los grupos "escuelas que aprenden" me enriquezco y también tengo la posibilidad de lo que aprendí en la maestría. Entonces, ya me siento al lado del compañero de PTA, que tiene un doctorado en educación y digo: "no, no... yo no estoy lejos de lo que él conoce". Lógicamente, hay unas distancias conceptuales porque yo, por ejemplo: de esas didácticas que nos ayudaron a enriquecer, el grupo de Maire, que trabajó esa parte cultural, el vallenato y el folclor, la música vallenata, yo había vivido de cerca esa experiencia con los profesores de PTA y dicen: lo novedoso, el "boom", la enseñanza a través de la música. Yo decía: a mí me preocupa y me llama la atención el cómo, entonces, explíquenos cómo lo desarrolló, en qué consiste, qué impacto tuvo eso, hubo transformación, los estudiantes que aprendieron, 
qué habilidades desarrollaron, qué competencias, para qué... y empieza la disertación. Nosotros podemos apoyar.

Hay que mirar también los niveles en lo que se enseña y la complejidad con la que se enseña, entonces, plateado así, yo no veo esos niveles de complejidad a los que se quiere llegar y finalmente, no es escuchar una canción por escucharla, sino estudiarla desde lengua castellana que es lo que estamos hablando, y decir cuántas rimas, cuantos versos, etc. Si yo veo que esto se hace interdisciplinario o no hay una correlación entre esto entonces, somos 5 en la maestría del colegio y todo el mundo comenzó a hacer sus aportes, al contrario, pienso que hicimos cosas interesantes y ahorita mismo tenemos a todos los compañeros y ahí es donde el rector sale con la expresión: "me deben pagar, él quiere que nosotros sigamos impactando en la institución, como lo hemos venido haciendo y que eso no solamente sea visible en el bachillerato sino también en la primaria".

Entonces, estamos tratando de abrir unos espacios para que tengamos esa posibilidad de llevarle a los compañeros de primaria esta experiencia significativa. Hay un proyecto que estamos organizando en la institución que tiene que ver precisamente con las experiencias didácticas a nivel de todos los cursos y eso lo estamos amarrando para organizar un perfil de estudiantes por nivel, un perfil de competencias por nivel y categorizar, hemos hecho una matriz para poder categorizar las capacidades de las competencias por estos mismos niveles que pretendemos alcanzar. Es un proyecto que tenemos allí y lo queremos amarrar con esas experiencias didácticas de los compañeros y de las mismas experiencias que nosotras hemos vivido. Él (rector) dice: ¡Síganme pagando, me encanta esto... síganme pagando...! (risas)

Ahorita tiene es el tema ¿Cuándo empezamos el doctorado? Por ahí hay algo en el sonajero, pero no nos convence, entonces, nos hemos quedado así, un poco quietas.

E: Adela, un poco quisiera escucharte de cómo fue esa relación inicial con tus compañeros de maestría, con los profesores, incluso una relación muy cercana con la misma universidad, ¿cómo fue eso? 
Adela: Bueno, yo de la Santo Tomas no tenía ni idea, nunca había conocido sus instalaciones, planta física, eso también fue interesante, porque sentirse uno, con personas que saben lo que están haciendo, que saben para donde van, que tienen esa capacidad de inyectarle al auditorio esa misma energía y que tenga claro esas mismas metas. $Y$ sumado a eso, se encuentra uno con un recurso humano (el de la propia institución) que es amigable, que es cercano, que es certero de la manera en la que se dirige a uno y las condiciones físicas y locativas de la institución, que son de mucha comodidad. Uno dice, aquí se conjuga todos los elementos. ¿qué más pides? Por eso yo llegué a mi casa y le dije a mi esposo, definitivamente vengo enamorada. Se conjuga todo lo que uno espera y uno dice no es fácil pensar en un horario, la carga del viernes y todo el sábado, pero cuando uno ve semejante confort, uno dice... más bien sigamos. Y recuerdo esa anécdota, que tuvimos de la primera clase, que se fue la luz. Y de pronto, por esa situación la clase no se detuvo.

Todo el mundo abrió las ventanas, buscaron la manera de que hubiera luz, todo el mundo prendió su celular y miraba su material y seguía leyendo como si nada. Y la luz tardó como media hora en llegar, y nadie se fue, todo el mundo estaba ahí pegado, como decimos aquí en la costa, "con hambre" y desesperados de que los estén alimentando más y más. Las discusiones eran acaloradas, pero eran muy respetuosas y académicas. Uno se podía tardar todo el tiempo en esa discusión. Entonces, el recurso humano es muy valioso, tanto el que la universidad brindó aquí en Valledupar, como los profes que vinieron, y por eso citaba a algunos de ellos, que son todos, son de una calidad humana impresionante y ya como grupo, siempre sentí lógicamente un mayor acercamiento o de alguna manera una cierta complicidad entre los mismos de la institución, pero eso no quiere decir que no existiera una atmosfera de complicidad a nivel de todo el grupo, individualidades como en todo grupo pero sin ninguna molestia y sin ningún reparo y nunca nos sentimos como extraños, siempre fuimos muy buenos amigos. Casi que hermanitos para muchas cosas. Esos momentos de Gloria de cantar y de hacer que la cosa fluyera y se desestresara uno, Rodri con sus locuras... Rovira con sus panes, son momentos 
que a uno lo llenan y de vez en cuando nosotros tenemos el grupo interno de la institución de la maestría y decimos por favor que se repita y que pase algo para podernos volver a reencontrar. Queremos volver a estudiar. Para tener esos momentos de encuentro. En estos días, ayer, precisamente publicaba Tatiana una foto en el congreso de Bogotá y yo decía por favor que se repita.

E: Sí. Tienes toda la razón, eso hace falta. Adela, ¿Qué sentido tiene para ti y para los que te rodean el haber hecho una maestría? Cuando digo los que te rodean, es tu familia, tus amigos, tus estudiantes...

(Silencio)

Adela: Bueno, a nivel personal fue reafirmar lo que siempre... yo nunca había visto una parte personal mía y todo el mundo la veía y me decía y me comentaba. Por ejemplo, en alguna ocasión Gloria se refería en unos términos muy bonitos hacia a mí. Son rasgos de la personalidad, resaltando rasgos de la personalidad de uno, yo nunca me había percatado de esa situación, de que de pronto uno tiene ese poder de empatía, de afinidad, de ser, como dice la psicoorientadora del colegio, que soy muy asertiva, ella siempre me muestra que soy muy asertiva en la toma de decisiones. De pronto eso lo había escuchado a al psico-orientadora, pero nunca a un par y a alguien desconocido para mí.

A nivel personal sacié esas ansias de querer estudiar y de tener conocimiento. A nivel personal me siento muy contenta con la formación que he recibido y me ha servido de mucha ayuda. Eso ha impactado a mi familia, a mis hijas que están en un proceso de crecimiento, ellas ven en mi ese ejemplo y me dicen"mami, si vas a hacer el doctorado, no te preocupes, ¡animo! Nosotros te apoyamos, ya sabemos que necesitas mucho tiempo para ti, pero nosotros te apoyamos"

Mi esposo me dice: - "me siento orgulloso, sabias que podías hacerlo y yo no voy a ser impedimento para que continúes con tu formación"

(Silencio)

En la institución, si empiezo desde el rector, esa manera en la que él me ha acogido y me ha dado responsabilidades, creo que esos son resultados no solamente de lo que ya sabía cómo docente, sino que vio que yo no fui a perder 
el tiempo y allá no se va a perder el tiempo, sino que realmente uno se va a formar allá. Él esta tan a gusto, que quiere que la institución se llene de eso.

E: ¿En tus compañeros?

Adela: En mis compañeros, muy motivados, de hecho, ya teníamos compañeros como tres o cuatro que hicieron la maestría, pero también que no han tenido posibilidad, por ejemplo, tengo una compañera de educación física que llora y se le caen las lágrimas, incluso ella quería hacer la maestría, pero no aplicó por su perfil de educación física. Otro compañero no aplicó por la edad. Ellos se quedaron muy conmovidos por no poder hacerlo, ellos están buscando hacerla, pero no como algo despectivo, sino que ellos siempre tienen algo que aportar.

E: Pero habrá uno que otro que siempre siembra recelo ¿no?

Adela: Pues sí, sobre todo aquellos que empezaron, voy a ser muy clara (risas) Hay compañeros que empezaron primero que nosotros con la Universidad Nacional y ellos empezaron con un aporte, a ellos se les había dicho inicialmente que era el $100 \%$ condonable y ellos empezaron, pero no sé qué situación se presentó allí y ellos tenían que pagar el 50\% de la maestría, y ya en los últimos semestres ellos tenían que pasar completamente gratis un recurso y creo que así fue al final, muchos de esos compañeros se quedaron en el proceso y no se han podido graduar por el tema de la manera cómo se orienta la investigación y el tema de las tutorías. Entonces, lo clave y lo fundamental es que la universidad tenga muy claro cuáles son los propósitos de la investigación e inicialmente, tengan unas líneas de investigación y digan qué procesos tiene que ver con la investigación y tenga al frente de estos procesos a gente muy comprometida y responsable. Porque esos comprometidos y responsables lógicamente van a hacer que los estudiantes trabajen y hagan de su resultado un producto y si ese engranaje se está dando, lógicamente, uno termina en los tiempos deseados, con un producto deseado y con unos resultados excelentes o muy buenos.

Desafortunadamente, yo creo que, los compañeros de esas maestrías no han tenido esa posibilidad y entonces, también dije: - “ide la que me salve con el tema de Venezuela!" no solamente por los conflictos socioeconómicos que se 
están gestando, sino porque tengo una compañera que se presentó junto con nosotros en esa oportunidad e hizo todo el proceso, pero le han cambiado a su tutor como unas tres veces y la situación es virtual y se ha complicado esta situación virtual, lógicamente un tutor viene y deja su parte, luego dice que esto no sirve, entonces, hasta el 10 de septiembre tuvieron la posibilidad de filmar video para las video clases, entonces ella me decía: ¡yo creyendo que... y mira cómo está la situación!. Empezamos esa carrera, la empezamos de ultimas y ya afortunadamente terminamos. Desde ese punto de vista sí hay cierta molestia, dicen: "tan picadas ellas, como pudieron y ahora dicen ascender con esos dichosos videos" que nadie tampoco tiene asegurado que sí podamos ascender. Hay múltiples factores que o solamente son en la formación de uno, sino todos sabemos que está el tema de disponibilidad presupuestal, está un tema delicado y hay que mirarlo con lupita, y es el tema de que a nosotros nos evalúan pares también y que a veces uno quiera o no, eso debe ser subjetivo.

E: claro, absolutamente.

Adela: Entonces esa subjetividad puede matar a cualquiera, lo que a mí me parece que estuvo excelente, con una súper fundamentación y otros dicen: "no, sencillamente no me gustó" por ejemplo, tenemos la experiencia de mi esposo, él hizo video para la primera propuesta, y yo digo, no puede ser que lo que yo te ayudé a montar este malo, miró el reporte de las calificaciones, que no le gustó al evaluador: el tema de la clase. Entonces, cuando uno mira y digo: "clima de clase": tengo idea, pero no se fundamenta y empiezo a leer y a llenarme de estos y pienso que el tipo "se pelo" (risas)

Absolutamente, qué fue lo que no le gustó... porque si uno mira la rúbrica, que ahorita nosotros tenemos la posibilidad de analizarlas, uno no está lejos de eso. Yo pienso que, sin demeritar a los profes del escalafón anterior, ellos se molestan muchísimo, nosotros los del 1278 de alguna manera estamos obligados a trabajar con calidad. Se nos exige muchísimo y ellos vienen con una rutina que no soportan en ningún momento, entonces yo dije: -bueno ni que fuera un profesor rutinario, memorístico, etc. Para no seguir de pronto degradando la situación y se hace lo que toca hacer. 
E: Adela, igracias por ese relato! 


\section{Historia Bertha Robles}

E: Iniciamos la historia de vida de Bertha, para contextualizarnos, quiero que me cuentes ¿Dónde vives?, ¿Cómo es ese lugar dónde vives? ¿Qué lo hace especial?

Bertha Robles: Profe, mi nombre es Bertha Robles, vivo en la zona rural del municipio de Albán, vivo con mis padres. Nací aquí hace 41 años. Esta vereda es muy bonita, lo que la hace única es la gente, es muy amable, colaboradora, trabajadora. La fuente económica del municipio y especialmente de mi vereda es el café. Mi vereda es pequeña, tiene 472 habitantes.

(Silencio)

E: ¿Toda tu familia vive aquí?

Bertha Robles: Si, toda mi familia vive aquí.

E: ¿Cuántos hermanos tienes acá?

Bertha Robles: Cuatro hermanos y tengo una hermana que está en Armenia, ella es terapeuta.

E: ¿Y tú cultivas café?

Bertha Robles: Sí, mi papá me dejó un pedazo, donde están los postes de energía, toda esa parte. Son dos hectáreas de café.

E: ¡Bastante!

Bertha Robles: Sí. Mucho no, pero sí.

E: ¿Y para dónde sacan ese café?

Bertha Robles: Para San José.

E: ¿Y quién lo seca y todo? ¿Tu?

Bertha Robles: Nosotros, mi papá, todos madrugamos. Pero mi cuñado como fue el alcalde hace 4 años y tuvo buenas relaciones. Tiene un amigo y compra el café, pero de otra manera, no como lo hacíamos tradicionalmente, cuando lo pilábamos, lo lavábamos, lo secábamos, etc. El café que él compra es diferente, solamente lo pila y lo seca rápidamente con toda la miel del café. Él lo compra la otra semana, para mandarlo a Suiza. De cómo salga la calidad del café depende el precio de este. 


\section{E: ¿Y qué más cultivan acá?}

Bertha Robles: Acá cultivamos tomate chonto, todo eso que usted mira, todos los plásticos e invernaderos, son cultivos de tomate. Ahorita, una vecina tiene un proyecto de tomate, pero sin químicos, totalmente natural.

E: Bueno, tú trabajas en la escuela de acá. ¿Está de qué colegio hace parte?

Bertha Robles: Hace parte del Politécnico Juan Bolaños. Fue inaugurada en 1960, en ese entonces, trabajaba una sola profesora, "la maestra" le decían, ahora ya se ha venido perdiendo este nombre, pero hay que defenderlo.

E: ¿Todos los niños que van a la escuela son de acá? ¿Cuántos son?

Bertha Robles: Si, son de acá de la vereda y son 37 estudiantes, aunque hay otros estudiantes de veredas vecinas, porque ellos dicen que los profesores de acá son buenos. Entonces se vienen a estudiar acá.

(Risas)

E: ¿Qué tiene la escuela? ¿Cómo la describes?

Bertha Robles: Esta escuela está formada en dos bloques, en la parte de arriba tiene la sala de informática y el restaurante escolar y en la parte de abajo tiene tres aulas, la biblioteca, el patio de recreo. $Y$ es, es amplia y bonita porque tiene un corredor grande y esto hace que, en estos tiempos de invierno a los estudiantes, les gusta madrugar y a eso de las 6:30 a.m. ya estén en la escuela.

(Risas)

E: ¿Hasta qué horas están en la escuela?

Bertha Robles: Hasta las 12:30 o 1:00 p.m. Como aquí el clima es bien templadito uno trabaja hasta las 11:30 académicamente y en las siguientes horas ya nos toca colocar asignaturas optativas, por ejemplo, artística o algo que no les quede muy pesado, porque el clima es fuerte, es bien caliente y ya empiezan a sofocarse.

E: ¿Qué enseñas allá?

Bertha Robles: Yo le doy clase a los estudiantes de preescolar, segundo y cuarto, este año. De todas las materias a todos, a todos, todas. Con los de preescolar obviamente se trabaja por dimensiones. 


\section{E: ¿Qué es eso?}

Bertha Robles: Dimensiones, técnica corporal, cognitiva. Esas dimensiones.

$\mathrm{E}:$ ¿Cómo son tus estudiantes?

Bertha Robles: Mis estudiantes son muy cariñosos. Son obedientes, cuando les digo al salón es al salón, son juiciosos, aunque no falta uno que otro que desobedezca, pero sí.

E: Bueno, hay algo que me gustaría que me hablaras, sobre lo que haces en tus clases.

Bertha Robles: En mis clases yo hago de todo.

E: ¿Que es de todo?

Bertha Robles: Bueno, pues como es tradición, en las mañanas, cuando iniciamos la clase hacemos la oración agradeciendo al dios todopoderoso por la vida y por la oportunidad de estar allá en la escuela. Les digo a los estudiantes, que muchos niños no pueden asistir a una escuela como lo hacen ellos. Y hacemos ese espacio espiritual, dando gracias y encomendando la jornada académica.

Luego se dan las clases según el horario que hay que hacer, si es castellano, por ejemplo, miramos los temas, obviamente las clases las dividimos en tres etapas: inicio, desarrollo y un cierre.

En el inicio, siempre se inicia con los saberes previos, hacemos un cuento o los sacamos a jugar, dependiendo del tema.

Luego, nos centramos en el tema, la explicación y todo lo desarrollado con el contexto, finalmente, se hace un taller de evaluación sin decirles a los estudiantes que esto es una evaluación, entonces, cuando ellos piensan la clase ya está evaluada. Yo personalmente, no les digo nada sobres las evaluaciones, solo cuando es final de tema. Ahí se les hace un taller y un examen. Pero en sí, en clase yo les hago un taller, pero ellos ni saben que los estoy evaluando, de eso depende el progreso y el avance en el conocimiento de ellos.

Luego miro la calificación de cada uno. Hay algo que yo hago con ellos cuando algunos estudiantes no entienden al momento, muchas veces me desplazo a las casas de ellos en horas de la tarde y les explico. 
E: Eso es otro trabajo. Ahí es donde me nace la idea de cómo han sido esos vínculos con la comunidad, porque me imagino que el reconocimiento con la comunidad es bastante. Porque hacer esa labor de ir a las casas después de la jornada a explicarles, y hagas unas clases. Yo me imagino que la comunidad lo valora mucho.

Bertha Robles: Sí. Ellos son bastante gratos. Lo que pasa es que hay casas muy distantes y es preferible yo ir donde ellos a que ellos vengan a mí.

E: ¿Cómo así distantes? por ejemplo.

Bertha Robles: Distante: de la escuela al sitio donde viven, por ejemplo, hay algunos estudiantes que se gastan una hora de salida y las casas están cerca al río. La escuela está muy lejos y son niños pequeños. La distancia de los niños que salen de allá es muy lejos, entonces, pues, un sábado, yo me traslado a donde ellos.

E: ¿Además vas un sábado?

Bertha Robles: $\mathrm{Si}$, porque entre semana tengo que preparar la clase y con los que viven relativamente cerca, si les digo que vengan a mi casa y yo trabajo desde las 4.30 hasta las 5:30 p.m.

E: ¿En la escuela?

Bertha Robles: No, en mi casa. Si, porque lo de la escuela se trabaja normal, pero ya después, los invito a mi casa.

E: ¿Y si hay niños que van? ¿A ellos les gusta ir a tu casa?

Bertha Robles: Si claro, porque yo les doy café y galletas.

E: Y ¿Qué hacen aparte de la jornada? Por ejemplo, el sábado que vas hasta la casa del niño que vive más retirado ¿Qué haces en ese día?

Bertha Robles: En ese día, ellos desarrollan sus tareas, juegan y aprovechamos ese espacio, ya que el sábado no hay tanto trabajo para los padres de familia, porque el sábado ese es "día del mercado" aquí, entonces, ellos van al mercado y más o menos llegan a las 10:00 a.m., a esa hora yo ya estoy con los niños. $Y$ mire que esto me ha dado mucho resultado porque me enfoco en el estudiante que tiene más necesidad de explicación y de que yo le profundice más el tema. Yo sé que hago una "clase personalizada" 
E: ¿Tú cuantos niños tienes en tu salón?

Bertha Robles: Tengo 22 estudiantes.

E: $Y$ de esos 22, por ejemplo, ¿Cuántos van a tu casa?

Bertha Robles: A mi casa los que están cerca van el lunes en la tarde, por ejemplo, David, Julián los espero a ellos, los espero a las tres de la tarde para profundizar un poco el tema que no quedó muy claro y como la jornada es hasta las 12:30, ellos salen para poder avanzar y que no se me queden, la idea es que todos aprendan todo.

E: Esa es una gran labor.

Bertha Robles: Si y como docente de la comunidad todo gira en torno al docente, no solamente son labores académicas sino también son otras las que uno hace, por ejemplo, dígase ya en diciembre que es la novena, en semana santa también.

E: O sea que la comunidad ya sabe que tú eres la que lidera ese tipo de celebraciones. Y ¿si te apoyan? ¿La comunidad es agradecida?

Bertha Robles: Si la comunidad es bien agradecida. Lo tienen en cuenta a uno. Por ejemplo, cuando es día dxlx maestrx me dan detalles en nombre de la comunidad, en nombre de la familia. Uno no espera eso, pero son detalles bonitos. Todos estos de detalles y este cariño me motivan para seguir haciendo esta labor y esta lucha. Porque la educación rural es compleja, no es lo mismo que los estudiantes de la ciudad, ellos lo tienen todo. En cambio, aquí tenemos que rebuscar los recursos del medio, la señal del internet es demasiado lenta, el internet es muy escaso y regular.

E: ¿Las edades de los niños de que son? ¿De unos seis años en adelante?

Bertha Robles: No, son de cinco años hasta trece años, de preescolar hasta quinto de primaria. Hay un estudiante que tiene 17 años y está en grado primero porque tiene necesidades especiales, y su edad mental no le permite avanzar, su edad cronológica de 17 años, pero su edad mental es la de un niño de 6 o 7 años, entonces toca ir luchando. 
E: Algo más que me quieras contar del contexto o que de pronto quieras resaltar, porque es que resulta que tú naciste acá, te criaste acá y ahora eres docente y trabajas acá. ¿Cuántos años llevas trabajando?

Bertha Robles: Llevo 19 años trabajando aquí en mi vereda.

E: Y ¿Dónde trabajaste antes?

Bertha Robles: Antes trabajaba en otra vereda, muy lejos de mi casa, casi a hora y media. Tenía que madrugar mucho. Luego me casé y quedé embarazada, en ese entonces, tenía mi nombramiento por contrato y tuve que pedirle al alcalde que por favor me contratara nuevamente, una vez hablé con el alcalde y le pedí el traslado a mi vereda, porque habían bastanten estudiantes en ese entonces. En esa época había cuatro profesores, eran 76 estudiantes y daba para tener cuatro docentes, ahora la población ha ido disminuyendo y a estos docentes los han ido trasladando a otras escuelas, y ahorita estoy con otro compañero, pero con el temor a quedar sola.

(Risas)

Del contexto, los padres de familia de esta comunidad son muy colaboradores, se realizan mingas para tener la escuela limpia.

E: ¿Qué son mingas? ¿Cómo basares?

Bertha Robles: No. Las mingas son actividades que se realizan los viernes, para limpiar la escuela, para recoger el café, porque la escuela también tiene 300 palos de café, los cuales sirven el mantenimiento y recursos de la escuela. Entonces, por lo general se hacen los últimos viernes de cada mes, nosotros enviamos una nota a los padres de familia, para que asistan y se les lleva un control. También, se organizan las madres de familia para el aseo de la escuela en general, ellas hacen el aseo de las instalaciones los domingos, también se les envía una nota y las organizamos en diferentes grupos. Es algo que fortalece mucho a esta labor de docente, porque siempre cuando se tiene el apoyo de la comunidad la vida es más llevadera.

(Silencio prolongado) 
(...) Esa parte de que yo no tuve, la oportunidad y que hubo muchos inconvenientes en el momento de terminar, el bachiller, porque mis papás no tenían los recursos.

E: Tú eres normalista. ¿Cómo es eso de normalista?

Bertha Robles: Por sugerencia, a mis papás les sugirieron que me mandaran a una Normal porque veían una mejor salida.

E: ¿Eso en que año fue?

Bertha Robles: Eso fue en 1991. Cuando fui a octavo grado de colegio. Ya bachiller pedagógico.

Entonces, yo no sabía que la Normal era exclusivamente para los profesores, yo pensaba que este era un colegio normal, entonces, cuando ya empezaron las prácticas, pues eso no me importaba, me empezaron a llevar a observar los profesores, cómo se daban las clases y todo eso, y uno iba y ya los niños le decían a uno profe. (Risas)

E: O sea ¿esas prácticas donde las hacías? En una escuelita.

Bertha Robles: En una escuela anexa a la Normal.

E: Ok.

Bertha Robles: $\mathrm{Si}$, pero yo no veía que mi responsabilidad o que mi trabajo iba a ser la docencia. Yo lo único que quería era salir del contexto y trabajar en una oficina. Luego, me gradué de bachiller pedagógico y a los 15 días me dieron trabajo de docente.

E: ¿Bachiller pedagógico es todo el bachillerato, hasta once?

Participación 3 (esposo): Hasta ese año, en 1995, las Normales estaban autorizadas a promocionar bachilleres pedagógicos para trabajar en primaria, a partir del 2001 ya pasaron a ser Normales Superiores con dos ciclos o dos niveles más que son 12 y 13 .

Bertha Robles: Entonces, ya me dieron trabajo de una, en la vereda Tambo Bajo, como dije, esta quedaba a una distancia de hora y media más o menos caminando.

E: Espera ¿caminando? 
Bertha Robles: Si claro, tenía que coger por toda la trocha por un año. Lo que me faltó contarte es que allá en la Normal conocí a mi esposo Bernardo, resulta que quedé embarazada en grado 11 . Me tuve que casar porque vengo de una familia conservadora, todo el embarazo tuve que caminarlo y luego ya por influencias políticas me trasladé a donde estoy ahora, en mi vereda, es muy bonito trabajar aquí, porque está la gente que quiero, porque aquí está mi familia. Luego, la población fue disminuyendo, así mismo los docentes hasta quedar sola, me imagino. (Risas)

E: Bueno, hay una parte en la que tú hablas y dices que no conocías tus intereses de ser docente, y no te imaginabas nunca ser docente. Entonces, ¿Cuáles eran esos intereses? Tú ahorita dijiste que te imaginabas en una oficina de secretaria o más de administración, pero no tanto que te lanzaran al agua como docente. Cuéntame un poco sobre eso.

Bertha Robles: Sí claro, como se dio la oportunidad de trabajar ya en la docencia, pues para mí lo importante era tener un trabajo y unos ingresos, me empezaron a pagar mi primer mes y pues empecé a trabajar con más ganas. Los primeros años fueron muy difíciles, pero luego con $\mathrm{mi}$ esposo decidimos prepararnos más y hacer la licenciatura a distancia en 1997.

Participación 3 (esposo): Empezamos en el 1997, pero luego tuvimos que retirarnos porque estábamos en ese estado de que éramos municipales y estábamos propensos a que nos sacaran por intereses políticos, pero afortunadamente en el 2000 se dio un concurso y ya nos estabilizamos, la dejamos por año y medio, pero después retomamos a la universidad y terminamos la licenciatura.

Bertha Robles: Sí. Obviamente cada paso que uno da en información académica es muy importante y beneficiosa para uno y para los estudiantes. La comunidad de aquí es muy trabajadora, colaboradora, solidaria, están pendientes de sus hijos... aunque no todos, pero en su gran mayoría están allí, y yo sé que cuento con ellos para hacer las labores que tengo que ejercer. De ahí en adelante uno quiere superar y superar, por ejemplo, hacer una especialización. 
E: Pero iantes de la licenciatura tu hiciste algún otro curso aparte de la Normal?

Bertha Robles: No, solo la Normal y después ya pasé a hacer la licenciatura.

E: ¿Qué licenciatura?

Bertha Robles: La licenciatura en educación básica primaria.

E: ¿En qué universidad?

Bertha Robles: En la Universidad Javeriana.

E: Y ¿Cómo fue ese proceso? Es a distancia, ¿De qué trataba esa licenciatura? ¿Cómo fue esa formación y las prácticas? Como ustedes ya trabajaban, eso se lo validaron por prácticas, me imagino. ¿Cómo era eso?

Bertha Robles: $\mathrm{Si}$, nos mandaban unos módulos, los analizábamos y teníamos clase presencial más o menos una vez al mes, allí nos explicaban la estructura del módulo, cómo había que leerlo, luego, íbamos a otra clase presencial y hacíamos evaluaciones sobre esos módulos. También, presentábamos trabajos escritos. Obviamente, para mí fue algo difícil, porque estaba embarazada de mi segundo hijo y por eso fue muy complicado el traslado y otras cosas. De ahí, con la estabilidad laboral, porque participamos en el concurso de méritos, lo pasamos y hubo otras condiciones que mejoraron nuestra calidad de vida, el $80 \%$ podría decirse, porque como era trabajo municipal nos pagaban prácticamente lo que el alcalde quería. Hasta después que empezamos a trabajar con el gobierno y ahí las cosas ya fueron muy diferentes. En esa época nosotros nos ganábamos un salario mínimo, no nos pagaban prestaciones ni nada de eso. Vinimos a conocer eso cuando pasamos el concurso.

$\mathrm{E}:$ ¿Cuánto duró la licenciatura?

Bertha Robles: 5 años. Luego tuve mayor profundidad teórica e hice las prácticas con mayor conocimiento.

E: La pregunta es, ya siendo docente en ejercicio hiciste la licenciatura; ¿eso ayudó mucho?

Bertha Robles: Sí claro, bastante.

Participación 3 (esposo): Sí claro, porque tú con todas esas prácticas que haces, te puedes dar cuenta que cometes errores, pero los puedes corregir en 
ese mismo momento y es precisamente con esa sustentación teórica. Como también puedes ver cosas que estás haciendo bien, pero en esa formación de la licenciatura, mira que hay cosas nuevas que se pueden desarrollar y además nos da oportunidades para cambiar las cosas que antes estabas haciendo y hacerlas de una forma distinta o más apropiada.

E: Claro, ustedes tenían la ventaja de la práctica.

Bertha Robles: Sí y además que yo, desde que me gradué ya estaba trabajando así.

Participación 3 (esposo): Claro, y también hay que tener en cuenta que los maestros que observaban nuestras clases y valoraban nuestras prácticas exigían bastante y la formación de la Normal era muy buena. Desafortunadamente, a uno como maestro le dan buenas teorías y bases, y tú las haces muy bien, pero cuando ya llegamos a asumir el trabajo como docente en propiedad y asumir un grupo, te olvidas de tantas cosas que hiciste como estudiante y que pierden la calidad de las prácticas, porque cuando eras practicante llevabas una cantidad de material y tantas ideas que después se pierden. Esos detalles sí lo ponen a uno a pensar, ya que, por ejemplo, hay salones en los que uno no siente un buen ambiente escolar. $Y$ uno dice, cuando era practicante le arreglé en salón a mi tutora de práctica, entonces, porque no voy a arreglan el mío.

El de Bertha sí es un salón de clase porque tiene una adecuación muy bonita. Bertha Robles: Sí, es que a uno le nace. Como se dice, yo ya me encariñé con la profesión. Ya el cariño que expresan los niños hace que yo lo de todo y lo entregué todo, hasta inclusive, mi esposo también lo hace, él también da clases extras en la tarde.

Participación 3: $\mathrm{Si}$, nosotros vamos a las casas de los niños menos favorecidos. E: Yo le estaba diciendo a ella que eso es un ejercicio muy bueno. Ir hasta la casa de un niño a dar clase no lo hace cualquier docente, o sea eso es difícil. Participación 3: Si es difícil, pero en nuestro contexto, yo entiendo a la gente o xlx maestrx de una ciudad, donde hay lugares a los que es muy difícil llegar y conocer la vida del estudiante, nosotros acá sí, sabemos quiénes son sus 
padres, sabemos cómo viven. En cambio, en una ciudad grande es muy difícil conocer esto.

$\mathrm{E}$ : $\mathrm{Si}$, en ciudad es muy difícil que el docente vaya hasta las casas, eso solo se puede hacer en espacios como estos.

Participación 3: Inclusive yo para no ir a las casas porque siempre se me hace más dispendioso, yo llamo a los padres de familia y los cito en el colegio, nos reunimos por una hora y media y trabajo con ellos, pero ya en actividades muy puntuales y eso ayudó mucho porque no los descuido tanto y los acompaño más en su proceso. $Y$ en la casa no es que les ayuden mucho.

E: Bueno, Bertha, toda esa práctica que me cuentas y toda esa información que has recibido, empezando por la Normal, ha contribuido para que tu sigas pensando que es necesario formarse como docente y estar actualizado, a pesar de que eres docente en ejercicio, necesariamente, uno debe estar actualizado, y eso da paso para hablar de la maestría, entonces, ¿Qué experiencias han impulsado que tu continuaras con tu formación en ejercicio?

Bertha Robles: Claro, te voy a contar toda la realidad, resulta que cuando me dijeron que hay una Maestría en Educación, pero solamente es tales estudiantes, me hubiese gustado hacerla, entonces, me tomé el atrevimiento de llamar al rector e informarle que había una convocatoria para las maestrías, le dije que no estaba en el grupo por algunas razones, pero le dije que me inscribiera. Él me dijo que, sí me inscribía, pero que si la rechazaban no era su culpa.

E: $Y$ ¿Por qué no estabas en ese grupo?

Bertha Robles: Porque supuestamente tenía que ser solo para los que trabajaban en jornada única, yo no estaba en esta, pero sí hacia parte de la institución, entonces, esto me daba moral y esperanzas de poder participar en esta maestría. Me gusta actualizarme, me gusta estar al día, si hacen un curso yo soy la primera que levanto la mano para ir. Entonces, pasé y mis compañeros se enteraron.

Al comienzo de la maestría, pues como todos pensábamos que nos iban a decir todo lo que teníamos que hacer, resulta que no. Todo lo teníamos que 
descubrir poco a poco. Uno se tenía que ir documentando. Y a través de los diferentes autorxs, uno se daba cuenta que la cosa era diferente. Ustedes los tutores cada vez que teníamos clase de investigación, había momentos en los que parecíamos que íbamos bien, pero otros en los que no, siempre lo mirábamos de otra manera. Hasta que llegó el momento en el que nos dimos cuenta de que estar en la maestría es investigar. Pero a la vez, ustedes (tutores) nos investigan a nosotros. Eso me ha servido mucho en mis prácticas.

E: O sea la maestría ¿Esa formación que tu recibiste sí cumplió con tus expectativas? Tú me dices que esas expectativas iniciales, eran yo voy a hacer una maestría y me van a dar, lo que me decía un profesor un día una receta para ser mejor docente. Lo que yo le decía era que ustedes ya son docentes y que no necesitamos darles ninguna receta porque ya están ejerciendo y construyen su práctica. Entonces ¿Han mejorado tus prácticas?

Bertha Robles: Sí, bastante, mis prácticas han mejorado en un $100 \%$, porque yo antes hacía de una manera no tan buena, ahora hago diferente y busco otra forma de llegarle mejor al estudiante para que entienda y comprenda mejor cualquier tema. Cada vez que voy dando alguna clase, un tema, siempre me acuerdo de mis tutores y trato de buscar algo nuevo para que al estudiante le agrade, como nuestro proyecto de investigación es de lectura comprensiva, eso enlaza todas las áreas y busco que mis estudiantes lean porque les guste y no porque les toque. $\mathrm{Y}$ a ellos ya les gusta leer mucho, mis estudiantes son muy especiales, por ejemplo, hay dos niñas que nunca van al recreo, sino que siempre se quedan leyendo, me piden libros.

He implementado algunas estrategias, como la de la biblioteca de aula que ha sido el eje para que los niños lean con más amor y sientan más interés. Todos los días los niños llevan sus libros a casa para que lean con sus papás, quienes saben de esta maestría y las nuevas estrategias que implemento, además, me han apoyado mucho, preguntándoles a los niños sobre las cosas que ellos leen. Los resultados se notan en las pruebas que uno les hace. Han mejorado bastante sus resultados, como lo decía anteriormente ellos no saben cuándo los estoy evaluando. 
E: Esas transformaciones que tú me dices en tu práctica se supone que el contexto de la universidad y las formaciones que has adquirido son las que han repercutido en esas transformaciones. ¿Cómo te ha parecido en términos formativos, pedagógicos y de ambiente? Quizás se han construidos vínculos con tus otros compañeros, con los profesores que están en la maestría, que han generado este tipo de transformaciones.

Bertha Robles: Si, inicialmente, cuando llegué a la universidad, se relaciona con otros docentes de otros municipios, que comentan situaciones y uno aprende mucho de ellos que comparten experiencias. Uno crece enormemente, para mis prácticas algunos compañeros me han dado recomendaciones, porque uno ya entra en confianza con ellos y ya entra a ser parte de esa familia, somos una familia en la universidad, ya nos conocemos muy bien, han pasado muchos meses en los que hemos compartidos juntos, entonces eso me ha formado bastante.

Otra parte es en la formación académica siempre, recuerdo que los autorxs me enseñan, así ellos no estén aquí presentes, pero a medida que uno va leyendo, va contextualizando esas lecturas y eso hace que cada vez uno enriquezca más sus prácticas pedagógicas.

E: En términos de esa construcción del saber pedagógico, ¿Sí se puede decir que la maestría brinda herramientas para que tú construyas tu saber pedagógico, en términos del ser maestrx, en términos de didáctica, de aportarle a tus estudiantes ciertas herramientas para su proceso de aprendizaje, que aporte a tu práctica y que construyas esa pedagogía para poder trasmitir lo que tú sabes?

Bertha Robles: Mira que yo antes no leía mucho. No era muy fanática a los libros. Solo leía porque las especializaciones que yo hacía me obligaban y pues no me nacía a leer como ahora, entonces, me doy cuenta de que el cambio comenzó en mí, para yo poder cambiar a mis estudiantes y que el saber y el conocimiento lo tiene uno allí, sino que hay es que apropiarse de ese conocimiento y agarrarlo, cada vez leer más, para aportarle a mis estudiantes nuevas estrategias. 
(Silencio)

E: Bueno Bertha, entonces, retomando tu relato, ¿Por qué crees que es importante realizar una maestría? ¿Qué piensas que deja el trayecto, el paso por una maestría en términos de impacto en tu práctica y has podido ver algunos cambios en tu práctica como docente?

Bertha Robles: Mire profe, anteriormente he realizado algunas especializaciones para mejorar mis prácticas, pero ahora que estoy en la maestría, me doy cuenta de que por muchas especializaciones que yo realice, la maestría es mucho más profunda, además una especialización es superficial, no se centra en un tema específico, mientras que la maestría lo llena de mucha fundamentación teórica, las practicas con los muchachos han cambiado notoriamente.

E: Bueno, frente a eso, ¿Qué sentido crees que tiene esto? Primero para ti y segundo para las personas que te rodean.

Bertha Robles: Es muy importante para mí, me va a ayudar mucho profesionalmente como personalmente. Personalmente, mi autoestima está muy elevado, mi hoja de vida ha mejorado y sé que me va a abrir muchas puertas, porque una maestría siempre tiene gran auge y en mis prácticas obviamente con mis estudiantes se ha notado más el cambio, ya he observado cambios en ellos durante este tiempo que he estado haciendo la maestría.

E: Me puedes describir un ejemplo de esos resultados.

Bertha Robles: Antes, uno daba los contenidos, los explicaba, pero no le daba la importancia, que ahora le estoy dando a mis prácticas, y como estoy llevando a cabo mi proyecto, que es de lectura comprensiva. Cada tema y cada contenido que veo con los muchachos lo centro y lo enfatizo con la lectura comprensiva y observo que a los estudiantes les nace y les gusta leer. No sé en qué momento se dio esa forma en que los chicos cambiaran la lectura en vez de otras actividades.

He observado en tres estudiantes particularmente, que en los descansos antes se sentaban a observar a los demás chicos, en cambio ahora se dedican a leer y eso es muy satisfactorio para mí. 
También el cambio en le comunidad, ellos saben que los días que yo no estoy sobre todo los viernes es porque me estoy preparando y ellos se sienten orgullosos porque ven en mí una líder de la comunidad y saben que, si un líder se prepara, la comunidad va a progresar más.

E: Que bien. La comunidad te apoya. Bertha ¿Qué diferencias puedes ver entre los que hacen la maestría y los que no la hacen? relátame eso.

Bertha Robles: Mire profe, la diferencia es que hay ocasiones en las que mis compañeros tratan un poco de aislarse, dicen que allá están los de la maestría, pero yo obviamente trato de acércame a ellos y estar en las mismas actividades que se realicen, pero no deja de haber cierto recelo en esa parte.

E: Bueno, entonces tú dices que hay un poco de recelo, porque ellos ven que ustedes se van a estudiar y tienen que quedarse a reemplazarlos.

Bertha Robles: Exactamente, por ejemplo, los fines de semana, los viernes cuando viajamos. Hay que pedir los permisos. Aunque hay otros compañeros que a uno lo felicitan y se alegran de vernos a nosotros hacer esto, pero no todos son así. Yo espero poder contribuirles a ellos, compartirles mis experiencias, lo que he aprendido y también estos conocimientos. 


\section{Historia Tita Manjarrez}

E: Bien, buenas tardes, estamos con el relato de Tita Manjarrez. ¿Cómo estás? Tita: Muy bien gracias.

E: Bueno, entonces inicialmente vamos a comenzar con unas preguntas de contexto... ¿Dónde vive? Que describas cómo es ese lugar, ¿Qué lo caracteriza? ¿Allí mismo trabajas? 0 ¿trabajas en otro lugar?

Tita: Ok. Yo estoy viviendo aquí en Valledupar hace 5 años. Es un lugar que me acogió. Por situaciones personales vivo acá, esta es una ciudad hermosa, arborizada, tranquila y con muchas opciones al nivel profesional, en el ámbito de la educación, con muchas posibilidades de surgir y de ir superándose, me parece que la parte política, a pesar de los malos manejos, ha aportado mucho a la educación y a la profesionalización docente y yo he sido beneficiada de esas políticas, ya que desde el momento que llegué aquí he podido participar en muchas capacitaciones. No solamente en el lenguaje, que es mi área sino también en recreación y deporte, inglés, en didácticas y siempre me ha gustado mucho mi campo laboral por ese aspecto. Hace aproximadamente 607 meses dejé mi colegio de planta donde era docente de básica primaria en cuarto y quinto del área de inglés, informática y educación física, por situaciones de que había varios docentes en lenguaje tomaron la decisión de dejarme en inglés y a los otros docentes en lenguaje. Estoy hace 7 meses iniciando con el programa Todos Aprenden, un programa del Ministerio de Educación Nacional. Me trasladé del lugar de mi trabajo hasta acá, en un colegio de Valledupar que se llama Loperena Garupal en sus sedes de primaria, Divino Niño y 20 de Julio. Ha sido una experiencia fenomenal porque lo que yo estoy haciendo es un acompañamiento directo en el aula a los docentes. Acompaño, miro su didáctica en el aula, luego nos reunimos y preparamos alguna didáctica que yo los llevo, luego los acompaño a realizar esta clase y hacemos una retroalimentación y una tabulación de datos con los estudiantes. Mirando los procesos que se lograron y que no se lograron dentro del aula, además, de unas capacitaciones alternas. 
Me ha gustado mucho, el proceso de que se tenga en cuenta que a pesar de no hacer parte del cuerpo directivo de la institución se tiene mucho en cuenta los aportes que nosotros podemos llegar a hacer desde el programa PTA, que es la sigla que tiene.

E: ¿De dónde eres?

Tita: Bueno, Yo soy sincelejana, nacida, criada y todo allá. Como digo cuestiones familiares me trajeron acá, todavía no me acomodo $100 \%$ en Valledupar, porque extraño mi tierra, porque uno la conoce y se siente más cómodo, hasta en el ámbito laboral. Encontrarse con las personas que hicieron su proceso en el mismo colegio, es algo que te favorece porque la experiencia puede llegar a compararse y es precisamente allí, donde la formación de una manera muy formativa puede llegar a mejorar sus prácticas de aula. Pero todavía no he tenido esa dicha de trabajar por lo menos en el colegio que estudié, que fue la Normal Superior y siempre me tracé eso como un propósito, llegar a ser docente en ese colegio que me formó.

E: ¿Pero allá en Sincelejo trabajaste?

Tita: Bueno yo terminé mi bachillerato en el 2002, como normalista con énfasis en pedagogía, cuando precisamente en ese año se acababa el normalista en 11 y se podía salir a trabajar. El año inmediatamente anterior empezó lo que se conoce como ciclo complementario y uno tenía que hacer cuatro semestres estudiando y yo los continúe. En el 2004 me gradué como normalista superior y en el 2005, inmediatamente empecé a trabajar nombrada por el Estado. En el municipio de Sucre que se llama Guaranda, Sucre. El cual queda lejísimos, limita con Achi, Bolívar y Nechi, Antioquia en frente del río Cauca. Cuando llegué en el 2005, era una zona demasiado peligrosa, de un lado del río estaba la guerrilla y del otro la policía. Entonces, gracias a Dios una sola experiencia, que no la quiero repetir de un solo tiroteo. Pero "bien". Cuando empecé como normalista, de pronto las bases sobre el manejo de grupo y pedagogía estaban bien establecidas, ya la parte de la didáctica, que es donde uno empieza a darse cuenta del proceso y de cómo se diseña, cómo me va, qué puedo mejorar. En este proceso lo que es la parte didáctica se maneja con la 
experiencia, gracias a dios, se me presentó la oportunidad de poder seguir estudiando a distancia con la Corporación Universitaria del Caribe CECAR y mis pretensiones, inicialmente eran pasarme a artística, pero cuando me dijeron que para pasarme a artística tenía que devolverme a segundo semestre, yo no quise perder esos dos semestres y continué en quinto semestre de lenguaje, terminé y me gradué de licenciada en el 2009 y cuando era licenciada me salió un traslado, un poquito más cerca de la capital que se llama Oveja, Sucre. Pero también me toco en la parte rural, que también es zona roja, en los Montes de María y tenía que viajar todos los días, salía de mi casa tipo 4 de la mañana y llegaba tipo 3:30 de la tarde, ya tenía también a mi primer hijo, mi esposo vivía ya en Valledupar. Eso de pronto me obligó un poco para buscar la oportunidad de un empleo acá, para poder estar con mi familia. La experiencia en Guaranda también fue muy satisfactoria en el sentido que me tocaron unos niños que cuando estaban en sexto de primaria, venia de Guaranda de trabajar en primaria y en preescolar y aquí ya empecé a trabajar en bachillerato, excepto hasta once, pero cuando llegué solo había en sexto y séptimo, entonces, con el profesor que me acompañaba, entre los dos fuimos abriendo los otros cursos.

El proceso fue un poco difícil, las llegadas al colegio, cuando llovía no se podía hacer clase, eran dos horas caminando, pero aun así se trabajó mucho con proyectos pedagógicos: huertas escolares, piscicultura y desde esos proyectos trabajamos todo lo que era la escritura, la oralidad, les hablo de lengua que es lo que conozco, porque lo de matemáticas lo daba otro profesor. Trabajamos las lenguas, las ciencias sociales, quienes eran los que vivían, cuáles eran los pueblos, todo. El contexto de la institución que hace que xlx maestrx busque la estrategia y la didáctica adecuada para llegarles a los estudiantes y para que a ellos se les facilite aprender.

E: ¿Y cuando llegas a Valledupar cómo es esa realidad?

Tita: Cuando llego a Valledupar me nombran en el 2012 en Valledupar, llego al colegio Institución Educativa de Patillal, llego con mucha expectativa, me recibe el coordinador, me dice usted va a hacer la directora de un salón, aquí 
tiene estos documentos, este es el observador, esta es la programación de la clase... ¿algo más? - "todo claro"

De entrada, el colegio me presentó a mí una organización como tal, y yo dije: aquí hay que hacer las cosas mejor que como las vengo haciendo porque aquí es una organización, que en las dos instituciones en donde yo ya había trabajado.

Efectivamente, cuando uno llega nuevo uno quiere mostrarse, lo que uno sabe de una manera muy respetuosa, ¡claro! Y obviamente el coordinador y el rector se dieron cuenta de eso, que le digo y llegar aquí fue una superación personal, porque me tenían en cuenta; por ejemplo, si tenían una dificultad me decían: qué podemos hacer, tenemos que planear un acto cívico para esto, qué debemos hacer... cuando hacíamos reuniones de área buscábamos planes de mejoramiento, yo dirigía la cuestión de planes de mejoramiento con los compañeros de primaria, y eso me ayudó mucho a "encarretarme" con Valledupar y con Patillal, más específicamente de querer. Yo sacaba tiempo, después de clase me quedaba en el colegio a hacer refuerzos con los niños, les hacía actividades lúdicas, me invitaban los sábados, entonces, como que me querían tanto que yo empecé a querer esta comunidad.

En cuanto, a la parte de profesionalización, cuando llegué a Patillal, ya yo tenía un semestre de mi especialización, y pensé en pararlo, porque la estaba haciendo en Sincelejo, y la idea de vivir en Valledupar, era dejar la viajadera y al venirme para acá entonces, tenía que viajar a Sincelejo para estudiar, pero menos mal estuvo ahí mi familia y mis papás, diciendo: -no, esos seis meses, no es nada, terminarla. Efectivamente, la termine, hice la especialización con la Corporación Juan de Castellanos, en planeación educativa y planes de desarrollo, fue excelente, fue una experiencia, como le digo en verdad se nota el cambio de nivel a nivel, o sea uno siente el cambio, en el tipo de trabajo y en el tipo de investigación en los proyectos, que se hacen cada uno de estos niveles. El proyecto lo hice con Patillal precisamente, lo había empezado con el colegio de Ovejas, pero me tocé reformarlo de una manera brutal y terminarlo con Patillal, pero fue una experiencia excelente, donde yo puse a los niños a entrevistar a los juglares de la música vallenata que vivían allá y de eso, ellos 
exponían qué fue lo que hicieron. Algo como lo que normalmente se hace en clase "léame ese cuento y explíqueme que entendió", en este caso ese cuento o el texto era real, y vivencial, entonces, el niño tenía más propiedad para hablar de lo que se estaba preguntando, porque él lo vio, él lo vivencio y tuvo la oportunidad de preguntar lo que quería. Luego de eso nació una propuesta de hacer un semillero de decimeros, con un decimero de Patillal porque a pesar de que tiene un gran reconocimiento, este se está perdiendo. Ya no hay niños que componen, hay pocos niños que tocan un instrumento. Entonces, esta es una preocupación de la comunidad y yo quise aportar a eso. (Silencio)

Y de ahí para acá, este año ya cambié de colegio, pero sigue siendo mi colegio, estoy contratada por un tiempo determinado, hasta que este se acabe.

E: Otra vez, ¿Cómo así? Explícame...

Tita: Cuando yo salí de Patillal fue porque se dieron cuenta que gané el examen de ascenso y había terminado maestría, entonces vieron en mí, idoneidad para el cargo de tutora, es decir, enseñarle a algunos maestrxs, a mirar y no a criticar, sino a sugerir unas didácticas que ya viene preestablecidas del MEN, la idea es que ellos las utilicen en el aula, pero uno tiene que saber indicarles cómo aplicarla en el aula y que no crean que es otro trabajo. Sino que hace parte de esa misma responsabilidad en el aula. Entonces, en Patillal hay un reemplazo para mí, hay una persona que tiene mi puesto en el momento que el programa Todos a Aprender termine, yo vuelvo a mi colegio.

E: Y eso cuanto es, cuánto tarda, mejor dicho.

Tita: Bueno, ese proyecto nació con la ley de Santos, el presidente y todo el mundo comenta que inició con Santos y termina con él. Pero como ya está bien enfocado, bien montado y ha tenido buenos resultados, lo que el programa quiere es llenarse de requisitos, para mostrarle al nuevo presidente que llegue que realmente eso sí está favoreciendo la educación en Colombia y que este presidente dé aval para continuar. Pero eso no se sabe... realmente va hasta el 2018, legalmente. 
E: Bueno Tita, devolvámonos un poquito a que me cuentes cómo es el proceso de la Normal ¿Cómo es estudiar en una Normal y salir normalista?

Tita: ¡Espectacular! Inicialmente, mi mamá siempre me decía y lo recuerdo mucho... que yo tenía vocación para ser maestra porque los niños se la iban mucho conmigo, pero yo le decía: -mami, pero es que a mí no me gusta, yo no me veo en un salón con una "muchachera" pidiéndome cosas. Ella me decía: pero es que mira, luego tu no ves cuando los niños te buscan para que les explique alguna tarea, ellos te entienden y no se demoran ni una hora aquí.

Entonces yo le dije que quería estudiar en un colegio de Sincelejo que se llama ITI, Instituto Técnico Industrial. Porque a mí me gustaba el dibujo técnico, la mecánica y ella me dijo: - no, usted no va a estudiar eso, usted va a estudiar en la Normal. Mejor dicho, yo entré a la Normal de guardaespaldas, porque mi hermana era una "joyita”, a pesar de que solo había mujeres, pero se perdía del colegio, entonces, cuando mi primera clase en la Normal me coge un profesor de ciencias sociales, pasa la lista y dice Tita Manjarrez, yo digo presente y él me dice: ¿tú eres hermana de Angélica Manjarrez? Y yo le dije: sí. Se cogió la frente y yo dije, fichada. Luego me dije a mí misma: -yo no soy Angélica y ellos tienen que conocerme a mí.

Comencé mi proceso, en esa época había profesores de exploración vocacional, de pedagogía, cuando se utilizaba todavía la tiza. Le daban clase a uno de cómo escribir en un tablero con tiza, para que esta no se le cayera en la cara y luego evitar problemas de cuerdas vocales o de respiración, cómo se debía borrar, cómo escribir en un cuaderno, cómo hacer una cartelera, desde sexto de bachillerato. Eso era impresionante, dentro del pensum, estaban todas esas materias y en ese entonces, en colegio tuvo varias jornadas, había una jornada única que duraba hasta las tres de la tarde, tuvo también doble jornada que terminaba hasta las cinco. Y luego, al final, ya cuando estaba en once, volvió a la jornada normal. Porque eran alrededor de 4000 estudiantes y no alcanzaban a estar todos en la mañana. Siempre me destaqué también en la Normal, le dan muchos espacios a uno, para expresar lo que piensa y lo destacan cuando uno maneja algunas cosas, por ejemplo, cuando yo estaba en once, hacia parte del 
comité de acreditación y calidad, porque la Normal estaba en ese proceso de calidad y me sacaban de clase a trabajar con el rector y con los docentes. También, era la presidenta del colegio superior y el diseño de la evaluación para el proceso de acreditación de alta calidad, lo diseñé yo, con ayuda de los profesores, yo les daba las ideas y ellos aportaban desde su dominio conceptual y luego con la psicóloga decidíamos donde podían quedar posesionadas. Lo que se hacía con el ciclo complementario, siempre no lo preguntaban porque éramos los primeros prácticamente, entonces nos apoyaban, nos ponían unos retos impresionantes, explicar por ejemplo unas teorías con señas y señalizaciones. Fue una experiencia que, a pesar de ser difícil en ese momento, después de tanto tiempo uno se da cuenta de que aclaró muchas cosas, siempre me encuentro por ahí a un profesor que ya está jubilado, y eso de encontrarte con ese profesor que te quería rajar, eso a mí me parece muy bonito.

También si había reuniones de profesores no se perdían clases. El estudiante a partir de noveno estaba totalmente habilitado para cuidar una actividad que dejara algún maestrx. Cuando se podía hacer, cuando eso se podía hacer, porque actualmente los estudiantes no se pueden quedar como un encargado, jamás. Pero en ese momento sí se hacía. Entonces, nosotros desde noveno comenzamos a hacer prácticas. Así nosotros no planeáramos las clases, teníamos que explicarles a los niños lo que ellos no entendieran, y si uno no entendía entonces uno iba hasta las salas de profesores, le preguntaba al profesor, el profesor le explicaba y luego uno regresaba al salón, a continuar con la actividad y eso era más o menos unas tres o cuatro veces al mes, y ya cuando una llega a la práctica del ciclo complementario, uno ya sabía lo va a hacer al aula, solamente que hay unos requisitos para preparar clase, unos proyectos de aula, a interactuar con ese proceso, que no se hace en noveno, decimo y once.

En mi experiencia de práctica en la Normal, hice un proyecto de aula, sobre el aprendizaje colaborativo, con unos niños de cuarto de primaria que estudiaban en un colegio que quedaba al lado de la cárcel de Sincelejo y todo ese sector eran invasiones. Entonces, los niños tenían muchas habilidades y la idea mía 
era hacer que todas esas habilidades se unieran e hiciera un producto conjunto, entonces, el trabajo se hizo a través de la lectura y la expresión corporal, entonces, ellos tenían unos textos y debían representarlos a través de su expresión corporal. En drama o en bailes. Llegaron a la comprensión de un texto a través de ejercicios de expresión corporal.

Bueno, también me acuerdo de que cuando me gradué del ciclo complementario lloré mucho, porque a pesar de que no quería estudiar allí, yo amaba tanto mi escuela que, si me permitieran devolver el tiempo, volvería a estudiar allí. Le dieron la mención de honor por sentido de pertenencia, a una muchacha que hablaba cosas tan feas del colegio y yo que era la consejera, fui personera del colegio, hacia aquí y allá. Y a pesar de que me dieron una mención de honor por haber hecho $\mathrm{mi}$ proyecto de aula que había sido meritoria y me había quedado en nota de 4.90. No me importaba a mí eso, a mí lo que me importaba era que todos supieran que a mí me gustaba esto, de manera que yo me enamoré del cuento, en todas las fotos salí con los ojos y la nariz roja pero bueno.

(Risas)

E: Bueno, y ¿Cómo fue ese pregrado? Me dices que lo estudiaste a distancia.

Tita: Si, el pregrado lo hice a distancia.

E: ¿Es licenciatura en qué? perdón.

Tita: Licenciatura en humanidades con énfasis en lengua castellana e inglés. El pregrado, fue una experiencia muy diferente y no fue tan satisfactoria, en el sentido de que las clases eran cada 15 días, por módulos, entonces, Ixs maestrxs que de pronto trabajan a distancia y más aún que en esa época no existía el internet, todo no era tan fluido. Es más, era prohibido dejar trabajos por internet, porque no todos tenían esa capacidad de entregar trabajos de esa manera, entonces, el profesor solo le calificaba a algunos y a otros no. Había muchos "café internet", porque se estaba metiendo el cuento del internet, pero no, para ellos era mejor poner trabajos, llevarlos al aula, exponerlos y explicarlos, retroalimentarlos, afortunadamente, todas las prácticas que había en la licenciatura nos las aceptaron en los propios colegios que estábamos 
trabajando y como sabían que nosotros veníamos de Guaranda, obviamente teníamos que hacer las practicas allá. Los procesos eran por módulos, terminaba uno y arrancaba el otro. Entonces, no había un seguimiento, ni una continuidad entre un proceso y el otro, por ejemplo, si veíamos practica 1, era un módulo de cuatro sábados, pero solamente asistíamos dos, cortaban y en el siguiente veíamos la practica 2 . Entonces, lo que quería era graduarme y esa era la única forma en que lo podía hacer, pero sí traté de buscar la manera y de sacarle lo mayor que podía. En ese momento, hice mi proyecto en inglés, mi proyecto de aula lo hice con una compañera que se llama Andrea Córdoba, era mi amiga del colegio, quien me llevaba un año, ella estaba en 11 y yo en 10. Ella termino 11 y entró a ciclo y yo más atrás. Cuando salimos nos nombraron juntas, nos nombraron en Guaranda a juntas, entonces, salimos con la misma normalista (énfasis en lengua castellana), pero a ambas se nos facilitaba más el inglés, entonces, si ella hacia un seminario yo también, lo hacíamos siempre así, pero de una manera muy formativa, tratábamos de superarnos. Entonces, cuando decidimos hacer la licenciatura, hicimos el proyecto con énfasis en inglés, cómo enfocar la enseñanza del inglés a través de las imágenes ilustrativas, que es la primera parte que se evalúa en una prueba saber. En la prueba saber hay 6 que se evalúan y la primera que siempre aparece, son imágenes en contexto. Entonces, la idea era que nuestro proyecto es la enseñanza del inglés en niños de primaria a través de imágenes ilustrativas, cómo el niño podía explicar dónde encontraba entonces ellos tenían que encontrar por ejemplo en qué parte se podría encontrar el letrero de Don't speak o en qué parte pueden encontrar cualquier otro, para que ellos manejaran mucho el contexto de las imágenes en inglés.

E: Bien, ¿y luego hiciste la especialización?

Tita: Si, luego hice la especialización.

E: ¿Qué ahí fue el proyecto de Patillal?

Tita: Sí.

E: Y ¿Cuánto tiempo pasó desde que hiciste la especialización e ingresaste a la maestría? 
Tita: La especialización la terminé en el 2012 y la maestría la inicié en el 2015. O sea que pasaron tres años.

E: En esos tres años ¿Qué otros estudios hiciste?

Tita: En esos tres años como ya lo dije, Patillal me dio la oportunidad de hacer la ejecución de ese proyecto que venía haciendo en la especialización. Y esto dejó ver a los directivos que yo andaba pilosa trabajando, y la comunidad si decía, por ejemplo, vimos a la profe Tita en casa de Chiche Maestre. Vimos a la profesora en la casa de José Vélez. Entonces, ya las personas me conocían a pesar de que llevaba tres meses en el pueblo, empezamos a hacer capacitaciones en deporte, ese mismo año llevé a dos estudiantes a las finales de las pruebas nacionales "supérate con el deporte", aunque yo no era la maestra de educación física. Al otro año, pasaron dos niñas a las finales de las pruebas "supérate con el saber" y estamos hablando de las dos áreas que se evalúan en las pruebas de "supérate con el saber" que era lenguaje y matemáticas. Pero es porque los profesores eran muy apáticos a participar en este tipo de actividad.

La única capacitación que hice en esos tres años fue un diplomado en evaluación por competencias, que precisamente nos llamaron de Cecar. Porque estaban abriendo una sede en Valledupar, y no invitaron a hacer ese diplomado en Valledupar para los egresados, con un rubro bastante económico y como la directora es amiga mía, me llamó y me dijo que fuera a hacerlo y que dijera que iba de parte de ellos, para que me lo dieran e hicimos un diplomado.

E: Bueno, entonces arrancas en el 2015 la maestría. ¿Cómo arranca esto?

Tita: Bueno el rector nos llama. Nosotros ya estábamos enterados de que el Estado estaba tratando de buscar unas políticas para ayudarles a lxs maestrxs para profundizar en su formación. Pero al colegio no le había llegado ninguna convocatoria, solo la de ciencias naturales y química que era con la Universidad Nacional. Entonces esa no aplicaba para nosotros y los que empezaban en Patillal. Cuando nos llaman y nos dicen que estaban habilitadas para lenguaje y matemáticas, yo no lo dudé y más con las condiciones, que lo único que iba a necesitar era mi disposición y mi trabajo, no lo dudé en ningún momento. 
Empezamos cinco, la profesora María Julia que fue la que se retiró por un problema de salud y entre los cuatro que quedamos tuvimos que seguir, dos compañeras que estaban que se salían y continuamos porque ya no nos podíamos salir. Entonces, este proyecto empezó. Yo estaba muy optimista y nerviosa cuando me llamaron a la entrevista de la universidad Santo Tomas, no sabía qué contestar o qué me iban a preguntar. Yo realmente no sabía y estaba bastante impaciente. Llegó el día de la entrevista, la doctora Ana Elvira, me decía que me relajara. Me preguntó que quién era yo, qué hacía, por qué me gustaba esta profesión, qué expectativas tenía con la maestría y empecé a hablar como estoy hablando en este momento y a comentarle todos los proyectos y las ideas que tenía, unas que había ejecutado y otras que tenía en mente, que han estado siempre ahí, pero que no les había dado mucho tiempo. Ella me dijo, es simplemente conocerte, luego, pasamos a hacer un ensayo, tuve una buena experiencia con hacer ensayos porque a mí, el que me enseñó a hacerlos no fue mi profesor de lenguaje, sino mi profesor de filosofía, y el primer ensayo que hice, que para mí era la producción más perfecta, que yo la leía y no me creía que yo lo hubiera escrito. Pero, cuando se la mostré a mi profesor de filosofía, eran casi 8 páginas de un cuaderno pequeño, él no había leído la mitad de la primera hoja, cuando me dice: -eso no sirve. Y yo le dije, pero cómo así profe, lea algo más, que ahí hay más cosas. Él me dice: -ya lo leí y eso no es así. La verdad es que yo le respondí con una grosería y rayé todo el cuaderno.

A pesar de que yo seguí haciéndolo, él me dejó en recuperación en filosofía. Yo pensaba en que me dejará en decimo, no le haría más ensayos. Mi mamá fue la que se tomó el trabajo de hacerlo y se lo llevó al profesor, yo le dije a ella póngale su nombre porque si la ve que es mío lo pierdo. No sé cómo hizo ella, pero él me lo calificó y me puso 3.6. Me la pasé, pero yo no lo hice. Pero si sé que lo que hice esa primera vez, aunque no tengo el material para hacer un análisis de lo que pensé en ese momento que estaba bueno, para ver si en verdad lo estaba, pero bueno, no puedo. (Risas) 
De ahí en adelante siempre hacia yo misma mis ensayos y siempre me fue bien, con eso y con la redacción. Lo leo dos o tres veces y pregunto mucho cuando me siento, a pesar de que mi mamá, mi papá o mi esposo no están metidos en este cuento de la docencia, les pregunto qué harían ustedes desde su profesión. Ellos me empiezan a contar lo que harían y de ahí voy agarrando elementos para crear una idea nueva, innovadora y diferente que pueda aportar al proceso de los muchachitos en el aula de clase.

(Silencio)

E: ¿Cómo es que inicia ese proceso de la maestría?

Tita: Entonces empezamos el proceso de la maestría, llegan nuestros tutores, todos con la expectativa de decir cómo era eso, porque si sabíamos que era de un nivel bastante alto, pero no sabíamos cómo íbamos a reaccionar a ello. Lo primero que nos dijeron era que pensáramos en una idea y algunas necesidades que tuviera nuestra institución educativa y frente a eso algunas ideas para empezar a trabajar. Todos nos quedamos mirando y nadie se atrevió a preguntar nada. Todos éramos desconocidos, entonces, la tutora nos dijo: -es que la investigación y el proyecto lo vamos a iniciar ya. Otro profesor de filosofía dijo: -qué interesante que no dejemos este trabajo de investigación para los últimos semestres. Es decir que todos habíamos tenido la misma experiencia, de que tanto en el pregrado y la especialización los trabajos de especialización quedan a lo último.

Entonces, empezó el proceso, teníamos incógnitas y preguntas, no entendíamos muchas cosas. Cuál fue la primera impresión, decíamos, por ejemplo, el problema de lectura, inventábamos una solución y cuando las mostrábamos a nuestros tutores, ellos decían ¿Cómo sabes que esa es la que va a funcionar si todavía nos has hecho un trabajo de campo o una observación? Entonces, qué nos toca hacer, otra vez hacia atrás. Entonces, qué tenemos que hacer... miren, deben hacer un diagnóstico y ahí colocábamos las necesidades de nuestra institución educativa. Empezábamos a trabajar con los indígenas e hicimos un proyecto de inclusión de indígenas con las TIC, pensábamos que íbamos a cambiar al mundo con ese proyecto. De ahí, pasamos a la transversalidad, que 
es un tema que se ha trabajado desde muchos años, pero que realmente en las instituciones educativas no se ven, éramos tres de lenguaje y uno de matemáticas, no se podía ver, porque además de que éramos de diferentes áreas, unos estábamos en bachillerato y otros en primaria y en diferentes sedes. Cómo trabajamos un proyecto transversal. Era nuestra inquietud. Empezamos, hasta que definimos un tema específico y era precisamente la desmotivación de los estudiantes en el aula de clase con algunas enseñanzas que se mostraban un poco tradicionales y que al muchacho le parecía tan repetitivas que se le tornaba la clase totalmente aburridora, entonces, empezamos a trabajar el tema de motivación y pasaba, uno o dos meses, luego reunión con tutores nuevamente, mostrábamos lo que habíamos adelantado y ellos decían: - "y tú cómo vas a hablar de motivación, si la motivación tiene aspectos psicológicos y tú no estás haciendo maestría en Psicología. Tú maestría es en didáctica". Y otra vez vuelva y empiece.

Un día nos sentamos en mi casa, los cuatro compañeros y yo le dije: hasta dormida creo que estoy pensando en eso, quién maneja la didáctica, xlx maestrx, entonces, la investigación debe estar basada en $x l x$ maestrx pero que proyecte un resultado en los estudiantes. No debemos hablar de los estudiantes. Todos me quedaron mirando, se preguntaban ¿será que es así' y yo les decía: -claro que sí, así es que hay que montarlo.

Empezamos a montar las ideas, qué estrategias didácticas podría utilizar un profesor para mejorar. Ya la motivación no era lo primero, sino qué didáctica podían ayudar a mejorar los niveles de motivación en el aula. Seguíamos con la motivación. Firmes.

Luego, hubo otro encuentro con los profesores y decían que ahora si íbamos bien, pero la motivación si estaba perdida, porque lo que ustedes deben trabajar es los procesos de enseñanza y aprendizaje. No van a mejorar la motivación, la motivación se mejora en el momento en que el proceso de aprendizaje y el proceso de enseñanza, que es la didáctica, sea realmente atractivo para los estudiantes. Si esta no era atractiva no habría motivación. No podíamos entrar por motivación porque no era una carrera de psicología. 
Empezamos otra vez, a reformarla, mientras tanto en las profundizaciones que se hacían de manera virtual, teníamos dos maestrxs que nos estaban ayudando, que nos colocaban actividades para hacer el estado del arte. 0 sea que otras investigaciones se habían hecho referente al tema, cómo era la redacción que se venía a hacer en la investigación y empezamos a conocer las normas APA. Entonces “¡apa pa’ aquí y apa pa’ ya!”

(Risas)

Con ese proceso, cuando los tutores nos reúnen nuevamente y nos dicen que vamos a empezar el marco teórico, lo que hicimos fue que cogimos lo que habíamos hecho con el otro profesor y lo pusimos ahí. Cuando el marco teórico lo empieza a leer la asesora referente a lo que teníamos planteado, dice que no es por ahí. Hay algunos teóricos que les pueden aportar a sus ideas, pero como tienen redactado no funcionaba lo que nosotros íbamos a hacer.

Efectivamente, lo leímos y si pensábamos que estábamos perdidos, eso fue en el primer y segundo semestre y ya nos sentíamos como pez en el agua y estábamos metidos en el cuento. Pensábamos que íbamos bien, ya esto iba para adelante. Cuando otra vez se mueve y la maestría pasa de ser en educación a ser una maestría en didáctica específicamente. Entonces, el formato que veníamos trabajando en investigación cambia todo, los ítems cambian, se mete lo que es el enfoque, empezamos a trabajar nuevamente ese enfoque, empezaron a hablar sobre la cibernética. Y cuando yo escuché por primera vez lo de la cibernética, yo imaginé que eran las TIC, porque yo en la vida había escuchado sobre eso.

(Risas)

Cuando ya empezamos a preguntar sobre eso, yo creía que había entendido sobre el tema. Pero me seguía sonando que era como por la parte de computadores. Gracias a dios nos hicieron una capacitación, con la doctora Ana Elvira y ella de una manera muy didáctica, la verdad. Nos hizo entender ese proceso y tanto no lo hizo entender que, para el próximo simposio de esa fecha, cuando nosotros participamos en este, hablamos de la cibernética con un empoderamiento y una cuestión que apenas terminamos nos aplaudieron y 
yo pensaba, será que me entendieron, porque a mí me costó entenderlo. Entonces, uno de los muchachos si fue muy consciente y llegó hasta donde mí y me dijo: -yo quisiera que me explicaras un poco más sobre eso de la cibernética y yo muy amablemente le explique como yo lo había entendido, como lo veía desde afuera y como lo veía interactuando luego que hago con ese proceso. Me dijo que estaba bien.

Esos simposios también fueron para mí muy importantes para que el día de la sustentación final estuviéramos como mínimo seguros de lo que estábamos hablando, independientemente de la nota. Porque realmente lo que estábamos hablando no era nada inventado, fue algo que construimos de día, de noche, de madrugada, los sábados, trasnochados, y no era nada de que uno estaba tratando de cruzar teorías de otros, sino que es esto lo que estoy haciendo. Tanto así, que en la sustentación dije que había sido sencillo. No tuve que hablarles con palabras técnicas ni científicas para que entendieran lo que habíamos hecho en el proyecto. Creo que así he llegado yo. Cuando volví al colegio dije que la cosa no es tan complicada, ese concepto que habla Morín, la complejidad, la cosa no era tan compleja. Lo complejo se los damos nosotros porque de lo simple sale lo complejo y lo complejo vuelve a lo simple. Todo eso lo entendí con la maestría. Yo les decía a los profesores cuando llegué, que empecemos a hacer la proyección de la propuesta a dos años, vamos a hacer este trabajo con la profesora Elsa, Carlos y Sandra. - pero y si pasa esto-, es que no ha pasado, esperemos que pase.

Entonces, frente a esa situación, cuando uno tiene ese dominio conceptual, hablando de la didáctica, uno ve las cosas totalmente diferentes a como se veían antes, para uno antes todo era un complique, por cualquier recurso. La idea no es buscar el problema, la idea es buscar la solución. Y bueno, es más que todo en líneas generales fue el proceso de la maestría.

E: ¿Qué práctica crees que ha cambiado? ¿Han cambiado algunas prácticas de tú labor? ¿Cómo valoras esa formación? Como supongo que ha habido cambios en tus prácticas. ¿Cumplió las expectativas la maestría? 
Tita: Sí, totalmente. Cumplió las expectativas, porque, cuando regreso a mi colegio, en básica primaria, yo me dije, aquí hay una meta que muchos no habían cumplido, y con este dominio conceptual que tengo ahora de ya no ver problemas sino soluciones, voy a lograr este año, que estos niños me vayan a sacar a mí los mejores resultados de las pruebas saber, empecé un proyecto en donde los niños hacían actividades para las pruebas saber e identifiqué desde mi experiencia cuál era la principal necesidad de los niños, y empecé a trabajar, pero ese proceso terminó el 9 de abril cuando me nombraron acá como tutora, entonces, en cuarto y quinto que son mis cursos que manejé, no he tenido la posibilidad de hacer una nueva práctica en clase. Pero me dieron esta oportunidad y para mí sí me hubiesen dado esta oportunidad antes de la maestría no hubiese sido igual. Porque lo primero que yo encontré en el colegio que me tocó, no había ni plan de clase, ni preparación, entonces, dentro de una de las estrategias que iban a mejorar en la problemática que se estaba trabajando en Patillal, la primera propuesta fue, reestructurar el plan de clase, entonces, yo llegué y le dije a la rectora: -a mí no me corresponde el plan de clase porque no soy el coordinador, pero si aquí no hay esto yo no puedo trabajar y si no se arreglan las programaciones yo no voy a trabajar. Porque yo necesito esos dos documentos para poder integrarlos con lo que me están diciendo a mí que debo traer. Pero esa propiedad, quién me la da, la maestría, saber que la didáctica está en mis manos y yo debo saber de ella, para lograr el objetivo o el propósito que tenga con la actividad o el trabajo que vaya a hacer. La rectora dijo listo. Entonces, hice tres reuniones, una, con los docentes de la mañana, otra con los de la tarde, y otra con los de la otra sede. Entonces, le dije, cómo planean ustedes. Había profesoras que planeaban en un cuaderno, otras en hojas blancas sin un título y sin nada y ahí escribían lo que iban a hacer en la clase. Bueno y de dónde sacan los temas, y decían, -yo tengo ese libro que esta allá, los temas que salían ahí eran los que iban trabajando. Yo les decía: -muéstrame los estándares, los DBA, ellas respondían, -los estándares están en la programación. Les pedía la programación y en una sede había una, en la mañana otra, en la tarde otra. Entonces, en menos de un mes 
yo recogí toda esa información, que son precisamente procesos que se realizaron en la maestría, empecé a organizarla. $Y$ al momento en que iba organizando la información de los docentes yo le anexaba lo que necesitaba en mi trabajo, de tal manera que ellos no se dieron cuenta en qué momento yo me metía el PTA en el plan de clases del colegio. No se dieron cuenta, y antes de llevársela a los docentes, le dije a los coordinadores y a la rectora que tenía esta propuesta, mírenla, revísenla, si tienen duda me preguntan, quitaron algunos ítems, pero por cuál los podemos reemplazar, porque es importante que los profesores hagan una reflexión de sus prácticas. Eso es otra cosa que conseguimos con la maestría, la reflexión de la práctica. Si no hay una reflexión de la práctica no hay un proceso formativo, y si no hay un proceso formativo xlx maestrx lo único que está haciendo en el aula es llevar una cantidad de actividades para mantener ocupados a los estudiantes. No hay más nada. Y cuando ya la rectora y coordinadora le dieron el visto bueno, se los llevé a lxs maestrxs, vamos a trabajar, así y así, inmediatamente empecé, actividad de exploración, ellos decían, eso es cuando uno hace la ronda. Les propuse que se trabajaran los círculos de lectura (unas lecturas que traen un objetivo preestablecido por xlx maestrx, o sea no es leer por leer) usted va a leer ese cuento con los niños, pero ese es el cuento que le va a ayudar a enseñarle tal tema que quiera dar, y eso tiene un proceso, en esa actividad y exploración tiene que haber un antes, durante y un después.

Preguntan que cómo hacerlo, ahí tiene 20 propuestas de cómo hacerlo. Les llevé todas las herramientas para que el trabajo para mí fuera fructífero. Eso logró una empatía con las tres sedes que estoy trabajando y de pronto la empatía, la facilidad que tengo para explicarles las cosas y los temas hacen que ellos me funcionen en el sentido de llevar al aula las estrategias que yo les sugiero y que les propongo, porque, en este momento, todos los están haciendo, en lenguaje, matemáticas, sociales y ciencias naturales. A las otras áreas, les digo, que, si quieren hacerlo, está bien, también ellos las implementen, pero a mí me gusta que no solamente lleváramos el proceso de lectura y escritura a cargo de la profesora de lenguaje, todos hacemos parte de 
este proceso y todos debemos aportar. Estuve en una visita de una profesora de ciencias naturales que hizo una lectura sobre la reproducción animal, y empezó con un círculo de lectura, con un libro que se llama ¿cómo mover un hipopótamo? Entonces, iban viniendo todos los animales de la selva y buscaban una estrategia para mover al hipopótamo que estaba atravesado en un puente y no los dejaba cruzar al otro lado, a ninguno. Resulta que a pesar de que ellos hicieron un análisis literario de ese, e hicieron una comprensión de lectura, lo que la maestra utilizó de ahí para la reproducción fue un juego. Ahora, vamos a hacer una lista de los animales que están en el cuento y averiguar cuál es el tipo de reproducción que tiene cada uno de esos animales. Entonces, los niños ya sabían de qué animales estaban hablando y para ellos no era extraño, sabiendo que ya venían conversando de eso, entonces, este se reproduce de manera sexual, asexual, este no necesita pareja, etc. $Y$ empezaron a dar dos clases, una de lenguaje y una de ciencias naturales, y los muchachitos no sabían eso, pero la maestra estaba consciente que estaba haciendo una clase de lectura y de comprensión de lectura al inicio de las clases de ciencias naturales. Entonces, esa ha sido una experiencias que he hecho yo y es lo que estoy tratando de hacer en Patillal, que no empiecen a cambiar porque lo que xlx maestrx hace en el aula, está bien, eso fue otra de las cosas que me enseñó la maestría, lo que xlx maestrx hace en el aula es totalmente positivo, solamente que hay un momento, que la práctica no se ejecute bien, entonces, lo que pretendemos en esta proyección que todavía se está ejecutando, es que ellos cojan eso que hacen, pero aplíquenlo bien, póngale un orden, donde debe ir. Le ponen un orden, agreguen un poco de picante y le pongan una cascarita. Que el muchacho cuando esté haciendo eso, vea realmente que está en una carrera de obstáculos y en la medida que él vaya derrumbando un obstáculo va a querer derrumbar otro y otro. Pero si se la ponen fácil, no hay ánimo y si se la ponen muy difícil, entonces, lo que va a pasar es que el muchacho va a decir, no sé, no entendí y no va a haber ninguna producción.

E: Bueno Tita, a parte de las transformaciones que hay en el quehacer docente ¿crees que hay transformaciones en el ser docente? 
Tita: Sí. También en todos los aspectos, yo creo que con el posgrado mejora la forma de ver la profesión, el saber que desde ese dominio conceptual que yo tengo, todas las transformaciones que puedo hacer y todas son posibles si me lo propongo y eso se refleja en el ámbito familiar, cultural y social. Uno se convierte en una persona totalmente crítica de las cosas que pasan alrededor de uno, uno no se queda con lo primero que le dicen, más bien conversa, pregunta. Si hay una experiencia en $X$ lugar: oye yo quiero saber de eso. Es como no quedarse en esa mecánica de voy para el colegio trabajo, pero me voy para mi casa y me siento a ver televisión.

Fíjese que no se si lo sabía, no sé si se lo había comentado de pronto en alguna ocasión, la palabra de nuestra investigación que fue optimizar, utilizamos esa para arrancar la investigación, optimización de la didáctica. Optimización del quehacer docente a través de la lúdica como estrategia didáctica, yo desde mi posición como maestra de lenguaje, el concepto de optimización es mejorar, pero un día estaba precisamente explicándole ese concepto a un profesor, pero él era de matemáticas y me dijo ¿Optimizar cómo? Porque es que, si tú me vas a hablar de optimizar, para optimizar tú tienes que dejar otra cosa. Le dije, no, no entiendo. ¿Qué me estas queriendo decir? Él me dijo, desde estadística si tú quieres optimizar el recurso de tu empresa, tienes que disminuir unos gastos. Tuve la cabeza dando vueltas enseguida, porque nosotros discutiendo con los asesores por la palabra optimizar, le dije, que se sentara aquí y le explicara esa duda, y empezó a explicarme, y lo entendí, pero no le encontraba respuesta a lo que yo había pensado, entonces, llegué a mi casa y empecé a buscar en internet. Le pregunté a mi esposo, a mi papá y a mi mamá, y me fijé que aún seguía siendo validada desde mi área. Llegué a la conclusión de que para optimizar la práctica docente hay que dejar de hacer prácticas erróneas, entonces, pude realmente trazar esos dos conceptos, desde la parte literaria con la parte matemática y llegué a esa conclusión, entonces, precisamente, la parte ser docente, la maestría, el proceso de investigación, el proceso del posgrado le ayuda a uno, le favorece a uno, porque uno está a la 
expectativa de todo lo que pasa alrededor, y si es en el ámbito de la educación, aún más. Porque uno siempre tiene algo que decir.

E: Finalmente Tita, ¿Qué sentido tomó hacer una maestría? no solamente para $\mathrm{ti}$, porque ya lo dijiste, sino para los que te rodean, tu familia, tus colegas, tus estudiantes.

Tita: Bueno, mis estudiantes felices y hasta más. Es más, cuando hice la sustentación, que todavía estaba en Patillal, y los muchachos sabían que estábamos en sustentación, yo les dije, que había pasado la sustentación y al día siguiente todos se trajeron sus almuerzos e hicimos un compartir. Ellos me preguntaban, profe ¿pero usted que hacia allá? ¿Hacia clase como las de nosotros? Me decían... yo les decía, allá lo que nosotros estudiábamos era lo que les podíamos traer a ustedes para que aprendan de una manera más fácil y sencilla, entonces por ese lado, la magíster y los profesores me felicitaban, porque a la final, aunque de pronto lxs maestrxs más antiguos, porque en Patillal la mayoría son antiguos, siempre había querido hacer estos estudios, más que por el cartón y ascenso. Yo creo que nosotros, por las dificultades de ascenso quien se mete a esto es porque lo quiere hacer, por ese lado. Entonces, yo me convertí en un ejemplo a seguir de mis compañeros, ellos cualquier duda que tenían, cualquier duda, me decían y más porque dentro de la propuesta propusimos en plan de clases de las áreas trabajadas, me llamaban en la noche o los sábados nos sentábamos a hacer los planes de clase de la otra profesora, pero yo estaba con ella, para guiarla y efectivamente, el colegio me trajo esos resultados de apreciación con los docentes, aunque yo siempre me he hecho querer, pero ya en el ámbito profesional, ya como soy más creíble porque sienten que lo que yo estoy diciendo realmente va a favorecer su práctica.

En el ámbito de la casa a pesar de que soy la tercera de mis tres hermanos fui la primera que me gradué con mi profesión, aunque fue de normalista y solo fueron los primeros cuatro semestres, pero fui la primera que me gradué. Cuando yo me gradué de normalista, mi hermano iba como en séptimo semestre de ingeniería agrícola y mi hermana no estudió, ella se fue a vivir con su 
esposo. Cuando mi hermano se va de pasantía, se graduó casi que dos años después de haber terminado y hecho las pasantías, cuando él regresa de las pasantías, yo ya soy licenciada, entonces, como que mis papás, a pesar de que yo era la última, los únicos cartones allá en la pared eran los míos, ellos se sentaban a hablar conmigo y me decían que se sentían muy orgullosos. Con la maestría y después de la especialización, mi esposo siempre ha querido estudiar, pero él es policía y eso no le permite tiempo, él me queda mirando y me pregunta, yo no sé tú como haces, para hacer tantas cosas, te admiro mucho y mis hijos, ellos no me pueden decir que no quieren hacer una tarea porque ellos ven que yo me la paso estudiando, que me estoy preparando y que les estoy dando un ejemplo. Les digo que lo que estoy haciendo lo hago por mí y porque me gusta, pero también es por ellos para que se den cuenta que no es fácil. Les digo que ellos tienen que hacerlo, y hacerlo bien porque o si no es mejor no hacer nada. Mi hijo tiene 8 años. Tú me haces las cosas bien más o menos, tampoco, no te pido que seas el mejor estudiante de tu salón, pero sí que hagas lo mejor de ti. No más. Si no eres el primero, no me interesa, pero quiero que des lo mejor de ti. Todo eso se lo he dicho yo por todo lo que he aprendido. Yo creo que, para mí, ya tengo otra meta y voy a empezar este lunes que viene. Voy a empezar a hablar inglés, porque considero que si mi título de profesional dice que soy licenciada en humanidades con énfasis en lengua castellano e inglés y no domino el inglés, estoy mal. Pero es una concientización que he logrado tener ahora, porque antes yo decía que lo que sabía de inglés me servía para la básica primaria que es donde yo trabajo y que no me iban a pasar a bachillerato, ya yo no me pongo a mirar si lo necesito o no lo necesito. Tengo un cartón y cada vez que alguien me pregunta ¿tú que eres? Yo digo soy docente de lenguaje e inglés. $Y$ me pasó que un dio un tipo me cogió y me hablo en inglés y yo quede mal.

Tampoco me gustaría decir que soy de español nada más, porque sé que no es así, entonces esa es mi meta ahora. Maestría, curso de inglés y doctorado. Ahora estoy en una lista para hacer un doctorado en Venezuela, vamos a ver si sale, pero dicen que lo van a hacer un grupo grande de acá y entre el grupo se 
va a recoger para traer xlx maestrx hasta acá y no tener que viajar a Venezuela, entonces yo estoy ahí presta. Porque la verdad, estar fuera de la universidad es mamón, yo no puedo estar quieta, a mí me gusta mucho estar leyendo, estudiando, preguntando, haciendo y me gusta mucho este proyecto, me encanta, porque pienso que hay muchas cosas que en los colegios no se hace, hablando del sector público, por ejemplo, en el colegio que estudia mi hijo se van 18 niños para Panamá por cuenta del Estado porque presentaron unos proyectos de ciencia en la Universidad Andina y por ejemplo, un proyecto de una niña que vive cerca de mi casa es sobre la comida vegana, nada de animales. Yo me pregunto ustedes creen que nosotros con la formación que tenemos no podemos tener a un niño en una de esas ferias de ciencias. O sea, qué tiene que la niña hable de la comida vegana, que son frutas, verduras, que la leche de almendras, que no pueden comer carne porque para la preparación tu consumes tantos litros de agua y que si no la consumes estas favoreciendo el recurso para más años de agua. Ese discurso lo puede manejar un niño de una institución pública.

Hace unos días tuve una experiencia que de seguro casi salgo corriendo en una reunión de un megacolegio, yo jamás había entrado a un megacolegio, cuando entro allí y veo esa estructura física, yo no lloré por pena, pero se me puso el corazón chiquitico, porque los que estamos acá, llevamos 20, 30 años, trabajando en un colegio que es de renombre en la ciudad y que no tenga ni siquiera un aula múltiple, una sala de profesores, unas unidades sanitarias dignas, unos salones dignos, bien pintados. Yo llegaba a un colegio de estos que llega el Estado y se gasta 5000 millones de pesos para entregárselo al sector privado para que lo maneje desde la educación pública. Eso no tiene nombre y esas injusticias a mí me dan un dolor, pero yo sigo firme en mi causa y trató de hacer lo mejor que puedo por lo niños.

E: ¡Gracias, Tita! 


\section{Historia Mateo Díaz}

E: Bien, buenas tardes. Vamos a empezar con el relato de vida del profesor Mateo Díaz, él vive en el municipio del Peñol, del departamento de Nariño. ¿Cómo describes este lugar?

Mateo: Bueno, muy buenas tardes. Mi nombre es Mateo Díaz. Soy docente. Soy del municipio del Peñol. He vivido en un municipio aledaño que es el Tambo, ubicado a 20 minutos del Peñol. El Peñol es una región de personas trabajadoras, campesinos humildes que trabajan el campo y quieren salir adelante, que luchan porque sus hijos cambien de vida. Porque les ha tocado muy duro, entonces, es un lugar en el que hay mucho por hacer por la niñez, es una parte donde viví mi infancia, nací, crecí allá y ya por cuestiones profesionales salí de allá. Pero estoy ejerciendo mi profesión en este momento acá en el Peñol. Entonces, es un lugar en el que tengo muchos recuerdos de infancia, muchas experiencias de vida en este corregimiento de San Francisco, donde está la institución, que me impulsan a hacer de mi labor algo para apoyar y aportar a esos jóvenes y a esas señoritas, que de pronto por sus situaciones económicas se les dificulta salir adelante. Trató de hacerles ver que todos estuvimos en algún momento en esta situación y qué con el esfuerzo y la voluntad pudimos seguir adelante y ahora quisiera contribuir a que otros puedan lograr esas oportunidades que yo no tuve. Quisiera ayudar a esos muchachos. Este es un corregimiento (San Francisco) que me impulsa y que me da muchas razones para ejercer mi profesión.

E: ¿Tú estudiaste en el colegio donde laboras?

Mateo: No. Cuando yo estudié no existía este colegio. Era el colegio que había en la cabecera municipal. Yo estudié en la Institución Jorge Eliecer Gaitán de donde yo residía en ese momento quedaba una hora y quince minutos. Nos tocaba a pie todos los días de 7 a 1 de la tarde. A veces nos tocaba regresar a pie porque en ese tiempo no teníamos transporte, ni desayuno. Eran unas condiciones bien difíciles, pero el apoyo de nuestros padres fue fundamental. Nos impulsaban a que teníamos que estudiar y teníamos que seguir adelante y 
aunque había unas condiciones difíciles, íbamos a estudiar porque pensábamos que el estudio nos permitiría mejorar nuestras condiciones. Así lo hacíamos todos los días, muchos estudiábamos allí. Éramos como 50 jóvenes, señoritas en ese momento, pero sí nos tocaba viajar mucho.

E: ¿La formación de este colegio era bachillerato académico o tenía algún tipo de énfasis?

Mateo: No, era un bachillerato de tipo académico, tanto en el momento que estudié como en el que hay ahora, es académico. Aunque es una región muy agrícola y está en la zona rural la modalidad ha sido académica. Pensábamos que sería de pronto más beneficioso un énfasis en la parte agropecuaria para que los estudiantes cuando salgan de la institución. Que algunos que no pueden seguir estudiando, tengan la formación, que les permitan poder desenvolverse en su entorno, en su vida práctica, esa ha sido siempre la visión que se ha tenido, pero no hemos llegado a plasmar eso. Hay muchas exigencias que no las podemos cumplir, entonces, todavía seguimos con esa modalidad académica.

E: Quisiera que me hablaras un poco más sobre cómo es ese colegio donde laboras. De pronto cuándo nace, me decías que no estaba. Cuántos estudiantes atiende, dónde está ubicado.

Mateo: Bueno, la institución donde me encuentro laborando actualmente es una institución relativamente nueva. Yo estudié allá cuando era una escuela (la escuela mixta rural de San Francisco) eso fue en 1985, en ese tiempo yo estuve estudiando allá. Era una escuela muy humilde, una escuela de tapia y en un mismo salón estábamos todos de primero a quinto. Ha cambiado muchísimo, ha ido progresando, se ha cambiado la infraestructura y a partir del año 1999 y 2000 ya empezó el bachillerato, empezó el grado sexto y de ahí ha venido progresando en los diferentes grados.

Los docentes que participaron en este proceso, hay algunos que todavía están: la profe Olivia, vecina de aquí, el profe Víctor, fueron docentes que estuvieron cuando era escuela y en ese proceso de creación de la institución han trabajado muchísimo para la infraestructura, la creación de aulas, todo ha sido trabajo de la comunidad, ellos han hecho festivales, mingas y así se ha ido aumentando la 
infraestructura. Ya hoy en día tenemos una institución nueva, de una infraestructura nueva, aunque es reducida en espacio, con lo cual tenemos siempre un problema de aglomeración de estudiantes, porque el espacio es muy reducido. Pero, las instalaciones son nuevas y realmente hay un buen ambiente de trabajo, muy cálido entre los docentes, somos varios docentes los de allá y eso ha hecho que todos trabajemos para el mismo lado, buscando siempre aportarles a nuestros jóvenes. Esta institución por el momento es modalidad académica, obviamente, trabajamos toda la mañana, todavía no estamos en jornada única y atendemos en este momento 314 estudiantes, entre niños y niñas, todos son hijos de campesinos.

E: ¿Casi todos son de la zona del Peñol?

Mateo: Todos son de la zona rural del Peñón.

E: ¿Cuántos habitantes tiene el Peñón?

Mateo: No tengo claro el dato, pero creo que son alrededor más de unos 27.000 habitantes (todo el Peñol) pero el lugar donde nosotros nos encontramos, nuestra institución tiene un eje de acción de más o menos unos 6.000 habitantes, ese es el radio de acción donde estamos ubicados. Ya las demás veredas todas llegan a la cabecera municipal, a la institución de la cabecera municipal, esa es una institución nueva, ahora hace unos cinco años fue construida, una infraestructura grande, nueva y es una institución que tiene más o menos unos 1.000 estudiantes. Pero la nuestra sí es pequeña, solamente, para el corregimiento de San francisco.

Que más le podría decir de nuestra institución; tenemos unos niños muy activos, les gusta mucho el deporte, son inquietos, pero también están influenciados por ese trabajo rural y ese trabajo del campo y eso hace que ellos pierdan de cierta manera mucho interés por el estudio, ellos ven en el campo la oportunidad de trabajar y de conseguir un sustento, no ven que el estudio les pueda brindar algo más. Entonces, ellos miran el inmediato, el momento, y por esa razón, los niños desde edad temprana empiezan a ayudar a sus padres en las labores del campo, a algunos ya les empiezan a pagar algo.

E: ¿Sobre los 8 año más o menos? 
Mateo: Sobre los 8, 9 o 10 años, muchos de los niños ya saben de las labores del campo, ellos se inclinan por ese lado de conseguir plata. Dicen muchos a veces, que están aquí por familias en acción, por ejemplo, o por los proyectos que hay. Entonces, es una situación que tenemos, un trabajo duro para cambiar esa mentalidad en el estudiante, el decirle que el estudio es lo que le puede servir. Que no hay que mirar solo el momento sino la proyección para su vida y para su fututo. Entonces, hay un trabajo bastante grande en cuanto a cambiar ese pensamiento.

E: Claro, me imagino que en sexto empiezan 30 estudiantes, pero de ese mismo curso a 11 ¿Cuántos llegan?

Mateo: Aunque, podemos decir que la deserción es mínima en la institución. Si empezamos con 30 estudiantes podemos terminar con unos 27, por decir algo. Aunque la deserción es mínima, es muy grande el esfuerzo que hacen los docentes por mantenerlos, porque hay muchos que se van, se retiran, entonces, empezamos el trabajo de los docentes, irlos a buscar, a ver, a que regresen a la institución. Entonces, muchos regresan y dicen, por ejemplo: "no, es que como me vinieron a buscar, por eso vine" entonces, ahí empieza el trabajo del docente que empieza a decirle que no lo haga por obligación sino más bien como una oportunidad de vida. Pero afortunadamente, hemos logrado que la deserción no sea muy alta.

E: Y cuando ya se gradúan, me imagino que hay otra complicación, porque muchos de los que se gradúan prefieren continuar con las labores del campo, que pensar en ir a la universidad, por ejemplo.

Mateo: Sí. Hay algo paradójico, porque muchos de los estudiantes que salen del grado once, el primer año que salen no quieren ir a estudiar, no quieren estar en la universidad, no les interesa, quieren estar libres y no tener responsabilidades. Eso es lo que buscan en el colegio y cuando están en grado 11 pasa eso, ellos piensan que salen y ya no van a tener nadie que los moleste. Pero llega y pasa ese primer año del grado once, entonces, cuando ya se enfrenta a la labor y al trabajo del campo, empiezan a pensar que es muy duro, y tal vez dicen que sí es mejor estudiar. Pero ya para algunos es muy tarde, 
porque ya han pasado ese proceso de formación, de preparación, muchos empiezan a hacer ese proceso por su cuenta, por el ICFES y ya han ingresado. Se puede decir que hay bastantes estudiantes que ingresan a varias universidades, alrededor de un 30\% de nuestros estudiantes que están en las universidades. Ya hay varios profesionales, de hecho, hace un mes se graduó uno de nuestros egresados, en medicina en la Universidad Nacional. Fue un logro para nosotros, tener nuestro primer médico, tenemos otro estudiante estudiando derecho. Muchos otros están estudiando otro tipo de carreras.

E: Supongo que a donde van a parar muchos de estos chicos, es a los técnicos. Mateo: Muchos cursos de formación técnica.

E: Aquí, en el municipio ¿hay instituciones que les ofrecen técnicos, tecnológicos o profesionales?

Mateo: Realmente, aquí en el municipio del Peñol, los cursos de nivel técnicos son muy pocos. Algunos convenios que hace la alcandía con el SENA, es la única entidad que ha venido a dictar algunos cursos, pero no hay extensiones de la universidad.

E: Necesariamente, tienen que trasladarse.

Mateo: Sí, ellos necesariamente tienen que trasladarse a la capital, Pasto. Porque no hay acá en la región, entonces, eso dificulta aún más que los jóvenes y los habitantes de este municipio son de escasos recursos económicos, entonces, eso es una limitante para entrar a estudiar. Pero, aun así, hemos logrado que muchos empiecen a estudiar y yo creo que, si en ultimas, cuando están en el proceso de formación, el estudiante de bachillerato y en el colegio como que nos les interesa el estudio, dicen: - "oye mejor me quedo trabajando acá", pero cuando ya se enfrentan en realidad al trabajo que es duro. Porque yo donde viví, soy campesino de nacimiento, trabajé el campo, trabajé la tierra, me gradué de 15 años y me fui a estudiar medicina a Ecuador, estuve 8 meses, pero por problemas de salud me tocó regresarme, no quise saber más nada del Ecuador, me vine aquí otra vez y dije: “mejor yo me quedo trabajando en el campo" empecé a cultivar cebolla, tomate y así lo hice tres años, hasta los 18 , cuando yo estaba en un momento de trabajo en un día de esos soleados, 
me puse a analizar y dije esto no va conmigo, desde hoy no quiero volver a trabajar en el campo, no porque me demeritara sino porque era muy duro. Al día siguiente me fui, dije: mañana me inscribo a la universidad y así fue, me inscribí, afortunadamente, tenía un buen puntaje en el ICFES, pasé a la universidad de Nariño a estudiar y pues, continué mi carrera y ahora estoy acá. No ejerciendo la profesión que estudié. Porque mi profesión es química pura, no es el perfil del docente, pero ingresé al concurso docente del 2005 por una oportunidad laboral. Soy sincero, y digo, "por una posibilidad laboral". Ya cuando llegué a laborar en este campo, sentí que, aunque no era la vocación mía, es un trabajo que tiene mucha responsabilidad y que de mí dependen muchas vidas y el futuro de muchos jóvenes que están en las mismas condiciones que yo estuve. Toda esa experiencia de vida que yo tuve me ha permitido enriquecer para poder hacer mejor mi labor.

E: ¿Cuánto llevas en el colegio?

Mateo: En el colegio llevo trabajando 10 años. Llevo de docente 11 años, estuve primero un año de docente en el municipio de la Policarpa, la zona de la cordillera era muy lejos de la capital del departamento. Estuve un año y de allá, tuve la posibilidad de que me trasladaran al Peñol y precisamente a mi tierra y a mi casa. Específicamente, a San Francisco. Se dieron las posibilidades y así fue como llegué a San Francisco.

E: En esos 10 años que has estado de docente aquí en el colegio. ¿Te han tocado situaciones difíciles? de pronto en un orden social, de conflicto ¿o eso se vivió antes?

Mateo: Bueno, realmente cuando yo ingresé a la docencia, antes de ser docente yo vivía acá en el municipio del Peñol y era una situación bastante difícil en cuanto a lo social por la propagación de los cultivos ilícitos en toda la cordillera. Eso generó muchos problemas de tipo social y mucha violencia, en ese momento yo no era docente, cuando yo ingresé a la docencia, ya estaba en esos procesos de erradicación de los cultivos, aunque las secuelas y todo eso todavía quedaban allí. La violencia todavía seguía, menos acentuada, pero había. Durante estos 10 años yo podría decir que aún hay muchas consecuencias 
de eso. Pero la verdad, los estudiantes son calmados y no se dejan influenciar mucho por esa parte de la violencia. Con problemas complicados de manejar con los estudiantes en un contexto social, no hemos tenido problemas en la institución. No falta cualquier riña entre los estudiantes de palabras o algo así, pero problemas graves afortunadamente, no hemos tenido (con los estudiantes). Aunque el municipio y la región sí se caracteriza y es muy señalada por la agresividad, pero esta agresión no es en los jóvenes, esta se ve más en los adultos y en las personas mayores, que todavía llevan discusiones y enfrentamientos de tiempo atrás y que todavía las llevan. Pero en los estudiantes, yo diría que es parte y producto de la formación de la institución, ellos han venido cambiando esa mentalidad y los jóvenes hoy en día son muy sanos. No se mira eso de que se maltraten o se violenten entre ellos, entonces, vamos cambiando ese panorama de violencia, eso lo hemos analizado en la institución y hemos visto que la institución está haciendo un efecto, porque antes había una fiesta y nadie quería ir, solamente la fiesta era para la gente del corregimiento, de las otras veredas nadie iba allá porque era una región muy nombrada por la agresividad. Hoy en día hacen campeonatos y llegan de todo lado, de otras veredas y de otros municipios, pero es porque la juventud de hoy en día ya ha cambiado y creemos que eso es parte de la influencia de la educación de la institución.

E: Tú eres docente de Química. ¿De qué grados?

Mateo: Yo soy docente del área de ciencias naturales, más específicamente, del área de química, trabajo en química en los grados noveno, decimo y once. También, dicto a veces en los grados séptimo u octavo, ciencias naturales. Esos son los grados en los que yo trabajo, como le decía yo no soy licenciado, soy químico.

E: ¿Qué haces en tus clases? Descríbeme una clase ¿Cómo es?

Mateo: Puedo decir que este proceso formativo ha cambiado mucho mis clases.

E: Bueno hagamos una cosa... descríbeme una clase antes de este proceso formativo, ya hablamos de él y una clase ahora. 
Mateo: Veamos, por ejemplo, yo antes como profesional de la química, uno tiene una formación científica y uno cree que lo importante es que el estudiante se aprenda ese contenido y yo enseñaba tal y como a mí me enseñaron, con una disciplina rígida. Yo pensaba también que la disciplina era mostrarse con una "cara de bravo" y que nadie le pueda decir a uno nada.

Entonces, yo llegaba a la clase: "muy buenos días, todos se sientan, nadie se mueve de su puesto, quiero que todos se estén quietos, la disciplina es lo primero" entonces, cuando empezaba la clase, veíamos la temática y empezaba a explicar, así como me enseñaron a mí en mi colegio. Esa era la temática, se trataba sobre esto y esto, la explicaba, en algunos casos después de hacer una explicación, les dictaba todo lo que ya les había explicado, terminaba la temática, pasaban una o dos clases y seguía con la evaluación y nadie podía decir nada. Yo era muy rígido, a mí me enseñaron así y uno piensa que eso es lo correcto. Ahora, ya entendí que la disciplina no se gana con ser serio, con ser bravo, la disciplina se gana en el momento en que se empieza a interactuar con los estudiantes a darles confianza y ellos con esa empatía que vamos generando, a su vez, ellos generan un interés en la clase que evita que realicen otras cosas. Eso fue algo que me ocurrió en esta parte, fue un seminario especial e importante que fue el de humanismo. Me gustó mucho ese porque me aportó cosas necesarias en ese sentido. Yo ahora llego, digo buenos días, cómo están, cómo amaneciste, cómo estás hoy... bien profe. Entonces, empezamos a coger esa empatía y luego sí les digo: "ya charlamos, ahora si vamos a empezar la clase" vamos a trabajar, a aportar todos, vamos a participar todos, colaborémonos, me colaboran y así yo les puedo colaborar.

Digo la temática y empiezo a preguntar, a ver qué saben ustedes de esto o con qué lo relacionan. Ahí es donde yo aprovecho lo que ellos me dicen y empiezo a encarrilarlo de tal manera, entonces, los empiezo a meter allí, los pongo a trabajar en grupos de trabajo. Les entrego unas fotocopias. Les digo que analicen la información, que la comprendan y luego las socializamos, les entrego a unos una parte a otros otra parte de la temática y de esa manera empezamos a socializar y cada uno hace su aporte. $Y$ de esa manera vamos 
abordando la temática y se empieza a trabajar de una manera cooperativa. No todos hacemos la misma tarea, pero sí aportamos una partecita para la comprensión de esa temática, trabajamos en grupo, hacemos una puesta en común, empezamos a socializar, y, a veces, también debatimos cómo evaluar. Qué quisieran hacer en la evaluación. Eso me ha cambiado bastante, las clases han sido más amenas.

E: $\mathrm{Y}$ tus estudiantes, ¿evidencian ese cambio? ¿Ha habido reacciones? ¿Qué te han dicho?

Mateo: Sí. Me dicen que ellos pensaban que yo era muy bravo y que no me podían decirle nada. Que he cambiado mucho, ahora nos permite hablar, conversa con nosotros, me pongo a veces a comentarles experiencias de mi vida, me dicen que es muy bonito lo que usted nos comenta, que les aporta mucho. Muchos de los profesores también me han dicho: "profe a usted definitivamente sí le ha servido mucho la maestría, porque se mira un cambio muy grande en usted. Sobre todo, en esa parte del carisma con los estudiantes. Porque antes sí me consideraba que era una persona muy seria.

E: Muy hermética.

Mateo: Muy hermética con los estudiantes, ahorita reconozco un error muy grande que estaba cometiendo. Porque no quería que un estudiante me fuera a decir nada, solo lo que yo decía, y es así. Entonces, ahora a cualquier estudiante lo dejo que hablemos y que debatamos. Esto es muy importante en este proceso que él construya su conocimiento, pero de una manera social, conversar con otros.

E: Mateo, el colegio queda en la comunidad donde prácticamente creciste ¿Cómo son esos vínculos con esta comunidad? O sea, muchas de esas personas te vieron crecer, otras son contemporáneos tuyos. ¿Cómo son estos vínculos? ¿Cómo es esa relación? Y ¿Cómo impacta en tu práctica docente?

Mateo: Resulta que, me doy cuenta hoy en día, de que un gran porcentaje de los padres de familia que tenemos hoy, son las personas con las cuales yo viví mi niñez y mi época de trabajo de campo, con muchos de ellos compartimos trasnochos echando agua en un cultivo, entonces, los conozco mucho, conozco 
a los papás, con los que fuimos compañeros de escuela, ese es el vínculo que tengo, muchos padres que son más mayores. Me conocen, algunos fueron mis patrones cuando trabajaba en el campo y me pagaban el día.

El vínculo que tengo con esta región es un vínculo muy afectivo, (silencio) el cual me vincula y me invita a meterle todo el empeño para que estos jóvenes sigan adelante, como les decía anteriormente.

En las reuniones les hablo a los padres, porque a los estudiantes a veces hay que hablarles un poco fuerte. Con un tono más altico, no agresivamente sino con un tono más fuerte, entonces, les digo que si yo tengo que llamarles la atención sus hijos es porque realmente quiero que ellos tengan la oportunidad que nosotros tuvimos y ellos muchas veces dicen: sí, porque usted estuvo acá y ahora tiene un nivel de vida diferente, y ahora nos está colaborando con los muchachos. Entonces, la gente me apoya mucho, me reconoce, tengo mucho respaldo en la comunidad, por parte de los padres de familia. Aunque, no quisiera decir esto, muchos de los padres de familia y muchos de los docentes me dicen que yo debería ser el rector de esta institución, porque quieren que los estudiantes y la institución progresen.

\section{E: Pero es por ese vínculo que tienen.}

Mateo: $\mathrm{Si}$, y también porque uno quiere que la institución salga adelante. Que los estudiantes salgan adelante, que no se queden allá, que sigan estudiando, que sean profesionales y que, si quieren seguir en el campo, lo hagan, pero desde otro punto de vista o enfoque, con una profesión. Por ejemplo, tengo unos primos que son agrónomos, zootecnistas y tienen sus fincas y trabajan de manera tecnificada. Entonces, eso es lo que quiero, si le gusta tanto el campo vaya estudie, prepárese y regrese. Pero para eso tenemos que nosotros los docentes impulsarlos, eso es lo que yo trato siempre y les hablo a los estudiantes para que no hagan lo mismo que me tocó a mí.

E: Quisiera que me hablaras un poco de tu pregrado, tú no eres licenciado. ¿Cómo fue ese pregrado, esa formación como químico? Yo te lo pregunto porque me imagino que uno como profesional y no como licenciado no pensaría en ser docente. Tendría otras proyecciones laborales. ¿Cierto? 
Mateo: ¡Exacto! Yo cuando ingresé al pregrado en química, fue en un momento de decisión y de decir quiero cambiar este nivel de vida, este trabajo tan fuerte que es el campo y me inscribí. Me inscribí por dos carreras, ingeniería de sistemas y química. Yo dije -la que me salga. Incluso yo diría que son las cosas que a veces Dios le pone a uno en el camino. Yo ese día solo tenía plata para inscribirme a un programa, y yo me iba a inscribir en ingeniería de sistemas, yo sé que fue lo que pasó ese día en Pasto, quería otro programa, valía 5.000 pesos más y yo no los tenía, recuerdo que estaba en la parte de arriba del potrerillo, que queda al lado del estadio la Libertad, y allí estaba un vecino que había llegado de vender cebolla. Me fui allá y le pedí el favor de que me prestara 5.000 pesos más. Él me los presto y me tocó venirme caminando hasta la universidad de Nariño, pero me inscribí a los dos programas. Ahí en ese momento metí química, yo solo iba a inscribirme en ingeniería de sistemas. Y cuando ya salieron los resultados, ingeniería de sistemas quedó de opcional y química pasé de una. Yo lo único que quería era estudiar, no estaba por ingeniería de sistemas, entonces, empecé a estudiar química. Cuando hice el primer semestre, realmente me iba a retirar, ya había pasado tres o cuatro años fuera del sistema educativo y pierde el hilo del estudio.

E: ¿Eso en que año fue?

Mateo: Eso fue en agosto de 1997. Terminé el primer semestre, lo pasé. Pero dije: no vuelvo, voy a terminar el primer semestre por terminarlo, pero al segundo no vengo. Luego dije: mejor hago un curso técnico de enfermería, un año y mejor me pongo a trabajar. Terminé el primer semestre y salí a vacaciones y veía que unos primos me decían que ya entraban a tercer semestre, entonces, yo decía, yo ya voy a segundo, como que me entraron las ganas. Ingresé a segundo semestre, en el primer mes recuerdo que salió un listado de los estudiantes que tenían beca, para matricula, de alimentación, por el promedio, entonces este era de 4.7. Yo tenía un promedio más o menos de 4.1 y dije: "sí ellos pueden, yo porque no voy a poder" y me propuse en ese segundo semestre, dije: este segundo semestre yo tengo que ganarme esa beca. Me puse a estudiar duro y me encontré con un compañero con el que hicimos un 
buen equipo de trabajo, él precisamente fue el que se ganó la beca y yo me le pegué. Con el hacíamos trabajos de laboratorio. Llegamos y quedamos él primer puesto y yo, segundo puesto, pero por promedio nos dieron la beca a los dos.

E: ¿De matrícula?

Mateo: Beca de matrícula y beca de alimentación. Recuerdo que nos daban desayuno y almuerzo en la universidad, y de ahí en adelante todos los 9 semestres tuve matrícula de honor, beca. Yo me enfoqué en el estudio. Había momentos en los que uno salía los fines de semana a divertirse un rato, pero entre semana solo me enfocaba en el estudio. Con mi compañero logramos todos los semestres mantener ese nivel, nunca nos ganaron las matrículas otros. Fue una experiencia muy buena, aprendimos muchísimo y el trabajo de grado no lo hicimos acá en la universidad de Nariño. Empezamos a trabajar desde el sexto semestre en la universidad del Valle. Como éramos los primeros, no había proyectos de investigación, entonces, nos tocó empezar a buscar y un profesor doctor del Valle nos ofreció esa posibilidad y nos fuimos hasta Popayán, él estaba metido en un seminario, charlamos con él y nos propuso un trabajo y nos dijo vengan a trabajar en vacaciones, entonces, terminábamos semestre en Pasto y nos íbamos a Cali a trabajar con él. Del sexto semestre en adelante no tuvimos vacaciones y empezamos a trabajar con él, en el trabajo de grado con mi compañero e hicimos un muy buen trabajo, estábamos en grupo de investigación muy reconocido, trabajamos también con universidades de España, con el instituto de cancerología de Estados Unidos, nosotros sintetizábamos unos nuevos compuestos, los enviamos para allá, para pruebas biológicas, para pruebas de fungicidas en Alemania. Todo esto nos permitió hacer un trabajo muy bueno, hicimos dos publicaciones, una en Estados Unidos y otra en Gran Bretaña, con otros investigadores de la universidad del Valle, y de las universidades de allá, que tenían los convenios con los investigadores de la del Valle, hicimos dos investigaciones con otras personas de España y fue un trabajo muy bonito, una experiencia muy grande y enriquecedora y así fue cómo llegamos a la sustentación de nuestro trabajo. Tenía mucha acogida el 
trabajo, era el primer trabajo de grado, y con todo ese "bombo" que se había dado, ese auditorio estaba completo el día de la sustentación, estábamos muy bien preparados y mi compañero que era el pilar mío, en el momento de sustentar se bloqueó. Los nervios le jugaron una mala pasada y se desmayó. Entonces, a mí me tocó hacer toda la presentación. Como lo habíamos hecho en conjunto cada uno conocía el trabajo y logré sacarlo adelante, logramos una tesis laureada en la universidad, hay dos tesis laureadas en química en la universidad de Nariño y la primera es la nuestra.

E: ¿Solo dos tesis?

Mateo: Solo dos tesis hay laureadas, hasta hace dos años tenía conocimiento en este último año no sé. Pero hasta ese tiempo tuve conocimiento. Tuvimos un gran promedio y nos graduaron con grado de honor a los dos compañeros, de la promoción que iniciamos fuimos los primeros que nos graduamos y los únicos que nos graduamos en ese año. Porque a los otros les tocó hacerlo en un año más porque hubo diferentes tropiezos, se quedaron diferentes materias, etc. $Y$ de los que iniciamos nosotros fuimos los únicos que no graduamos en química. Una carrera muy dura y exigente.

Yo estudié medicina 8 meses y estudié química y podría decir que la química es mucho más complicada que la medicina. Es una carrera muy dura y exigente. Es una ciencia, y, por lo tanto, requiere de mucho esfuerzo y dedicación, es teórica, experimental y tiene que uno fundamentarse en todo, lleva muchas cosas.

E: Yo supongo que cuando te graduaste con honores, eso es un orgullo, muy grande ¿Cuáles eran esas proyecciones? Porque es que tú me estas contando que tienes una experiencia prácticamente como investigador de la química. ¿Qué pasó con esa proyección?

Mateo: Bueno, cuando nosotros llegamos de allá, nosotros eventualmente vinimos de Cali con la proyección de hacer el doctorado. Nosotros trabajamos muy bien con los doctores investigadores y ellos nos ofrecieron presentarnos para el doctorado de las becas de Colciencias, eran unas becas que financiaban los cuatro años. Dos en el Valle y dos en España. Eran muy buenas 
oportunidades y nos iban a postular allá. Entonces, teníamos esa visión, llegué acá, pero, entonces, hubo un candidato de El Peñol que ganó la alcaldía, él le había colaborado a mi familia y está también a él. Entonces, me llamaron y me dieron la posibilidad de trabajar como secretario de gobierno. Yo estaba recién salido quería algunos recursos, no era lo mío, pero mis visiones eran estudiar o irme a trabajar a una industria. Me gusta mucho la parte práctica, el laboratorio, y la cambié totalmente, lo que había estudiado por la parte administrativa. Me iba bien en la parte administrativa, porque conocía a la gente y tenía muy buenas relaciones. Ahí conocí a quien es hoy mi esposa, empezamos una relación y después de dos años decidimos casarnos. Las posibilidades del Valle todavía seguían, nos habían dado la oportunidad de estudiar cuando quisiéramos. En ese momento ni mi compañero ni yo estábamos interesados, él empezó a trabajar en el laboratorio de la universidad de Nariño. Yo estaba por acá, pero ninguno de los dos fuimos.

Después de eso terminé en la alcaldía, me pasé a un proyecto de investigación, aquí en el Tambo, en la planta piloto. Me dieron la posibilidad de coordinar ese proyecto, tres años (2004, 2005 y 2006) estuve trabajando allí. Ese proyecto me gustaba porque era práctico, se acabó la financiación y como tenía trabajo, no le ponía cuidado a la posibilidad de estudio. Luego salió el concurso, ya estaba casado.

E: ¿Cuántos años tenías en ese tiempo?

Mateo: En ese tiempo tenía 28 años. Salió el concurso docente, yo me inscribí. Como una posibilidad de trabajo y me fui. Pasé el concurso, salí y entré a trabajar... entonces, miré que la parte laboral me fue llevando por otro camino, tuve otras oportunidades de trabajo y fui dejando a un lado la parte del estudio. Ya cuando estuve en Policarpa, pensé en retomar nuevamente lo del estudio, porque el ambiente allá era un ambiente complicado y difícil.

$\mathrm{E}$ : ¿En qué términos era complicado?

Mateo: Los estudiantes allá eran un poco agresivos. De hecho, muchos amenazaban a docentes, tenían problemas y enfrentamientos entre grupos armados al margen de la ley y la policía, nosotros quedábamos en el medio del 
fuego armado. Por eso preferí salirme de allí, e irme a estudiar y más con la posibilidad de la beca. Me fui a presentar la entrevista, pasé la entrevista, el examen, todo. Me estaban esperándome, para iniciar en el segundo semestre de ese año, en agosto; en ese mes me fui a presentar las pruebas y en el siguiente periodo semestral o sea en febrero o marzo tenía que ingresar, resulta que en julio cuando ya tenía un cupo, surgió el proceso de la reubicación y me trasladaron acá. Entonces, llegué a mi tierra, me dije estoy trabajando, estoy con mi gente y no me fui a estudiar. Me quedé acá, aunque económicamente la remuneración era mínima, pero igual me quedé aquí, porque irme para Cali, implicaba dejar a mi esposa, irme solo y mi esposa también se iba a quedar sola. En cambio, acá tenía trabajo y me quedé. Afortunadamente, empezaron los procesos de ascenso, de reubicación salarial en concursos y en evaluaciones que hemos presentado, afortunadamente, he pasado muchas de ellas, y económicamente ya mejoré y no he tenido la opción de irme por ese lado, me enamoré de la enseñanza y de la docencia.

E: Pero ¿Cómo llegaste a ser docente? Es la pregunta ¿Cómo fue ese tránsito de químico a docente de química? O sea, debió haber algo allí ¿Cómo fue esa experiencia? ¿Hiciste algunos cursos de docencia o algo?

Mateo: Yo cuando ingresé, ya nos exigieron a nosotros un curso de pedagogía, es un curso que hicimos en cinco meses, porque éramos profesionales no licenciados, entonces, nos exigían eso para hacer el nombramiento en propiedad, hicimos eso, pero realmente para yo irme a dictar esas primeras clases yo no sabía qué hacer, yo pedí los cuadernos de una prima que apenas se había graduado del once y le pedí el favor de que me los prestara y con esos cuadernos yo empecé a enseñar porque en realidad yo no sabía cómo hacerlo ni qué enseñar en el colegio Policarpa. Cogía los cuadernos y empezaba dictar y a tratar de explicar. Eso era lo que yo hacía, yo no sabía que más hacer. No tenía conocimiento de plantear estrategias o de una planeación de clases mucho menos, entonces, llegaba a la clase miraba el cuaderno, y a veces con ese mismo les dictaba. Luego, poco a poco empecé a hablar con mis compañeros docentes, para saber qué es lo que hay que planear, lo que teníamos que 
hacer, pero realmente yo podría decir que todo lo que aprendí fue de manera empírica que fui aprendiendo mi trabajo docente. Ya el trabajo formativo, sí me han dado unas bases sólidas y teóricas.

E: La pregunta es: antes de iniciar la maestría, Mateo ¿no hubo ningún curso? Mateo: No. Yo no he hecho ningún curso.

E: Ok. Continua.

Mateo: Yo hacía mis clases de manera empírica.

E: Tu aprendiste a enseñar química de manera empírica. Con tus compañeros y con la práctica.

Mateo: Yo empecé a mirar qué puedo hacer aquí para cambiar un poco, no dictarles. Fue así, que con otro compañero que también es químico, y él entró a trabajar al colegio Javeriano de Pasto, que es uno de los más renombrados, es privado. A ellos los capacitaban mucho para la enseñanza, entonces, empecé a hablar con él. También químico, que se graduó un año después de mí. Empezamos a hablar bastante y él me decía has esto, has lo otro. Me prestaba unas cartillas, donde decía la preparación de la clase. Entonces, empecé a hacer eso, a implementar el trabajo en grupo, el trabajo en guías. Eso empezó más o menos hace unos cinco años y en el colegio yo no miraba a otro docente que hiciera más que dictar y explicar. Yo empecé a hablar con mi compañero y él me decía que allá, trabajaban en grupos, con guías y nos poníamos a analizar. Me fue hablando de eso, fui empapándome de eso e incluso empecé a meterme por ese lado en el trabajo de la institución y después el rector se dio cuenta y dijo que todos los docentes empezaran a implementar eso. Por decir algo yo empecé a innovar en la institución por mi propia cuenta, metiendo algunas cositas diferentes y ya con la maestría me aportó más.

E: Eso que tú dices de esa experiencia, que adquiriste para ser docente, eso posiblemente haya sido un impulso para decir que, sí querías hacer esa maestría, para ver qué pasa.

Mateo: Sí. Yo sentía que tenía esa debilidad en docencia que me hacía falta, siempre había pensado en hacer este proceso formativo, no se me había dado la oportunidad de hacer este proceso, de pronto por recursos económicos, porque 
esto es bastante costoso, me interesaba, pero no tenía las condiciones, afortunadamente, el gobierno sacó el programa de las "becas para la excelencia docente", en el primer corte no salimos y se me bajo un poquito el ánimo. Luego, salió el segundo cohorte y ahí sí salimos, fuimos unos de los primeros. Entonces, le dije al rector que me incluyera porque yo estaba muy interesado en hacer parte de ese proyecto. El rector entró en el juego de conocer a los otros docentes, porque yo solo no podía ser, debía haber dos, entonces, a los otros compañeros que no son de nuestro estatuto no les beneficiaba en nada, entonces, para qué se iban a meter en esto. Empezamos a conversar con el rector y logramos involucrar a ellos. Entonces formamos el grupo. Pero la verdad sí llenaba todos esos vacíos que tenía y superaba mis malas clases haciendo un proceso formativo. Todo eso me llevo a hacer eso.

E: Claro, con este proceso formativo como magíster en educación; ¿Qué practica ha cambiado? 0 ¿Qué practicas? 0 sea, ya después de que tú dijiste, yo quisiera fundamentar más esa práctica que he adquirido empíricamente.

Mateo: Bien ahí podía decir, en cuanto a la importancia de la puesta en práctica, todo este proceso formativo me ha permitido empezar a reflexionar de lo que estoy haciendo en el aula, qué estoy haciendo y para qué lo estoy haciendo. Para qué hago estas actividades, entonces, es empezar a hacer esa reflexión sobre la práctica y ver que no todo está acabado, en el sentido de que yo diseño una estrategia para una clase, esa estrategia me sirve con unos estudiantes y con un grado, pero de pronto yo tengo que empezar a reevaluar dentro de la misma práctica qué puedo mejorar, qué puedo cambiar, qué me hace falta. Empezarla a alimentar para irla mejorando, eso de cierta manera me ha permitido y me ha hecho ver que cuando yo digo que la química es simplemente experimental y práctica. No solamente lo puedo ver, porque como yo en la universidad solo veía la práctica en los laboratorios, esto me ha permitido que el laboratorio no es simplemente el aula donde están todos los aparatos, sino que este puede estar en cualquier lado hasta en mi ambiente, en mi entorno, el contexto rural que está allí es un gran laboratorio. Los estudiantes tienen cosas y podemos hacer muchas experiencias con cosas 
cotidianas que ellos manejan, experiencias caseras y empiezo a ver que los recursos están allí y que no me puedo limitar porque no tengo laboratorio, pero todo esto lo he podido mejorar porque uno empieza a leer, a mirar y ver experiencias y artículos de otros que han hecho algo así, entonces, uno piensa en hacer lo mismo. Con los docentes, compañeros de otras instrucciones y con los que son de la misma área empezábamos a hablar, por ejemplo, con el profe Oscar, empezábamos a charlar, a preguntar sobre las clases. Entonces, uno empieza a hacer esa interacción y empieza a fortalecer esa práctica. Esos vínculos son bien importantes. En las profundizaciones cuando interactuábamos con docentes de Sincelejo, Valledupar, empezábamos a exponer nuestras experiencias y a proponer actividades didácticas. Tomábamos una temática o una didáctica y la trabajábamos de alguna manera. Empezaba a mirar cómo hacían ellos y veía lo que me servía, eso nos ha servido mucho. Yo creo que, a todos, es enriquecedor todo este proceso.

E: Cosas y experiencias nuevas con las que te encontraste en la maestría. ¿La maestría cumplió con tus expectativas?

Mateo: Sí, yo creo que la maestría cumplió con las expectativas que teníamos, digamos en el campo desde la didáctica, con todo esto de las profundizaciones me ha ayudado a verme como docente diseñador de estrategias para la enseñanza porque nos hicieron ver que la didáctica no está escrita y no le van a decir a usted haga esto de esta manera para hacer esta clase. No, la didáctica la construye uno, uno es el diseñador y uno debe ser el que crea e innova en las situaciones.

Entonces, eso me aportó mucho, cuando venían a darles charlas sobre didáctica yo me imaginaba que nos iban a dar una "receta" para dictar las clases. Entonces, ya comprendí que no eso y que la didáctica la construyo a diario con mis estudiantes, cuando me pongo a analizar y a piensas, eso fue algo nuevo. Algo nuevo, que nos pasó a varios, es ese cambio de mentalidad, en cuanto a la concepción de lo qué es la investigación. Cuando yo entré a la universidad yo vi, la concepción de la investigación como ciencia pura, por el método científico que tengo que partir de una observación, luego, formulo las 
preguntas, reviso los trabajos, hago un diseño experimental y luego, saco hipótesis, entonces, uno mira ese tipo de formación en investigación. Cuando yo llego acá y empiezo a ver otro tipo de investigación, empieza un choque... yo decía, que así no es investigar, cómo, no hay un fenómeno para observar. La investigación que hacemos acá es una investigación fundamentada con unos enfoques, por ejemplo, desde los enfoques activistas salen de diferentes formas y no necesariamente tienen que partir de una observación. Puede partir desde otros hechos, y los instrumentos, yo no estaba familiarizado con ellos, que las entrevistas, que cómo se hace, entonces, esta parte de cómo se hace investigación ha sido novedoso y nuevo para mí.

E: Mateo, ¿Por qué crees que es importante hacer una maestría y un estudio específico?

Mateo: Creo que es importante este proceso formativo, es necesario para los profesionales, sobre todo cuando estamos vinculados a una profesión y ya tenemos definido un perfil laboral, nos ayuda a enriquecer mucho, a mejorar el desempeño laboral. En este caso de la docencia es fundamental hacer este proceso que ayudan y contribuyen para que nosotros podamos hacer una labor en el cual salgan beneficiados los estudiantes, que muchas veces por desconocimiento y falta de fundamentación, a veces cometemos muchos errores que pueden llegar a perjudicar al niño. Pero cuando uno tiene este proceso formativo da muchas bases para uno tratar de hacerlo un poco mejor de lo que se lo venía haciendo.

Entonces, los procesos de maestría sí son importantes para que cualquier profesional, mejore esa cualificación y ese desempeño en el campo que estemos ocupando.

E: ¿Qué sentido ha tenido ese hacer una maestría? En el caso de tu familia, tus colegas y en la reacción de tus estudiantes.

Mateo: Hacer este proceso de maestría ha sido algo muy beneficioso en el caso de mi familia, mi esposa me ha apoyado mucho de forma incondicional, se siente muy orgullosa de que ya vaya a ser magíster y algo muy importante, veo que mi hijo dice que también quiere ser magíster y ser profesional. Él cuando 
me veía haciendo todo ese proceso se aburría, pero ahora dice que soy un ejemplo para él y he sido la imagen de él, entonces, dice que también quiere ser así.

En los estudiantes, también. Ha habido muchos con los que he hablado y me dicen que les parece muy bonito poder seguir estudiando, dicen que quisieran ellos también tener la posibilidad de hacer lo mismo. Algunos de los estudiantes que han egresado están haciendo licenciaturas y dicen: "ojalá tengamos la posibilidad de realizar esos procesos formativos, entonces, alrededor ha habido un impacto positivo.

E: Cuéntame de pronto esa relación con tus compañeros de trabajo. Quizás hay algunas dificultades ("él está haciendo una maestría, yo no" "ahora se va a creer más") esa relación.

Mateo: Sí, cuando empezamos este proceso formativo, pues realmente como en todo proceso y como es una investigación intervención, donde empezamos a hacer una intervención en el aula con observaciones, muchos docentes se sintieron un poco tocados y decían por ejemplo, " si ustedes son los que están estudiando por qué me vienen a involucrar a mí" o "este es un trabajo que tienen que hacer ustedes, entonces, hay un rechazo en cierta medida, empezamos a hacer reuniones y a hablar con ellos para demostrarles que nosotros como maestrantes lo que queremos es contribuir en cierta manera a que todos empecemos a trabajar en una misma dirección y que todos empecemos a aportar para mejorar nuestro proceso de enseñanza para aportarle a los estudiantes. Hubo muchos docentes que no nos apoyaron mucho, algunos han pensado de que como soy el magíster me voy a creer mucho, pero en realidad he tratado de compartir con ellos todo este proceso, cualquier cosita que voy aprendiendo les voy compartiendo y les voy diciendo en los momentos de descanso empiezo a charlarles y les digo por ejemplo que así no es la evaluación y ellos empiezan a ver que también se miran beneficiados con ese proceso y empiezan a entender que han aprendido más cosas, unos dicen que es muy bonito y muy bueno. 
Cuando socializamos la propuesta, con los docentes de ciencias naturales, unos de bachillerato y otros de primaria, me dicen que les comente más, que les diga cómo lo deben hacer. $Y$ están más interesados en apropiarse más, conocerlo más a fondo y así yo los voy guiando y les voy colaborando y queremos continuar mejorando. Dos docentes que en este momento también quieren hacer la maestría, están por aparte, aunque por la edad no la pudieron empezar con nosotros, porque el programa tenía unos límites. Me comentaba una docente de ciencias naturales que se matriculó en una universidad para hacer la maestría, y me decía que ella quería continuar con ese proceso formativo para mejorar su desempeño. Todo eso empezaba a contagiar a los docentes, aunque había algunos (los más antiguos y que están a punto de jubilarse) que son los que no quieren saber nada. Pero la mayoría de los que son jóvenes, son accesibles y receptores para que uno les pueda decir algo y lo toman de buena manera.

E: Bueno Mateo, igracias! 


\section{Historia Adolfo Calles}

E: Buenas tardes, vamos a iniciar con la historia de vida de Adolfo, él es docente del departamento de Nariño. Adolfo, ¿Cómo estás?

Adolfo: Muy bien, gracias.

E: Adolfo, ¿tú dónde vives? Y ¿cómo es ese lugar?

Adolfo: Actualmente, vivo en Pasto. Es un lugar en el que tuve que radicarme por razones familiares y de salud, porque inicialmente, viví unos años en Ipiles, entonces, quise que mi futuro fuera en Ipiales porque ya tenía muchas razones para hacerlo y me radiqué formalmente en Pasto hace unos siete años. Este ha sido mi eje como tal y siempre ha sido este el mismo sitio, siempre me he tenido que desplazar normalmente por dos horas. Y que ha inferido de que este cerca de casa para cumplir ambos compromisos, laborales y de la casa.

E: Adolfo ¿Qué caracteriza a Pasto? ¿Qué es lo que más representa a esa ciudad... fría? (risas)

Adolfo: Aquí en nuestro medio dentro del aspecto cultural, siempre lo que más se valora es la calidez humana, es decir; el hecho de que usted haya dicho frio hace pensar que todo digamos, realmente tienden a ser como en silencio. Pero realmente, cuando uno se acerca a las personas siente la calidez, se siente uno como en casa. Todos recibimos dentro de un aspecto cultural muy amablemente a la gente, sobre todo la gente que no es de nuestro medio se siente alagada y satisfecha, de que encuentran un lugar cómodo, tranquilo y en un ambiente en el que podamos dialogar, también, somos personas que creemos en nuestro territorio, en nuestro mundo, en nuestro diario vivir y en lo que hacemos. La ciudad se presta para hacer muchas cosas. No es un ambiente de condición, no es un ambiente de apuros, es un ambiente donde uno puede controlar fácilmente sus quehaceres, su agenda de trabajo y se presta para muchas actividades que uno pueda ejercer durante la jornada.

E: Muy bien, cuéntame donde trabajas, cómo se llama el colegio donde trabajas. 
Adolfo: Yo, estoy trabajando en la Institución Educativa San francisco de Asís, queda en el municipio de lles, es un municipio que tiene aproximadamente 5.000 habitantes, es un municipio bastante pequeño, está hacia el sur del departamento de Nariño, a dos horas aproximadamente desde la cuidad de Pasto. $70 \mathrm{~km}$ de recorrido hay de Pasto a Iles.

E: ¿Cómo es este lugar? ¿Qué lo caracteriza? (al municipio de lles)

Adolfo: Lo fascinante del municipio de lles, me parece que es ese arraigo cultural, esas costumbres sanas de la gente campesina. Esa amabilidad con al que uno se encuentra, y desde que usted va en la vía, sin conocerlo lo saluda, eso me parece maravilloso. A mí me parece fascinante, todo el mundo se saluda así nunca se haya cruzado palabra, pero si el saludo es muy amable y maravillo. Desde el primer día en que llegué fue lo más maravilloso que, aunque nadie me conocía todo el mundo me saludaba. Y con todos son así, con cualquier persona que pasa. Entonces, esos son unos de los elementos que más me gustan. Lo otro, el espacio social también permite ver muchos valores en las personas. Quizá el hecho de estar alejados de muchos de los eventos que pueden suceder en nuestra sociedad moderna hace de un encuentre en ellos lo más natural de lo que es una familia y una sociedad. Eso me parece muy bonito. He tenido la oportunidad... y de hecho la próxima semana reanudo mis visitas a las familias, tengo dos compromisos para la próxima semana, ya me están esperando.

E: ¿Cuál es tu labor visitando a las familias?

Adolfo: Simplemente es dialogar. Es un diálogo con ellos, de personas. En el que yo les digo cómo veo a sus hijos dentro de ese espacio académico, cómo visiono en ellos su futuro, cómo quiero que integren la familia en el proceso escolar y que no lo dejemos solamente con un espacio donde él únicamente pueda ir a hacer sus estudios y en la tarde volver sin preguntarle qué es lo que hizo, cómo le fue, qué de nuevo aprendió, qué le paso, que pueda socializar con los papás. Entonces, yo me acerco a ellos y trato de decirle a ellos que traten de compartir esos espacios de cómo le fue. Porque los hijos realmente se ausentan 8 horas y quizás más porque algunos viven muy distantes del colegio. Pero quizá nosotros tenemos más tiempo de interactuar con ellos que 
ustedes. Entonces, ellos me reciben con amabilidad y dialogamos en esos espacios. En cómo esa formación, esa educación tiene que ser un proceso desde todos los espacios donde el niño se encuentra y visionar un futuro para ellos, entonces desde allí, se maneja esa perspectiva de las visitas.

$\mathrm{E}$ : ¿Cómo es el colegio donde laboras?

Adolfo: Es un colegio pequeño, desde la parte física usted se acerca y siente que hay una soledad interior, porque se ven unos espacios en donde usted no ve, a gente haciendo bulla, estruendos, sino que se ve un ambiente tranquilo. Yo me pongo a pensar que es porque hay una dinámica tan humana en ello, que ellos ya saben y están comprometidos en lo que están. De hecho, muchos docentes sin necesidad de estar, los estudiantes ya saben cuál es su camino, su recorrido y cuál es su espacio por seguir y lo aprovechan. Hay excepciones, pero, ese es el ambiente que se genera, este un ambiente en el que usted no encuentra bullicio, allí la gente no se dispersa, que estén haciendo actos de indisciplina, sino más bien usted encuentra espacios donde la gente se compromete a un trabajo.

Nuestro colegio es muy pequeño, son 140 estudiantes y esto hace que nuestra educación y nuestro ejercicio de contacto con ellos se más humano. A cada uno le conocemos su nombre, a cada uno le sabemos dónde vive, sabemos cuáles son sus gustos, sabemos cuándo van recorriendo su camino y sabemos cuál va a ser. Sabemos las ideas, los nuevos pensamientos de ellos, hay chicos a los que les gusta escribir, hay una niña que se llama Heidi y que le fascina, ella está ansiosa de que lean sus escritos y que por favor le ayuden a publicarlos, está en ese proceso. Hay otros que les fascina la parte deportiva y se esmeran por demostrar esa parte y que unos los alague diciéndoles que sí están habiendo un buen progreso. Y de hecho lo hacemos día a día. Cositas tan humanas como esas nos acercan mucho a los estudiantes, con ellos dialogamos en muchos espacios. No solamente en el espacio escolar como tal, sino en otros espacios, estamos en contactan con ellos, dialogando algunos eventos, cómo están sus familias, entonces, nos cuentan las historias de los papas y son ambientes muy bonitos, los que hemos podido estar cerca de ellos. 
Al hablar de los estudiantes lo primero que uno ve por aspectos culturales es que son tímidos y de hecho lo son, cuando uno se acerca por primera vez a un muchacho, se ve en ellos que las respuestas vienen en una sola palabra, un sí o un no. Incluso, eso uno, lo ve con los niños más pequeños, cuando entran a grado 6 se les mira a ellos, algo "calladitos", como que si me dicen algo me alzan a ver, perfecto, pero si me quiero alzar a ver me agacho. Entonces, es una sensación que se ve en todos los chicos, por ese mismo ambiente. Pero a medida que uno va compartiendo con ellos, genera unos espacios de trabajo, de normas, de claridades en muchos aspectos que conserva esa relación entre docente y estudiante, que nunca la hemos perdido, y que esa relación se vuelve un poco más amena, un poco más cordial y un poco más amable, un poco más genuina en muchos aspectos, y se conserva ese diálogo, pero igual no hemos perdido el hecho de ser docentes, porque uno dice, pues bueno porque no ser amigos, entonces, a veces uno pierde el rol como tal y se han presentado casos de exceso de confianza, en los que ya se vuelve muy difícil manejar esos espacios. Como se ve en otros lugares o cómo en la misma institución se ha presentado, entonces, nunca dejamos ese rol, pero si manejamos esos espacios, lo que la informalidad sea parte del diario vivir y del aprendizaje.

E: ¿Ellos son estudiantes, niños y niñas de zona rural?

Adolfo: Absolutamente todos son de zonas rurales. Por algunas circunstancias dos estudiantes han tenido que irse a vivir al casco urbano. Solamente son dos estudiantes de 140 . Son muy definidos, pero por razones de trabajo, los padres han tenido que irse a vivir a Ipiales. Los demás, viven en la vereda o en otras veredas aledañas. Sus espacios de interacción solamente son del grupo de familias o de vecinos que se encuentran en la zona en la que ellos viven. Es más, uno los ve "maravilladamente" en las tardes, en un kiosco digital, haciendo consultas de tareas, realizando cualquier actividad, buscando informaciones divertidas. Entonces, uno puede encontrarse en la tarde a varios de nuestros estudiantes los que viven cerca, porque los que viven en zonas más apartadas se van a hacer sus labores del hogar o con su familia.

E: ¿Cuántos años llevas trabajando en esta institución? 
Adolfo: En esta institución llevo trabajando 17 años, el 18 de octubre del 2005, me "arrecuerdo" mucho, porque fue una fecha demasiado especial para mí, el hecho de haber ingresado a allá con una resolución en propiedad que me decía: usted ahora es docente de esta institución. Eso también fue maravilloso, de llegar ese día yo dije, de aquí no me muevo. Porque anteriormente, mi labor era por contratos, entonces, lo removían a uno de un lugar a otro y no se era parte de la dinámica del ejercicio docente en rigor de las instituciones.

E: Adolfo ¿Cómo describes tu labor aquí en este colegio? ¿Gustas de la labor que haces aquí en esta institución?

Adolfo: Sí. Alguien había comentó una historia en algún momento y utilizó una frase, dice: estoy en un trabajo, que me fascina hacerlo, que me encanta, que me divierte, encuentro todo lo que necesito en ese espacio y además me pagan, decía. (Risas) Entonces, esa persona se sentía feliz, y uno siente en ese mismo espacio, uno siente que está en un lugar donde gusta hacer lo que se está haciendo. Me pongo a pensar me sentiría en otro espacio, pero en ese como tal me siento fascinante. (silencio)

E: Entonces, íbamos en que te pregunto ¿Cómo describes tu labor es esta institución?

Adolfo: Es una actividad en la que me fascina estar. La docencia es un espacio, que desde que he tenido la posibilidad de encontrarme en este espacio y me ha fascinado y cuando uno empieza a dialogar con las personas y que ellas vean que uno puede tener elementos para compartir, orientar y visualizar, la labor que uno hace se vuelve enriquecedora. El hecho de ver en ellos una sonrisa, esa satisfacción, unas gracias, a uno lo hace sentir bien, tengo, por ejemplo, personas que han egresado y ellos me hablan, yo los llamo y siempre con gratitud. Es muy gratificante, entonces, describo mi labor como donde yo sé que día a día hay muchas cosas para disfrutar, para compartir, para conocer y estructurar con ellos y eso me hace sentir muy bien. No me imaginaria en otro espacio en el que tendría que trabajar. Tendría que evaluarlo desde muchos aspectos, pero lo que en estos momentos estoy haciendo me parece que es una gran labor. 
E: ¿Qué materia dictas en el colegio?

Adolfo: Estoy dictando actualmente matemáticas. Que es parte de la formación y de la esencia con la cual participé en el concurso, y además dicto otra materia, física, con los grados 10 y 11 . Allí hay unos elementos, siempre me preguntan qué porque yo docto física. Yo ahí veo unos elementos muy anteriores para que haya mirado que es una de las materias que más me fascinen. Y para complementar, la educación física, me parecen esos espacios de relajación muy importantes, para compartir. A nivel recreativo, porque realmente no soy la persona idónea, ni en la institución tampoco hay una persona que lo haga, pero sí tratamos de compartir estos espacios de deporte, ya no son momentos en el interior de un aula, sino que se ve una convivencia externa también en ellos.

E: ¿En qué fue tu pregrado?

Adolfo: Yo, cuando salí del colegio, no tenía como intención de estudiar, puesto que por generaciones ninguno de mis familiares había pasado el bachillerato, de hecho, hasta ahora la única familia, tanto de papá y de mamá que ha salido del bachillerato hemos sido nosotros, y que hemos tenido la oportunidad de llegar un poco más allá, de la parte académica, entonces, todos mis primos, anteriormente, si el caso terminaba el grado 11, tanto de papá como de mamá. Mi papa apenas es bachiller y mi mamá solo terminó la primaria. Un año antes de que yo ingresara a la universidad, mi hermano ya se había inscrito en la universidad de Nariño, iba a estudiar agronomía e ingreso, sino que las condiciones económicas eran tan limitadas, que no había ingresos para uno más. Entonces, teníamos que esperar o encontrar la forma de ingresar de otra manera, así que resolvimos trabajar en el día y estudiar en la noche, esa era como la condición en ese momento y de hecho lo hice. Tuve unas actividades laborales que no eran tan grandiosos, pero me alcanzaba para solventar la situación. Estudie tecnología en administración financiera, en una institución que era mixta, privada y con recursos públicos, era muy económico estudiar. Recuerdo que el primer semestre, valía 150.000 pesos, pero a medida que fueron subiendo los semestres, hubo una normatividad que hizo de que eso 
se privatice. Ya en el quinto o cuarto semestre, prácticamente no había ningún subsidio por parte del Estado y tocaba pagarlo plenamente. Entonces, el séptimo semestre fue bastante difícil en ese sentido. Desde allí, ya las condiciones económicas fueron mejorando, tuve un receso después de esa tecnología e hice un trabajo de grado para una empresa, esta empresa acogió ese trabajo de grado para ejecutarlo y eso nos garantizó dos cosas importantes que recuerdo ahora: un trabajo de grado meritorio, y, que la empresa reconociera económicamente y una vinculación por un año a esta. Dos de nuestros compañeros entramos a esa empresa a trabajar, porque ellos decían: les vamos a pagar, pero lo que más les va a valer a ustedes es la experiencia y lo hicimos, me dieron una supervisión de ventas en una agencia en Tumaco, trabajé todo el año allá, porque ese era el compromiso y mi compañero con el que hicimos el trabajo de grado, lo hizo en Pasto en la parte de supervisión de bodegas.

Ese pregrado propiamente fue en administración financiera, fue el ejercicio que laboralmente fui ejerciendo, porque propiamente la visión de negocio era lo que aspirábamos en nuestra casa, entonces, por qué no estudiar parte de esa esencia, y las condiciones ameritaron hacer estos estudios y las circunstancias fueron las que me llevaron a estudiar eso. De pronto lo que me hubiera gustado estudiar era una ingeniería civil, de hecho, tuve una beca para estudiar en la Universidad Nacional. Porque los resultados de mi colegio me dieron esa opción, pero los costos de desplazarse y de alojarse en otra ciudad rebasaban lo que los ingresos de la familia daban. Eso fue frustrante porque mis resultados en las pruebas de Estado y en la evaluación que hice para entrar a la Nacional sí ameritaban para entra allá. Pero no me dejé. Entonces fue más, no de gusto, sino de acomodarse a ese tipo de circunstancia y de saberlas aprovechar.

E: Esta pregunta es fundamental. Administrador financiero. ¿Cómo llegaste a la docencia?

Adolfo: Cuando yo estaba en administración financiera, el último semestre una institución que se llamaba Politécnico Central, aquí en Pasto requería un 
docente para legislación comercial y para algo sobre presupuestos, hubo un familiar, un tío, que está en esos campos de la docencia a nivel universitario y me dijo: usted sí está preparado para estas áreas, le dije que sí. Entonces, yo alterné en el último semestre prácticamente con la docencia, y me empecé a enrolar en esa parte de la docencia, pasó un ciclo en el semestre y me dieron otras cátedras, de hecho, mis compañeros se burlaban antes de salir de la universidad, me decían, "yo me voy a poner a estudiar, porque si no Adolfo nos va a empezar a dictar clases aquí". Miré como esa posibilidad y ellos se pusieron a hacer especializaciones y otras cosas más. Por allí me empezó a gustar la docencia, trabajé con ellos y esa primera experiencia de trabajar con chicos, con jóvenes prácticamente en unas cátedras. Posteriormente, estuve haciendo otro ejercicio en otro Politécnico y las cosas de la vida hacen que esto desaparezca y quedé en un espacio, donde ya no había posibilidades de seguir con ellos, sin embargo, hice unos estudios sobre formación pedagógica en la Universidad Mariana, y conocí a alguien especial allí, que era un rector de un colegio indígena. Él también vino a hacer sus cátedras para escalonarse, él para escalafonarse y yo para adquirir unos nuevos elementos para poder seguir eso ejercicio. Pasó cerca de un año y me lo encuentro en un evento familiar, al rector de este colegio, que era sacerdote y me invita, como estudié con él e incluso hicimos el trabajo grupal con él. Me invitó al colegio indígena, hablamos con el alcalde y a través de un contrato, porque no se podía de otra forma, me lo dieron por seis meses. Él me preguntó que, si me le medía y le dije listo, vamos, sabíamos que las situaciones laborales acá no estaban muy favorables y me vinculé con ellos. La experiencia en ese colegio fue supremamente increíble. El hecho de que haya estado 4 años en ese colegio indígena hizo que mi perspectiva profesional cambiara totalmente. Hice una especialización, mientras estaba en esa institución y mi proyecto lo basé en las matemáticas para este tipo de comunidades, fue muy valioso lo que pude hacer allá, me pareció fascinante. Me fortalecí fuertemente en este espacio, yo creo que esa institución fue la que marcó la diferencia en mis acciones laborales. Porque, de hecho, mientras yo estaba en ese colegio había algunas otras 
propuestas aquí en la ciudad, pero no con la misma magnitud ni con la misma continuidad de como yo lo veía allá. Allá, lo veía más a largo plazo, que acá, porque eran cositas temporales. Entonces, fueron 4 años, desde el 2000 hasta el 2003. Esos cuatro años me sirvieron inicialmente, para aventurarme en ese campo de la docencia, mientras estaba en ese colegio indígena, en el que yo tenía que salir de Pasto a un municipio, que es Barbacoas, y desde allí caminar cuatro horas para llegar al colegio, esa era mi rutina. Salía a los 8 de la mañana, llegaba a las 12, almorzaba y desde la 1 hasta las 5 de la tarde dictaba la clase. Nos daban el viernes, entonces, yo salía el jueves. Las circunstancias hicieron que tomara la decisión de retirarme, en un momento en el que la situación social se había vuelto tan difícil, en el que uno podía ver a muchos de nuestros estudiantes vincularse a grupos ilegales, y verlos un día con uniforme y después de unos días con un arma, era algo que no lo hacía sentir cómodo a uno, a pesar de que uno manejaba una relación prácticamente de afectividad con ellos, pero uno no les podía decir que no lo hicieran y mucho menos irse en contra de algunas cosas allí. Posiblemente, lo único que uno atinaba a decirles era: "piénselo bien" "hay muchas opciones" "evalúe toda".

Entonces, uno se miraba cuando en otro aparecía en otros espacios, y eran unos espacios difíciles de salir, y lo más triste y doloroso era ver a los mejores estudiantes perderse, desaparece o morir. A uno le dolía el corazón, le daba mucho dolor, créame que uno lloraba en esos espacios, porque daba la sensación de que algo faltó. ¿Qué pasó con tal estudiante? Murió en tal encuentro, uno decía: que pérdida tan grande y ver que eran estudiantes que tenían un futuro impresionante y con una capacidad de análisis, trabajo, de colaboración. La esencia como persona era grandiosa. Uno les decía, usted, como indígena se va directo a una universidad y usted va a ser el próximo profesor de acá, usted va a ser el próximo médico; porque uno les veía una capacidad grandísima y no sé qué motivaciones, razones tuvieron por otros espacios que, prácticamente los perdimos. Incluso, después de que salí, uno o dos años después, aún tenía contacto con ellos, y me contaban historias, de que los encontraban después de un tiempo, llegaban después de un tiempo y de 
otros llegaban solamente los restos. Eso era una cosa que en realidad a uno le dolía mucho el corazón, eso me marcó mucho y me acercó mucho a las personas, el ver en ellos que antes de lanzarse a un solo espacio y a un solo camino deben explorar todo les marca tomar decisiones. Entonces, eso es lo que hago ahora, hacer que los chicos, las decisiones que tomen en su debido momento deben ser estructuradas, con tanto valor y tan consensuadas con las personas más cercanas, de tal manera que ellos fijen una meta que sea mucho más apoyable por todos los demás. Eso me hizo pensar demasiado y me hizo cambiar muchas situaciones de lo que uno ve en una comunidad. Salí por varias razones, mientras yo estaba allá, tenía la posibilidad de trabajar en una universidad.

El día más duro era el jueves, porque yo le pedí al colegio que me asignaran todas las horas muy junticas, de manera que el jueves pudiera saliera más temprano, salía a las 10 de la mañana del colegio, entre las 10 y 2 de la tarde viajaba hasta el pueblo, y entre las 2 y las 6 de la tarde viajaba hasta Ipiales, a las $6.30 \mathrm{pm}$ estaba en la universidad, tenía que iniciar las clases, es decir, tenía que hacer un viaje de 8 horas para llegar la universidad. Y, trabajaba de $6.30 \mathrm{pm}$ a $10.30 \mathrm{pm}$, a las $10.30 \mathrm{pm}$ iba al terminal, el bus que salía directo Ipiales-Cali era el que me servía para que me llevara a Pasto. (Silencio)

Entonces, llegaba tipo 1 de la mañana a la casa, dormía tranquilamente y al otro día me iba a las cuatro de tarde para llegar a las 6 y dictar mis clases y regresarme en la misma rutina, eso sí, tenía mi viernes libre. Pero se admiraba la gente de verme salir todo sudado y cansado de un colegio, darme un baño, me arreglaba cuando llegaba a Ipiales y un familiar que estaba ahí, me daba chance de ponerme una ropa más adecuadamente, para ir a la universidad, una corbata e ir a dar mis clases. Yo llegaba a mi casa encorbatado, después de salir, ¡imagínese! Con tenis, en épocas de lluvia, con barro, llegaba al pueblo, me daba un baño e iba al colegio. Y, entonces, yo alterné las dos actividades en el último año, quizá fue un poquito más, tal vez fue año y medio entre el colegio y la universidad. 
Posteriormente, los sábados, me vinculé a una asociación de campesinos, se llama Asociación para el Desarrollo Campesino, trabajaba de lunes a jueves en un lugar, lo jueves y viernes en otro, y los sábados en la asociación. Lo maravilloso fue que esa entidad hizo un proyecto en el que yo participé y me dijo, miré, lo necesitamos toda la semana a usted, toda la semana. Porque necesitamos trabajar no con un asociado sino con cuatro más. Entonces, me pusieron a pensar. Las circunstancias allá ameritaban que era difícil la vida, porque algunos de mis compañeros perecieron, otros se retiraron, otros se quedaron. Los que éramos más equilibrados en el manejo de la información, no tuvimos ningún percance, aunque nos confundía. Alguien nos confundía en algún momento, ahí vienen los guerrilleros, en pleno juego. Eso nos asustó, y lo que primero le dije frente a esa comunidad, que usted tiene que mirar antes de decir las cosas, mire en qué situación esta, el hecho de que haya hecho eso nos compromete y nos pone en riesgo, si algo nos pasa es su culpa. Porque era un retén. Nosotros pasábamos por el retén porque teníamos que ir a trabajar.

$\mathrm{E}:$ ¿Un retén de grupos al margen de la ley?

Adolfo: Exacto, entonces llegaron, nos vieron pasar a un profesor y a mí. Como nos ve salir de la montaña, creyó (el guerrillero) que éramos parte de otro grupo al margen de la ley. Entonces, me tocó decirlo en voz alta, que cualquier situación que nos pase era culpa de ellos. Les dije: averigüen en qué situación estamos, somos docentes y de hecho me voy a trabajar a una universidad.

Las circunstancias hicieron que yo me viniera a trabaja acá.

E: ¿Eso fue en Ipiales?

Adolfo: Fue en Ricaurte, en la zona de Piedemonte costero. Era una zona donde era difícil todo.

E: Zona guerrillera.

Adolfo: Zona guerrillera, donde usted cada $10 \mathrm{~km}$ se encontraba grupos distintos, paramilitares, guerrilleros, policías, ejército. El uno le pregunta: ¿usted los vio por allá, que están haciendo, donde están, etc.? Uno tenía que ser muy retórico con las respuestas, esto fue en los últimos días que trabaje 
allá. Pero, como las circunstancias, no lo pensé dos veces y tomé la decisión de retirarme. La universidad me acogió 12 años, en Ipiales.

E: Es el momento, en el que todavía estas con la asociación.

Adolfo: Sí, de hecho, mañana tengo que trabajar (risas), pero no lo estoy haciendo porque he tenido otras situaciones flexibles, entonces, ya me radiqué en Ipiales, pero mi ejercicio docente en la educación empezó allá.

E: ¿Eso en que año fue Adolfo? Que te radicaste en Ipiales.

Adolfo: Eso fue en el 2004, porque en el 2003 renuncié formalmente allá. Hasta diciembre llegué, pero ya empecé a trabajar acá durante toda la semana, trabajaba en la asociación, aquí en Pasto en las mañanas, e iba en las tardes allá (a la universidad). Luego, la asociación terminó su proyecto, año y medio que estaba y propiamente tenía que estar en la universidad por las noches, entonces, tuve la oportunidad, la misma directora de la universidad me dijo, que me fuera al Colegio Filipense, que era donde arrendaba la universidad, hablé con la monjita, yo ya había hablado con ella, pero en una charla informal, que necesitaba un docente de física, Entonces, yo me le medí. La monjita me hizo una entrevista y me vinculé formalmente, en ese colegio estuve dos años.

\section{E: Y entonces...}

Adolfo: Me acogió la monjita e hicimos un buen proceso, era colegio de niñas. Digamos dentro de lo colonial, hijas de papás con dinero o como se dice de “papi y mami”, entonces, era difícil el manejo, pero después de estar en una institución indígena, con sus costumbres, su cultura y sus conflictos, era una situación muy distinta y bueno, en este nuevo colegio, era una armonía distinta a la que estaba acostumbrado. Era un colegio de ciudad, mientras allá, llegaban a caballo, acá, las niñas llegaban en carro. (Risas)

Era una historia muy distinta, entonces, y me ponía a reflexionar, yo me decía: “caramba, las cosas como cambian en este colegio" es que aquí había unas niñas que los papás las traían en sus buenos carros, llevaban a las niñas impecables, hermosísimas, con sus sacos y su vestimenta revisada de lado a lado, hasta una medallita, que, si no estaba bien puestica, primero se la 
acomodaban y así entraban a la institución. Era una pulcritud impresionante. El ritmo distinto.

\section{E: Cambio radical.}

Adolfo: Cambio totalmente radical. Era una cosa impresionante, pero también dentro de la misma institución, había una misma dinámica. Lógicamente, el mundo de ellas era mucho más diferente. El hecho de ser niñas consentidas, muchas de ellas, se prestaban para que en el salón hubiera su recochita, sus burlitas y todo eso. Pero, entonces, uno desde el principio llega con una seriedad en su trabajo, sin aislarlas. El hecho no es de aislarlas, porque sería difícil el manejo, sino que de integrar desde un punto en el que uno si pueda con ellas conversar desde el rol que a cada uno le compete, se pasó todo un año y se presentaron unas pruebas, a las niñas les fue súper bien, de hecho, la monjita me felicitó, le pareció el ejercicio muy bueno, porque me dijo: “lo vamos a vincular el próximo año, no me diga nada más" "usted por favor, no se me comprometa que aquí va a seguir"

Me asignó tres materias. Pero, era la parte que ya había hecho una especialización. Entonces, lo que me dijo ella, me arraigó más a lo que estaba haciendo. Ella al decirme que sí me necesitaban en el colegio, quiere decir que una valoración muy buena. De hecho, la universidad, también hacia unas evaluaciones a sus docentes y siempre muy formal, la directora de ese momento de la universidad, cada año evaluaba a los docentes, ya los que tenían una valoración sobresaliente les daba una especie de diploma y un reconocimiento. Créame que eso me hacía sentir muy bien, que me ubicara siempre en los primeros lugares, y me dieran ese reconocimiento, entonces, me sentía muy cómodo allá, porque los que evaluaban eran los estudiantes y el hecho de tener experiencia no solo con estudiantes de colegio, sino también con estudiantes de universidad y de avanzada edad porque de hecho muchos de mis estudiantes, eran mayores que yo, eso me hacía sentir más maravillado. Pero el ambiente de colegio, esa experiencia de compartir el compartir y alimentar muchas cosas es fascinante. Porque en el colegio como tal no había muchas opciones como las que antes vivía, (en el colegio indígena). El hecho de 
hablar con ellas y de formar un ambiente de convivencia no se prestaba, prácticamente, los grupitos de niñas se aislaban, el docente no interactuaba en sus espacios. Mas bien, la rectora decía que este espacio es para que los docentes descansen, conversen con sus compañeros, se tomen un café. Entonces, no había un espacio de interactuar más allá, escasamente, de la relación académica docente y estudiante.

En el segundo año, mientras yo ya estaba listo para arrancar mi proceso, en ese tiempo trabajaba en calendario $B$, yo ingresaba en el mes de agosto y la rectora dijo: "bueno, sus contratos están listos aquí para arriba, pero como yo sé que ustedes acaban de hacer un examen para el concurso docentes del Estado, entonces, voy a dejar estos contratos un poquito retrasados, mientras ustedes hacen eso". Porque de lo contrario ustedes se tendrían que ajustar a lo que dice el contrato, entonces, todos los docentes estábamos en esa dinámica. Pasó uno y dos meses y como no había respuestas, entonces, estábamos a punto de firmar, cuando de un día para otro nos dicen, mañana tienen que estar en Pasto y seleccionar donde van a trabajar. En el día anterior, no sé cómo fue que llegó una lista de colegios, y pues el máximo sueño era de quedarse cerca de Pasto, pero eran todos lejanos, en los pueblos más distantes y que nunca había ido. Imagínese uno tomar una decisión de a qué colegio voy. Por ejemplo, un colegio San Luis, de la vereda $X$ y del municipio $X$, entonces, uno decía que era difícil, porque hay compañeros de que estaban a 10 o 20 hora de su hogar y eso les implicaba salir cada mes a ver sus familias, o casos más extremos, cada seis meses, decían otros, y dormir en habitaciones, entonces, era una decisión muy difícil porque no conocía la ubicación de los colegios.

El día anterior lo que hice fue lo siguiente, tomar el listado, de hecho, lo tengo en una carpeta, como parte de lo que uno ha vivido, eso es maravillo guardar esas cosas, en ese listado decía, Colegio San Francisco de Asís, colegio San Isidro, etc. Y el municipio, entonces, yo llamé para averiguar, pero ese tiempo no había celulares, así que había dos opciones: llamar al puesto de policía o a la parroquia, y créanme que en esa tarde empecé colegio por colegio de los más cercanos a Ipiales, empecé a llamar a todos los colegios y me daban 
respuesta o bien de la parroquia o bien de la policía, porque no había otra opción. El colegio que más me parecía cercano, era un colegio que estaba cerca del municipio de Pasto que se llama Buesaco, pero que desde allí había que caminar y coger un transporte de 8 horas para llegar al colegio, no lo recuerdo, pero casi tomo la decisión de que ese era al que tenía que llegar porque quedaba a menos minutos de Pasto y créame que más de un compañero de los que yo conocía se quería ir para allá. Al mes, renunció y se devolvió porque era un lugar en el que le costaba más su pasaje y su transporte que su salario. Entonces, tomé la decisión acertada después de que por lo menos me acerqué, luego empezamos a llamar y a evaluar algunas de los lugares donde tenía que tomar la decisión. Afortunadamente, también estaba trabajando en el SENA, estuve allá por un año, y desde el SENA tuve la oportunidad de ir hasta lles. Entonces, ya en mi mente, Iles me parecía un lugar en el que yo ya había ido, pero no sabía la vereda en que me tocaba, llamé a alguien conocido en lles, tenía un teléfono que estaba entre mis contactos que buscaban proyectos de crianza de cuyes. Había una persona que me habló y me dijo que era cerquita y que si me iba en carro duraba por hay unos 20 minutos. Y dije, este es el lugar. Ahora tenía que ir al otro día a la secretaria y ser uno de los 5 primeros en las pruebas para matemáticas, porque de los 2000 que se presentaron solo había cupos para 22, porque ese era el expediente. Yo por fortuna tuve el segundo puesto. Entonces, llegó una señora y tuve que decirles que se ubicaran de acuerdo con el orden. La decisión fue trascendental porque el tercer puesto era en un lugar mucho más apartado. Desde allí he estado, he querido buscar otras opciones, pero por el rigor que eso tiene y por la convocatoria y todo el tema jurídico ha sido muy difícil buscas otras opciones de traslados. Me he arraigado en ese proceso y aquí estamos.

E: Bueno, es una trayectoria de formación docente muy complicada y bastante interesante.

Adolfo: Sí, de hecho, con los únicos que no he podido trabajar realmente son con niños de 10, 8 o preescolar. Sería bonito vivir también esa experiencia de 
tener que compartir con niños de primaria, pero no como el profesor titular, pero a partir de los 10 años hasta muchos años arriba sí. (Silencio)

E: Bueno, Adolfo con esa trayectoria que tienes como docente ¿cuáles han sido las experiencias que has ganado formándote como magíster?

Adolfo: Le cambia mucho la percepción del rol de maestrx, o sea, realmente la cambió, yo sé que desde el pregrado uno miraba que todo proyecto debía ser desde el esquema cuantitativo. Incluso antes de este ejercicio en la maestría, todo mi mundo era cuantitativo, impacto que genera tal cosa... todo era numérico y estadístico y se utilizaban métodos exactos. Un ejercicio anterior al de la universidad, antes de la maestría, fue trabajar en un proyecto con una empresa, que lanzó este proyecto, inicialmente, lo hizo la universidad de Nariño, pero también desde el Ministerio de Educación, para generar ciertos proyectos que impacten a las instituciones. Nos hicieron la invitación a todos los docentes, cada uno lo hizo y calificamos dos ejercicios. Entonces, ya fue un compromiso continuar con el ejercicio porque ya había un presupuesto, entonces, continuamos con esos ejercicios y ya en la siguiente fase solamente califiqué uno. Pero, entonces, ahí me encontré con el tropezón más fuerte, y fue mi visión del trabajo cuantitativo sobre el trabajo cualitativo, cuando ya a uno le decían que el cambio se genera desde el impacto de tales elementos, a decirle que es la percepción que se tiene de tal fenómeno. Entonces, el hecho de que se diga percepción, hacia un cambio sustancial, pero era muy necesario hacerlo. Incluso en algún momento alguien habló en una conferencia que estuve sobre investigación social. Yo decía que era algo muy subjetivo, incluso debatí con la persona conferencista, de cómo uno puede tomar la postura en el que se está tomando una determinación a su propio modo y no al mío. Yo decía que era un diálogo cuantitativo diciendo que hay unos elementos en el que usted puede comprobar que eso sí existió. Mi mundo daba vueltas al inicio, y llegué acá y para rematar cambió mucho, estaba en un conflicto total. Ver esa situación desde un mundo mucho más cualitativo y ver una sociedad que juega en muchos espacios en la construcción de un conocimiento y de una historia, de un proceso, entonces, hace de que uno ya vea la estructura de la docencia 
desde otra percepción, no a los numero sino a los elementos que hacen parte de esos resultados, incluso, mis valoraciones son distintas, a pesar de que soy docente de matemáticas, ya no lo veo tan cuadriculado, y hay espacios diferentes y de flexibilidad, y ahí, de conocer a los estudiantes desde otras facetas, me hace de que yo también pueda valorar esos elementos que han hecho crecer a los estudiantes. Por eso es por lo que yo me integro más con los estudiantes, discuto, veo otras situaciones. Hay estudiantes que quieren hacer las cosas, otros que desean hacer las cosas y otros que aparentan hacer las cosas, entonces, uno logra un acercamiento con ellos y uno ya se da más cuenta de eso. Por eso ha sido maravilloso estar en una institución en la que trato a todos mis estudiantes por su nombre y comparto algunos pequeños espacios, así hablemos de fútbol, deporte, de algo diferente, momentos familiares, de la producción de papa, de leche, de asuntos que están cercanos a ellos. Esos elementos hacen también que yo como docente vea cómo ellos crecen en sus procesos. Me encarriló en este mundo, desde la maestría eso me cambió, el hecho de que yo vea que no solamente, el de las situaciones es el estudiante, yo también veía que los problemas venían de parte nuestra. La palabra más sonada desde los lineamientos del MEN, siempre ha sido el aprendizaje, si, esta tiene gran cantidad de elementos. Pero ya con una convicción de que el ejercicio formal del docente tiene que marcarse en los procesos de enseñanza, en esa didáctica, en ese proceso, para llevarla al otro campo que es macara un mundo diferente y desde una visión distinta a la que se tenía. Entonces, ya se manejan todos los esquemas que desde las teorías ustedes nos han propuesto, y que las hemos apropiado, y que empezamos a ver el ejercicio docente desde un esquema en el que el protagonista también es el docente y no solamente el estudiante, el docente es el constructor, facilitado de la enseñanza.

E: Indudablemente ha cumplido tus expectativas la maestría.

Adolfo: Claro, me cambio. Incluso, hablando con el rector, él dijo que ya tiene un plan diseñado para el próximo año de cómo abordar los procesos que tenemos en compromisos. Todavía mi cabeza da vueltas, pero trato de no llevarlo a terrenos, pero la idea es cómo impactar en la institución con lo que 
uno sabe y llegar con eso a la institución, de hecho, los otros compañeros de la institución, algunos lo ven como un ejercicio adicional de estudios, pero el rector lo ve como un reto. Nos dice que tenemos que hacer algo más. Que deben demostrar algo más a los demás compañeros.

Entonces, sí ha cambiado totalmente, incluso mi actitud como docente en un área que realmente cobija unas expectativas distintas en términos de hacerla más asequible a los estudiantes. Porque llenar el tablero con una serie de fórmulas y de números, parece no interesarle mucho a los estudiantes, el tratar de contextualizar eso y hacer que esos elementos se vuelvan cotidianos, que el estudiante los pueda recrear en algo que ve todos los días, eso es lo que ahora mi tablero trata de decir, cada vez algo distinto.

E: Adolfo, ¿cómo fue ese primer semestre de formación como magíster? Puedes relatarme un poco de ese primer semestre, cómo fue conocer docentes de otras instituciones, el trabajo en grupo, la relación con los docentes de la maestría. Adolfo: Créame que me sentí en un espacio cómodo. No puede decir que me sentía perdido con esto nuevo. Yo comentaba anteriormente, que uno de mis retos grandes era poder hacer los estudios de maestría, de hecho, la tenía dentro de mi proyección. Se dio esa oportunidad y yo era la persona más entusiasmada en estar acá. Venía con toda la intención de estar acá, de hecho, mis compañeras que tenían las posibilidades y los requisitos motivarlas para que hiciéramos en trabajo, el ejercicio. Otros desistieron en el camino, otros no cumplieron los parámetros que se requerían. Pero me iba a sentir frustrado porque veía que cada uno se iba retirando, iba saliendo y uno de los requisitos, era que al menos debía haber más de un docente, entonces, yo me sentía con la preocupación y trataba de alentar todo ese proceso para seguir, para tratar de continuar y, de hecho, avanzamos. La relación entre todos me parecía en la que todos estábamos con esa expectativa de llegar, de aprender, de explorar, de identificar algunos nuevos elementos con los cuales uno puede hacer su ejercicio laboral y con todos los compañeros del grupo, que estuvo aquí manejamos una relación de compañerismo muy activa, con mucha fluidez en lo que se conversaba, siempre había un tema de conversación con ellos, porque 
siempre había algo que decíamos acá. Siempre alguien se acercaba y hablaba y salía algún tema de conversación. También había unos más cercanos con los que uno podía explorar, hubo otros elementos para trabajar y compartir, pero siempre el tema de conversación fue esa parte de estudio, esa fue la esencia, por lo menos mis relaciones con ellos eran de estudio. Fue un ambiente agradable en el que todo el mundo se sentía con el mismo objetivo. Todo el mundo se identificaba con lo mismo. Nadie estaba perdido aquí.

E: Adolfo, tu hablaste de que efectivamente hay transformaciones en la práctica docente con el estudio de magíster. ¿De qué tipo son? Te estoy hablando de un tipo pedagógico, de un tipo socio educativo, del contexto en el que te encuentras, lógicamente, hablamos de un tipo disciplinario. ¿de qué tipo has considerado esas transformaciones en tu práctica?

Adolfo: Creo que usted menciona todos los elementos que ha habido acá, realmente ha habido cambios en la forma de ver y de actuar como docente, no es tan fácil decir cómo ha cambiado la forma de actuar, pero realmente sí, porque cuando uno antes llegaba solamente con un saludo: "buenos días, por favor su cuaderno, vamos a hacer la siguiente presentación y ustedes me recuerdan lo que vimos la clase pasada" esa podía ser siempre la rutina. Pero, el hecho de que usted llegue antes de entrar a clase, y trate de motivar a sus estudiantes y tenerlos en un espacio donde todos se sientan concentrados. Dejar unos cinco minutos para hablar de un tema en el que todos se sientan identificados y que eso los lleve al tema, es algo que lo estoy haciendo. Y, de hecho, tengo que "cranearme" con la última noticia que hay en el momento, yo tengo que acercar esa parte a mis clases. Yo acerco esos elementos de contexto al tema. Ya el tema esta estudiado, esta analizado y revestido de toda la información, lo que tengo es que acercar a mis estudiantes al interés de ese tema. Eso es algo que lo estoy practicando y que antes no lo veía tanto, de pronto si, llegaba un día, una charla sobre algo que tenía que ver con lo humano, con la formación; pero el hecho de integrar esos elementos pedagógicos con los elementos humanos ha hecho de que los chicos sientan más afectos por uno. Sean más afectivos, y son personas que yo no sé, algunos le 
hacen caso o no, pero cuando uno les conversa y si es un regaño se hace con sutileza y ellos lo reciben con gusto, porque saben que realmente es algo que a ellos le va a servir. Porque uno no debe hacer el papel solamente de aquí estoy yo, usted está allá y todo lo que le digo a usted lo va a tener en cuenta y que todo lo que yo le diga usted tiene que respetarlo, uno peca en eso, porque a veces uno se vuelve demasiado directo en esa línea de acción, que no solamente se escuche el nombre del estudiante cuando él diga presente y que esta sería la única palabra que él diría en todo el día. Ahora se generan espacios, de hecho, se habían generado antes pero no con una visión distinta, el hecho de que conversemos, charlemos y de que todos se sientan cómodos. Le decía, anteriormente, de que son tímidos, porque parte de esa cultura ha hecho que los chicos se sientan tímidos en muchos espacios que no conocen, pero por eso abrimos los espacios de motivación para poder manejar eso. El proceso incluso de la propuesta de trabajo que estamos realizando, permite de que nosotros manejemos esos espacios de habilidades comunicativas con ellos, y lo estamos haciendo, porque realmente eso es lo que necesitamos fortalecer y es algo que nació de un estudio, de un diagnostico bastante amplio, en donde lo primero que se miraba eran todas las variables, y lo que primero que se delimitó son las variables, que uno sabe que puede tenerlas a la mano. que debilitábamos eran las variantes que no deben tenerlas a mano, que puede contralar, porque uno cómo va a jugar con algo que no tiene a la mano, pero de lo que uno puede asegurar de sus estudiantes de lo que se está aprovechando.

E: Adolfo, ¿qué sentido o qué sentidos se han formado con el hecho de hacer una maestría para ti, pero también para los que están a tu alrededor? Para tu familia, para tus colegas, tus estudiantes... ¿Qué reacciones hay en ellos?

Adolfo: Empecemos con mis estudiantes, el hecho de que ellos vean que un grupo de docentes están estudiando, les hace sentir una motivación. Lo primero que vieron es que nosotros debemos estar preparados y seguir unos estudios, uno en cualquier época de la vida puede iniciar sus estudios y seguir adelante y ustedes siendo jóvenes proyéctense. Porque ellos a veces no ven la magnitud de lo que es el estudio, y la ventaja y lo grandioso que puede ser que le den 
esa oportunidad de estudiar, háganlo; no tienen otros compromisos, ni obligaciones extremas que tengan que cumplir, tiene todas las opciones para ser buenos estudiantes y para que la familia los apoye en el proceso, entonces, ellos lo ven con agrado y como un reto, el hecho que lo vean preocupado por las tareas, los trabajos, eso es bonito también. Porque cuando uno puede conversar se siente bien.

Los docentes, algunos lo ven como llamativo, el que nuevo dirá, qué nuevo traerá, lo nuevo que habrá para compartir.

E: Pero frente a eso, cuando tus colegas lo pueden ver llamativo ¿Qué conocimientos trae? Enlazando con estas consecuencias supongo que también trae esa apatía, que él está haciendo esa maestría y porque viene a decirnos los aspectos que tenemos que mejorar.

Adolfo: Sí, eso se da, uno los convence porque es el tema de uno, de hecho, cuando estaba con mis compañeras de estudios, hay otros docentes que están a mi lado y me dicen: - "oiga cómo es esto de tal cosa", por ejemplo. Hablamos de esos ejercicios y muchos empezaban a decir: "ya viene este, con esos temas que a mí no me interesan” por ejemplo. Es normal, uno podía saber quién lo hace con naturalidad y quién no. Algunos me felicitaban. Pero prácticamente, desde lo personal no estoy muy entusiasmado de mostrar un título, que soy magíster, sino que mis acciones los van a llevar a ellos, a que en algún momento vean que los que yo hice está bien y hagan lo mismo. Que van a replicarlo. Esa es mi idea. (Risas)

Por eso es por lo que estoy hablando fuertemente con el rector para pensar en cómo plasmar eso y tratar de socializarlo con hechos, evidencias y procesos y que diga: "mire, esto me parece llamativo" y ellos en una forma natural, empiecen a decir, que quieren conocer el material para replicarlo en sus clases. Nos pidan el material para ver si pueden hacer lo mismo. Gracias a esto, lo que he tenido en mi docencia, creo que eso es lo importante, porque a veces uno se llena la boca diciendo que soy magíster. Lo mío no es eso, para mí es un reto mucho mayor donde yo pueda demostrarme con hecho de que puedo estar 
en posición distinta, que puedo compartir, contribuir y colaborar, y de que las personas que están ese proceso tengan

Con mi familia, es algo caótico. Porque mi situación familiar siempre dificultó muchas otras cosas. El hecho de dejar los espacios que antes compartía con ellos, el hecho de que se entienda que ha sido un reto y que es algo para afianzarse en otros aspectos lo han entendido. De hecho, hoy no estoy compartiendo con ellos, pero saben para qué es esto y va a haber un momento en el que voy a devolver todos esos espacios que he dejado de compartir con ellos. No son espacios perdidos, sino que se aplazaron. Mi familia me cedió esos espacios y ahora tengo que compensarlos.

E: ¿Meta cumplida?

Adolfo: $\mathrm{Si}$, yo me siento feliz. O sea, lo de mañana lo siento como demostrar que hemos hecho un buen trabajo y que ha valido la pena, pero lo que sigue es un compromiso mayor de lo que hemos hecho hasta ahora. Yo no puedo quedarme ahí y no me voy a quedar, tengo que demostrar que realmente ese paso valió mucho la pena. Mucha gente se vanagloria diciendo que lleva varias especializaciones, pero uno se pregunta, dónde están todos estos títulos, en hechos. Entonces uno dice, tiene tal especialización, pero no ha significado mucho, pero yo considero que con este nuevo reto cumplido tengo que trabajar mucho para demostrarlo con hechos no solo con mostrar el cartón. Porque alguien podrá decir que lleva varias especializaciones.

E: Bueno, Adolfo, gracias. 


\section{Historia Lulo Corrales}

E: Bien, buenos días esta es la historia de vida con Lulo Corrales, ella es docente en el municipio de Túquerres, Nariño, en la Institución Técnico Girardot, nos va a contar un poco de su historia y de su relato. Bueno Lulo ¿Cuál es tu lugar de residencia y cómo es tu municipio?

Lulo Corrales: Hola, buenos días. Vivo aquí en Túquerres, en el barrio San Nicolás, es el barrio más antiguo y grande que tiene Túquerres, es un barrio muy bonito, yo me críe practicante allí, viví mi niñez, mi juventud y ahora sigo viviendo aquí. Quiero mucho este barrio.

Nací acá en Túquerres hace 43 años, es una ciudad muy bonita, muy acogedora, clima frio, pero la gente muy querida y amable, quiero mucho a mi pueblo porque es una ciudad donde nos conocemos todos. Últimamente, ha crecido vertiginosamente, pero se manejan lazos de familia de unión entre nosotros y es una ventaja porque uno sabe con quién está tratando, a quien le puede ayudar, cuando suceden los problemas nos enteramos fácilmente. Es una ciudad tranquila aun en medio de las dificultades que se presentan, pero así sigue siendo tranquila en comparación a otros pueblos vecinos. Es una ciudad donde la forma de vida todavía es fácil, este es un pueblo agrícola entonces encontramos muy fácilmente los productos. No es costosa la vida acá. Tú puedes transportarte, no necesitas tomar vehículos para llegar a donde quieras ir, porque los lugares son cercanos. Entonces, la forma de vida es más fácil acá, es un pueblito que ha crecido mucho, ya tenemos bastante progreso, 0 sea, uno ya mira que la ciudad cada vez va avanzando más, construyen muchas cosas y uno ve que la tierra donde nació poco a poco va creciendo.

Toda la vida he vivido aquí en Túquerres y me gusta mucho.

E: ¿Trabajas aquí mismo?

Lulo Corrales: Sí, trabajo acá en Institución Educativa Técnico Girardot. Queda a tres cuadras de mi casa.

E: ¡Muy cerca! Ok, y ¿Cómo es esa institución? ¿Tiene más sedes? 
Lulo Corrales: Sí, esta institución tiene tres sedes, aquí donde estamos es sede centro $y$ las dos primarias, que una es Pio $X$ y la otra es Fátima. Aproximadamente, tiene 953 estudiantes entre preescolar y grado once. Trabajamos con jornada única. Es un colegio relativamente pequeño en comparación con las otras instituciones que hay acá, pero tiene una historia muy bonita porque se ha ido forjando desde su creación y se ha ido construyendo poco a poco, esta institución lleva 18 años ya como institución, pero ha ido fortaleciendo sus procesos, entonces, es muy bonito trabajar aquí. Los niños son muy pilos, son niños que vienen la mayoría de sector rural, son trabajadores, aquí tenemos muchos niños que trabajan y estudian, tenemos muchos niños que tienen que terminar la jornada escolar y siguen trabajando, son jóvenes que tienen otro concepto de vida porque les cuesta tener las cosas que tienen.

Es una institución que dentro de este municipio es reconocida. Aquí por ejemplo, se trabaja la parte técnica y eso hace que sea diferente a los otros, porque aquí por ejemplo, se le enseña a los muchachos, lo que es modistería, ebanistería y electricidad, ellos aparten de lo académico aprende otras cositas que le sirven para defenderse, porque no todos tiene la oportunidad de ir a estudiar a la universidad, ya que no tienen los recursos suficientes, entonces, como ellos ya tiene los conocimientos desde el colegio, lo que hacen al salir es que ellos hacen un técnico y crean sus empresas. Tenemos estudiantes que se gradúan y los que estudiaron modistería, ya ponen su tallercito, o los de ebanistería, igual, trabajan elaborando sus productos, entonces, esa es una ventaja de este colegio porque les da herramientas para que ellos puedan trabajar.

E: ¿Y qué enseñas acá?

Lulo Corrales: Aquí enseño informática. Tengo 6 años de trabajo acá.

E: ¿En qué grados?

Lulo Corrales: Del octavo al once.

E: ¿Que enseñas en informática? 
Lulo Corrales: En informática, yo enseño de todo. (Risas) Por ejemplo, en octavo trabajamos la parte de los cálculos, con las hojas de cálculo. En noveno, trabajamos con diseño, elaboración de animaciones y diseños. En decimo trabajamos todo lo que es diseño gráfico, fotografía, ese decimo es muy chévere porque los muchachos aprenden bastante, todo lo que es de creaciones, retoques fotografías y se explora bastante la creatividad de ellos, a mí me gusta trabajar mucho en este curso porque me gusta mucho la parte de fotografía y diseño y todo lo relacionado. $Y$ en once se trabaja lo que es la programación, HTML, diseño web. Pero. junto a eso yo trabajo mucho la parte de informática desde lo humano, a mí me gusta mucho desarrollar en los muchachos habilidades, siempre yo les digo a ellos que la maquina es eso, no tiene sentimientos, yo me gasto buena parte de mi clase hablándoles a los muchachos para que empiecen a desarrollar esa estima, la misma creatividad, porque es que de alguna u otra manera aunque la tecnología ha ayuda mucho en los avances, pienso que también ha retrocedido un poco, porque ahora las relaciones son virtuales, ya no hay ese apego, los muchachos ya no juegan, no leen, no pintan, porque todo está en la máquina. Entonces, para ellos las mismas relaciones, es máquina, ya no salen y eso es lo negativo, así que yo trato que esa parte la exploren y la trabajen mucho más de cerca con sus amigos, con sus familias, que sean chicos que pregunten, exploren, dejar un poquito ese "copiar y pegar", porque, también se han mecanizado mucho en eso, y trabajar más la parte humana, la cual se ha perdido mucho con la tecnología y esta nos está dejando. Porque la tecnología avanza mucho en eso, pero no en la parte humana.

Yo ínsito mucho en eso y con mis estudiantes me gasto mucho tiempo hablándoles, trabajando y haciendo actividades en ese sentido. A parte de eso les trabajo mucho con la lectura, la comprensión, para que ellos utilicen esa parte del lenguaje y utilizando los computadores, también pueda expresar sus ideas, entender los textos, y que puedan utilizar internet no solo, para jugar, chatear, para perder el tiempo, sino para buscar cosas que les ayuden y que sean prácticas. Ellos por lo general llegan a la sala de sistemas y si no tienen 
actividad, entonces, por lo general se meten a YouTube, a descargar música, mirar videos y juegos, pero no los llevan más allá. Entonces es irles metiendo como esa parte del uso creativo del internet y de todo lo que es tecnología para su formación personal.

E: ¿Hace cuánto trabajas allá?

Lulo Corrales: 6 años.

E: ¿Siempre has estado trabajando en el área de informática?

Lulo Corrales: Si, aquí en el colegio sí.

$\mathrm{E}: \mathrm{Y}$ ¿antes donde trabajabas?

Lulo Corrales: Antes trabajaba en Piedra Ancha, otro municipio que queda relativamente cerca, a una hora más o menos de acá.

E: Y ¿allá que enseñabas?

Lulo Corrales: Allá trabajaba en primaria.

E: Como docente integral que llaman ¿cuántos años duraste trabajando allá? Lulo Corrales: Yo trabajé lo que es Ricaurte y Piedra Ancha. Primero en Ricaurte, que es más lejos de acá, como a dos horas.

E: ¿También en institución pública?

Lulo Corrales: $\mathrm{Si}$, esos años para mi fueron muy importantes porque yo me formé como maestra allá, me hice como maestra allá y trabajé en primaria en las dos instituciones.

E: ¿Y cuántos años duraste por allá?

Lulo Corrales: A ver, llevo trabajando desde hace 15 años entre Ricaurte y Piedra Ancha, trabajábamos allá todas las áreas y por lo general, siempre me daban siempre primero y luego, me los dejaba hasta tercero, luego, me daban un quinto y luego otra vez volvía a primero. Yo prácticamente me formé allá. En esa zona, es una zona cálida, porque queda cerca a la costa. Son zonas cálidas, las cuales diferían mucho de mi tierra y el problema era la violencia que se veía allá.

E: ¿Y tú ibas y volvías?

Lulo Corrales: No, yo me quedaba toda la semana y el viernes volvía. Esa es una zona muy bonita para trabajar, pero la violencia es tenaz. 


\section{E: ¿En qué términos la violencia?}

Lulo Corrales: Guerrilla, paramilitares, uno tenía que estar a veces en enfrentamientos con guerrilla, a veces uno iba a la escuela y tenía que encontrase con esa gente.

E: ¿Y te viste con un momento así? Cuéntame uno que te acuerdes, un enfrentamiento de esos, porque esto es una situación que en la escuela se debía vivir de una forma tenaz.

Lulo Corrales: Sí claro viví muchas veces.

E: ¿Y llegaban a la escuela?

Lulo Corrales: Sí, claro. Yo trabajé en Ricaurte en una escuelita que quedaba de vía principal a 20 minutos me gastaba en llegar a la escuela, era una carretera, un caminito. Esa zona era tremendamente ocupada por ellos.

E: 0 sea, tú llegabas al pueblo y del pueblo a la escuela caminabas 20 minutos.

Lulo Corrales: Sí. En ese trayecto uno se encontraba con esa gente porque la escuela, aunque estaba cerca de la vía, estaba también cerca de la zona boscosa, zonas que prácticamente eran desoladas, incluso eran vías que iban para la montaña y esas son las zonas que la guerrilla frecuentaba. Entonces, la guerrilla bajaba y uno se los encontraba y muchas veces, por ejemplo, llegó una época en la que era tan critica la situación, que por ejemplo, los lunes cuando uno llegaba a la escuela, esta era como la chancha, estaba la capillita, la cancha y la escuela y las casitas próximas a la escuela, entonces, uno llegaba y esa cancha uno la encontraba llena de camiones, mulas, buses, camionetas, porque, la guerrilla la noche anterior secuestraba los vehículos y los llevaba para la escuela. Entonces, los ubicaban ahí y los niños allí y los dueños de los vehículos tenían que negociar el rescate de sus carros. Esas negociaciones las hacían allí en la sede y en las gradas de la escuela, entonces, las llevaban allá para que rescataran sus carritos.

$\mathrm{E}:$ ¿Y entonces como hacían clase?

Lulo Corrales: Ahora imagínese profe cómo hacíamos clase, si los muchachitos solo miraban como hacían eso, ellos cargaban su fusil y todo. Eso, por un lado, y, por otro lado, imagínese la zozobra de decir bueno, esta gente está acá, 
imagínese, la vía estaba a 20 minutos, el ejército no tardaba en llegar y se formaba allí un caos. Esta gente por lo menos tenía la precaución de cuando se acercaba el ejército, decían que cerraran la escuela y decirnos que nos fuéramos porque sabían que ya iba a llegar el ejército, no recuerdo bien el término que utilizaban para nombrar el ejército, entonces, uno tenía que salir corriendo.

E: $O$ sea, que ellos ise quedaban en la escuela y hacían que los civiles se fueran?

Lulo Corrales: Sí, claro, la última vez que yo estuve allá era tan tenaz esta situación, tan crítica, que a uno le daba miedo llegar allá, porque aparte de que encontraba eso, se los encontraba en la vía, y uno iba solo y se encontraba a esa gente y a uno le daba mucho miedo.

E: ¿Tú cuantos años tenías Lulo?

Lulo Corrales: Yo tenía 28 años, yo era "desempacadita". Yo fui a aprender allá.

E: Tú te formaste allá.

Lulo Corrales: $\mathrm{Si}$, yo me hice allá maestra, imagínate uno encontrarse esa gente con esos fusiles y además esas caras.

E: ¿Y nunca te preguntaron nada cuando ibas caminando?

Lulo Corrales: No, nunca, nada, por lo general, siempre me llevaba un compañero en la moto, él me recogía y nos encontrábamos. Pero cuando me tocaba caminar preciso me los encontraba y uno sufría pensando en lo que esa gente le pudiera hacer a uno.

E: ¿Pero nunca se metieron con las profesoras?

Lulo Corrales: No, nunca. Eso si ellos llegaban y de repente se perdían.

E: ¿En la otra escuela era algo similar?

Lulo Corrales: No, allá era más fácil. En Piedra Ancha no. En Ricaurte si era tenaz, incluso yo no estuve en el último enfrentamiento que hubo, que creo que fue por milagro.

E: Cuando dices que confrontación, es que hubo toma.

Lulo Corrales: Sí. 
E: ¿Eso en qué año más o menos era?

Lulo Corrales: Eso fue como en el 2004. Cuando la situación era critica con las FARC. Ese día recuerdo que nosotros trabajábamos con la Planada, con la parte de proyectos ecológicos trabajaban bastante, entonces, me acuerdo de que ese día había una capacitación, venia una doctora del Ministerio de Cultura y otra del Ministerio del Medio Ambiente. Ellos venían, nos hacían la capacitación y se quedaban en la planada y bajaban, tenían su transporte, nosotros teníamos que estar a las 8:00 a.m. en la escuela para la capacitación. Yo vivía en Piedra Ancha.

E: ¿Cuánto tiempo hay de Piedra Ancha a Ricaurte?

Lulo Corrales: Media hora. Mi sitio de residencia era Piedra Ancha, entonces, yo todos los días viajaba, ese día recuerdo que se me hizo tarde, entonces, yo salí de Piedra Ancha, faltando 15 minutos para las 8:00. Yo necesitaba más de media hora, porque de Piedra Ancha a Ricaurte era media hora, y de la carretera a la escuela unos 10 o 20 minutos. Recuerdo que me encontré un amigo y él me llevo en la moto, hasta la escuela. Cuando llegamos a Chucuné, así se llamaba el lugar donde nos quedábamos para caminar hasta la escuela, pero mi amigo me iba a llevar hasta la escuela, pero cuando desde arriba fuimos mirando los tanques del ejército y me dice ese muchacho "profe, como que se dañó esto porque llegó el ejército". Entonces imagínese, el ejército estaba en Chucuné, nosotros no sabíamos si ir o no.

E: Y ¿allá ya estaban las representantes de los Ministerio?

Lulo Corrales: Claro, todos ya estaban allí, yo era la única que no llegaba. Cuando el muchacho, me pregunta que si nos vamos o nos regresamos. Cuando él dijo eso, empezó todo, empezaron a soltar esas bombas y a dar tiroteos. Y la gente empezó a corres como locos.

Fue el caos ese día, yo dije que todo fue obra de Dios, porque en ese tiempo no había ningún tipo de comunicaciones, los celulares eran lujos. Luego, yo me regresé a mi casa. Me devolví a mi casa, a Piedra Ancha, y, entonces, todos mis compañeros, los profesores se quedaron allá, las señoras del Ministerio y el asunto era que no se enteren de que eran del Ministerio, porque las secuestran. 
Después de que pasó eso, al día siguiente ya en las noticias, decían que se habían tomado la vereda y que había empezado el enfrentamiento desde las 8:00 a.m. hasta las 3:00 p.m. nadie pudo moverse de allá.

E: ¿Pero en ese momento no había niños?

Lulo Corrales: No, porque no había clase, menos mal. Pero ese enfrentamiento fue terrible, tuvo que ir la Cruz Roja a negociar para que pararan un momento, saliera los civiles y ellos siguieran con su enfrentamiento. Entonces, en ese momento lograron salir los compañeros de allá, todo el pueblo quedó prácticamente vacío, y siguieron los enfrentamientos como una semana. Eso fue como en diciembre. Fue como lo más crítico que viví allá.

Luego en enero, ya no quise trabajar más allá y me trasladaron a Piedra Ancha, aunque allá también había tomas, pero Piedra Ancha era más segura porque era la cabecera municipal, era el pueblito y era más seguro. Si había tomas, pero nunca viví, así como lo viví allá.

Me acuerdo, algo que me dejó en blanco, también en Piedra Ancha, fue cuando estaba embarazada de mi segundo hijo, recuerdo que tenía 8 meses, y tenía que ir hasta Pasto a hacerme de las últimas ecografías, entonces, teníamos que madrugar (ya estábamos en Piedra Ancha) a las 5.00 de la mañana, y preciso esa gente solía tapar las vías, nadie se movía y empezaban a secuestrar carros. Se los iban llevando para la montaña, porque en Piedra Ancha había una zona que se llamaba la Oscurana, se desviaba a una vía más pequeña y metían a todos los carros para allá, y secuestraban gente y todo eso. Recuerdo que eran la cinco de la mañana cuando llegamos allí, nos salió un tipo allá, vea profe, esa vez yo si sentí mucho miedo, pensé lo más horrible, pensé que nos iban a secuestrar y yo en el estado que estaba. Esa vez sentí lo más horrible. Cuando, Llegó ese tipo y le dijo a mi esposo que bajara el vidrio y que de donde veníamos. Además, nos hicieron llevar el vehículo a un lado. En ese momento dije "nos secuestraron"

Mi esposo le explicó que yo iba a dar a luz y la tengo que llevar al hospital, el tipo me dijo que me bajara y yo estaba pálida del susto, y como estaba ya bien 
gorda yo le decía que yo no me podía bajar. Hice un teatro y el tipo no se quiso meter con nosotros.

\section{(Risas)}

Luego dijo aquí no han visto nada si nos preguntan allá y nos dejó ir. Esa vez yo si la vi grave. Pero luego salí de allá y ya gracias a Dios llevo seis años los que llevo trabajando acá.

E: Si, ya estas más tranquila.

Lulo Corrales: Sí, claro acá ya no se vive nada de lo que vivimos allá, es que esas zonas son fuertes. Vivir esa violencia es terrible.

E: Si y me imagino que más uno como docente ¿no?

Lulo Corrales: $\mathrm{Si}$, ya uno lo conocen.

E: Y me imagino que en esas escuelas había poquitos docentes.

Lulo Corrales: Sí, éramos 5 o 6. Bueno, la guerrilla, las ideologías que tenían eran interesantes, lo de la paz, la justicia, pero el problema, fue que cuando empezó a narcotizarse la guerrilla, ya comenzaron los secuestros, las extorsiones, por ejemplo, yo tenía compañeros que tenían que pagarle cada mes a la guerrilla, los extorsionaban, los amenazaban y como supuestamente los profesores éramos las personas que más ganábamos plata, pues la situación para nosotros era muy crítica, en esos últimos años que pase allá.

E: ¿Y cómo fue el traslado? ¿Tú lo solicitaste?

Lulo Corrales: Sí, el alcalde de ahora Álvaro Palacios es muy amigo mío, en ese tiempo él era diputado y me ayudó. $Y$ nos dijo que iba a ayudarnos a salir de allá, porque era muy peligroso, mi hija ya estaba a punto de graduarse de bachillerato y mi hijo era muy pequeño, él veía que era muy peligroso e hizo todo y con la ayuda de la Secretaria de Educación de ese tiempo me trasladó y me ayudo bastante.

E: Llevas 6 años trabajando acá ¿Cómo te has sentido? ¿Cómo es la relación con la comunidad? ¿Cómo son tus estudiantes?

Lulo Corrales: Todo es chévere, yo le cuento que la llegada aquí también fue otro reto. (Risas) 
Porque yo trabajaba en primaria y mi especialidad es ciencias naturales, siempre me ha gustado la informática, pero solo aprendía por empirismo, "cacharreaba y cacharreaba" e iba aprendiendo. Cuando trabajaba allá siempre me dedicaba también a la informática, pero mis títulos por ningún lado iban por la informática, yo soy licenciada en ciencias, hice dos especializaciones en ecología, pero, por ningún lado la informática, así que cuando Álvaro estaba gestionando mí traslado y estábamos buscando un colegio que se llama el Teresiano, el cual es privado, es la Normal, inclusive de este fue del que yo me gradué.

E: Es privado. ¿Es la normal?

Lulo Corrales: Sí.

Allí me encontré con una profesora que me dio clase en primero de primaria y me dice que iba a renunciar, que gestionara el puesto que iba a quedar. Yo le avisé a Álvaro y él me apoyó. Todo lo que estábamos haciendo era para entrar al Teresiano, incluso las profesoras me preguntaban que cuando iba a empezar y que ya estaba el curso listo, que fuera rápido. Porque allá me conocían. Solo era el rumor de que llegaba al Teresiano, pero resulta que alguien se me adelantó, no sé qué hizo, porque como en esas cosas utilizan mucha palanca, ella tenía mejor palanca que la mía.

Entonces, supuestamente a mí me iban a mandar a hacer un remplazo de una profesora que trasladaron de una vereda cercana que se llama los Arrayanes al Teresiano, y a mí me iban a mandar cubrir la vacante de ella, pero Álvaro no aceptó e hizo que me dieran la vacante del puesto en Túquerres, recuerdo que me dijo que la única opción que había era el Técnico Girardot, yo pensé que era en primaria y además que era ciencias. Yo dije, esta perfecto. Pero él me dice que no, que era en bachillerato, que el rector estaba necesitando un ingeniero de sistemas, entonces, yo le dije que yo no podía trabajar allá porque yo no era ingeniera de sistemas, él me dijo que igual yo manejaba bien la tecnología que me hiciera un cursito, pero que tenía que llegar allá. Recuerdo que un día me llama un día el que estaba haciendo la gestión desde Pasto, me dice que la única opción es en el técnico Girardot como docente bachillerato en 
la parte de informática. Lo toma o lo deja. Me he metido ahí y llegué, el rector, el profesor Javier fue mi profesor y ya lo conocía, entonces, le dije que no tenía la especialidad, pero que ya había hecho algunos cursos pequeños, pero igual así él me dejo. Porque me conocía, aunque lo que necesitaba un ingeniero.

Recuerdo que el primer curso que él me soltó fue octavo y toda la primaria. Entonces, me tocaba andar por todas las sedes todo el día, me tocaba muy duro.

E: $Y$ ¿las otras sedes quedan muy retiradas de aquí?

Lulo Corrales: La de Pio X queda cerquita, pero la de Fátima si es lejos, en la salida. Así me tuvo el primer año, en ese año me tocó duro porque tuve que leer, aprender, profundizar y hacer una especialización en informática. Después, al año siguiente ya me dio hasta once, tuve que defenderme.

E: Pero ¿sin primaria?

Lulo Corrales: $\mathrm{Si}$, me quitó primaria y así he aprendido, pero desde que llegué nunca he tenido problemas, los muchachos me quieren, nunca he tenido problemas con los estudiantes, jamás. Al contrario, siempre he tratado de ayudarlos, me han dejado muchas veces la dirección de grados once y ellos me quieren mucho. Me gustaría que usted por ejemplo le preguntara a cualquier estudiante, siempre he tratado de ayudar a la gente, no he tenido problemas tampoco con los padres. Los compañeros si, como en todo lado venimos a trabajar, algunos nos caemos mal otros bien. Pero en cuanto a los chicos si hacemos un buen trabajo.

E: Bueno Lulo, entonces continuamos. Quisiera que me cuentes que estudiaste, cuál es tu especialidad, dónde estudiaste, ¿cómo fue eso?

Lulo Corrales: Listo. Mi pregrado fue en educación básica con énfasis en ciencias naturales, estudié en la Universidad de Nariño. Fuimos el primer grupo con la extensión de la universidad en Túquerres y $\mathrm{mi}$ formación fue semipresencial, teníamos clase aquí en Túquerres y los fines de semana, cada 15 días trabajábamos en Pasto. 
Fueron 5 años, fue una experiencia muy chévere, porque a mí siempre me ha gustado las ciencias naturales y la biología y fue interesante el proceso, aunque, prácticamente lo hice porque ya estaba metida en el cuento de la docencia, pero mis ideas y mis metas estaban encaminadas por otro lado.

E: ¿Tenías otros intereses? ¿Tú no pensabas ser docente?

Lulo Corrales: No, yo no quería ser docente, lo que pasó es que yo estudié en el Teresiano, en la Normal, aquí en Túquerres, me gradué con la promoción de 1991 y cuando uno estudia en la Normal, lógicamente uno no tiene definida la misión. Yo estudié en un colegio de monjitas y allá lo preparan a uno para ser docente, pero yo no sentía que esta fuera mi vocación, no me atraía ni me llamaba la atención. A mí me matricularon en ese colegio, porque era un colegio privado, en el que la familia piensa que uno aprende más, que lo cuidan más, incluso, yo hice desde la primaria allí. En ese tiempo era solo femenino, pero ahora es mixto.

Me metieron allá como para estar mejor. En ningún momento a mí me llamó la atención ser docente, es más, cuando en bachillerato teníamos que hacer las prácticas docentes, para mí era una tortura tener que ir a dictar clases a los niños, aunque no lo hacía mal. Preparaba las clases, me iba bien, pero no me gustaba, era una tortura las prácticas docentes, entonces, a uno lo obligaban a llevar un "parcelador de clases", lo revisaba la profesora de práctica docente, luego, la directora del curso donde uno iba a ir, cada uno le ponía en rojo las observaciones de la clase y uno tenía que ir a dictar clase como pudiera.

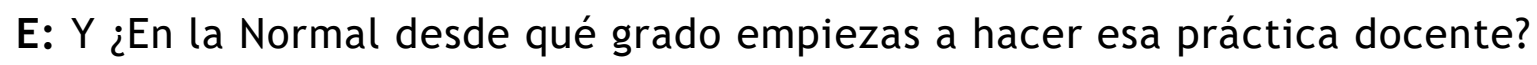

Lulo Corrales: Desde decimo y once, nos ponían a dictar clase a estudiantes de la Normal. Entonces, a uno le decían que los temas para desarrollar la clase. En ese tiempo no había internet, ni computadores, entonces a uno le tocaba hacer carteleras, los dibujos, y tenía que ser muy ordenado, la letra tenía que ser pulida, decorar las cosas, incluso ni siquiera había diseños para hacer una cartelera, en ese tiempo uno mismo tenía que hacerlo. Aprendí bastante en la parte de creatividad y ser recursivo, uno en muchas ocasiones tenía que 
inventar los juegos, leer bastante, ir a la biblioteca y consultar sobre los temas.

Luego, uno tenía que hacer su preparador de clases, lo presentaba a la directora de práctica docente, luego a la directora de curso y ahí le indicaban lo que uno tenía que hacer.

E: ¿Tu cuantos años tenías ahí?

Lulo Corrales: 16 años, me gradué a los 18. Entonces, uno aprende allí, pero no se enamora de la profesión. Yo tenía algunas compañeras que sí les encantaba y sí querían ser maestras, pero a mí no me nacía, es más, trabajar con niños me parecía durísimo y terrible y, a uno, por ejemplo, cuando esta sexto, séptimo, octavo y noveno lo llenaban de mucha teoría, entonces, recuerdo que dictaban muchas clases, había profesora de administración educativa, de psicología, comportamiento y salud. A uno le decían que teníamos que hacer todo esto porque íbamos a ser profesores. Nos hacían repetir las cosas y nos hacían grabar, me acuerdo de que tenía una profesora de administración educativa y ella, nos hacía memorizar todo, códigos, leyes y a mí me parecía odioso eso. A uno le decían que cuando sea profesor, debía llevar unos libros reglamentarios. El registro de asistencia, de notas, seguimiento. Lo ponían a grabar eso y nunca me llamaba la atención a hacer eso, pero se debía hacer todo eso en las prácticas, pero como para cumplir el requisito para graduarme.

Nunca me llamó la atención, porque me parecía mucha presión. Yo hacía estas prácticas, pero como para cumplir el requisito, como para graduarme. Ya cuando me enfrentaba a los muchachos, había unos niños muy bonitos porque eran muy inocentes y cuando llegábamos a darles las clases, se tiraban a abrazarnos, porque las directoras eran muy aburridas, solo los tenían en clase, y cuando llegábamos nosotros los sacábamos a jugar, los hacíamos correr y les hacíamos actividades lúdicas. Entonces, esos niñitos cuando llegaba la práctica eran felices, y cuando nos íbamos a ir lloraban, que cuando íbamos a volver. Como la primaria y la secundaria quedaban en secciones diferente, los niños llegaban a nuestros cursos, al once, nos iban a buscar y a visitarnos. 
E: Y ¿en esa práctica cuántas estudiantes iban a un solo salón? 0 era un salón por cada persona.

Lulo Corrales: No, nosotros nos repartíamos los cursos, yo recuerdo que íbamos 3 personas por salón, entre las tres nos dividíamos la clase, yo recuerdo, que nos enseñaban que la clase se divide en tantas partes, la motivación, la introducción, el desarrollo del tema, la evaluación. A mí siempre me gustaba hacer la motivación y la introducción, no me gustaba dictar la clase, está siempre era para la chica que más era pilosa. Por lo general, las motivaciones siempre eran con juegos, con dinámicas. Al final, la directora nos hacia las observaciones, si la clase estuvo mal o bien, o qué había que mejorar, eran muy estrictas y nada les gustaba, pero igual los niños quedaban muy contentos. E: ¿Las profes eran monjas?

Lulo Corrales: No, algunas sí, pero las que trabajaban en primaria no, pero las que nos dictaban el bachillerato sí. Ahora uno analiza, porque en ese tiempo nos decía, miren la clase estuvo mal, porque los estudiantes no dan cuenta de los contenidos vistos, las profesoras decían que los niños no sabían nada, pero nosotras salíamos de las clases y veíamos a los niños juiciosos y felices, contentos. Ellos se divertían y cuando ellas les hacían las evaluaciones escritas, ellos quedaban en blanco, entonces, decían que nuestras clases no daban resultado.

Pero ahorita sí decimos que las clases sí daban resultados. Entonces, yo no me enamoré de esa profesión en ese momento. Yo quería ser abogada, quería graduarme y seguir estudiando derecho, pero cuando me gradué, terminé y no sabía qué hacer, mi mamá es docente, ella trabajaba en una escuelita en el campo. Y ella me dijo que la acompañara a la escuela.

E: ¿Cuándo ya saliste del colegio?

Lulo Corrales: $\mathrm{Si}$, cuando no tenía que hacer, porque mi puntaje en el ICFES no me dio para entrar a una universidad a estudiar derecho. Entonces, mi madre me dijo que la acompañara a la escuela y me fui con ella, yo le ayudaba a dar clase y a cuidar a los niños, a llenar los boletines, y un día el alcalde de ese tiempo quien también era muy amigo de mi mamá me propuso un trabajo para 
que recibiera mis pesitos. En ese entonces, no había concursos, era muy sencillo entrar al Magisterio. Eso fue en el 93, cuando el alcalde le dijo a mi mamá que me iba a dar un contrato, para recibir unos pesitos y no ande gratis, él era muy buena gente, y me acuerdo de que me fui a trabajar con mi mamá por un año, que me dieron el contrato. No era mucho lo que ganaba, pero me servía mucho. Yo acompañaba a mi mamá, pero aún no sentía que me gustaba ser maestra. Entonces, pensé en ahorrar y volverme a presentar en la Universidad para empezar a estudiar derecho. Entonces, trabajé un año, se terminó el contrato, y luego de eso, el alcalde me dice que ya se me había terminado mi contrato, pero que como mi mamá ya había cumplido el tiempo de jubilación, que eran los 50 años, pero ella podía trabajar hasta los 64 años, ella me dice un día, -mija yo ya me jubilé, ya recibo mi pensión, le voy a dejar la plaza para que usted siga trabajando como maestra.

E: ¿Cuántos años tenías en ese tiempo?

Lulo Corrales: Yo tenía 20 años. Mi mamá adoraba ser maestra, ella era muy consagrada y también la querían mucho donde estaba. Para ella dejar la docencia era dejar su vida. Yo no sabía que decirle, y mi mamá me dice que ella me dejaba por que el ingeniero Luis Eduardo, nos iba a ayudar para que yo siguiera trabajando. Me pareció feo decirle que no, porque prácticamente, ella me estaba dando su herencia y su vida. Entonces le dije que sí, y desde ahí en adelante me he metido en la docencia.

E: Entonces ¿tú desde cuando empezaste a hacer la licenciatura?

Lulo Corrales: Yo empiezo mi licenciatura cuando empiezo a trabajar.

E: O sea, que tú empezaste en la escuela donde trabaja tu mamá.

Lulo Corrales: Sí, después me trasladaron a Ricaurte y allá me formé como docente y una vez ingresado al Magisterio, ya no hay vuelta de hoja atrás, meterse a lo que uno ha hecho. Me inscribí a la de Universidad de Nariño.

Me inscribí en ciencias naturales porque era lo que más me gustaba y fui metiéndome más en el cuento, sino que uno cuando ya le toca solo, enfrentarse a un grupo, es en donde se empieza a formar como docente, porque uno en el bachillerato no le dan nada, simplemente es una teoría. En las prácticas de la 
universidad, era distinto, porque estaba la directora de grupo, la asesora de práctica y las compañeras de práctica, uno se sentía respaldado y si se presentaba un problema le ayudaban a uno.

Luego a uno le toca esforzarse más, porque era muy diferente, en el colegio uno tenía el apoyo de las otras compañeras, de los profesores y luego, cuando empecé a trabajar mi mamá me ayudaba mucho. Pero cuando a uno le toca solo, cuando uno se enfrenta a los niños, uno se pregunta qué hacer, cómo hacerlo, y ya yo no me podía poner a leerle cuentos ni nada de eso. Entonces, ahí es donde empieza a pensar en cómo llegarles a los estudiantes, que es lo que realmente hace un verdadero docente.

E: Pero me imagino que tu formación de pregrado fue mucho más fácil, por la experiencia que tenías.

Lulo Corrales: Sí claro, allí prácticamente uno refuerza lo que en el colegio aprende y como yo, ya estaba trabajando miraba las cosas desde otro punto de vista y les ponía más interés. Tuve profesores muy buenos en mi pregrado, ellos me llevaban a analizar, a pensar, a hacer las cosas más allá de lo académico, la información que nos dieron en el colegio no se compara. En la universidad uno ya empieza a perfilarse.

E: Bueno, ¿tú terminas tu pregrado más o menos en que año?

Lulo Corrales: Yo terminé mi pregrado en el 2000.

E: ¿En el 2000 ya trabajabas acá?

Lulo Corrales: No, yo trabajaba en Ricaurte, yo vine a trabajar aquí en el 2012.

E: Hace 6 anos. Bueno, ¿qué hiciste luego de la licenciatura? ¿Cursos o especializaciones?

Lulo Corrales: Sí, en todos esos años de experiencia, cuando uno tenía que ascender de escalafón, yo soy del escalafón antiguo, y tenía que hacer cursos de formación, diplomados de dos o tres meses, en temas de evaluación, de didáctica, eran de temas educativos.

Entonces, empecé a hacer cursos, luego de la licenciatura hice una especialización en ecología y terminé haciendo la especialización en informática. Tengo dos especializaciones. 
E: Tengo una pregunta ¿tú no sientes de pronto frustración por no estar dictando lo que estudiaste?

Lulo Corrales: No, porque cuando yo inicié el Magisterio yo trabajé en primaria, estaba en básicas, en ese momento, dictaba ciencia y nosotros en Ricaurte y en Piedra Ancha, trabajamos mucho la parte ambiental y le di mucho a lo que es ecología y a los proyectos ambientales.

E: ¿Y en estos 6 años?

Lulo Corrales: No, en estos 6 años no me he dedicado a lo que es lo mío con respecto a mi formación. Pero igual no me siento frustrada porque he aprendido mucho y si ahorita por ejemplo me regresan a dictar ciencias naturales me da durísimo.

E: Claro, tienes que volver a retomar nuevamente todos los conceptos, los libros y todo.

Lulo Corrales: Sí claro, ahorita me quedaría muy difícil volver a dictar ciencias, porque ahorita me estoy dedicando de lleno a esto.

E: Bueno, tú haces el pregrado y las especializaciones. Has estado muy preocupada por tu actualización, tu formación y por estár pendiente siempre, que a pesar de que estas trabajando te preocupas por tu formación. ¿Otros compañeros hacen lo mismo? ¿Cómo es el balance que haces de esa formación?

Lulo Corrales: Yo, por ejemplo, ya estoy en el último grado del escalafón, la 14 y se supone que no tengo que hacer ninguna formación, la mayoría de los colegas ( $\mathrm{y}$ es triste decirlo y aceptarlo) hacen sus especializaciones simplemente por el requisito para poder ascender en mi estatuto porque en el nuevo creo que es diferente.

E: Sí, en el 1278 es diferente.

Lulo Corrales: $\mathrm{Si}$, pero en el 2277, usted por ejemplo hace curso y asciende, pero llega a cierta categoría y tiene que hacer especialización. Porque uno no puede seguir ascendiendo con tan solo cursos así que eso era lo que hacían mis colegas. Para llegar a la 14 había que hacer otra especialización, escribir un libro o hacer una maestría. En mi caso yo hice una especialización para llegar a la 14, luego, se me presento la oportunidad de hacer una maestría. En este 
proceso me he encontrado con muchos docentes que me preguntan por qué vas a seguir estudiando si ya estás en la 14, que porque hago la maestría.

E: Y hablando de eso ¿Cómo llegas a la maestría?

Lulo Corrales: Yo empecé con la doctora Ana Elvira Castañeda quien nos hizo la entrevista, yo la hice con otros dos profesores creo que eran de Putumayo, nos hizo la preguntar de porque hacer una maestría y ellos dieron a entender que era para ascender y alcanzar un grado más en el escalafón, para mejorar los ingresos, a ellos los rechazo. En cambio yo respondí, que hacia la especialización porque necesitaba aprender, formarme y tener más experiencias para dar más de lo que he dado a mis alumnos, que esta era la entrega que yo sentía por mi carrera, y ella me preguntó que si ya estaba en el último grado del escalafón, qué me impulsaba a empezar la maestría, incluso a mí no me hacia el título, yo soy de las que cuando firmo algo, nunca me pondré magíster, porque pienso que a una persona no lo hace el título, sino lo que uno va a aprender allí, lo que uno se forma como humano o como persona se forma. Ese es mi sentido de formación, si yo por ejemplo termino la maestría y me dan la posibilidad de hacer un doctorado lo hago, no por el hecho de ser doctora, sino solo por el hecho de que voy a aprender más y voy a fortalecer más mi práctica. Sé que eso me va a dar resultado con los muchachos.

E: Antes de que sigas, no querías ser docente. ¿Cómo hiciste para cogerle cariño a esta profesión?

Lulo Corrales: Por los chiquitines, como empecé con ellos.

E: ¿Tú puedes decir que se construyó esa vocación? No como tu madre que nació con esa vocación.

Lulo Corrales: Sí, aunque para mí, yo lo tenía escondido, porque recuerdo que mi abuelo tenía una huertita en la casa, él sembraba muchas cosas, en especial, repollos y este lo siembra en surcos. Yo estaba muy pequeña y me gustaba jugar con una barita y con los repollos, ellos para mi eran los alumnos y yo era la profesora. (Risas)

Como yo tenía profesoras estrictas "bravas", hacia lo mismo con los repollos, los "regañaba" y los dañaba. Entonces, en mi casa mi mamá siempre se acuerda 
de eso, dice que supuestamente a mi o me gustaba, pero desde pequeñita siempre juagaba a ser maestra, a nosotros siempre nos sentaba y nos enseñaba como hace un profesor. Para mi yo tenía escondido ese talento, lo tenía guardado. Tal vez si a mí me hubiese nombrado bachillerato, no me hubiera enamorado de la profesión. Porque esos niños tienen un carisma especial, trabajar con ellos es muy diferente a trabajar con jóvenes, porque ellos tienen un apego, ese afecto, y un cariño muy especial. Uno empieza a desarrollar ese afecto maternal con ellos. Uno empieza a quererlos y a tener un apego muy especial, ahí es donde le empiezan a decir "te quiero mucho profe" y uno siente el cariño de ellos y ahí se va construyendo y cogiendo amor por la profesión.

E: Retomando con lo de la maestría, antes de que tuvieras la entrevista con la profesora Ana Elvira ¿cómo te enteras de que eres seleccionada?

Lulo Corrales: Por el rector, el profesor Javier nos pidió que lleváramos unos papeles porque había una convocatoria para una maestría a los docentes de jornada única, y que tuvieran menos de 45 años. Teníamos que llevar algunos papeles, la secretaría nos hizo llenar algunos formularios, eso lo mandaron a Bogotá, y un día nos dijeron que ya nos habían aceptado para la maestría y que teníamos que presentarnos con el Icetex y ya empezamos con el proceso.

E: ¿Fue una grata noticia?

Lulo Corrales: Sí claro, para mí fue genial, chévere.

E: ¿Cuántos compañeros tuyos estaban seleccionados?

Lulo Corrales: Los seis.

E: ¿Crees que para ellos fue una grata noticia en ese momento?

Lulo Corrales: Creo que para los 5, a una la logramos meter porque incluso ella se iba a retirar.

(Silencio prolongado)

A ella la rescatamos porque en la entrevista le dijo a la doctora que ella se iba a retirar y no iba a iniciar. Ella canceló el proceso. Entonces, nosotros le decíamos que no retirara, pero la mamá estaba enferma, entonces, le hablamos al profesor Javier y le hicimos ver que era una excelente oportunidad y además 
era una maestría gratis, no era con cualquier universidad, era buena, gratis, va a aprender, que no podía aprender esa oportunidad. Mandamos al rector para que la convenciera y ahora aquí está con nosotros.

E: ¿La formación que recibes si ha cumplido tus expectativas? 0 ¿Qué pensabas que era la maestría? ¿Cuándo entraste que expectativas tenías?

Lulo Corrales: Yo estaba segura de que la maestría era una formación más grande y amplia, uno a veces comete el error de pensar que allí a uno le van a decir cómo tiene que dictar las clases o como va a trabajar, uno se va como en ese sentido. En mi caso mis expectativas eran muy grandes, porque yo sabía que en la maestría iba a conocer mucho más en otro nivel a ser algo más grande, porque muchas veces las especializaciones son muy elementales y los postgrados que hice no me llenaron, porque eran muy elementales, solo fue por cumplir el requisito.

Cuando uno llega acá, uno se encuentra con docentes que saben más y más aún que son menores que uno y saben más que uno. Uno piensa que son jovencitos, pero, aun así, tienen doctorados, maestrías.

Uno piensa que se está quedando mucho en el proceso. Entonces, lo importante en un docente no es el título, sino la capacitación y la formación que recibe. Para mí esto fue muy impactante, encontrarse con gente que sabe y que exige, que le die, vaya y busque esto, lea esto, busque en las fuentes, es bueno y es lo que uno como docente debe de hacer todo el tiempo.

E: ¿Has encontrado algo nuevo en esta formación? O ya que vas a terminar porque ya estamos en la última fase, ¿se han cumplido todas tus expectativas? ¿Han sido modificadas? ¿Has cambiado algo en términos de tu práctica?

Lulo Corrales: Claro, en lo individual mucho, por ejemplo, a mí siempre me ha gustado leer, siempre he tenido ese hábito. Sin embargo, en mis temas como docente, en lo que es la didáctica, enseñanza, aprendizaje, todo lo que hemos mirado, lo he leído ahora. Porque yo trabajaba con las bases que me dieron en el colegio. Y He mejorado las bases.

E: Y, además, de las bases trabajabas más basada en la experiencia, en lo que tu sabia empíricamente. 
Lulo Corrales: Exactamente, entonces, uno como que se descuida mucho. No sabe que es didáctica ni que es enseñanza, entonces, uno se queda solamente con el conocimiento práctico. Pero entonces, acá yo aprendí a centrar eso, a manejarlo más en un lenguaje cotidiano, ya tuve que leer, para entender qué es eso, aunque soy docente.

Aquí, aprendí que tengo que leer para saber cómo definir lo que es enseñanza y didáctica, uno empieza a centrar las cosas, y en la parte formativa, pues más aun, porque uno, por lo general dicta sus clases desarrolla el tema y ya. Aquí, uno aprende otras maneras, por ejemplo, con las profundizaciones en ciencias, el profesor Guillermo dijo algo muy bonito que yo recuerdo siempre, decía, que nosotros no debíamos enseñar un concepto si haber trabajado, abordado, su historia ni su epistemología, entonces, no enseñamos bien el concepto, solo lo damos por el momento, pero nunca indagamos antes, ni consultamos las experiencias que se han trabajado con ese concepto. Es decir, uno solo llega y enseña, pero no hace un recuento sobre este. Entonces, uno aprende, y dicen, voy a enseñar esto...pero voy a consultar, a ver qué es.

E: ¿Y si los has hecho?

Lulo Corrales: Si claro.

E: ¿Cómo lo haces en la práctica? ¿Cómo lo haces en tu salón de clase?

Lulo Corrales: En el salón de clase ellos se despiertan, uno les explica, les dice que vamos a iniciar con esta pregunta, con alguna indagación... y uno cambia, son pasitos pequeños, no es que sea un experto, pero se está aprendiendo... se les da más teoría, pero llevándola a la práctica.

Yo he aprendido mucho, con la parte de la maestría. Bastante en la parte teórica y en la práctica.

Otra cosa que nos decía el profesor era la parte de los conocimientos previos de los muchachos. Uno muchas veces no cuenta con lo que ellos saben, parte de lo que uno quiere. Entonces uno aprende a escucharlos.

Aprendí también que uno nunca tiene que ver las cosas del lado negativo y que uno como docente siempre parte de los problemas de los niños. Es que ese niño no puede, no sabe, no dice, uno siempre va así, ve lo negativo, pero no 
empieza a trabajar desde lo positivo y eso es un aprendizaje valiosísimo. Entonces, uno mira los niños desde otra perspectiva, desde un lado más humano. Porque uno muchas veces empieza a recriminarlos, pero cuando uno se forma en ese sentido ya empieza a buscar cómo mejorarlo, uno aprende que no debemos hacer eso con ellos. Son aprendizajes muy valiosos.

E: ¿Cómo fue ese primer semestre en la maestría?

Lulo Corrales: Complicado, porque uno viene con esos procesos elementales. Entonces, uno esta enseñado, que llega el profesor, dicta su clase, y dice, háganse un ensayo y con eso ya estuvo. A los ocho días, va, de nuevo, un trabajo en grupo, y pasó. Acá no... acá desde el principio empezamos a leer, a investigar, a construir, desde el principio se empieza a producir. Por eso es muy difícil, yo por ejemplo para leer y escribir no soy tan mala, pero igual me costó mucho centrarme en lo que era. Al principio fue difícil para todos, pero después uno va cogiendo el hábito de estudio.

Otra dificultad es el tiempo, porque como nosotros trabajamos en jornada única hasta las 4:00 p.m. entonces uno de 7:00 a.m. a 4:00 p.m. se dedica exclusivamente al colegio, y la actividad del colegio, no termina a las 4 , porque uno tiene que llegar a casa, revisar cuadernos, evaluaciones, trabajos, preparar clases... mejor dicho, continua el trabajo... y más encima, las actividades de la casa, mis hijos, mi hogar. El tiempo era tenaz porque no alcanzaba para todo. Entonces si fue muy complicado el primer semestre, incluso ahora también y hasta más, por las profundizaciones, pero hay vamos avanzando.

E: ¿Cómo te ha parecido la formación que dan los profesores de la universidad? Lulo Corrales: Excelente.

E: ¿Cómo la puedes describir? ¿Cómo ha impactado en ti?

Lulo Corrales: Uno cuando es estudiante respeta al docente en la medida en que el docente sabe, yo pienso que esta es la manera de que un docente se gana el respeto de los estudiantes, en esa relación, no opera, la nota, ni la sanción... un docente se gana el respeto de sus estudiantes con lo que sabe...y en la maestría nosotros nos hemos encontrada con docentes que saben mucho, que manejan mucho su disciplina y eso hace que uno se exija mucho más, 
porque uno sabe que el docente conoce, sabe y así uno se exige más. En esta maestría me he encontrado con docentes que saben mucho, manejan mucho su disciplina y que le exigen para poder aprender.

E: ¿Y la universidad como tal?

Lulo Corrales: Bien, me gusta esa filosofía humanista que tiene con la filosofía de Santo Tomas, en la parte humana excelente. Hay una calidez cuando uno llega a las instalaciones de la universidad, desde el mismo portero, cuando uno llega allí es muy bonito, su ambiente es muy especial. Encuentra siempre su refrigerio rico, eso no se mira en todas las universidades.

Por ejemplo, en la universidad de Nariño a mí nunca me dieron un refrigerio, todo lo costeaba uno mismo. Acá no, las personas son muy amables aquí.

E: ¿Qué sentido ha tenido para ti la maestría y para los que te rodean? En este caso tu familia, tus estudiantes, tus colegas.

Lulo Corrales: Para mi familia, yo creo que para ellos es un ejemplo, mi hija se siente orgullosa de mí. Les demuestro a ellos que, aunque uno es mayor y tengo ya mi trabajo, todavía puedo seguir luchando por lo que quiero. Entonces, es un ejemplo, mi hija me apoya y mi hijo también, es excelente, mi mamá muy feliz, pues las mamás siempre lo ven chiquito y es el gusto que le doy a mi familia.

En los estudiantes, todo el tiempo me han conocido como yo soy, ellos saben que yo estoy estudiando, incluso, yo les digo a los estudiante de 11, cuando se quejan, que no tienen proyecciones, que no saben qué hacer, entonces, uno les dicen, que si yo, que ya tengo mis años, y todavía lucho por lo que quiero, y si se me da la oportunidad, si puedo estudiar derecho, lo hago, entonces, es como darles ese ejemplo, de que sí se puede y a muchos de ellos le llega eso. Y en el colegio, de todo se da, hay muchos colegas que me quieren y se alegran de lo que uno está haciendo.

E: Hay de pronto te hago la pregunta ¿Cómo es esa relación con los compañeros que no hacen la maestría? ¿Existen esas “envidias"?

Lulo Corrales: $\mathrm{Si}$, total. Aquí hay un ambiente tenso. Comenzando por el horario, porque a los seis compañeros, los viernes no dan las últimas horas, 
porque tenemos que viajar, es más, hay actividades que no las pueden hacer porque nosotros no estamos.

Entonces eso crea conflictos, de rivalidad, de que algunos compañeros no dejan avanzar. Y lo otro es que como hay compañeros a los que no les gusta cambiar, ni trabajar de esa manera, hay muchos roses. Porque hay compañeros que se creen que lo saben todo, porque son físicos, químicos, y no se dejan hablar. Entonces, si uno les lleva otras ideas se sienten disgustados porque no aceptan lo que uno les trae quizás novedoso. $Y$ son groseros, ese el problema, a veces hay maestrx que tiene tan alto el ego, que se les dice la verdad y ellos intentan llevarlo por otro lado se crean rivalidades y disgustos.

Aquí hay muchos colegas que tienen esa envidia por la maestría, pero no solo aquí, eso se da en todos los lugares y eso es un problema. Por fortuna, aquí los directivos, el profesor Javier, para todo lo que son capacitaciones y formación, él abre las puertas, no trunca los procesos, por fortuna tenemos el apoyo constante de él y abre las puertas. Por eso es por lo que nosotros tratamos de no desequilibrar las cosas, por ejemplo, nos vamos los seis y el colegio queda con problemas y se crea un caos, nuestra idea nunca ha sido crear ese tipo de cosas, siempre tratamos de ayudar, pero a algunos profesores eso no les gusta. Aquí por ejemplo nosotros al colegio le damos el $100 \%$, si hay que quedarnos hasta las 6:00 p.m. nos quedamos trabajando, cuando tenemos que salir, nos vamos, pero hacemos lo suficiente por el colegio, cosa que otros docentes no hacen, vienen y dictan su clase, y piden permiso por todo, hacen lo mínimo.

E: Bueno y de pronto con este panorama que dices, ¿se puede compartir aquí en la institución lo que tú aprendas en la maestría? ¿Crees que a pesar de que algunos colegas tienen resistencia, a otros tu si le puedes compartir las experiencias de la maestría? ¿Es posible?

Lulo Corrales: Si claro, no es todo el número de docentes, por fortuna son más los docentes que se interesan, hay docentes muy buenos aquí y con esa gente es con la que nosotros vamos, ahora, por ejemplo, nos sucedió algo curioso, nosotros siempre teníamos temor con el profesor de lenguaje, incluso, habíamos tenido roses, porque lo teníamos en el concepto de que él era el que 
sabía todo, no le gustaba nada. Pero cuando trabajamos con él, precisamente, él fue el que nos hizo entender las cosas como eran. Él dijo: “miren profesores los estudiantes no tienen la culpa de que no aprendan, nosotros somos los culpables de esto, algunos profesores no enseñamos bien"

Entonces desde ese momento hemos trabajado con él, y nos ha aportado mucho. Aunque teníamos el miedo de que no nos fuera ayudar. Él nos ha apoyado mucho. Para llegar al problema de investigación, él es clave para hacerlo.

E: ¿Qué expectativas tienes para cuando te gradúes? ¿Quisieras abrirte campo en docente universitario?

Lulo Corrales: Pues sería muy chévere.

E: ¿Si te gustaría?

Lulo Corrales: Si claro, aunque mi sueño es ser abogada, lo que yo quiero es salir de aquí, de Túquerres, porque ahorita mi hija está estudiando en Pasto, pero mi chiquito aun no, él está en séptimo. Entonces, yo quiero salir de acá para sacar a mi hijo y poderlos acompañarlos en otro lugar, porque sé que desde acá no puedo. Ahorita estoy con mi hijo y mi mamá, pero después cuando él se vaya voy a estar sola. Entonces, la idea es irme, para buscar otros espacios y otros lugares y si se me da la oportunidad de trabajar en una universidad, sería muy chévere, porque creo que no me siento tan inútil y si puedo dar la talla para eso.

Esas son mis expectativas y si puedo hacer un doctorado, hacerlo y continuar en lo que más pueda y quizás termine escribiendo un libro.

E: ¿Sobre qué?

Lulo Corrales: No sé, de pronto con mis relatos, a mí me gusta escribir bastante la poesía y quizás termine haciendo una compilación de eso. También puede que haga historias de vida de muchachos. Ya debe salir algo. Pero libros por ejemplo de pedagogía y eso como tal no creo. Lo haría más como por otro lado. 